
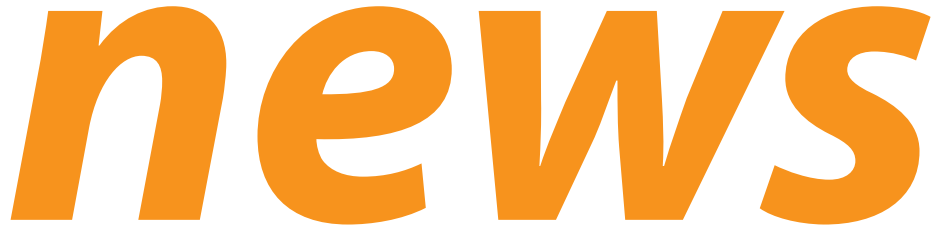

Vol $18 \cdot$ No $1 \cdot$ April 2010

Peatlands:

Paleoenvironments and Carbon Dynamics

\section{Editors:}

Stephen T. Jackson, Dan Charman, Louise Newman and Thorsten Kiefer

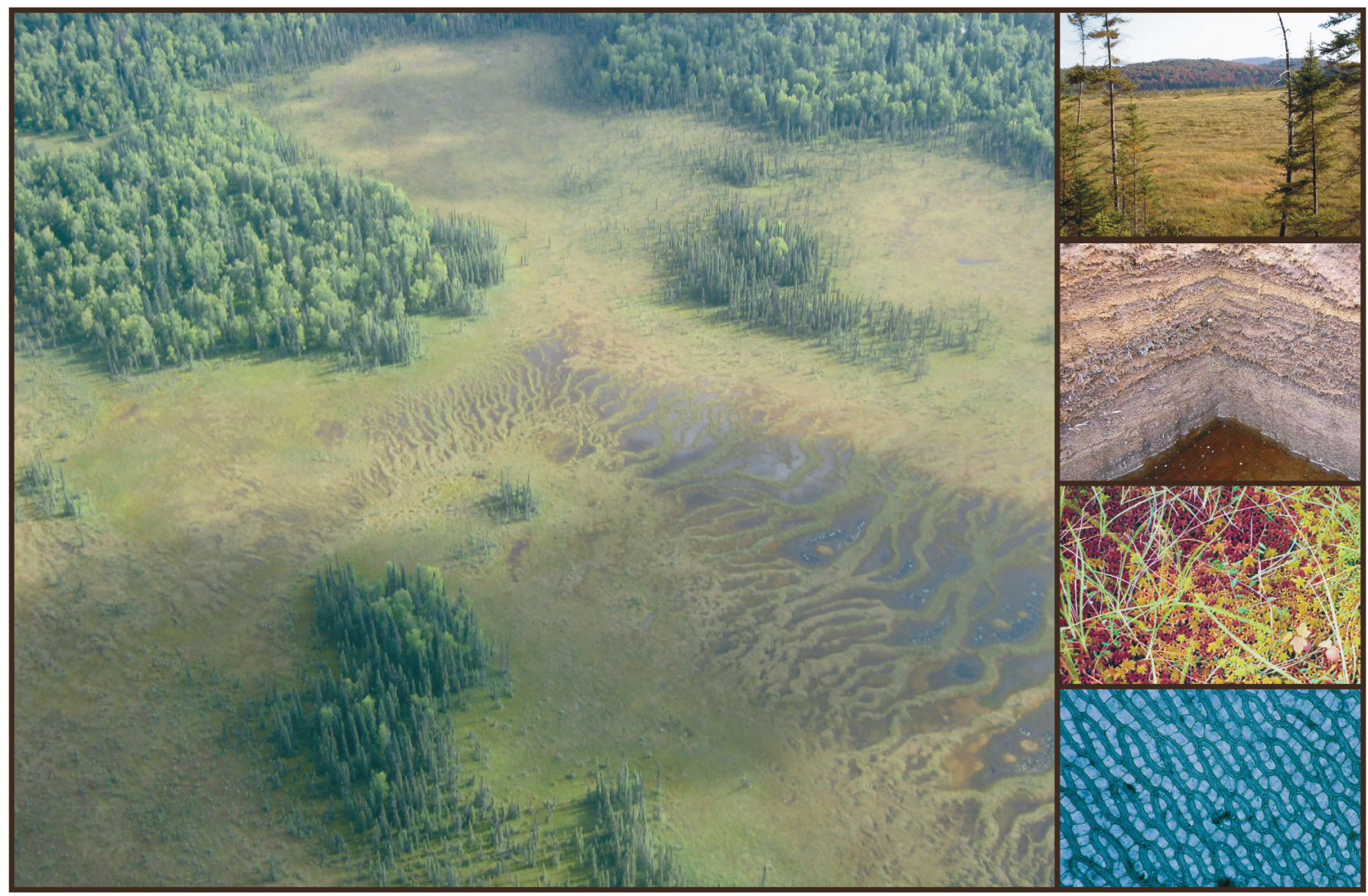

Peatlands are globally significant carbon reservoirs, and also comprise rich archives of past climatic and environmental change and carbon flux. This issue of PAGES news spotlights recent applications of peatland archives relevant to understanding the past, present and future of Earth. This composite image shows components of peatlands at varying scales; an aerial photo of an Alaskan peatland, a New York peatland at ground-level, an excavated Argentinean peat section, a close up of a Sphagnum (moss) peatland surface, and a photomicrograph of Sphagnum leaf cells. Photo credits on back cover. 


\section{New PAGES publications}

The proceedings of the PAGES $1^{\text {st }}$ Young Scientists Meeting are now published in the open access online journal IOP Conference Series: Earth and Environmental Science. See the short proceedings "tasters" on page 43 of this newsletter, and visit http://iopscience.iop.org/1755-1315/9/1 for full articles.

Furthermore, two special issues have recently been published, both arising from the PAGES supported "International Workshop on Late Quaternary Environmental Changes in Arid Lands", held in 2007 in Inner Mongolia, China. The first, edited by Xiaoping Yang and Louis A. Scuderi titled "Environmental changes in arid and semiarid regions" was published in Quaternary Research (73(1): 1-162). The second, titled "Land degradation and rehabilitation in ecologically fragile areas", was guest edited by Xiaoping Yang and Arthur Conacher and was published in Geophysical Research (47(1): 1-94).

Finally, a paper resulting from the PAGES-led IGBP-SCOR Fast Track Initiative on Ocean Acidification was published in Nature Geoscience (3: 196-200). Ridgwell and Schmidt compare the two major carbon cycle perturbations, that of today and of the Paleocene-Eocene Thermal Maximum, to provide "Past constraints on the vulnerability of marine calcifiers to massive carbon dioxide release".

\section{New PAGES committee members}

Three new members joined the PAGES Scientific Steering Committee (SSC) in 2010. They replace Jérome Chappellaz, Eystein Jansen, Peter Kershaw and Ricardo Villalba who rotated off the committee at the end of 2009 after six years of dedicated service.

Alan Mix, a Professor at the College of Oceanic and Atmospheric Sciences, Oregon State University, is a paleoceanographer with a broad background spanning stable isotope geochemistry, micropaleontology and marine geology, reconstructing hydrographic conditions and global-scale circulation changes on orbital and millennial timescales. Alan has a long history of participation

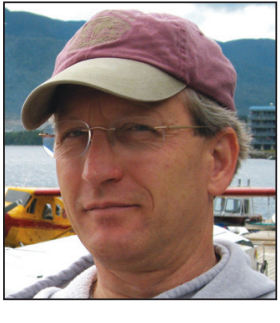
in community efforts, including the CLIMAP and EPILOG/MARGO projects on the reconstruction of the glacial surface ocean and the IMAGES and ODP/IODP programs on the exploration of the ocean and its sediment records.

Denis-Didier Rousseau is a Senior Scientist at the French Centre National de la Recherche Scientifique and Adjunct Professor at the Columbia University, New York. He has a wide range of experience in Quaternary research and paleoclimatic reconstructions, and has worked in diverse environments from Greenland to China. His central area of expertise is in eolian deposits (loess) and the associated climatic and environmental conditions. Denis leads the PAGES Working Group ADOM on last glacial atmospheric circula-

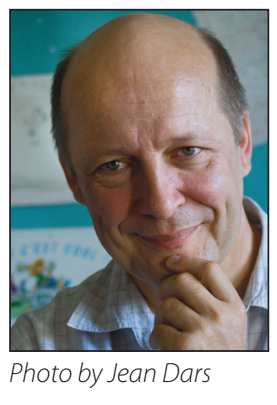
tion dynamics. Furthermore, he has done a lot for the international paleocommunity, as former vice president of INQUA, cofounder and co-chief-editor of the openaccess journal Climate of the Past, and as current president of the Climate division of the EGU.

Chris Turney is a Professor at the School of Geography, Exeter University, UK, where he leads the Environmental Change Research Group. Chris's research interests are varied, which has led to his substantial contributions to a range of areas including dating techniques, isotopic studies, archeology, climate science, fire and

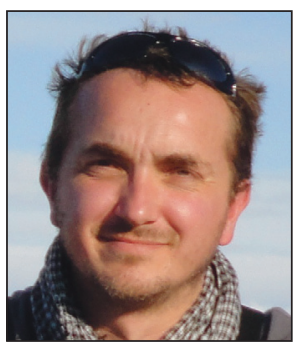
tree ring analysis. He is the current leader of the PAGES Aus2k Working Group on Australasian climate during the last two millennia and was the leader of the INQUA-INTIMATE (INTegration of Ice, MArine \&TErrestrial records 60 to $8 \mathrm{ka}$ ago) project and their Australasian and North Atlantic sub-groups.

The SSC also recently voted in two new Executive Committee (EXCOM) members: Takeshi Nakatsuka (Nagoya, Japan) and John Dearing (Southampton, UK) have taken over from Jérome Chappellaz and Ricardo Villalba.

\section{EXCOM meeting: New Working Groups and workshops}

At its November 2009 meeting in Switzerland, PAGES EXCOM adopted the "Synthesis of Transient Climate Evolution of the last 21-ka (SynTraCe-21)" project as a new Working Group (WG) centered in the Focus 3 "Rapid Climate Change" Theme. This WG will focus on climate evolution and abrupt climate changes over the last $21 \mathrm{ka}$. The WG is led by Zhengyu Liu, University of Wisconsin-Madison, USA.

EXCOM also granted support for 9 workshops of PAGES WGs and for 3 PAGES-relevant workshops from external groups. For more information see the calendar on page 42 of this issue or check the website on PAGES co-sponsored activities at http://www.pages-igbp.org/ cgi-bin/WebObjects/calendar.woa/wa/ support?year $=2010$

\section{PAGES networking online}

PAGES is now on Facebook and invites everyone to join (or become a "fan" in Facebook jargon) to receive real-time alerts and updates on science findings, events, jobs and other news relevant to paleoresearch. Try it out on http://www.facebook. com/pages/PAGES-Past-Global-Changes/311087195815

\section{Tim Partridge Obituary}

We note with sadness that Timothy Cooper Partridge, Professor at the University of the Witwatersrand in Johannesburg, South Africa, passed away in December 2009. Tim, a renowned paleoclimatologist, paleoanthropologist and hydrogeologist, served on the PAGES SSC from 1994 to 1999 and was a protagonist of the southerly perspective to the PAGES Pole-Equator-Pole transect (PEP III).

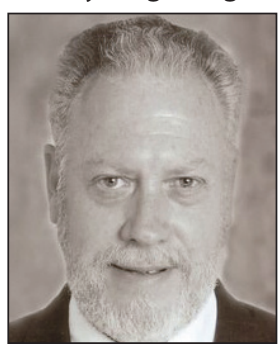

\section{Next issue of PAGES news}

The $2^{\text {nd }}$ issue of PAGES news for 2010 will contain a special section on "Paleofire" and will be guest-edited by Cathy Whitlock and Willy Tinner. If you would like to contribute, contact Cathy (whitlock@ montana.edu) or Willy (willy.tinner@ips. unibe.ch) directly. Equally welcome are "open" science highlights, meeting reports or program news (contact Louise Newman newman@pages.unibe.ch to contribute). Deadline for all submissions is 10 May. Find instructions for authors on the PAGES website at http://www.pages-igbp.org/ products/newsletters/instructions.html 


\title{
Editorial: Peatlands - paleoenvironments and carbon
} dynamics

\author{
Stephen T. Jackson ${ }^{1}$ and Dan Charman ${ }^{2}$ \\ 'Department of Botany and Program in Ecology, University of Wyoming, Laramie, USA; Jackson@uwyo.edu \\ ${ }^{2}$ School of Geography, University of Exeter, UK; d.j.charman@exeter.ac.uk
}

Some of the earliest records of global change came from peatland archives. As early as 1837, Japetus Steenstrup published stratigraphic and macrobotanical analyses of Danish bogs. His study not only inspired the pioneering paleoclimatology of Blytt and Sernander later in the century, but had more immediate influence on Lyell, Darwin and Forbes, supporting their conclusions from biogeographic patterns that Europe had undergone significant climate changes not long before.

Peatlands remain an important paleoenvironmental archive. They combine relatively rapid accumulation rates, copious in situ organic material, hydroclimatic sensitivity, and diverse paleoenvironmental proxies to provide a rich store of environmental history over much of the globe (Fig. 1). Furthermore, the peat that provides the archives plays a key role in the global carbon cycle as one of the largest soil carbon stores on Earth. This issue of PAGES news highlights recent and ongoing applications of peatland archives to important problems in paleoclimatology, human activities, and global carbon dynamics. Development of this special issue was inspired in part by discussions at an international peatland-archives workshop in Estonia in May 2009, jointly sponsored by PAGES, INQUA, Quaternary Research Association, U.S. National Science Foundation, and the University of Tartu.

Until recently, most peatland paleoclimate research has been concentrated in Europe, where density and distribution of peatland records is sufficient to support synoptic-scale studies. In the opening article, Frank Chambers and colleagues describe results from the ACCROTELM synthesis of late Holocene European multiproxy records, showing spatial coherence in major hydrological change that corresponds to independent lake-level records. Peatland archives are now also being increasingly exploited in paleoclimate studies in North America. Robert Booth and colleagues show that Medieval-period drought was much more extensive than previously thought, and explore links to broader changes in sea surface temperature variability. They describe a developing synoptic network of peatland records, deliberately designed to test specific hypotheses concerning mechanisms under- lying late Holocene drought occurrence and climate dynamics.

Many peatlands offer extraordinary opportunities for high-precision chronologies, by virtue of their rapid accumulation, lack of sediment mixing, and abundant carbon for dating. Maarten Blaauw and colleagues have used peatlands for the development of new statistical approaches based on wiggle-matching of chronologies that provide narrowed and better-defined uncertainty estimates. Here, they show a powerful application of this approach to enable probability estimates for synchroneity in events recorded in independently derived records. Although these techniques have been developed and tested on peat sequences, they have broad applicability to other sedimentary archives. Coupling of highly resolved chronologies with proxy data can yield decadal-precision records spanning several millennia. Van Geel and Mauquoy apply such peatland chronologies to assess the influence of late Holocene solar variability on climate of northern Europe. Finally, in the field of paleoclimate research, attention is turning to the potential for testing and calibrating high-resolution records against instrumental climate data. Lamentowicz and colleagues describe one such application from a high-precision peatland record from the Swiss Alps.

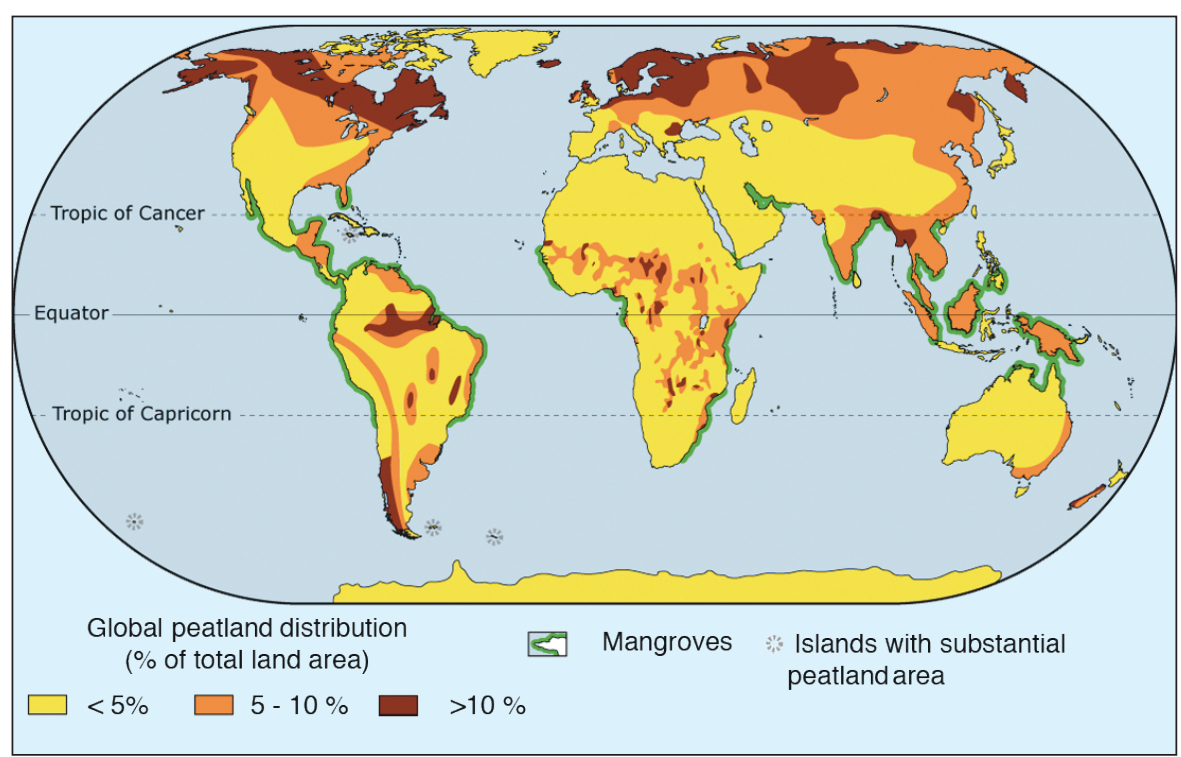

Figure 1: Generalized distribution map showing main areas of peatland occurrence expressed as a proportion of the landscape covered. Much of the existing work on peatland archives of past change has been concentrated in Europe and North America but other regions hold considerable potential. Even in areas where peatlands occupy only a limited proportion of the landscape, small peatlands often occur in hydrologically and microclimatically suitable locations. Based on Lappalainen (1996) and Charman (2002). isotope analysis. Erin McClymont and colleagues describe recent advances in organic geochemistry and compoundspecific analysis of stable isotope proxies in peatlands. These analytical advances are opening a wide array of opportunities for refined paleoenvironmental inference from peatlands, including reconstruction of temperature, hydrology, and carbon cycle processes such as methanogenesis. Bing Hong and colleagues provide an application of compound-specific stable-isotope analysis to the important and topical question of Holocene history of the Asian monsoon systems, using $\delta^{13} \mathrm{C}$ and $\delta^{18} \mathrm{O}$ analyses of sedge peat in China. François De Vleeschouwer and colleagues present a different geochemical perspective: analysis of trace metals (particularly lead) in European peatlands to identify background flux and deposition from human activities.

Peatlands are important in the Earth system as a vast carbon store, providing a very large long-term sink of carbon dioxide, but also acting as a source of methane. They have a higher carbon density

These studies all utilize well-established
peatland proxies: plant macrofossils, testate amoebae, humification indices, and pollen. An emerging frontier in peatland research is the application of organic 
than any other ecosystem, globally comprising some $550 \mathrm{Gt}$ C. As such, they comprise a vital component of the global carbon budget, and by providing time-series of site-specific carbon accumulation they can also play an important role in understanding many of the controls and feedbacks in global carbon dynamics. David Beilman and colleagues discuss the role of northern peatlands as carbon sinks during the Holocene, and reveal new insights into the contribution of these vast peatlands to the global carbon cycle emerging from analysis of large-scale patterns of peat accumulation and spread over time. Tropical peatlands are not as well known as northern and boreal peatlands, but are receiving increasing attention in view of their very high carbon density and potential for human- and climate-driven conversion from atmospheric sinks to sources. Sue
Page and colleagues discuss the extensive peatlands of Southeast Asia in this context and demonstrate the severity of impacts on the global atmosphere when such carbon-rich ecosystems are disturbed. Many tropical peatlands remain undiscovered or imperfectly known. Outi Lähteenoja and Katherine Roucoux describe recently discovered ombrotrophic (precipitation-fed) peatlands in the Upper Amazon basin, and discuss their importance for carbon cycling and their scientific potential as paleo-archives.

The interactions among climate, carbon and peatlands are complex, and there are substantial risks of unexpected feedbacks and rapid transformations. Understanding these interactions will require increasing engagement between the peatland paleoscience community and scientists studying processes of gas exchange and energetics in modern peatlands and related ecosystems. The final paper by Torben Christensen and colleagues highlights improved understanding of methane dynamics in peatlands in permafrost regions and argues for greater integration of process studies with peatland paleoscience to better understand methane flux in high-latitude settings. This argument is broadly applicable to peatlands throughout the world; linking process and paleo-studies in peatlands will help advance our understanding of peatland dynamics, climate variability and the risks of unwelcome carbon-cycle feedbacks in the centuries ahead.

\section{References}

Charman, D.J., 2002: Peatlands and environmental change, John Wiley, Chichester.

Lappalainen, E., 1996: Global peat resources, International Peat Society, Finland.

\section{Peatland archives of late-Holocene climate change in northern Europe}

Frank M. Chambers ${ }^{1}$, J.R.G. Daniell ${ }^{1}$ and ACCROTELM Members ${ }^{2}$

${ }^{1}$ Centre for Environmental Change and Quaternary Research, University of Gloucestershire, UK; fchambers@glos.ac.uk ${ }^{2}$ for list, please see online references at http://www.pages-igbp.org/products/newsletters/ref2010_1.html

\section{Peatland archives in northern Europe now provide multi-proxy decadal records of past environmental change for the mid and late Holocene.}

Peatlands in northern Europe have long been recognized as a climate archive, yielding the first climatostratigraphic division of the Holocene-the Blytt-Sernander scheme (Blytt, 1876; Sernander, 1908); however, their detailed exploitation awaited refutation of long-standing misconceptions about bog growth (cf., Backéus, 1990). Barber (1981) proposed instead that ombrotrophic (precipitationfed) bogs provide a continuous record of past hydrological change, because they are "directly coupled" to the atmosphere. Though omitted as a climate archive from Bradley's (1999) compendium of paleoclimatology, studies on peat bogs have since gained greater prominence (Chambers and Charman, 2004); a wide array of climate proxies has been developed, involving an increasing number of specialists from a range of disciplines (de Jong et al., in press).

European peat-climate research has concentrated on blanket bogs (e.g., western Ireland; UK uplands; western Norway) and raised bogs (e.g., central Ireland; Britain; Denmark; northern Germany; southern Sweden; Estonia; southern Finland; Poland; Czech Republic). High rainfall, typically $>1250 \mathrm{~mm} \mathrm{a}^{-1}$, sustains the blanket bogs, but raised bogs exist in areas of much lower precipitation. The latter owe their origin to low relief and impeded drainage, but their domed growing surfaces are (like blanket bogs) hydrologically isolated from groundwater. Some $90 \%$ of the mass of an actively growing bog is water, held mainly in the anoxic catotelm (bottom layer of peat permanently below the water table) where decay processes are markedly reduced compared with the thin upper layer of the bog, the acrotelm, which experiences a seasonally fluctuating water table, and in dry conditions can experience much higher decay rates.

\section{ACCROTELM project}

To examine the synchronicity, direction, magnitude, rate and causes of past climate changes in northern Europe, a recent, European Commission-funded project "Abrupt Climate Changes Recorded Over The European Land Mass" (ACCROTELM; Chambers et al., 2007a) included an East-West transect of ombrotrophic bogs, from Estonia and Finland to Ireland, for which proxy-climate data were generated for up to the past $4.5 \mathrm{ka}$. The E-W transect extended across the Atlantic to Newfoundland (Hughes et al., 2006), while a bog in northern Spain was included at the southern ombrotrophic limit. Lake sites also featured, allowing comparison with data on changing lake levels in westcentral Europe (Magny, 2006).

ACCROTELM researchers developed and applied revised protocols of three proxy-climate measures in "multi-proxy" studies of the bogs: (1) the degree of peat humification-largely a measure of the decay rate of peat before becoming incorporated in the permanently saturated catotelm (cf., Aaby and Tauber, 1975; Aaby, 1976; Blackford and Chambers, 1993; Borgmark, 2005); (2) quantitative leaf count macrofossil analysis (QLCMA) of vegetation remains in the peat-reflecting the former surface plant community (Barber et al., 1994; McClymont et al., 2008, 2009); and (3) the species assemblage of testate amoebae-used to estimate water-table depth, calibrated using a transfer function from modern "training sets" (Charman et al., 2007). Each proxy is (to a greater or lesser degree) dependent on the prevailing environmental conditions at the time of peat formation, and reflects (with some caveats) past climate. These three principal measures provided a continuous record of past climate change, with dating provided by AMS ${ }^{14} \mathrm{C}$ (Yeloff et al., 2006), ${ }^{210} \mathrm{~Pb}$ and spheroidal carbonaceous particles. 


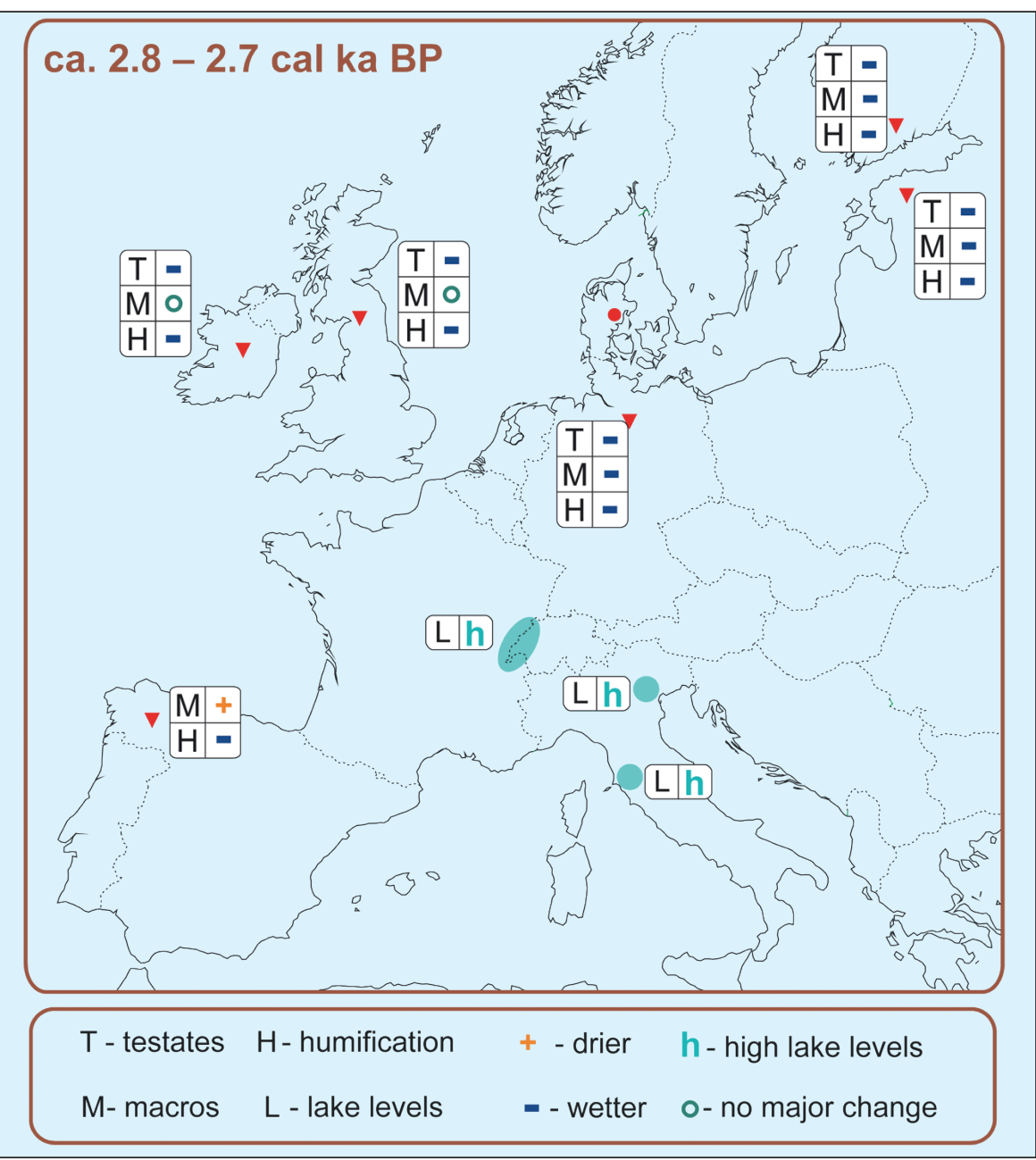

Figure 1: Schematic ACCROTELM project map, showing direction of change in the century following the "2.8 cal ka BP event", as indicated by up to three proxy-climate records at each of six bog sites (red triangles; red circle shows location of younger Danish bog site highlighted in Fig. 2) and coincident high lake-level records of lake sites. Note: plant macrofossil evidence from the bog site in Finland (see Väliranta et al., 2007) actually shows pronounced dryness commencing ca. $2.82 \mathrm{cal} \mathrm{ka} \mathrm{BP}$, so this schematic map is potentially misleading. (View ACCROTELM film at http://noorderlicht.vpro.nl/artikelen/31866284/)

\section{Abrupt climate shifts}

Additional analyses (e.g., pollen, biomarkers) were concentrated in three "Focus Intervals" of abrupt climate changes, centered on ca. 4.2 cal ka BP, 2.8 cal ka BP, and the period AD 800-1800 covering the Medieval Warm Period and Little Ice Age. Pollen analytical data were used to investigate the effects of climate changes on human populations (e.g., Yeloff et al., 2007a; Sillasoo et al., 2009); analyses of biomarkers were conducted to trace Sphagnum species (Bingham et al., 2009); non-pollen microfossils were also recorded (van Geel, 2006; Yeloff et al., 2007b).

The most coherent signal of past abrupt climate change is shown in the ACCROTELM site record ca. 2.8-2.7 cal ka BP, when proxy-climate measures from the majority of bog sites showed evidence of increased climate wetness (Fig. 1). Indeed, ca. $2.8 \mathrm{cal} \mathrm{ka} \mathrm{BP}$ is the most notable climate shift recorded in many European bogs, when increased wetness recorded in continental peat bogs, corresponding generally to the Blytt-Sernander Subboreal-Subatlantic transition, apparently coincides with a marked reduction in solar then reverted to higher moisture wh solar activity recovered. This hypothesis remains to be tested. Others have linked abrupt climate changes recorded in bogs with past solar variability (van Geel et al.,
1996; Chambers and Blackford, 2001; Speranza et al., 2002; Blaauw, 2003; Blaauw et al., 2004; Mauquoy et al., 2002, 2004; Plunkett and Swindles, 2008; van Geel and Mauquoy, this issue). Notable, however, is the record from ACCROTELM lakes, in which higher lake levels in west-central Europe, indicating cooler and wetter conditions (Magny, 2006; Magny et al., 2009), corresponded with the wetter climate inferred from most ACCROTELM bogs (Fig. $1)$.

ACCROTELM peatland data have decadal resolution (Väliranta et al., 2007), and in Focus Period III (AD 800-1800), reconstructions of water level changes from testate amoebae data (Fig. 2) imply a close relationship with putative solar-forcing, although the multi-proxy peatlands data are not unequivocal. The inferred magnitude of change reinforces evidence from other archives for the severity of the Little Ice Age in northern Europe.

\section{Spatial variability of the climate signal}

The controlling influence of water on peatland development led many peat scientists to assume that the paleoclimate records obtained from peat bogs largely reflect past changes in precipitation, rather than temperature. Comparisons between instrumental climate data and high-resolution water table reconstructions corroborate this, but show that the precipitation-evaporation balance largely determines water table changes (Charman et al., 2007; Charman, 2007; Booth et al., this issue). Summer temperature is a secondary influence, albeit a more significant one in continental settings (Charman, 2007; Charman et al., 2009). Generally, the ACCROTELM records showed considerable spatial variability of the European climate through time. This is unsurprising if the principal influence upon peatlands is precipitation, as it is to be expected that there would be less spatial coherence in a precipitation signal than in one of temperature.

\section{Future prospects}

Peat has played a major role in reconstructing the late Holocene of northern Europe, but ACCROTELM set an agenda indicating that a fuller picture of past European climate may be obtained when multi-proxy peat bog records are combined with data from complementary archives such as lakes (e.g., Magny et al., 2009), exemplified subsequently by de Jong et al. (2009) and Andersson et al. (in press). Peat can also reveal other climatic aspects, notably storminess, through examination of its in- 


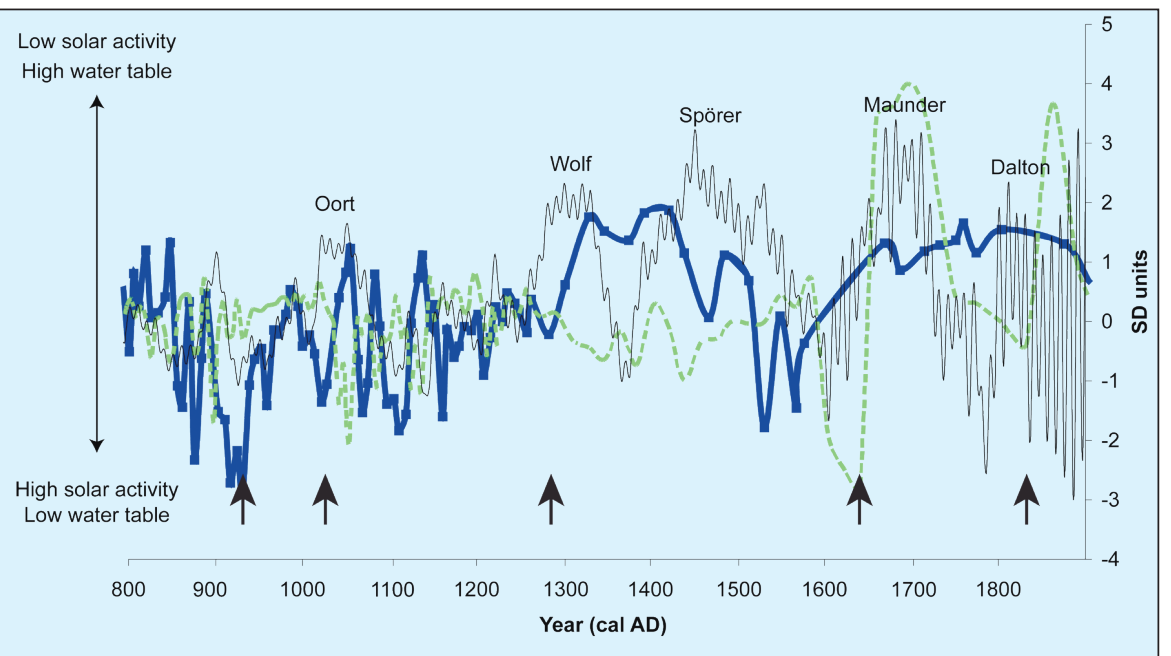

Figure 2: Focus Interval III (cal a AD 800-1800) of the ACCROTELM project, showing proxy-climate data from the Danish bog site: Blue line $=$ normalized testate amoebae water table reconstruction (inverted); Green dashed line $=$ plant macrofossil Dupont wetness index; Gray line $=$ normalized ${ }^{14} \mathrm{C}$ relative production rate (q). Arrows indicate start of significant rises in water table. Historical solar minima are indicated. Figure adapted from Mauquoy et al., 2008. For further discussion of solar-climate relationships in peat records, see van Geel and Mauquoy, this issue.

organic and elemental content (de Jong and research continues to extract a sepaet al., 2006; De Vleeschouwer et al., 2009), rate temperature signal from biomarkers.

\section{References}

Chambers, F.M., Daniell, J.R.G. and Brain, S.A., 2007a: Climate Change featuring the ACCROTELM project: dissemination of a European RTD project by film and DVD. In: Filho, W.L., Mannke, F. and Schmidt-Thome, P. (Eds) Information, Communication and Education on Climate Change-European Perspectives, Peter Lang, Frankfurt am Mein, 165-173.

Charman, D.J., Blundell, A. and ACCROTELM members, 2007: A new European testate amoebae transfer function for palaeohydrological reconstruction on ombrotrophic peatlands, Journal of Quaternary Science, 22: 209-221.

de Jong, R., et al., in press: Peatlands and climate. In: Dodson, J. (Ed.) Changing Climates, Earth Systems, and Society, Elsevier.

Magny, M. Peyron, 0 Gauthier, E, Rouèche, Y, Bordon, A, Billaud, Y, Chapron, E., Marguet, A., Pétrequin, P. and Vannière, B., 2009: Quantitative reconstruction of climatic variations during the Bronze and early Iron ages based on pollen and lake-level data in the NW Alps, France, Quaternary International, 200: 112-110.

Mauquoy, D., Yeloff, D., van Geel, B., Charman, D.J. and Blundell, A. 2008: Two decadally resolved records from north-west European peat bogs show rapid climate changes associated with solar variability during the mid-late Holocene, Journal of Quaternary Science, 23: 745-763.

For full references please consult:

http://www.pages-igbp.org/products/newsletters/ref2010_1.htm

\section{Using peatland archives to test paleoclimate hypotheses}

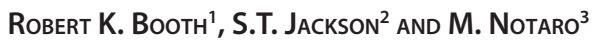

${ }^{1}$ Earth and Environmental Science Department, Lehigh University, Bethlehem, USA; robert.booth@lehigh.edu

${ }^{2}$ Department of Botany and Program in Ecology, University of Wyoming, Laramie, USA; ${ }^{3}$ Center for Climatic Research, University of Wisconsin,

Madison, USA

\section{A network of peatland surface-moisture reconstructions is providing a richly detailed, synoptic-scale perspective on past hydroclimate variability in many regions, well suited to investigate the spatial structure and dynamics of past hydroclimate changes.}

Synoptic networks of proxy records of hydroclimate variation provide an important means for identifying long-term relationships between oceanic forcing and continental-scale patterns of decadal- to centennial-scale drought variability, and for assessing responses of the coupled oceanatmosphere system to changes in external forcing. Tree-ring records provide the gold standard in this context, because of their demonstrated hydroclimatic sensitivity, temporal precision and accuracy, robustness of proxy inferences, and widespread distributions in space. However, tree-ring records are limited in temporal depth and spatial coverage, and inferences can be confounded by other factors, particularly in humid regions. Alternative archives are desirable to extend temporal depth, corroborate tree-ring inferences, and add complementary information and sensitivity at different time and spatial scales. Among the alternative archives are ombrotrophic peatlands, which are sensitive to hydroclimatic variation at decadal timescales, capable of sub-centennial chronological precision and accuracy, contain multiple paleohydrological and paleoclimatic proxies (Fig. 1a), and are widely distributed at mid- to high latitudes in the northern and southern hemispheres. Comparison of peatland proxies with instrumental records

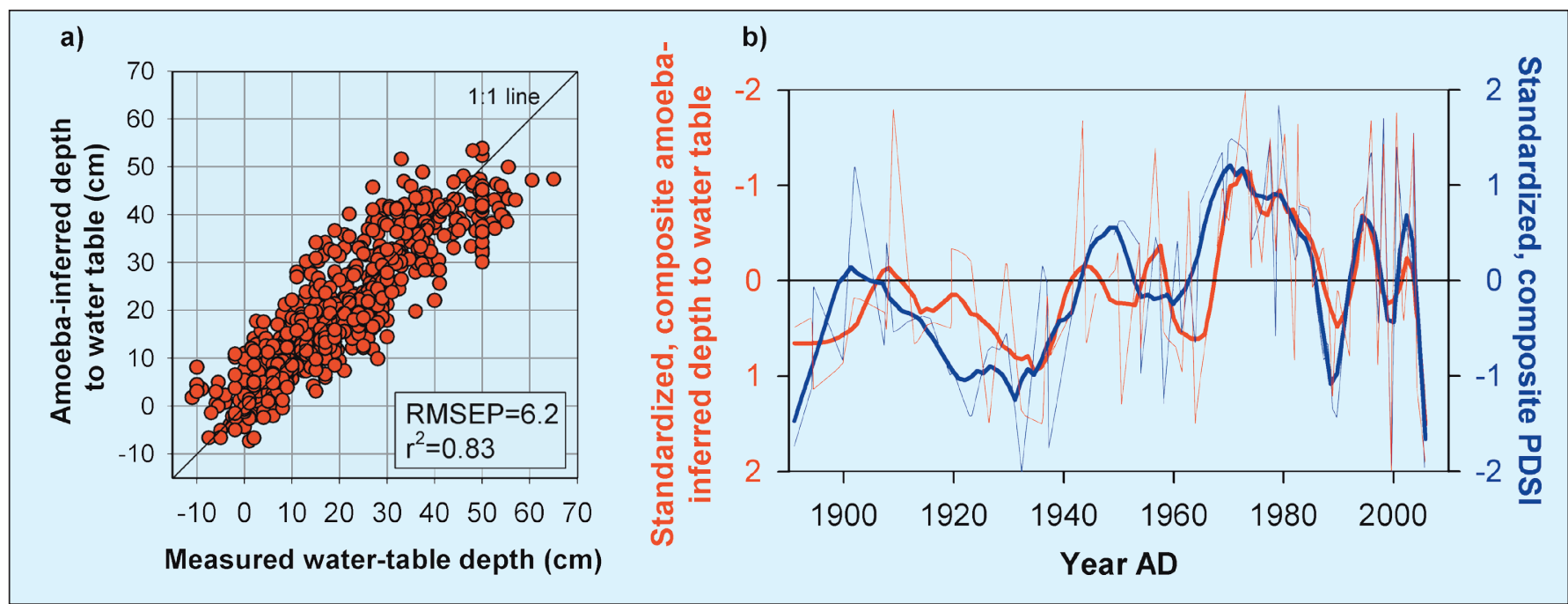

Figure 1: Validation of the hydrologic and climatic sensitivity of peatland surface-moisture reconstructions. a) Cross-validation of testate amoeba transfer function for mean annual water-table depth, based on over 650 samples from North American peatlands (modified from Booth, 2008). b) Comparison of a composite testate amoebae-inferred paleohydrological reconstruction (depth to water table) derived from three ${ }^{210} \mathrm{~Pb}$-dated peatland records (red lines) and instrumental records of Palmer Drought Severity Index (PDSl; blue lines) (data from Booth, 2010). Thick, solid lines show approximately decadal-scale smoothing of the composite datasets (thin lines). 
confirms the robustness and temporal precision of paleoclimatic inferences (Fig. 1b).

Over the past few years, significant advances have been made in our understanding of the response of peatland systems to climate changes, facilitating the climatic interpretation of peatland paleoenvironmental records. Peatland surface-moisture reconstructions generally reflect the length and severity of the summer moisture deficit, which in ombrotrophic peatlands is primarily controlled by summer precipitation (Charman, 2007; Charman et al., 2009). Temperature effects are secondary, manifested through evapotranspiration (Charman, 2007; Charman et al., 2009). Not surprisingly, good relationships exist between surface-moisture reconstructions and integrative hydroclimate indices such as the Palmer Drought Severity Index (PDSI) (Booth, 2010). However, because peatlands may undergo long-term developmental changes unrelated to climate (Charman et al., 2006), and are adaptive systems with internal processes that confer some degree of self-regulation (Dise, 2009), paleoclimate responses may not be recorded equally strongly at all temporal frequencies. For example, millennial and multi-millennial changes in surface moisture vary greatly among nearby sites in the United Kingdom (Charman et al., 2006), although shorterterm perturbations are generally coherent there and elsewhere in Europe and North America (Booth et al., 2006). Therefore, the hydroclimatic signal in peatland records may be most robust at multi-decadal to sub-millennial timescales.

\section{Investigating drought climatology}

An emerging network of peatland records in North America is providing new perspectives on moisture variability in humid regions, complementing and extending the tree-ring record from semi-arid regions, as well as hydroclimate histories derived from other natural archives. These efforts are motivated by the revelation that characteristic spatial modes of drought and precipitation variability, often with important centers of action in humid regions, have been driven in part by oscillations in sea-surface temperature (SST) anomalies sometimes spanning decades or more (Dai et al., 2004; McCabe et al., 2004, 2008; McCabe and Palecki, 2006; Seager et al., 2008; Woodhouse et al., 2009) (Fig. 2). Modeling efforts underscore the importance of these teleconnections, and are beginning to reveal potential underlying mechanisms (Sutton and Hodson, 2005, 2007; Seager et al., 2007). However, our knowledge of SST variability and associated teleconnections is primarily derived from a mere century of instrumen- a) 1 st EOF of annual PDSI (20\%)

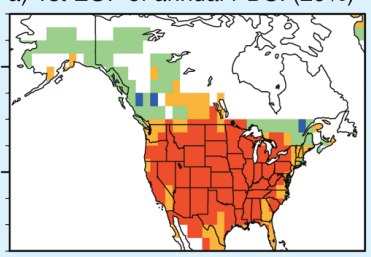

c) 2nd EOF of annual PDSI (12\%)

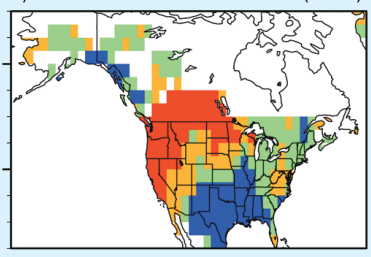

e) 3rd EOF of annual PDSI (10\%)

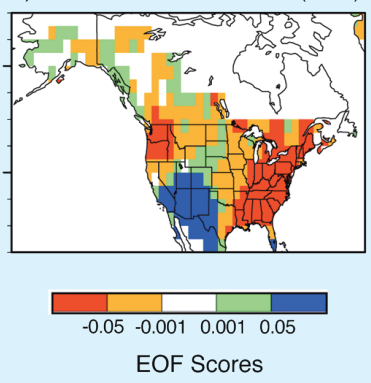

b) SST correlations with 1st EOF

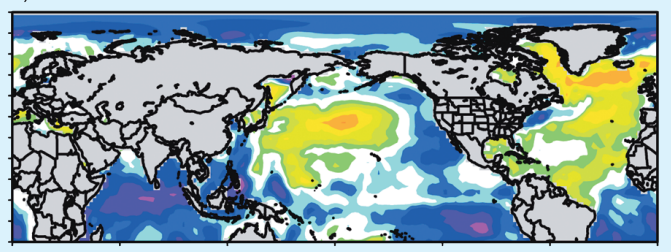

d) SST correlations with 2nd EOF

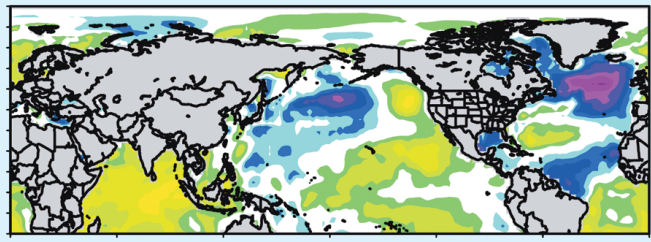

f) SST correlations with 3rd EOF

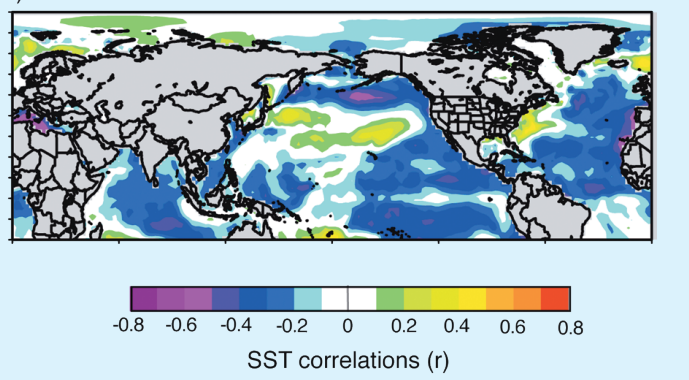

Figure 2: Natural modes of variability in low-pass filtered Palmer Drought Severity Index (PDSI) data from North America over the last century (1900-1998) as indicated by Empirical Orthogonal Function (EOF) analysis (a, c, e) (methods detailed in Booth et al., 2006). Percent variance explained by each EOF is indicated. Correlations between sea surface temperatures (SSTS) and the three dominant EOFs indicate SST patterns associated with dominant modes of hydroclimate variability $(\boldsymbol{b}, \boldsymbol{d}, \boldsymbol{f})$. A network of peatland records has been designed to test the hypothesis that similar modes of drought variability have affected North American hydroclimate during the past several thousand years, with ongoing work in the Great Lakes region, the Pacific Northwest, and northeastern North America.

tal records, and rising global temperatures are expected to alter the oceanic forcing of drought patterns in the coming decades (Jansen et al., 2007). In addition, the relative importance of oceanic forcings (i.e., Atlantic vs Pacific influences) on North American hydroclimate is still unclear (Sutton and Hodson, 2005; McCabe and Palecki, 2006; Cook et al., 2007; Goodrich, 2007; Graham et al., 2007; Seager et al., 2007; Feng et al., 2008; McCabe et al., 2008), as are relationships to synoptic modes of atmospheric circulation (Trouet et al., 2009; Helama et al., 2009) and external forcing (i.e., solar variability and volcanism). Delineation of past spatial modes of moisture variability, when interpreted in conjunction with the growing body of proxy SST records and estimates of changes in external forcing, provides a means to assess long-term dynamics of the coupled ocean-atmosphere system.

When viewed along with the tree-ring record and other natural archives, peatland reconstructions from the Great Lakes region of eastern North America reveal that many high-magnitude fluctuations in water balance during the past 3 ka were spatially extensive, extending from the western United States into eastern North America (Fig. 3; Cook et al., 2004; Mason et al., 2004; Booth et al., 2006; Shuman et al., 2009). Increased multidecadal- to cen- tennial-scale hydroclimate variability also characterized intervals with widespread drought (Fig. 3a). These widespread droughts may represent amplification or persistence of modes of decadal- to multidecadal hydroclimate variability similar to that of the last century (Fig. 2). For example, peatland records clearly indicate that Medieval Climate Anomaly (MCA) droughts, which have been well documented in the western US and Great Plains (central North America) (e.g., Cook et al., 2004; Mason et al., 2004; Daniels and Knox, 2005; Sridhar et al., 2006; Meko et al., 2007; Miao et al., 2007), also extended deep into the Great Lakes region (Booth et al., 2006; Shuman et al., 2009) (Fig. 3a). The widespread pattern of drought is similar to a mode of variability experienced during the $20^{\text {th }}$ century (Fig. 2a), although more records are needed to fully test this hypothesis, particularly from humid regions at mid-to high-latitudes.

Tree-ring based reconstructions of PDSI from the Great Lakes region do not clearly record the MCA droughts (Herweijer et al., 2007); therefore, hypotheses on the mechanisms underlying these events have tended to focus on atmospheric and ocean dynamics that induce drought in western North America only, such as prolonged La Niña-like conditions in the tropical Pacific (Cook et al., 2004, 2007). Although 


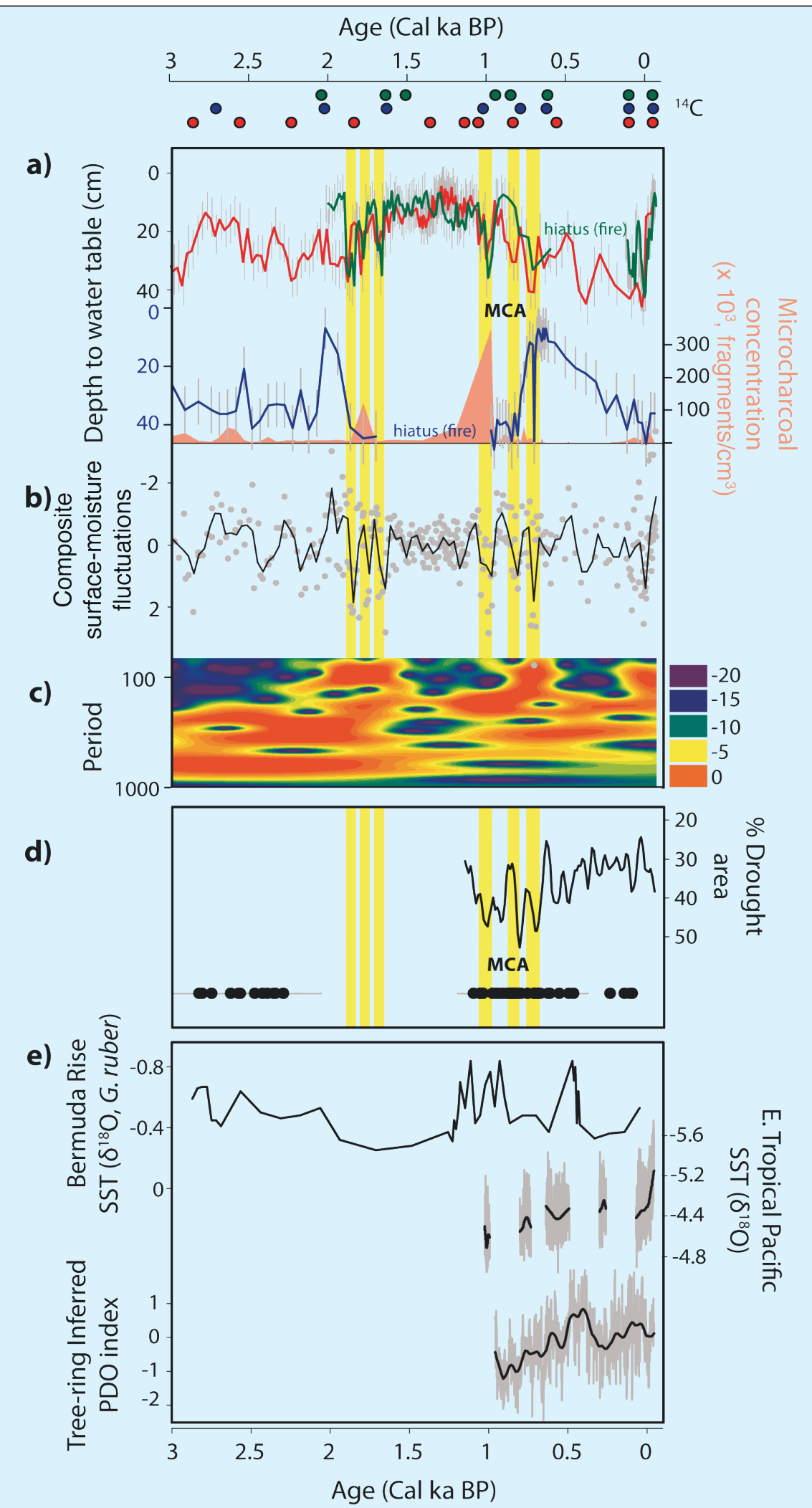

Figure 3: a) Ombrotrophic peatland archives of late Holocene environmental variability in the Great Lakes region (eastern N. America). Green: Hole Bog in north central Minnesota, Blue: Irwin Smith Bog in northeast lower Michigan, Red: Minden Bog in southeast Michigan (Booth et al., 2006, unpublished). Radiocarbon dates indicated at top and color-coded to match sites. All reconstructions based on testate amoebae (see Booth and Jackson, 2003; Booth et al., 2006). Bootstrapped error bars in gray ( $n=1000)$. Yellow bars indicate high-magnitude, multidecadal drought events that occurred at all three sites. A peat fire at $\sim 1 \mathrm{ka} \mathrm{BP} \mathrm{removed} \mathrm{lower} \mathrm{peat} \mathrm{from} \mathrm{Irwin} \mathrm{Smith} \mathrm{Bog,}$ micro-charcoal concentrations are shown in pink. b) Composite record from the three sites developed by removing the long-term patterns that may be unrelated to climate (Charman et al., 2006), standardizing the three datasets (gray dots; standardized units), and calculating a 50-year moving average (black line). c) Wavelet analysis of composite record highlighting increased centennial and sub-centennial variability during drought intervals.d) Tree-ring record of drought in western USA (black line; Cook et al., 2004) and records of dune activity (e.9., aeolian sand movement) on the Great Plains (black dots are activity dates with error bars; Goble et al., 2004; Mason et al., 2004: Miao et al., 2007), highlighting the widespread droughts of the Medieval Climate Anomaly (MCA). e) Atlantic (Keigwin, 1996) and Pacific (Cobb et al., 2003; MacDonald and Case, 2005) proxy SST records, from which preliminary patterns suggest that the MCA droughts may have resulted from the combined influence of anomalous Atlantic and Pacific SSTs, perhaps also linked to changes in the North Atlantic Oscillation (Trouet et al., 2009: Helama et the eastward and northward extent of the droughts in North America is still unclear, the occurrence of significant droughts in the peatland records from the Great Lakes suggests that additional hypotheses regarding mechanisms and dynamics should be explored, including modulation of Pacific influences by SST variability in the Atlantic source region. Recently, MCA modeling efforts have started to incorporate this idea (Seager et al., 2007; Feng et al., 2008). For example, using a set of modeling experiments, Feng et al. (2008) found that cold eastern Tropical Pacific SST anomalies could explain the intensity of the MCA droughts, a warm North Atlantic could regulate the geographic extent of the droughts, and the combined influence of SST anomalies in both basins was necessary to explain MCA drought severity and persistence. Similar patterns have been associated with widespread mid-continental drought during the past century (Fig. 2a, b) (McCabe et al., 2004, 2008; Booth et al., 2006). Continued development of the peatland network is currently underway in North America and in other circum-boreal regions of the Northern Hemisphere, and coupled with analyses of instrumental data, data-model comparisons, and dynamic modeling experiments will allow critical testing of this and other hypotheses on the mechanisms and dynamics of widespread, prolonged drought.

\section{Acknowledgements}

Research supported by grants from the National Science Foundation to Booth (EAR-0902441, ATM-0625298) and Jackson (ATM-0402660).

\section{Data}

Minden Bog testate amoeba data available from NOAA Paleoclimatology database (www.ncdc. noaa.gov/paleo/pubs/booth2003/booth2003. html). Other data will be made available via this database and the Neotoma Paleoecology Database (www.neotomadb.org/).

\section{References}

Booth, R.K., 2010: Testing the climate sensitivity of peat-based paleoclimate reconstructions in mid-continental North America, Quaternary Science Reviews, 29: 720-731. doi: 10.1016/j.quascirev.2009.11.018

Booth, R.K., Notaro, M., Jackson, S.T. and Kutzbach, J.E., 2006: Widespread drought episodes in the western Great Lakes region during the past 2000 years: geographic extent and potentia mechanisms, Earth and Planetary Science Letters, 242: 415-427.

Charman, D.J., Barber, K.E., Blaauw, M., Langdon, P.G., Mauquoy, D. Daley, T.J., Hughes, P.D.M. and Karofeld, E., 2009: Climate drivers for peatland palaeoclimate records, Quaternary Science Reviews, 28: 1811-1819.

Feng, S., Oglesby, R.J, Rowe, C.M. Loope, D. B. and Hu, 0, 2008: Atlantic and Pacific SST influences on Medieval drought in North America simulated by the Community Atmospheric Model, Journal of Geophysical Research, 113: D11101, doi:10.1029/2007JD009347.

McCabe, G.J., Betancourt, J.L., Gray, S.T., Palecki, M.A. and Hidalgo, H.G., 2008: Associations of multi-decadal sea-surface temperature variability with US drought, Quaternary International, 188: 31 40.

For full references please consult:

http://www.pages-igbp.org/products/newsletters/ref2010_1.htm| 


\title{
Peatlands as a model system for exploring and reconciling Quaternary chronologies
}

\author{
Maarten Blaauw ${ }^{1}$, J.A. Christen ${ }^{2}$ and D. Mauquoy 3 \\ 'School of Geography, Archaeology and Palaeoecology, Queen's University Belfast, UK; maarten.blaauw@qub.ac.uk \\ ${ }^{2}$ Centre for Mathematical Research, Guanajuato, Mexico; ${ }^{3}$ Geography and Environment, University of Aberdeen, UK
}

\section{Recent developments in statistical techniques enable quantitative assessment of the chronological reliability of radiocarbon-dated peatland profiles.}

The use of peatlands as datable archives of past climate and environmental change goes back for more than a century. Early age estimates were based on correlating peat stratigraphy within and among sites, assuming that specific horizons represented regionally synchronous events (Fig. 1). Peat layers with different vegetation or degrees of decomposition were thought to reflect past changes in climate (e.g., cooler, warmer, drier or wetter; von Post, 1946). The boundaries between these layers were then linked to the ages of environmental changes as inferred from independently dated archives (e.g., varve chronologies, links between pollen and archeological phases). These early peatland age-models were relative and imprecise, owing to their dependence on inferred synchrony of layers with imprecisely dated events in other archives.

\section{Radiocarbon dating}

The development of radiocarbon dating in the 1950s led to estimation of absolute ages for organic material such as peat. While deposits such as soils, oceans or lakes often contain little and/or heterogeneous carbon (e.g., blends of stable and labile organic components, hard water effects through carbonate seepage from surrounding bedrock), carbon is very abundant in peat and is mostly derived from the local, in situ, vegetation. As the living, contemporary plant matter on the bog surface becomes overgrown by new vegetation, cool, wet and acidic conditions combined with high decay-resistance of Sphagnum tissues in the accumulating sub-fossil organic matter, ensure slow decomposition. Therefore, most of the carbon in a slice of peat will generally have ${ }^{14} \mathrm{C}$ ages corresponding to the time at which that slice was accumulating at the original bog surface. Above-ground plant remains such as moss, seeds, stems, leaves or pollen are generally preferred over bulk material, because such selected remains will be contemporaneous with the depth of the peat, while bulk dates can contain a mix of contemporaneous and older or younger material (e.g., rootlets).

For recent peat deposits, additional dating techniques are available (e.g.,

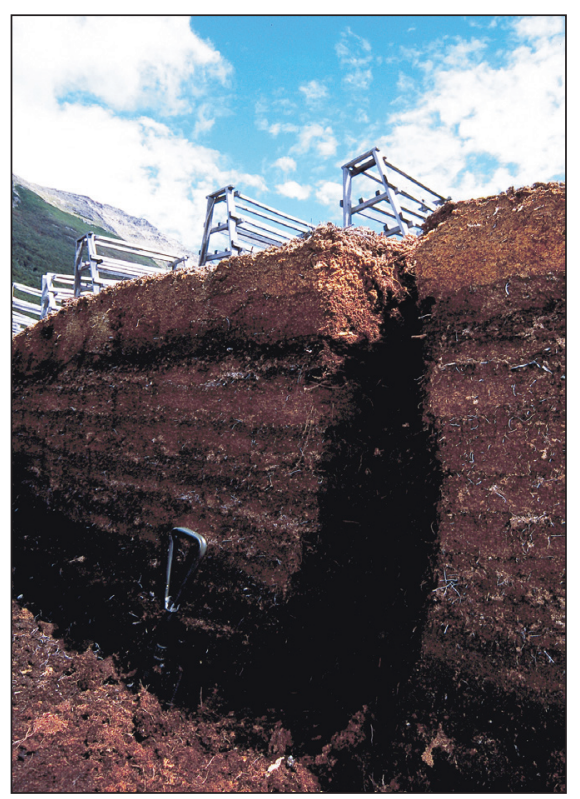

Figure 1: Section of a Sphagnum magellanicum raised peat bog in Tierra del Fuego. Note the 'layer-cake'stratigraphy where the changes from dark to humified peat can be traced for $\sim 50 \mathrm{~m}$.

bomb-peak ${ }^{14} \mathrm{C}$ dating for peat younger than c. AD 1960 (van der Linden et al., 2008), and lead dating for peat younger than c. AD 1850 (Turetsky et al., 2004)). Moreover, well-dated and geochemically identifiable volcanic ash (tephra) layers can provide valuable dating points, and can be used to align proxy archives between regions (Pilcher et al., 1995).

\section{Age-depth modeling}

Even though most peat contains abundant datable organic matter, it can be difficult to select sufficient above-ground macroremains from highly degraded peat. Moreover, selection and cleaning of material for ${ }^{14} \mathrm{C}$ dating can be time-consuming and ${ }^{14} \mathrm{C}$ dates are expensive. Therefore, generally only a few sample depths in a peat profile are dated. Moreover, ${ }^{14} \mathrm{C}$ dates themselves can show considerable scatter (Scott, 2007), and calibrated distributions can be irregular and wide. In order to provide calendar ages for each (dated or undated) depth of a core, some sort of modeling is needed. Each model has its specific advantages and limitations, and choosing a particular type of age-depth model will yield a distinct age-depth relationship (Bennett and Fuller, 2002; Telford et al., 2004).
A widely used basic age-depth model is linear interpolation between the dated levels (Bennett, 1994). This method assumes abrupt accumulation rate changes between each dated level, which for peat bogs seems an unrealistic scenario. Agedepth models that are considered more ecologically plausible and that take into account likely modes of peat accumulation, include (1) linear accumulation (over limited time intervals; Belyea and Clymo, 2001; Blaauw and Christen, 2005), (2) concave curves (through continuing decomposition of fossil matter in the peat deposit; Yu et al., 2001), (3) convex curves (with deposits slowing down their accumulation when close to a height limit; Belyea and Baird, 2006), and (4) Bayesian models that can include prior information on stratigraphy, accumulation rate and variability, and/or detect outlying dates (e.g., Blaauw and Christen, 2005; Bronk Ramsey, 2008; Blaauw et al., in prep.).

Confidence intervals of calibrated radiocarbon ages (Reimer et al., 2009) are often considerably larger than the original ${ }^{14} \mathrm{C}$ measurement uncertainties, especially during wiggles or plateaux in the calibration curve. For example, a date of $2.45 \pm 20$ ${ }^{14} \mathrm{C}$ ka BP (i.e., on the Hallstatt plateau) obtains a $95 \%$ range of 440 years on the calendar scale. Therefore, many ${ }^{14} \mathrm{C}$-dated peat chronologies possess centennialscale uncertainties. However, through matching dense series of ${ }^{14} \mathrm{C}$ dates to wiggles in the calibration curve (radiocarbon wiggle-match dating; van Geel and Mook, 1989), much higher precision chronologies can often be obtained (Christen et al., 1995; Kilian et al., 1995; 2000; Mauquoy et al., 2002; Blaauw et al., 2003; Blaauw and Christen, 2005; Chambers et al., 2007; see also van Geel and Mauquoy, this issue). Wiggle-matching performs best where the calibration curve has pronounced wiggles, often resulting in decadal-scale precision during the Subboreal/Subatlantic transition (Kilian et al., 2000) or during the Little Ice Age (Mauquoy et al., 2002; Fig. 2).

\section{Multi-site comparisons}

Until recently, most comparisons of proxy reconstructions between cores, sites and regions have been visual and rather sub- 
a)

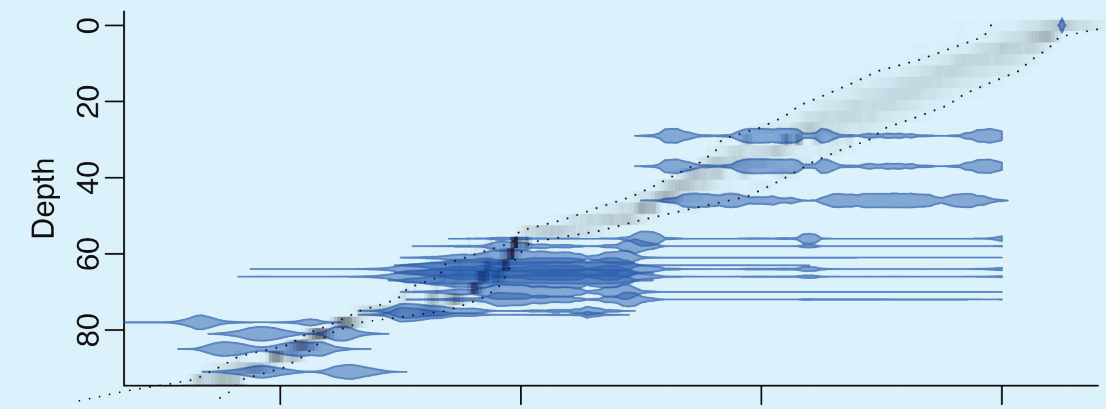

b)

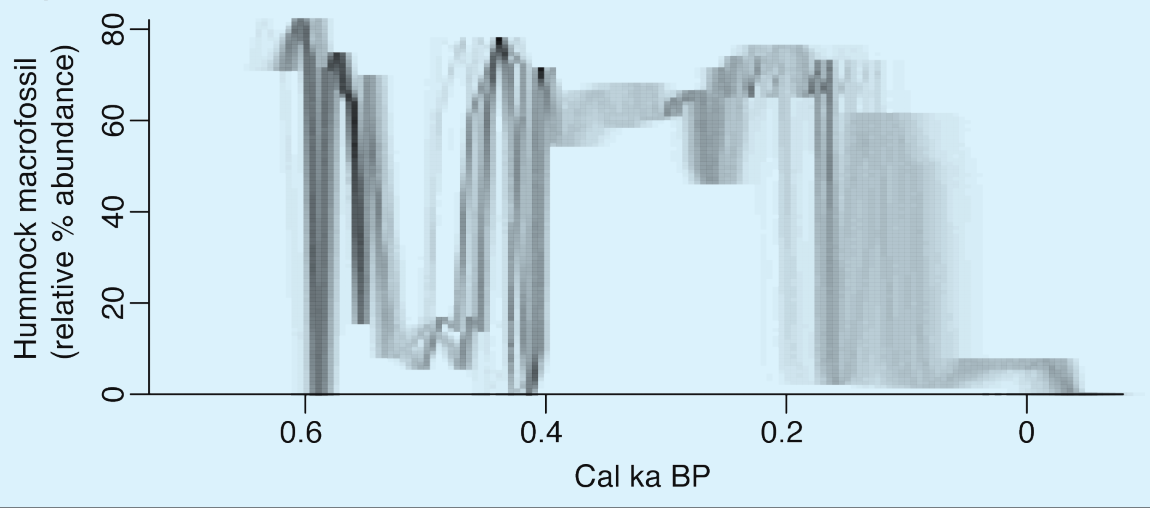

Figure 2: a) Bayesian age-depth model of a late Holocene peat core from Lille Vildmose in Denmark (Mauquoy et al., 2002). The model consists of many small sections of linear accumulation, with a degree of memory between neighboring sections (Blaauw et al., in prep.). Blue shapes are calibrated probability distributions of 17 radiocarbon dates (together with the core's surface, which is set at an age of AD 2000 \pm 1 ). Gray shapes show the posterior probability distribution of a) the age-depth model and $\boldsymbol{b}$ ) hummock macrofossil proxies (relative \% abundance of Sphagnum capillifolium). Dotted lines in (a) indicate 95\% confidence range. Abundant hummock proxies indicate relatively dry conditions on the bog's surface. Precisely and reliably dated core sections are plotted dark and narrow, while wide grey smudges indicate chronologically uncertain depths (Blaauw et al., 2007).

jective. Proxy curves from multiple sites are generally plotted on either independent or tuned timescales, after which synchroneity, leads or lags between sites are inferred through "eye-balling" or by drawing subjective lines connecting events be- tween sites. Recently developed statistical alternatives however can quantitatively assess leads and lags (Parnell et al., 2008) or synchroneity (Blaauw et al., 2007, 2010a) between independently dated proxy archives. A recent example is provided by

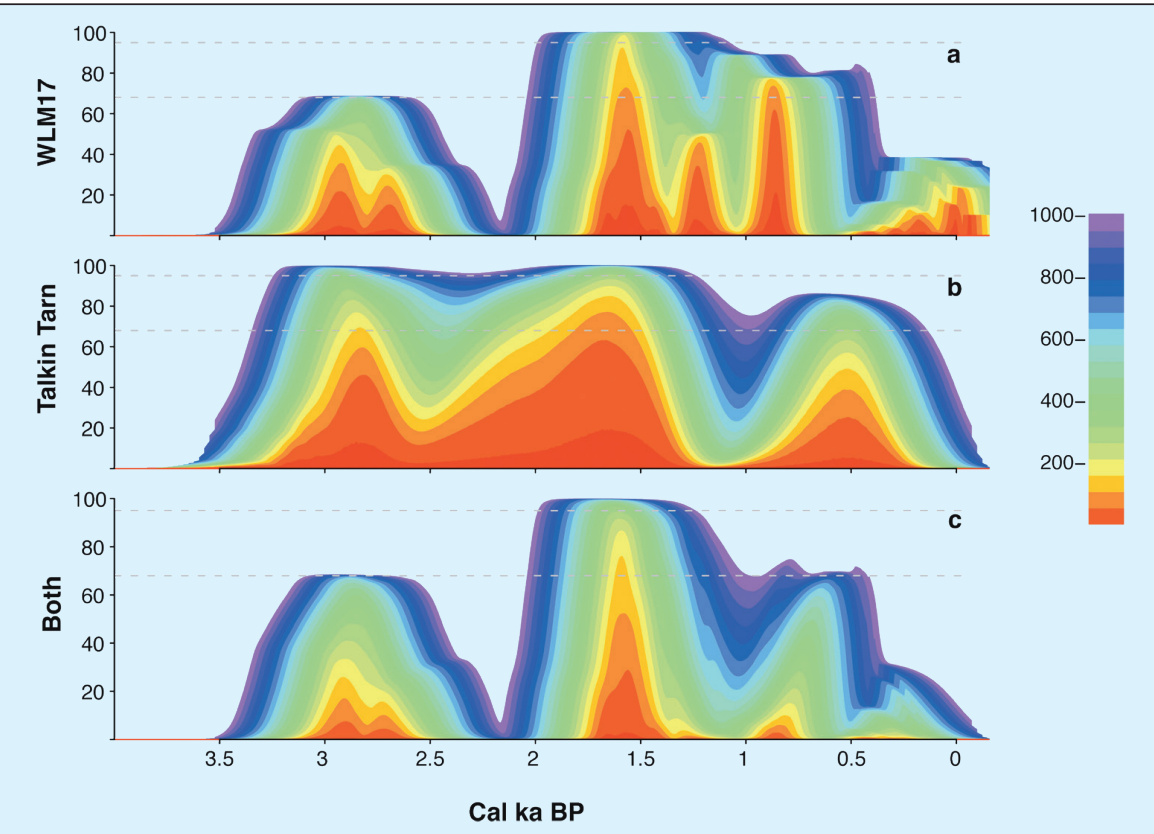

Figure 3: Events of increased moisture in two independently dated adjacent sites in northern England (Barber and Langdon, 2007; Charman et al., 2009); a) core WLM17 sampled from peat bog Walton Moss; b) lake sediment core from nearby Talkin Tarn. Probabilities of increased moisture in each of the sites during a period of time were calculated using a moving time-window approach (Blaauw et al., 2007, 2010) with window sizes of 10 to 1000 years, shown as rainbow colors in the probability histograms. c) shows the probabilities of simultaneous events between WLM17 and Talkin Tarn within specified time-windows. Dotted lines indicate 68\% and 95\% confidence levels, respectively. Taken from Charman et al. (2009) with permission from Elsevier.
Charman et al. (2009), who quantify the synchroneity of climate events between a peat bog and an adjacent lake in northern England (Fig. 3). Importantly, the degree of synchroneity of proxy events between archives depends on the chronological resolution of these archives. If chronological uncertainties of the archives are, for example, at the centennial scale, these archives cannot be used to answer questions at decadal resolution (Blaauw et al., 2007).

A wealth of paleoecological data has now been obtained from peat archives across the globe, and one of the remaining challenges is how to interpret these data in terms of quantitative past climate and environmental changes. By applying novel numerical methods to peatland chronologies, more realistic estimates can now be obtained for the spatio-temporal pattern of past environmental events (e.g., regional differences). Novel numerical methods are also being developed to assess the reliability of proxy records as quantitative archives of past climate and environmental changes. For example, Blaauw et al. (2010b) suggest that we cannot assume that every proxy change is necessarily forced by a single traceable external factor such as climate change (e.g., Blaauw et al., 2010a). Hopefully, such numerical methods will eventually enhance our understanding of the possibilities and limitations of peat archives for reconstructing past environmental change.

\section{References}

Blaauw, M. and Christen, J.A., 2005: Radiocarbon peat chronologies and environmental change, Applied Statistics, 54: 805-816.

Blaauw, M., Christen, J.A., Mauquoy, D., van der Plicht, J. and Bennett, K.D., 2007: Testing the timing of radiocarbon-dated events between proxy archives, The Holocene, 17: 283-288.

Blaauw, M., Bennett, K.D. and Christen, J.A., 2010b: Random walk simulations of fossil proxy data, The Holocene.

Charman, D., Barber, K., Blaauw, M., Langdon, P., Mauquoy, D., Daley, T., Hughes, P. and Karofeld, E., 2009: Climate drivers for peatland palaeoclimate records, Quaternary Science Reviews, 28: 18111819.

Turetsky, M.R., Manning, S. and Wieder, R.K., 2004: Dating recent peat deposits, Wetlands, 24: 324-356.

For full references please consult:

http://www.pages-igbp.org/products/newsletters/ref2010_1.htm 


\section{Peatland records of solar activity}

Bas van Geel ${ }^{1}$ and Dmitri Mauquoy ${ }^{2}$

IInstitute for Biodiversity and Ecosystem Dynamics, University of Amsterdam, The Netherlands; B.vanGeel@uva.nl

${ }^{2} \mathrm{~S}$ chool of Geosciences, University of Aberdeen, UK

\section{Rainwater-fed Holocene raised bog deposits in temperate climate zones are valuable archives of solar activity fluctuations and related climate changes.}

Past hydrological changes can be derived from the species composition and the degree of decomposition of peat-forming plants in raised bog deposits. More than 120 years ago Axel Blytt described transitions in raised bog deposits between dark, highly decomposed peat and light colored peat as evidence for climate change. Nowadays, the radiocarbon $\left({ }^{14} \mathrm{C}\right)$ method is generally used for dating Holocene climate-induced shifts in raised bog deposits. Yet radiocarbon offers more than the possibility to precisely date organic material. The changing atmospheric radiocarbon levels in the past are also a proxy for solar activity. We have found strong links between large ${ }^{14} \mathrm{C}$ fluctuations and major climate shifts.

\section{${ }^{14} \mathrm{C}$ wiggle-match dating and the \\ Sun}

The radioactive carbon isotope ${ }^{14} \mathrm{C}$ is produced under the influence of cosmic rays. When formed, the cosmogenic isotope radiocarbon is oxidized to ${ }^{14} \mathrm{CO}_{2}$, which becomes part of the carbon cycle. When plants and animals die, the uptake of carbon ceases and the decay of radiocarbon (half-life $5730 \pm 40$ years) to deduce age. Radiocarbon "years" are different from calendar years because the production of ${ }^{14} \mathrm{C}$ in the past was not constant, mainly due to changes in solar activity and related cosmic ray intensity. The ${ }^{14} \mathrm{C}$ timescale is calibrated by measuring the ${ }^{14} \mathrm{C}$ content of tree rings, dated precisely by means of dendrochronology. Changes in solar activity underlie fluctuations ("wiggles") in

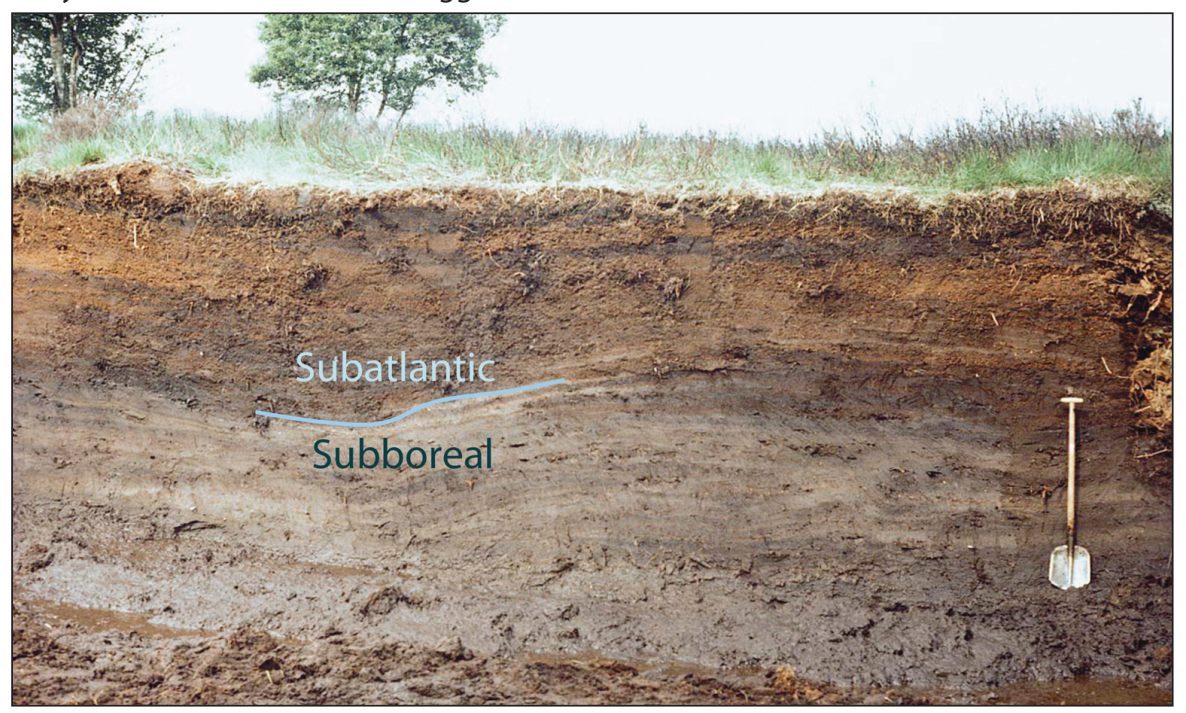

Figure 1: The Subboreal-Subatlantic transtion in a raised peat profile in The Netherlands. the ${ }^{14} \mathrm{C}$ calibration curve. Calibration of a single radiocarbon date usually yields an irregular probability distribution in calendar age, quite often over a long time interval. This is problematic in paleoclimatological studies, especially when a precise temporal comparison between different climate proxies is required. However, closely spaced sequences of (uncalibrated) ${ }^{14} \mathrm{C}$ dates of peat deposits also display the wiggles, which can be fitted to the wiggles in the radiocarbon calibration curve.

The practice of dating peat samples using ${ }^{14} \mathrm{C}$ "wiggle-match dating" has greatly improved the precision of radiocarbon chronologies (van Geel and Mook, 1989; Kilian et al., 1995; Blaauw et al., 2003). By wiggle-matching ${ }^{14} \mathrm{C}$ measurements, high-precision calendar-age chronologies for peat sequences can be generated, and several studies indicate that peatland surface wetness often increased together with rapid increases in atmospheric production of ${ }^{14} \mathrm{C}$ during the early Holocene, the Subboreal-Subatlantic transition (at ca. 2.8 cal ka BP; Fig. 1 and 2), and the Little Ice Age. Peat records from The Netherlands, the Czech Republic, the UK and Denmark show this phenomenon (Mauquoy et al., 2002a, b; Speranza et al., 2002; van der Plicht et al., 2004; van Geel et al., 1996, 1998). Because the production of radiocarbon is regulated by solar activity, periods of increased peatland surface wetness have been interpreted as evidence for solar forcing of climate change climatic shift towards increased humidity (equatorward relocation of mid-latitude storm tracks). The hypothesis is supported by palynological evidence. Areas that were initially hostile semi-deserts were converted into steppe landscapes with a high biomass production and carrying capacity. Newly available steppe areas could be utilized by herbivores, making them attractive for nomadic tribes. The equestrian Scythian culture expanded from Central Asia, and increased population density was a stimulus for westward migration towards south-eastern Europe.

Evidence for changes in peatland surface wetness, which coincide with grand solar minima during the Little Ice Age (Wolf, Spörer, Maunder and Dalton Mini- 


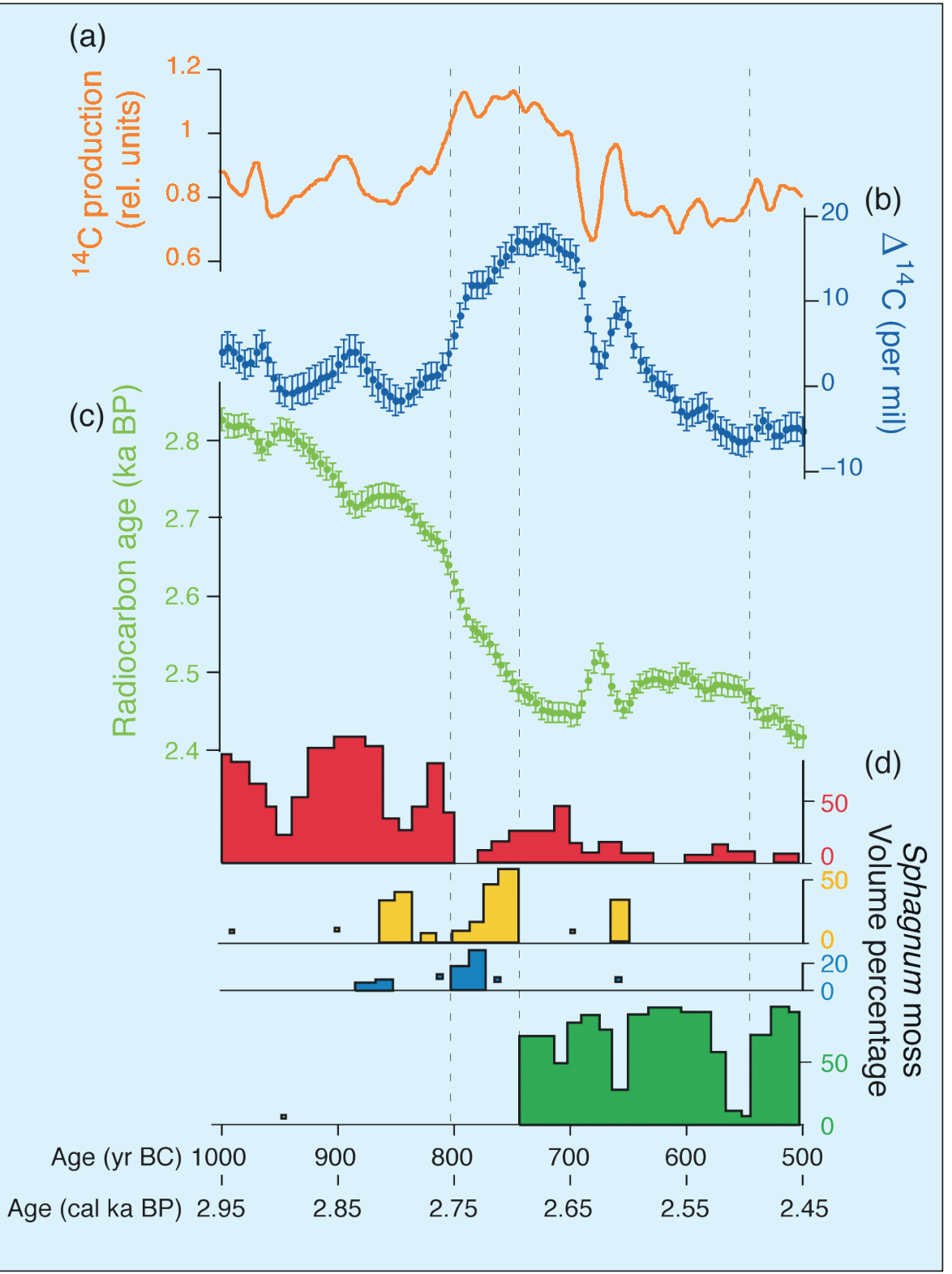

Figure 2: $\boldsymbol{a}$ ) Inferred changes in ${ }^{14} \mathrm{C}$ production (yellow). $\left.\boldsymbol{b}\right) \triangle^{14} \mathrm{C}$ is the deviation of the atmospheric ${ }^{14} \mathrm{C} /{ }^{12} \mathrm{C}$ ratio from a standard value in per mil (Stuiver and Pollach, 1977). The interval between ca. 2.8 and $2.7 \mathrm{cal}$ ka BP represents the phase of extreme climate at the start of the Subatlantic period: the rise of $\triangle^{14} \mathrm{C}$ and the ${ }^{14} \mathrm{C}$ production curve are related to a temporary decline of solar activity; $\boldsymbol{c}$ ) The ${ }^{14} \mathrm{C}$ calibration curve (Reimer et al., 2004). $\boldsymbol{d}$ ) Changes in composition of Sphagnum moss species during the Subboreal-Subatlantic transition (Engbertsdijksveen, eastern Netherlands; after van Geel et al., 1996; Beer and van Geel, 2008) reflect a sharp transition from relatively warm-dry (S. section acutifolia (red)) to cool wet conditions (S. cuspidatum (blue), S. papillosum (yellow), S. imbricatum (green)). Figure modified from Beer and van Geel, 2008).

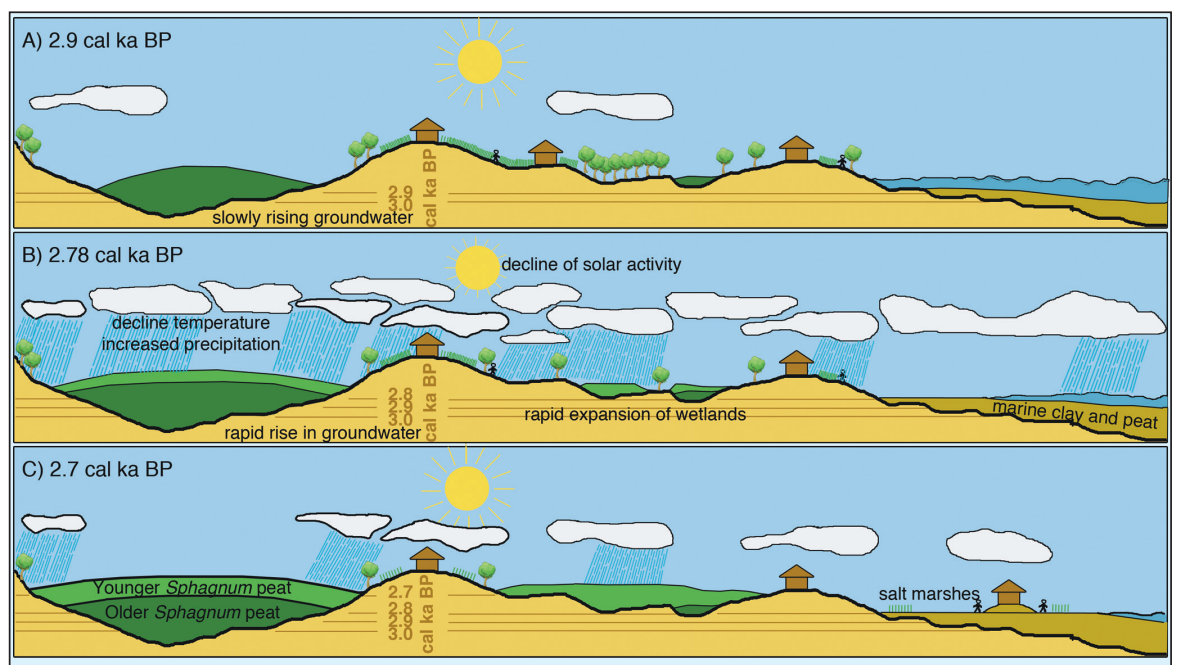

Figure 3: Landscape effects of solar forcing of climate change just before, during and directly after the Subboreal Subatlantic transition in the northern Netherlands (modified from van Geel et al., 1998; Beer and van Geel, 2008). ma), is presented in Mauquoy et al. (2002a, b) and Mauquoy et al. (2008). Replicate cores were investigated from one site in Denmark (2 peat profiles from Lille Vildmose) and northern England (3 replicate cores from Walton Moss). Paleohydrological reconstructions based on plant macrofossil and testate amoebae at a second site in northern England also record Little Ice Age climatic cooling (Mauquoy et al., 2008).

These increases in peatland surface wetness also coincide with some changes in solar activity; they are coeval with increases in the production of ${ }^{14} \mathrm{C}$. All of the peat profiles possess precise ${ }^{14} \mathrm{C}$ wigglematch dated chronologies, and the chronology from Lille Vildmose offers a very high-resolution record of climate change spanning the last $1.5 \mathrm{ka}$, with peat accumulation rates as high as $2-3 \mathrm{yr} \mathrm{cm}^{-1}$. The study by Mauquoy et al. (2008; see also Chambers et al., this issue) indicates a short lag (10-40 years) between the start of the rise in ${ }^{14} \mathrm{C}$ production and the hydrological response of the peat bog. We do not know the reason for this. Analyses of further peat profiles are needed to replicate this finding. Additional evidence for solar forcing of climate change comes from studies of marine sediments, stalagmites, ice cores and lake sediment, showing the sensitivity of the climate system to relatively small changes in solar activity (Bond et al., 2001; Neff et al., 2001; Magny, 2004, 2007).

\section{References}

Beer, J. and van Geel, B., 2008: Holocene climate change and the evidence for solar and other forcings. In: R.W. Battarbee and H.A. Binney (Eds), Natural Climate Variability and Global Warming: Holocene Perspective, Wiley-Blackwell, 138-162.

Mauquoy, D., van Geel, B., Blaauw, M. and van der Plicht, J., 2002a: Evidence from northwest European bogs shows 'Little Ice Age' climatic changes driven by variations in solar activity, The Holocene, 12: 1-6.

Mauquoy, D., Yeloff, D, van Geel, B., Charman, D. and Blundell, A., 2008: Two decadally resolved records from north-west European peat bogs show rapid climate changes associated with solar variability during the mid-late Holocene, Journal of Quaternary Science, 23: 745-763.

van Geel, B., Buurman, J. and Waterbolk, H.T., 1996: Archeological and paleoecological indications for an abrupt climate change in The Netherlands and evidence for climatological teleconnections around $2650 \mathrm{BP}$, Journal of Quaternary Science, 11: 451-460.

van Geel, B., et al., 2004: Climate change and the expansion of the Scythian culture after $850 \mathrm{BC}$, a hypothesis, Journal of Archaeological Science, 31: 1735-1742.

For full references please consult:

http://www.pages-igbp.org/products/newsletters/ref2010_1.htm 
Mariusz Lamentowicz ${ }^{1}$, W.O. van der Knaap ${ }^{2}$, J.F.N. van Leeuwen ${ }^{2}$, S. HangartneR ${ }^{3}$, E.A.D. Mitchell ${ }^{4,5,6}$, T. Goslar $^{7,8}$, W. TinneR ${ }^{2}$ and C. Kamenik $^{9}$

'Department of Biogeography and Palaeoecology, Adam Mickiewicz University, Poznań, Poland; mariuszl@amu.edu.pl

${ }^{2}$ Institute of Plant Sciences and Oeschger Centre for Climate Change Research, University of Bern, Switzerland; ${ }^{3}$ Physics Institute Climate and Environmental Physics, and Oeschger Centre for Climate Change Research, University of Bern, Switzerland; ${ }^{4}$ Swiss Federal Research Institute, Wetlands Research Group, Lausanne, Switzerland; ${ }^{5}$ École Polytechnique Fédérale de Lausanne (EPFL), Laboratory of Ecological Systems, Switzerland; ${ }^{6}$ Laboratory of Soil Biology, Institute of Biology, University of Neuchâtel, Switzerland; ${ }^{7}$ Faculty of Physics, Adam Mickiewicz University, Poznań, Poland; 8Poznań Radiocarbon Laboratory, Foundation of the Adam Mickiewicz University, Poznań, Poland; 9 Institute of Geography, and Oeschger Centre for Climate Change Research, University of Bern, Switzerland

High-resolution multiproxy studies on alpine peatlands reveal how environmental changes (including human impact) have influenced the developmental history of these unusual ecosystems. Here we summarize results of new paleoclimate reconstructions based on calibration and validation with the instrumental climate record.

Global warming is dramatically changing mountain ecosystems; glaciers are shrinking and current snow conditions differ considerably from those that existed 50 years ago (Laternser and Schneebeli, 2003; Wipf et al., 2009). Among various types of mountain ecosystems, peatlands stand out because of their ecologically and biogeographically unique flora and fauna, and their role as carbon pools and sinks. Peatlands are also highly sensitive to human impact and climatic change. Because peatlands accumulate records of their developmental history, including responses to climate changes, land-use and human impact, they represent a valuable source of information on past and ongoing global changes (Charman, 2002). However, paleoecological data on peatland development in alpine regions are scarce.

Most modern high-resolution multiproxy studies of mountainous regions have been based on lake sediments (e.g., Ammann, 1986; Ammann et al., 2000, van der Knaap et al., 2000). However, in the past decade, peatlands have been used to address specific questions that demand high spatial or temporal resolution. Small peatlands have been used to gain records of Holocene and Late-Glacial stand-scale dynamics (where "stand" is defined as an area of sufficient homogeneity to be regarded as a single unit; Dahlgren and Turner, 2010) (van der Knaap et al., 2003; Genries et al., 2009; Stahli et al., 2006). Such paleoenvironmental records may differ from more regional signals, such as those recorded in lacustrine sequences. For instance, Hofstetter et al. (2006) analyzed a small peatland $(0.05 \mathrm{ha})$ in the Southern Alps and suggested that important tree species (e.g., Abies alba, Castanea sativa) were present locally millennia before they could be unambiguously recorded in the larger (5-20 ha) lake archives.
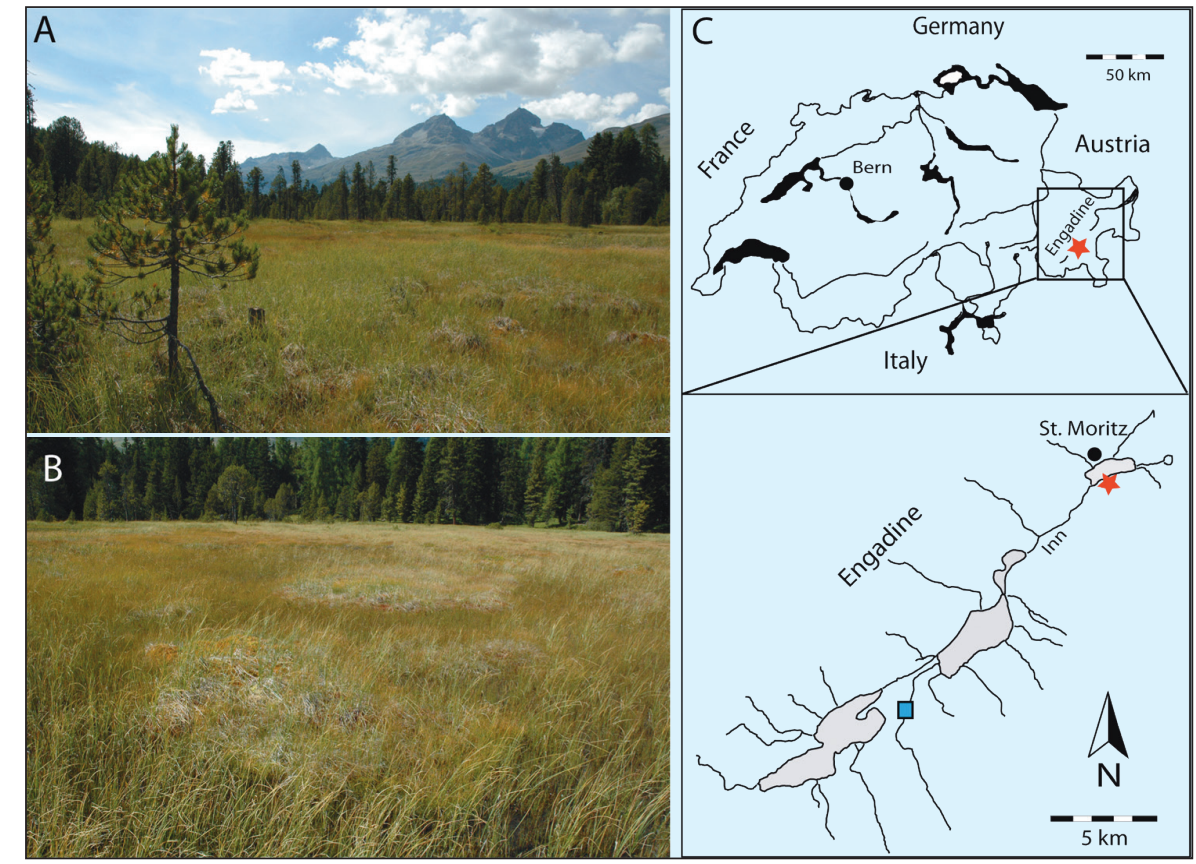

Figure 1: $\boldsymbol{A})$ The Alpine landscape where the peatland is situated; $\boldsymbol{B})$ Typical vegetation with Sphagnum fuscum hummocks surrounded by brown mosses and vascular plants, $\boldsymbol{C}$ ) Location of Mauntschas Mire (red star) in the Engadine region, Switzerland. The meteorological station Sils Maria is indicated by the blue square (Map modified from Lamentowiczet al., 2010).

It is currently not clear which factors have the strongest influence on peatland development. For example, the hydrology of alpine peatlands is controlled not only by summer precipitation but also by the amount and duration of snow cover. Addressing these issues requires integrated studies of modern peatlands and their history.

Multiple proxies in peat deposits can be studied at near-annual resolution, at least for recent centuries, but such studies are still very rare. Although time-consuming, they provide a temporally precise continuous paleoecological record. Moreover, peat archives from the last 150 years offer an opportunity to correlate reconstructed time series with instrumental meteorological data and other historical information. We use a high-resolution time series to validate transfer function-based quantitative reconstructions against measured climate variables (temperature and precipitation).

\section{Case study - Mauntschas Mire}

Within the framework of the EU project MILLENNIUM (http://geography.swan. ac.uk/millennium), we obtained a highresolution (near-annual) multi-proxy record from Mauntschas Mire, a subalpine peatland (1818 $\mathrm{m}$ asl) at the bottom of the Upper Engadin Valley in the southeastern Swiss Alps (Fig. 1). The site recorded local hydrological changes that can be related to local precipitation/temperature changes since $A D$ 1000. The aim of this multi-proxy study was to reconstruct climate and other environmental changes of the last millennium using the highest possible sampling resolution, close to anaim, the core was divided into $2 \mathrm{~mm}$ slices with the Damocles device (Joosten and nual whenever possible. To achieve this 


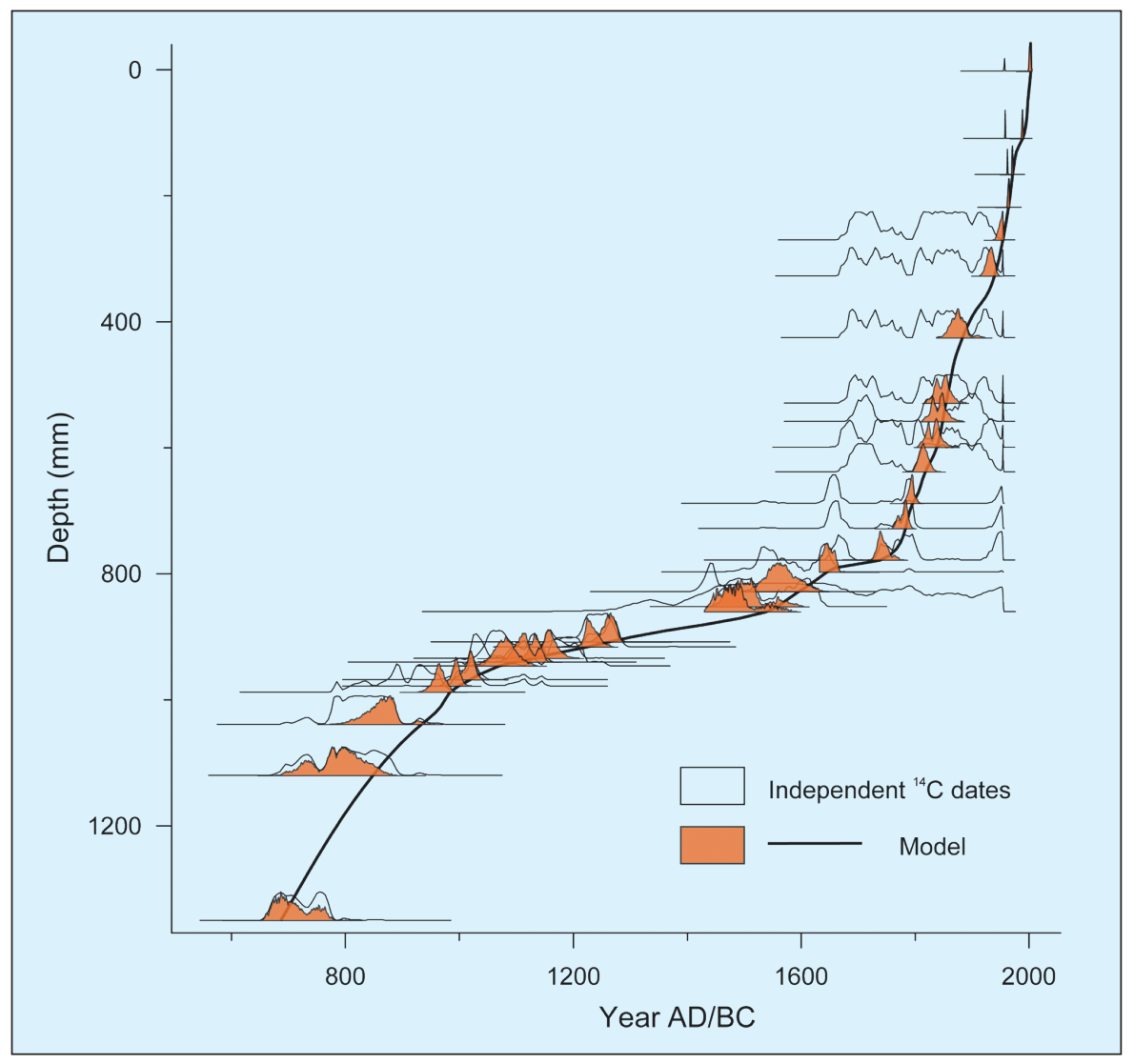

Figure 2: Age-depth model of the peat profile Mauntschas MA2, calculated with a free-shape modeling algorithm with information on relative changes of peat-accumulation rate. Open silhouettes show results of calibration of individual ${ }^{14} \mathrm{C}$ dates, treated as independent of one another. The best-fit age-depth model is shown with a solid line, while uncertainty of the model is illustrated with orange silhouettes (modified from Goslar et al., 2009).

De Klerk, 2007). High-resolution radiocarbon dating combined with advanced age-depth modeling (Goslar et al., 2009) and the study of plant macrofossils, pollen, stable isotopes and testate amoebae enabled precise paleoenvironmental reconstructions.

\section{Chronology - age-depth modeling}

An age-depth model, based on 29 radiocarbon dates spanning the last $1.3 \mathrm{ka}$, was constructed (Fig. 2) using the algorithm of free-shape modeling (Goslar et al., 2009). This algorithm searched for a reasonable compromise between fit of ${ }^{14} \mathrm{C}$ dates to the radiocarbon calibration curve, general smoothness of the age-depth line, and similarity of relative changes in the modeled sediment-accumulation rates to those suggested by independent data. The complicated shape of the age-depth curve was indicated by parallel fluctuations in concentrations of most pollen taxa, supported in the upper part of the profile by the record of anthropogenic spheroidal carbonaceous particles, and in some levels also by the ${ }^{14} \mathrm{C}$ dates themselves.

Uncertainty in the obtained model was assessed using Monte Carlo simulations. This uncertainty is 1-2 years in the post-bomb period (AD 1950-2004), does not exceed \pm 30 years between AD 1550- lated phase at the end of the $19^{\text {th }}$ century. The $\delta^{18} \mathrm{O}$ data from Sphagnum and Polytri- chum are highly correlated and lead to the conclusion that $\delta^{18} \mathrm{O}$ fractionation in both moss genera and in different parts of the plant occurs in a similar way. A multi-proxy analysis of $\delta^{18} \mathrm{O}$ and testate amoebae might reveal underlying hydrological processes in Mauntschas Mire (Lamentowicz et al., in prep.).

\section{Pollen based calibration-in-time}

Quantitative pollen-based reconstructions are challenging in mountainous regions because of vertical pollen transport across vegetation boundaries. Thus, instead of applying the usual calibrationin-space approach, selected pollen taxa were calibrated in time (AD 1954 - 2002) on temperature measured at the nearby meteorological station Sils Maria. This approach was based on the rationale that local factors controlling vertical pollen transport (e.g., slope, dominant winds, exposure) were constant at a site that is used for calibration and reconstruction alike. Calibration in time resulted in a cross-validated (jackknifed) root mean square error of prediction of $0.23^{\circ} \mathrm{C}$ for mean April-November air temperature (Kamenik et al., 2009) (Fig. 3). Potential anthropogenic effects, such as de- or re-forestation, were removed prior to calibration. This "calibration-in-time", which was carefully tested against measured temperature, was possible only because two crucial pre-conditions were met: near-annual to quasiannual sampling resolution and excellent dating (see above) provided by the ${ }^{14} \mathrm{C}$ bomb peak and spheroidal carbonaceous particles. Independent validation using the instrumental record revealed that pollen picked up decadal- to centennial-scale climate change during this period. Still, pollen-based reconstructions might be challenged by non-climatic factors, such as pre-industrial deforestation and fire.

\section{Other studies from Alpine peatlands}

Investigations of small peatlands can also help address important nature-conservation and forest-management issues. For instance, an ongoing interdisciplinary project is providing a scientific basis for natural and sustainable forest management in the Italian part of Switzerland (Valsecchi et al., 2010). In the northern Alps, a recent multi-proxy study investigating peatland development and its effect on landscape dynamics and tufa formation (Wehrli et al., 2010), showed that wetlands can reflect environmental changes at extra-local scales.

Alpine peatlands are underused as a source of paleoenvironmental informa- 

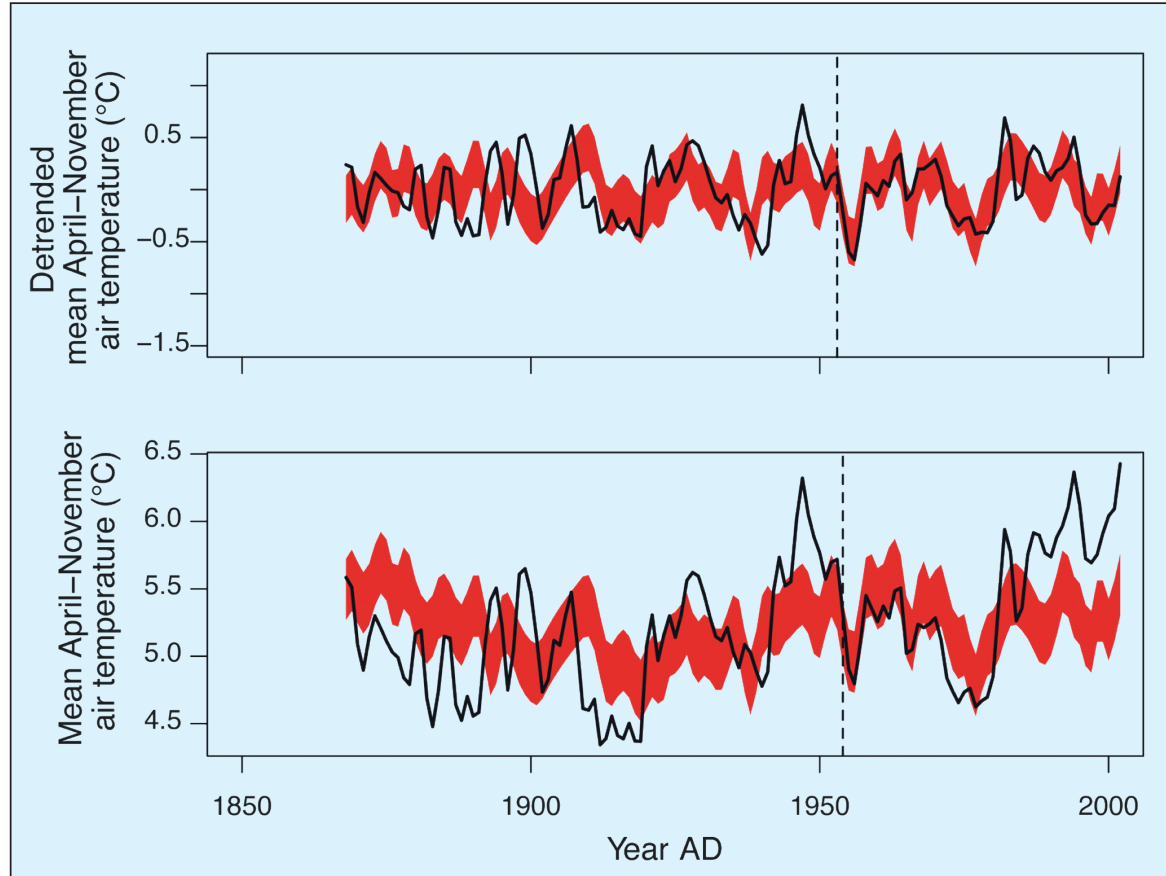

Figure 3: Confidence bands (95\%) of detrended (upper panel) and non-detrended (lower panel) pollen-based warm-season temperature reconstructions (red) versus measured temperature (solid black line) during the instrumental period. Pollen picked up long-term (at least decadal-scale) temperature changes (e.g., 1900-1950). Time series were detrended to reduce the effects of human impact. Calibration period (AD 1954 onwards) and verification period (pre-AD 1954) are delineated by a dashed vertical line (modified from Kamenik et al. 2009).

tion. There is potential for scientists to use peatlands in mountain regions as archives of past climate change and landscape transformation. However, peatland ecology and the relationship between climate and peatland development needs to be better understood.

\section{Perspectives}

The comparison of testate amoeba-inferred water table depth, $\delta^{18} \mathrm{O}$ data from Sphagnum stems, and instrumental climatic data revealed some interesting correlations. We now need 1) more high-resolution multi-proxy studies similar to that from Mauntschas to determine if these patterns can also be observed elsewhere, and 2) manipulative experiments to assess the relative influences of temperature, precipitation and water table depth on testate amoeba communities and the Sphagnum $\delta^{18} \mathrm{O}$ isotopic signal. Such combined studies will help understand which factors most strongly control the development of alpine peatlands, how these peatlands can be fully exploited for inferring paleoclimatic and environmental signals, and how they may respond to ongoing and future climate changes.

\section{References}

Goslar, T., Van der Knaap, W.O., Kamenik, C. and Van Leeuwen, J.F.N. 2009: Free-shape ${ }^{14} \mathrm{C}$ age-depth modelling of an intensively dated modern peat profile, Journal of Quaternary Science, 24 : 481-499

Kamenik, C., Van der Knaap, W.O., Van Leeuwen, J.F.N. and Goslar, T., 2009: Pollen/climate calibration based on a near-annual peat sequence from the Swiss Alps, Journal of Quaternary Science, 24: $529-546$.

Lamentowicz, M., Van der Knaap, P., Lamentowicz, Ł., Van Leeuwen, J.F.N., Mitchell, E. A.D., Goslar, T. and Kamenik, C., 2010: A nearannual palaeohydrological study based on testate amoebae from an Alpine mire: surface wetness and the role of climate during the instrumental period, Journal of Quaternary Science, in press DOl 10.1002/jgs.1295.

Mitchell, E.A.D., van der Knaap, W.O., van Leeuwen, J.F.N., Buttler, A Warner, B.G. and Gobat, J.M., 2001: The palaeoecological history of the Praz-Rodet bog (Swiss Jura) based on pollen, plant macrofossils and testate amoebae (Protozoa), The Holocene, 11: 65-80.

Wipf, S., Stoeckli, V. and Bebi, P., 2009: Winter climate change in alpine tundra: plant responses to changes in snow depth and snowmelt timing, Climatic Change, 94: 105-121.

\section{Stable isotopes and organic geochemistry in peat: Tools to investigate past hydrology, temperature and biogeochemistry}

ERIN L. McClymont ${ }^{1}$, E. Pendall ${ }^{2}$ and J. Nichols ${ }^{3}$

'School of Geography, Politics and Sociology, Newcastle University, UK; erin.mcclymont@ncl.ac.uk

2Department of Botany and Program in Ecology, University of Wyoming, USA; ${ }^{2}$ NASA Goddard Institute for Space Studies, New York, USA

Characterizing the stable isotope and biomarker geochemistry of peat cores enables reconstruction of key climatic and environmental variables in the past, including temperature, hydrology and the cycling of carbon.

\section{Proxy targets and the value of geochemistry}

Peatlands are valuable archives of terrestrial environmental change due to their sensitivity to the hydrological regime and the excellent preservation of organic matter. Peat geochemistry reflects the composition of the original peat-forming plant assemblage (which is itself dependent on air temperature and hydrology), and the subsequent transformation of that organic matter in the aerobic surface layer (the acrotelm) and the anaerobic catotelm (below the water table). Changes to air temperatures and water table depth are thus reflected in peat via changes to both organic matter input and its subsequent degradation (Fig. 1). Precipitation and evaporation cause isotopic fractionation of hydrogen $(\delta D)$ and oxygen $\left(\delta^{18} \mathrm{O}\right)$, so that the isotopic composition of the meteoric water used by peatland plants reflects a combination of precipitation source and peatland hydrology (Daley et al., in press). Stable carbon isotopes $\left(\delta^{13} \mathrm{C}\right)$ give important information on carbon pathways, including fractionation during photosynthesis (White et al., 1994; Williams and Flanagan, 1996), and the recycling of organic matter and consumption of $\mathrm{CO}_{2}$ and methane by microbial activity (Pancost et al., 2000).
Humic acid formation during degradation of plant material (humification) is a proxy for peatland wetness (Yeloff and Mauquoy, 2006). Total carbon and nitrogen contents also indicate wetness (McClymont et al., 2008), since drier conditions cause the plant remains to spend a longer time in the acrotelm, where degradation preferentially releases nitrogen over carbon (Kuhry and Vitt, 1996). However, isolating whether changes to biomass and/or peatland hydrology drive the humification or bulk geochemistry signals recorded in peat cores makes environmental interpretations of such records difficult (Yeloff and Mauquoy, 2006). Here, we discuss the 
potential for organic and stable isotope geochemistry analyses to determine more precisely the climatic and environmental evolution of peatlands (Fig. 1).

\section{Isotopic analysis of plant remains}

Different peat-forming plants can have distinct chemical characteristics that reflect their different water sources and biochemical pathways (Fig. 1). For example, Sphagnum mosses contain higher carbon/ nitrogen ratios than vascular plants (Kuhry and Vitt, 1996). The absence of functioning guard cells, which encircle the leaf pores used in gas exchange (stomata) and regulate the size of the stomatal opening, prevents control over water loss and gas exchange (Loader et al., 2007). Thus the isotopic composition of Sphagnum cellulose potentially records the isotopic composition of meteoric waters (Pendall et al., 2001). However, a bulk peat sample contains variable contributions from different plant sources, which limits efforts to isolate the controls over the signals recorded. Manually picking the remains of specific plants reduces such errors and yields a cleaner hydrological/climatic signal.

For example, White et al. (1994) exploited the differences in $\mathrm{CO}_{2}$ uptake between Sphagnum and sedges, recorded in their $\delta^{13} \mathrm{C}_{\text {cellulose' }}$ to reconstruct Holocene atmospheric $\mathrm{CO}_{2}$ concentrations, although temperature and humidity effects on $\delta^{13} \mathrm{C}$ had also to be considered. Sphagnum $\delta^{13} \mathrm{C}_{\text {cellulose }}$ has also been shown to be strongly related to mean air temperatures along a transect in SW Poland (Skrzypek et al., 2007). However, careful sample selection is required to minimize the impacts of inter- and intra-plant variability in Sphagnum $\delta^{13} \mathrm{C}$ (Loader et al., 2007).

A strong temperature signature in the $\delta D$ of Sphagnum tissues in Patagonian peatlands has been paired with humidity reconstructed from $\delta^{13} \mathrm{C}$ in Carex (a sedge genus) fragments to provide a record of Holocene climate change that is independent of vegetation change as recorded in pollen (Pendall et al., 2001). Sphagnum cellulose $\delta^{18} \mathrm{O}$ from Walton Moss (UK) was dominated by the precipitation $\delta^{18} \mathrm{O}$ (Daley et al., in press). Given strong modern temperature controls over $\delta^{18} \mathrm{O}_{\text {precipitation }}$ in the UK and also in Nova Scotia, Daley et al. (2009; in press) used Holocene Sphagnum cellulose $\delta^{18} \mathrm{O}$ to reconstruct paleotemperatures. However, the influences of evaporation/peatland surface wetness (Daley et al., in press), and changing $\delta^{18} \mathrm{O}$ of the precipitation source (Daley et al., 2009) under different climate regimes complicated interpretations. Adoption of multi-proxy

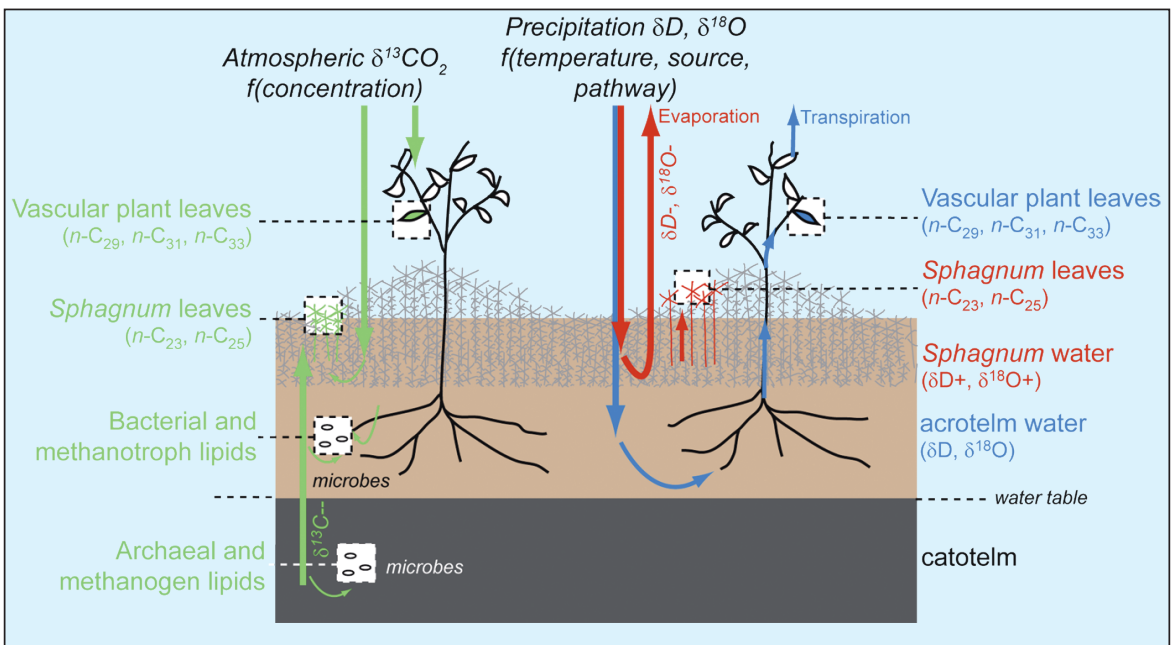

Figure 1: Conceptual model of water (blue, red) and carbon (green) pathways through the upper horizons of a peatland, including the isotopic fractionations associated with their utilization by Sphagnum (moss) and sedges $\left(\delta+\right.$ shows enrichment, $\delta$-shows depletion). The initial isotopic composition of water and $\mathrm{CO}_{2}$ are functions $(f)$ of a range of environmental factors as shown. Blue arrows follow the path of water used by sedges. Red arrows follow the path of water used by Sphagnum, which is affected by both precipitation (downward) and evaporation (upward). Fractionation also occurs along biosynthetic pathways. The impact of evapotranspiration on vascular plant isotopes is not shown because responses vary between cellulose and plant wax biomarkers. The aerobic acrotelm (light brown) occurs above the water table, at the peat surface. The anaerobic catotelm (dark brown) is found below the water table, and contains the peat archive of preserved organic material from which cores are taken. Adapted from Nichols et al. (2010).

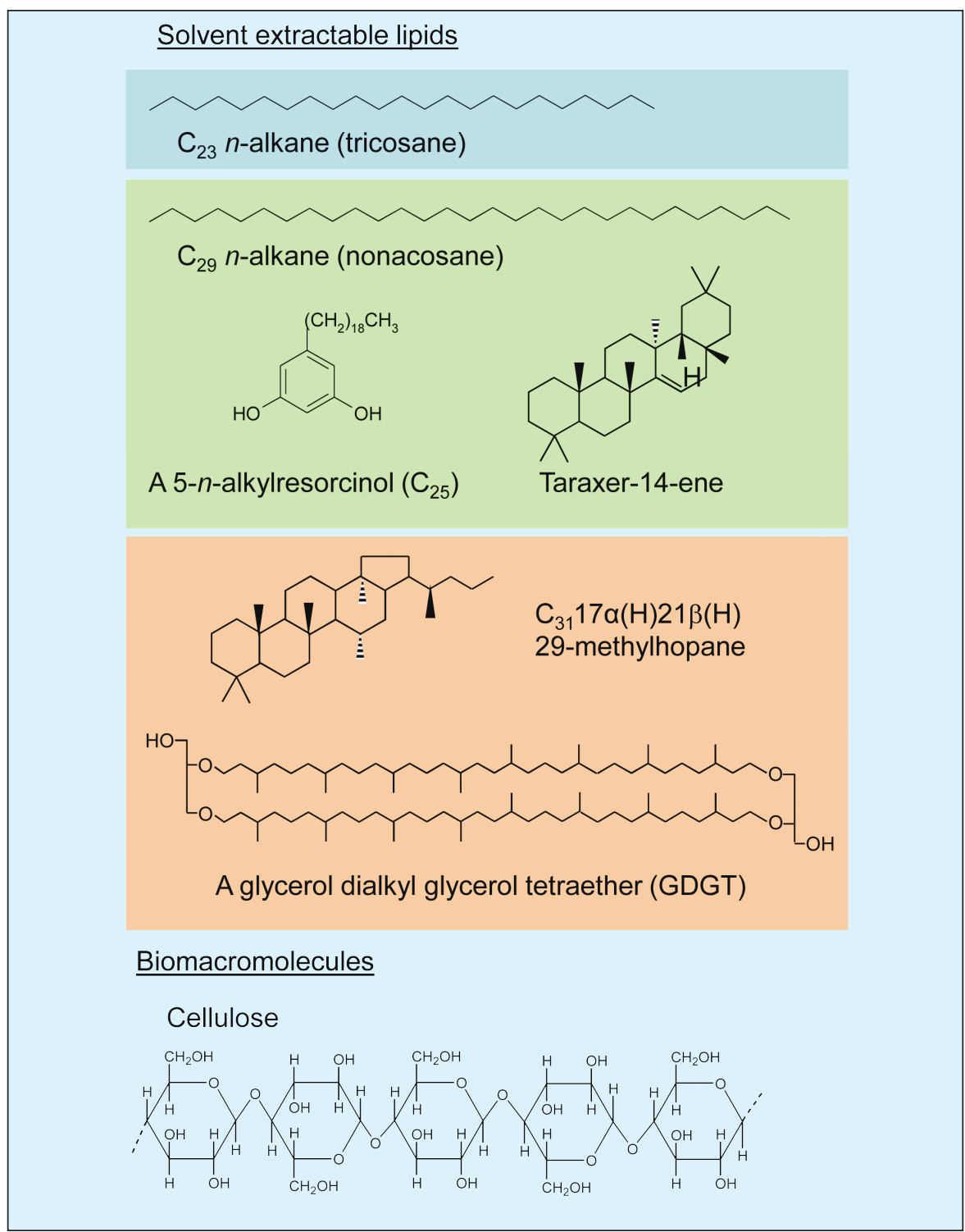

Figure 2: Chemical structures of selected biomarkers for either peat-forming plants, microbial activity, and/or diagenetic transformations of organic matter. Both solvent-extractable lipids and those requiring thermal degradation techniques for analysis (e.g., biomacromolecules) are shown. Only the partial structure of cellulose is shown. Lignin is also a common biomacromolecule, the structure of which is too complex to display clearly here. Blue shading = Sphagnum source; Green shading = vascular plant source; Orange shading = microbial source. 
strategies can help disentangle these various factors.

\section{Development of biomarker proxies}

Analyzing manually picked plant remains requires good preservation, which is not always characteristic of well-humified peats. Alternatively, organic geochemistry techniques can characterize bulk samples of peat, in cases where specific molecules or groups of compounds (biomarkers) are associated with particular peat-forming plants, microbial activity, or diagenetic transformations. Two principal methods have been employed in peats (Fig. 2): analysis of solvent-extractable lipids, and analysis of biomacromolecules via thermal degradation techniques (pyrolysis).

Compounds that are specific to particular peat-forming plants (Fig. 2) include the 5- $n$-alkylresorcinols (in sedges; Avsejs et al., 2002), a group of triterpenoids, the taraxeroids (in Ericaceae rootlets; Pancost et al., 2002), and a pyrolysis product of sphagnum acid, 4-isopropenylphenol
(Boon et al., 1986; van der Heijden et al., 1997). The most widely applied markers for peat-forming plants are the straight chain hydrocarbons from plant waxes, the $n$-alkanes, whose dominant chain-lengths differ between Sphagnum (usually $C_{23}, C_{25}$ ) and non-Sphagnum ( $>\mathrm{C}_{29}$ ) species (Baas et al., 2000; Bingham et al., 2009; Nichols et al., 2006; Nott et al., 2000). These relationships and the post-depositional stability of the $n$-alkanes have enabled changing plant inputs to be detected (Fig. 3) (McClymont et al., 2008; Nott et al., 2000). Compound-specific stable isotope analysis also allows simultaneous generation of isotopic information for both Sphagnum and non-Sphagnum species.

Mechanisms of organic matter degradation have been determined and linked to Holocene water table depths because microbial activity and chemical transformations are controlled by oxygen and hydrogen availability. Biomarker records of degradation include the stereochemical transformations of hopanes and the presence of anaerobic and aerobic microbial

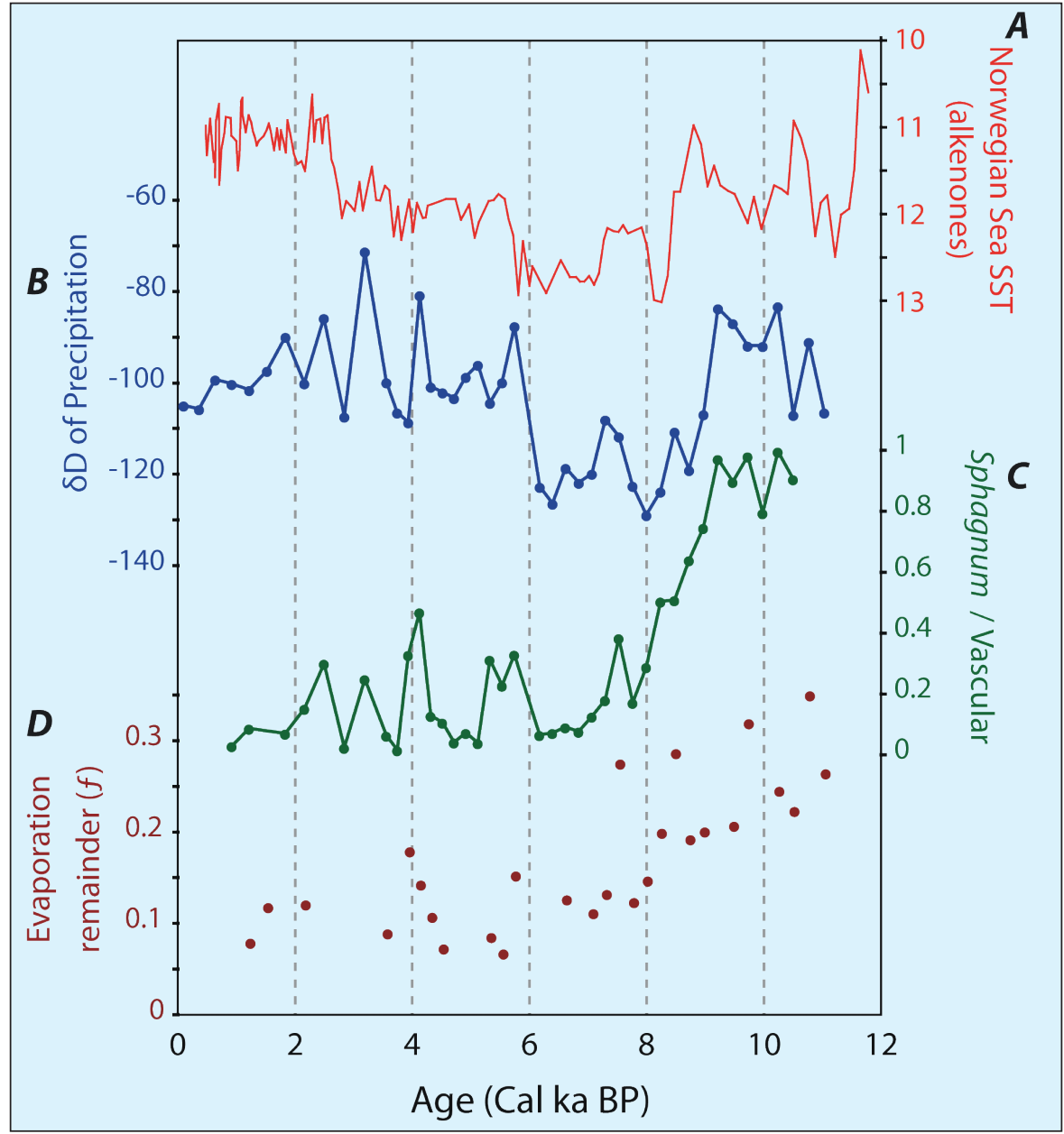

Figure 3: Biomarker records from a peatland on the Lofoten Islands of arctic Norway (modified from Nichols et al., 2009). A) Norwegian Sea Surface Temperature (SST) on inverse scale, plotted for regional context (Calvo et al., 2002). B) $\delta D$ of precipitation derived from $\delta D$ of the vascular plant biomarker, nonacosane. From $\sim 9 \mathrm{ka}$ to $6 \mathrm{ka}$, warm SSTS allowed for increased winter precipitation at the coastal Norway site, resulting in depleted annual average $\delta D$ of precipitation. $C$ ) The Sphagnum/Nascular ratio is an $\mathrm{n}$-alkane biomarker ratio indicating the relative contribution of Sphagnum and vascular plants to the peat. The contribution of Sphagnum to the peat declines rapidly with the decrease in summer precipitation at $9 \mathrm{ka}$. Sphagnum recovers at $6 \mathrm{ka}$, but not fully, indicating the region is drier during this period. D) " $f$ " is the fraction of water remaining in Sphagnum after evaporation, based on the comparison of the $\delta D$ of Sphagnum and vascular plant biomarkers. In this Norwegian peatland, evaporation increases as the region becomes cooler and drier. lipids in Holocene peats (McClymont et al., 2008; Pancost et al., 2003). Methanogenesis (formation of methane by microbes) in peats has been identified by the presence and $\delta^{13} \mathrm{C}$ signature of lipids derived from Archaea (Pancost et al., 2000). A pronounced increase in archaeal lipid concentration in the catotelm of Swedish peat supported this interpretation, and could potentially be used to assess water table depth (Weijers et al., 2004). The preferential degradation of plant macromolecules (e.g., polysaccharides, lignin) under aerobic and anaerobic conditions can also be detected (Schellekens et al., 2009). Applying these relationships down-core may offer insights into both changing water table depth and the biogeochemical response to such events.

\section{Application of compound-specific isotope analysis}

Ombrotrophic peatlands contain two distinct plant groups that potentially draw water from different reservoirs and are distinguishable by different leaf wax biomarkers (Fig. 1). Sphagnum uses water from within water-retaining (hyaline) cells and that held among the leaves and branches, which may be strongly affected by evaporation and therefore enriched in deuterium (D) relative to precipitation. In contrast, vascular plants use water from below the surface in the acrotelm, protected from evaporation and representative of precipitation $\delta \mathrm{D}$ (Nichols et al., 2009). Further fractionation during biosynthesis leads to vascular plant cellulose being systematically enriched relative to Sphagnum, and this is also reflected in $n$ alkane $\delta D$ (Menot-Combes et al., 2002). By measuring $\delta D$ of both vascular plant (peatland water before evaporation) and Sphagnum biomarkers (peatland water after evaporation), and assuming that vascular biomarkers were not affected by evapotranspiration, Nichols et al. (2010) calculated Holocene evaporation in north America. This approach has also enabled both peatland wetness and precipitation seasonality to be determined in Holocene peats from Norway, and subsequently linked to the sea-surface temperatures in the Norwegian Sea (Nichols et al., 2009) (Fig. 3).

Two major factors affect $\delta^{13} \mathrm{C}$ of Sphagnum biomarkers: Sphagnum water content and the amount of recycled methane contributing to the $\mathrm{CO}_{2}$ pool used by Sphagnum for photosynthesis. When Sphagnum is more saturated, the water film over the photosynthetic cells impedes the incorporation of $\mathrm{CO}_{2}$ and thus the plant becomes less selective against ${ }^{13} \mathrm{C}$ 
$\left(\delta^{13} \mathrm{C}\right.$ increases) and vice versa (Williams and Flanagan, 1996). However, the effect of recycled methane on $\delta^{13} \mathrm{C}$ of Sphagnum biomarkers has the opposite relationship with moisture. When the peatland is wetter, more methane produced at depth is respired by methanotrophs that are symbiotic with Sphagnum, the resulting low- $\delta^{13} \mathrm{CCO}_{2}$ is assimilated by Sphagnum and recorded in lower $\delta^{13} \mathrm{C}$ of Sphagnum biomarkers. During drier conditions, the reverse occurs (Nichols et al., 2009; Raghoebarsing et al., 2005). These competing factors necessitate careful interpretation of Sphagnum biomarker $\delta^{13} \mathrm{C}$ measurements.

\section{Conclusions}

Isotopic and organic geochemistry analyses of peats are valuable approaches for understanding past climatic and environmental change. The complexity of peatlands requires a multi-proxy approach to fully exploit the paleoenvironmental signatures contained within peat archives. Further research is also needed into the factors controlling the isotopic composition of different plant compounds (e.g., evaporative effects in plant waxes vs cellulose) to better understand the environmental signatures contained within them.

\section{References}

Daley, T.J., Barber, K.E., Street-Perrott, F.A., Loader, N.J., Marshall, J.D., Crowley, S.F., Fisher, E.H., in press: Holocene climate variability revealed by oxygen isotope analysis of Sphagnum cellulose from Walton Moss, northern England, Quaternary Science Reviews, doi:10.1016/j.quascirev.2009.09.017

McClymont, E.L., Mauquoy, D., Yeloff, D., Broekens, P., van Geel, B., Charman, D.J., Pancost, R.D., Chambers, F.M. and Evershed, R.P., 2008: The disappearance of Sphagnum imbricatum from Butterburn Flow, UK, The Holocene, 18: 991-1002.

Nichols, J., Booth, R.K., Jackson, S.T., Pendall, E.G. and Huang, Y., 2010 Differential hydrogen isotopic ratios of Sphagnum and vascular plant biomarkers in ombrotrophic peatlands as a quantitative proxy for precipitation--evaporation balance, Geochimica et Cosmochimica Acta, 74: 1407-1416.

Pendall, E., Markgraf, V., White, J.W.C., Dreier, M. and Kenny, R., 2001 : Multiproxy record of late Pleistocene-Holocene climate and vegetation changes from a peat bog in Patagonia, Quaternary Research, 55: 168-178.

Skrzypek, G., Kaluzny, A., Wojtun, B. and Jedrysek, M.-0., 2007: The carbon stable isotopic composition of mosses: A record of temperature variation, Organic Geochemistry, 38: 1770-1781.

\section{Peat cellulose isotopes as indicators of Asian monsoon}

\section{variability}

BING Hong ${ }^{1}$, M. UChIDA ${ }^{2}$, X.T. Leng $^{3}$ AND Y.T. Hong ${ }^{1}$

'State Key Laboratory of Environmental Geochemistry, Institute of Geochemistry, Chinese Academy of Sciences, Beijing, China; hongbing@vip. skleg.cn

Environmental Chemistry Division, National Institute for Environmental Studies, Tsukuba, Japan; ${ }^{3}$ Institute of Peatmire, Northeast Normal University, Changchun, China

\section{Stable isotopes in peat cellulose provide records of Asian monsoon variability in the Holocene and suggest persistent teleconnections between the Asian monsoons and North Atlantic climate variability.}

\section{Peat cellulose isotopes as proxy climate indicators}

A practical proxy for climate reconstruction for the Holocene epoch should be able to span about $10 \mathrm{ka}$ with decadal to centennial time resolution. Over the last 20 years oxygen and carbon isotope analysis of peat cellulose has been developed as a Holocene paleoclimate proxy (Brenninkmeijer et al., 1982; Hong et al., 2000, 2001; Ménot-Combes et al., 2002). Peat plant cellulose is a macromolecular polymer of interlinked dextroglucose molecules (Hong et al., 2009; and see McClymont et al., this issue), formed from oxygen atoms derived from the water used by the plant and carbon atoms derived from atmospheric $\mathrm{CO}_{2}$. The stable isotopic composition of cellulose oxygen and carbon is influenced by different physical and chemical processes. Oxygen isotopes $\left(\delta^{18} \mathrm{O}\right)$ in water molecules undergo temperature-dependent fractionation during condensation. Variations in $\delta^{18} \mathrm{O}$ of meteoric water are generally positively correlated with atmospheric temperature (Dansgaard, 1964). During photosynthesis, the $\delta^{18} \mathrm{O}$ signature of the source water is recorded in cellulose molecules. Source water for photosynthesis in many peatlands is primarily meteoric, although it may be enriched by evaporation. Vascular plants respond to variations in water availability and relative humidity by regulating the opening or closing of leaf stomata. This leads to changes in the stable carbon isotopic composition $\left(\delta^{13} \mathrm{C}\right)$ of atmospheric $\mathrm{CO}_{2}$ utilized in photosynthesis (Francey and Farquhar, 1982; Schleser, 1995). The amount of rainfall is also negatively correlated to the plant $\delta^{13} \mathrm{C}$ value; the larger the amount of rainfall, the smaller the $\delta^{13} \mathrm{C}$ value (Lee et al., 2005; Wang et al., 2008). Therefore, information on climatic changes is preserved in the $\delta^{18} \mathrm{O}$ and $\delta^{13} \mathrm{C}$ values of peat plant cellulose. Finally, plant cellulose is highly resistant to decomposition. Both cellulose and its isotopes are highly stable over periods of approximately $10^{5}$ years (Briggs et al., 2000). Peat plant cellulose isotopes therefore have significant potential as a bioindicator of paleoclimatic changes. Here we summarize the contribution of peat cellulose isotopes to the reconstruction of East Asian monsoon variability during the Holocene.

\section{Spatial variation of the EASM and peatland distribution}

Recent advances in extraction and purification of cellulose from bulk peat samples have allowed application of peat cellulose isotopes (Hong et al., 2000, 2001) to reconstruct the history of the Asian sum- mer monsoon (e.g., Hong et al., 2009). Peat deposits of northern China are largely dominated by sedges, so the isotopic sig-

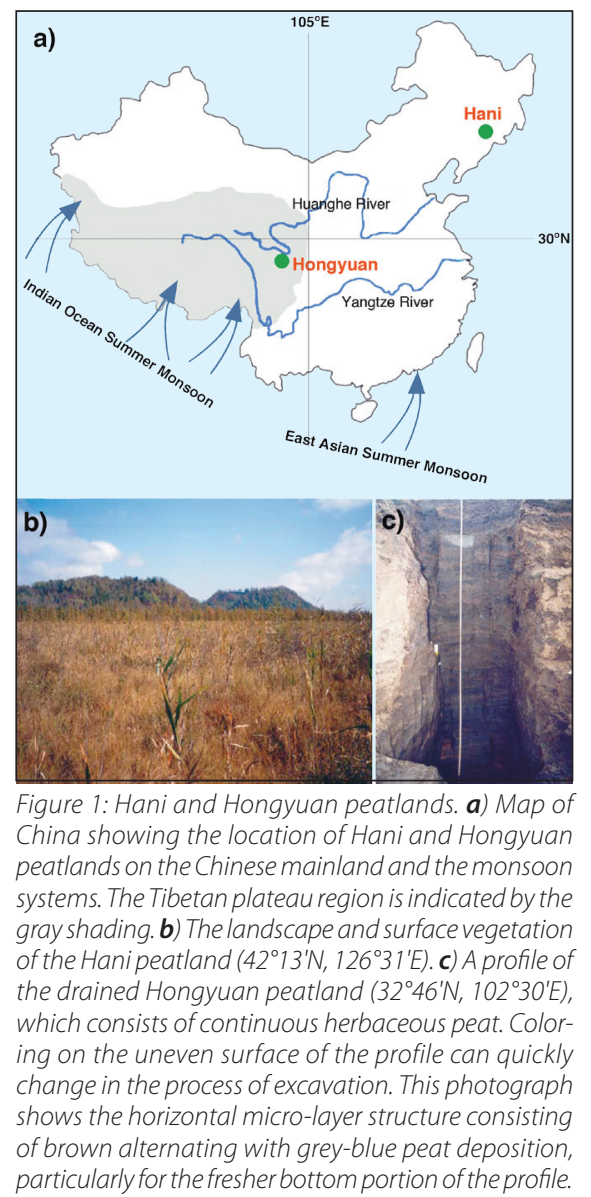


nal is not influenced by plant composition changes to any great degree.

The Asian summer monsoon includes two monsoonal systems, the Indian Ocean summer monsoon (IOSM) and the East Asian summer monsoon (EASM). Although they form independently of each other, these systems play an important role in water vapor transport and summer precipitation on the East Asian continent (Tao and Chen, 1987). In general, the EASM dominates east of $105^{\circ} \mathrm{E}$ longitude, whereas the IOSM has greater influence west of that longitude, particularly in the Tibetan plateau region (Fig. 1; Sun 1996, Hong et al., 2006).

There is significant interannual variability in rainfall amount and monsoonal strength within the EASM domain. This variability is controlled by intensity and position of the western Pacific subtropical high (STH) and by sea surface temperature (SST) variation in the equatorial Pacific. When SSTs take on an El Niño-like pattern, the STH tends to strengthen. This is accompanied by a strengthened Intertropical Convergence Zone, and stronger convection, especially in the tropical western Pacific. The STH over the western Pacific ocean shifts northward, leading to migration of a precipitation belt to the north of the Chinese continent. This results in an increase in rainfall in both the north and northeast regions of China, but at the same time, less rainfall in the middle and lower regions of the Yangtze River (Sun and Yin, 1999; Yin and Sun, 2000; Wu et al., 2003). In contrast, when SST variation in the equatorial Pacific takes on a $\mathrm{La}$ Niña-like pattern, the intensity of the STH tends to weaken, and the position of the STH over the western Pacific ocean moves south. This generally results in migration of a precipitation belt to the southern regions of the Chinese continent, leading to an increase in precipitation in southern China, but less rainfall in northern and northeastern China.

Only a strong EASM that originates from the South China Sea can expand to the northern regions of the East Asian subcontinent. Therefore, meteorologists commonly regard precipitation conditions in northern and northeastern China as representative of the variation in the strength of the EASM (Gao and Xu, 1962; Hong et al., 2006; Wang and Zhu, 2006). Fortunately, the most extensive, deepest and best-preserved peatlands occur in northeast China (for example, the Hani peatland) and in the Tibet plateau regions (e.g., the Hongyuan peatland) (Fig. 1). Peat cellulose stable isotopes in these two lo-

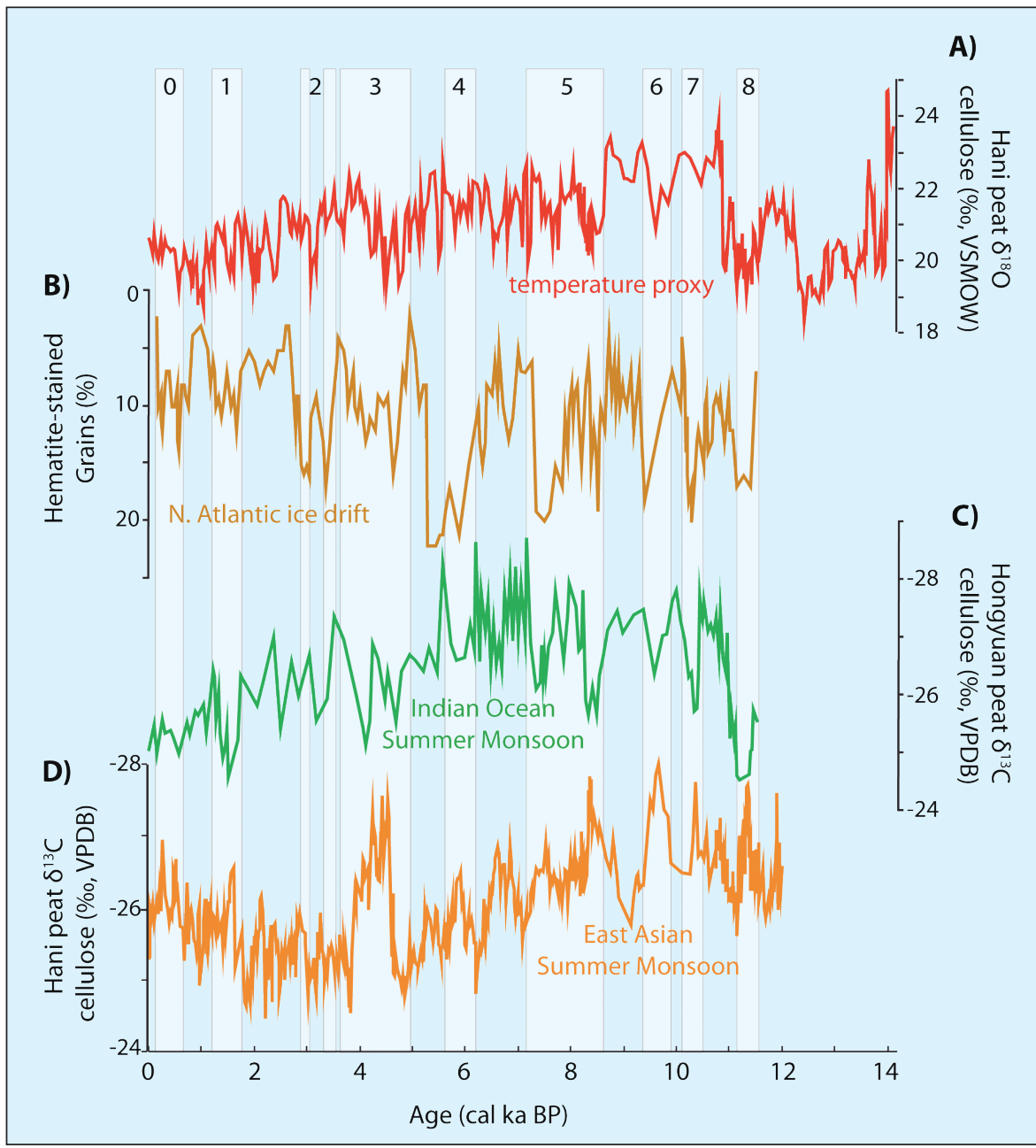

Figure 2: Comparison of the inverse phase variations between the two Asian monsoons and the climate changes of the North Atlantic and West Pacific Oceans. A) The $\delta^{18} \mathrm{O}$ temperature proxy record of the Hani peat cellulose (Hong et al., 2009). B) The drift ice record of the North Atlantic (Bond et al., 1997). C) Proxy record for the Indian Ocean summer monsoon (IOSM) from $\delta^{13} \mathrm{C}$ of the C. mulieensis cellulose in the Hongyuan peat (Hong et al., 2003). D) Proxy record for the East Asian summer monsoon (EASM) from $\delta^{13} \mathrm{C}$ of the Hani peat cellulose (Hong et al., 2005). Numbers from 1 to 8 indicate ice-rafted debris events of the North Atlantic, O indicates "Little Ice Age" event (Bond et al., 1997).

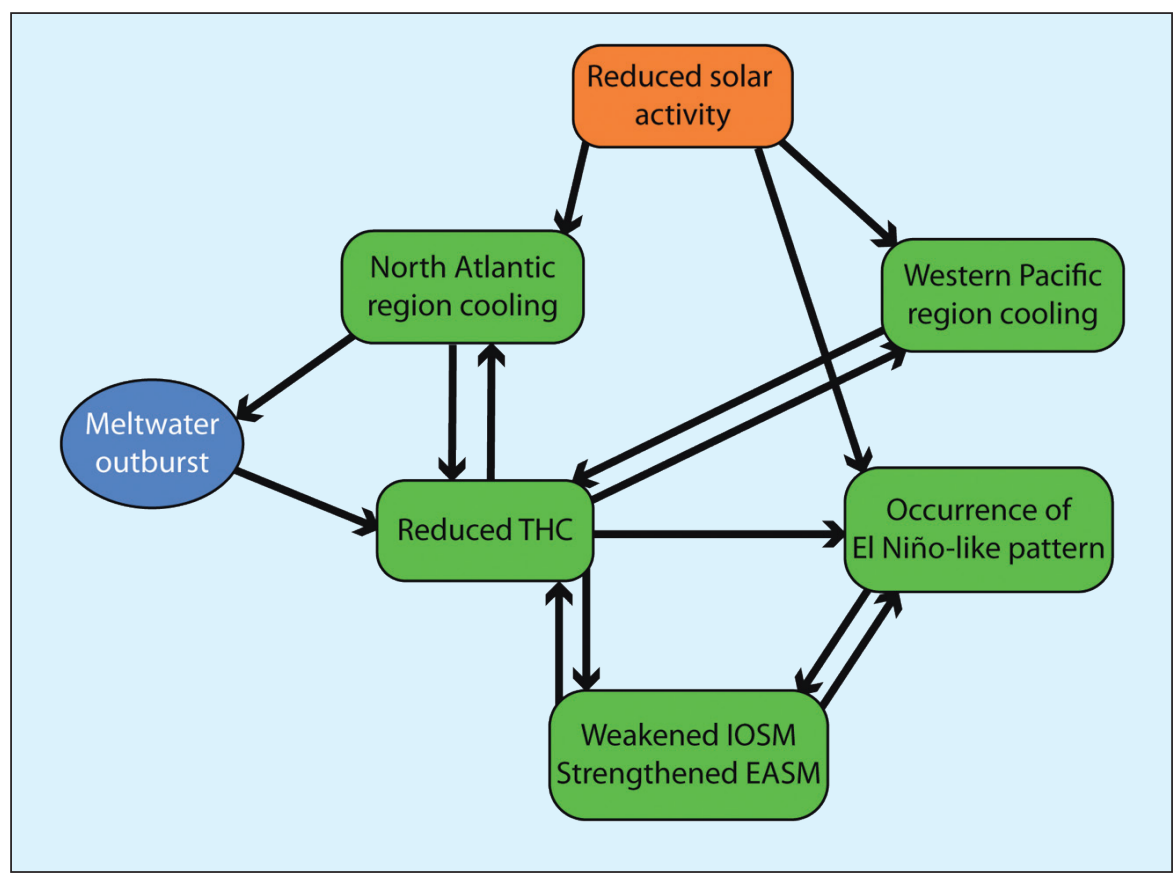

Figure 3: A conceptual model on global climate interconnections on centennial to millennial timescales during the period from the last deglaciation to the Holocene (Figure modified from Hong et al., 2009). In addition to synchronous abrupt temperature deterioration in the western North Pacific and North Atlantic regions, it also shows hypothesized interconnections between ice sheet variation at the high northern latitudes, ocean-atmospheric processes of the Equatorial Pacific, monsoonal activity in the middle-low latitudes, and solar activity. THC, IOSM, and EASM denote the ocean thermohaline circulation, the Indian Ocean summer monsoon, and the East Asian summer monsoon, respectively. 
cations therefore reflect variability in the EASM and IOSM respectively.

\section{Global connections of the Asian monsoon recorded in peat}

Comparison of the Hani and Hongyuan $\delta^{13} \mathrm{C}$ records has revealed the phenomenon of antiphase variations between the EASM and IOSM on centennial to millennial timescales (Fig. 2). Abrupt strengthening of the EASM and simultaneous abrupt weakening of the IOSM appear to have occurred at times that correspond to the nine abrupt ice-rafted debris events in the North Atlantic (Hong et al., 2003, 2005), suggesting global teleconnections between the North Atlantic, Pacific Ocean and monsoon systems throughout the Holocene. The anti-phase variations of the two Asian monsoons correspond to both reduced solar activity in the late Holocene and to meltwater events in the early Holocene. A conceptual model of global climate changes that summarizes the connections between ice sheet variations at high northern latitudes, oceanatmospheric process of the equatorial Pacific, monsoonal activity in the middlelow latitudes, and solar activity is shown in Figure 3. It remains for these interactive processes to be further examined and tested against new paleoclimate records. Peat cellulose isotope indicators could play an important role in this investigation because nearly all land regions affected by the processes mentioned above possess peatlands. A systematic global comparative study on peatland paleoclimatology would help test our hypotheses of monsoon variability as well as addressing other key paleoclimate questions (see e.g., Booth et al., this issue).

\section{References}

Hong, Y.T., Wang, Z.G., Jiang, H.B., Lin, Q.H., Hong, B., Zhu, Y.X., Wang, Y., XU, L.S., Leng, X.T. and Li, H.D., 2001: A 6000-year record of changes in drought and precipitation in northeastern China based on a $\delta^{13} \mathrm{C}$ time series from peat cellulose, Earth and Planetary Science Letters, 185: 111-119.

Briggs, D.E.G., Evershed, R.P. and Lockheart, M.J., 2000: The biomolecular paleontology of continental fossils, Paleobiology, 26: 169-193.

Hong, B., Lin, Q.H. and Hong, Y.T., 2006: Interconnections between the Asian monsoon, ENSO, and high northern latitude climate during the Holocene, Chinese Science Bulletin, 51: 11-19.

Sun, S. and Yin, M., 1999: Subtropical high anomalies over the Western Pacific and its relations to the Asian monsoon and SST anomaly, Advances in Atmospheric Sciences, 16: 559-568.

Hong, Y.T., Hong, B., Lin, Q.H., Shibata, Y., Zhu, Y.X., Leng, X.T. and Wang Y., 2009: Synchronous climate anomalies in the western North Pacific and North Atlantic regions during the last 14,000 years, Quaternary Science Reviews, 28: 840-849.

\title{
Peat as an archive of atmospheric pollution and environmental change: A case study of lead in Europe
}

\author{
François De Vleeschouwer ${ }^{1}$, G. Le Roux ${ }^{2}$ and W. Shotyk ${ }^{3}$ \\ 'Department of Ecology and Environmental Science, Umeå University, Sweden; francois.devleeschouwer@emg.umu.se \\ ${ }^{2}$ EcoLab (UMR 5245), National Center for Scientific Research, Université de Toulouse, France; ${ }^{3}$ Environmental Inorganic and Isotope Geochemis- \\ try Research Group, Institute of Earth Sciences, University of Heidelberg, Germany
}

\section{Inorganic geochemistry in peat deposits provides unique and valuable indications of human activities and consequent environmental changes.}

\section{European heavy metal pollution}

Ombrotrophic bogs are uniquely suited to provide records of natural and anthropogenic airborne particles because their surface layers are exclusively fed by atmospheric inputs (i.e., rain, snow, fog, dust), and hence offer the unique possibility to record atmospheric metal emissions at a relatively high time-resolution (centennial to decadal). Peat cores from such bogs are excellent continental archives of atmospheric lead $(\mathrm{Pb})$ deposition not only because they receive $\mathrm{Pb}$ solely from the air but also because they efficiently retain this metal despite their low pore-water $\mathrm{pH}$ (c. 4) and the seasonal variations in redox potential that should promote particle dissolution (e.g., Shotyk and Le Roux, 2005, and references therein). The high abundance of natural complex-forming organic acids guarantees the preservation of metal-bearing particles, especially lead.

It is of particular importance to document both background and actual metal fluxes because the atmospheric geochemical cycle of lead and other metals has been profoundly affected by human activities throughout the Northern Hemisphere for more than 3 ka (Nriagu, 1983). Human activities have significantly impacted the atmospheric emissions of a broad range of metals and metalloids (e.g., $\mathrm{Pb}$, copper $(\mathrm{Cu})$, zinc, cadmium, mercury $(\mathrm{Hg})$ ), as a result of the smelting of metal sulfide ores and the combustion of coal, both releasing particulates and aerosols (Pacyna et al., 2007, 2009). Given the ease by which it can be smelted and the number of possible industrial and commercial applications, $\mathrm{Pb}$ has been used by humans for more than 8 ka (Wertime, 1973). In addition, the stable isotopes of $\mathrm{Pb}$ allow "natural" $\mathrm{Pb}$ to be distinguished from various anthropogenic sources (lead ores, coal, gasoline), allowing one to track pollution sources and tackle the origin of long-range natural dust contributions during the Holocene.

Long-term $\mathrm{Pb}$ emissions over Europe have been unambiguously documented by analysis of peat cores from ombrotrophic bogs (e.g., Shotyk et al., 1998). Using $\mathrm{Pb}$ isotopes, Kylander et al. (2005) in Spain and Shotyk et al. (1998) in Switzerland have also shown significant variability in Saharan dust input over Europe during the Holocene. From a paleotoxicity point of view, the pre-anthropogenic emissions of $\mathrm{Pb}$-bearing particles are insignificant compared to late Holocene anthropogenic emissions. Moreover, their larger grain size (5-50 $\mu \mathrm{m}$ compared to $0.5 \mu \mathrm{m}$ for anthropogenic particles) and low solubility in natural conditions render them largely harmless for the environment and humans (Shotyk and Le Roux, 2005). The anthropogenic lead-bearing particles, due to their sub-micronic grain size, are easily incorporated in the environment and also in human beings by inhalation or ingestion. In addition, the amount emitted in the atmosphere, although fluctuating with climate and therefore representing a potential tracer for Holocene paleoclimatic changes, is negligible compared to the amount of anthropogenic lead-bearing particles emitted during the second half of the Holocene.

Geological archives are commonly employed to assess the extent of metal release to the environment, including the atmospheric fluxes and other predominant sources. During the past 50 years, bogs have become increasingly recognized as the best continental archives of atmospheric $\mathrm{Pb}$ deposition, especially in Europe (Fig. 1), a region that has contributed so much to global atmospheric pollution. A number of European bogs have yielded high-resolution reconstructions of atmospheric $\mathrm{Pb}$ deposition (e.g., Shotyk et al., 1998; Le Roux et al., 2004; De Vleeschouwer et al., 2009, and references 
therein). Since the last decade, there has been growing interest in: (1) the reconstruction of $\mathrm{Pb}$ inventories within and between regions, (2) the use of $\mathrm{Pb}$ and other trace elements to help solve archeological problems pertaining to archeometallurgy, and (3) the combination of palynological and geochemical studies to investigate human-environment relationship in mining areas (Jouffroy-Bapicot et al., 2007). In the first case, to better constrain pollutant inventories, it is necessary to first determine the pre-anthropogenic deposition rate of these compounds, and assess their natural variation in space and time (e.g., Kylander et al., 2005; Shotyk et al., 2001). In the second and the third cases, peat records offer the unique opportunity to provide a detailed, reliable chronology of metal pollution where archeological and/ or historical evidences are lacking (e.g., Mighall et al., 2009; Renson et al., 2008).

Studies on European bogs have yielded records of $\mathrm{Pb}$ contamination varying in intensity that are consistent with the known history of lead sulfide mining (Fig. 1). Isotopic studies covering the beginning of early metallurgy show local- to regional-scale $\mathrm{Pb}$ pollution (e.g., Baron et al., 2005; Cloy et al., 2005; Le Roux et al., 2004, 2005). During the Middle Ages, new mining areas in Europe (e.g., Harz, Germany; Wales, UK) were explored and consequently European bogs were more impacted in the vicinity of those new mining areas (e.g., Kempter and Frenzel, 2000; Le Roux et al., 2004; Fig.1). A strong link between mining activity and deforestation for charcoal production is also suspected in many places in Europe (e.g., Baron et al., 2005; Monna et al., 2004; Mighall et al., 2009). Since the Industrial Revolution beginning ca. $1750 \mathrm{AD}$, a dramatic increase in atmospheric $\mathrm{Pb}$ pollution began in Europe. Bogs also bear witness to long range atmospheric transport of pollutant aerosols. For example, $\mathrm{Pb}$ from mining in the Iberian Peninsula more than 3 ka has been detected in a Swiss bog (Shotyk et al., 1998), and atmospheric $\mathrm{Pb}$ (and antimony (Sb)) contamination dating from the Roman Period has been recorded in peat from the remote Faroe Islands (Shotyk et al., 2005). After the $2^{\text {nd }}$ World War, the $\mathrm{Pb}$ isotopic signal in western Europe tends to be more spatially homogeneous due to massive $\mathrm{Pb}$ emissions from leaded gasoline combustion (e.g., De Vleeschouwer et al., 2007, 2009). However, many peat records show clearly that coal mining was also an important, and sometimes dominant (especially in eastern Europe) source of $\mathrm{Pb}$ during the second half of the $20^{\text {th }}$ century (e.g., Farmer et al., 1997; Shotyk et

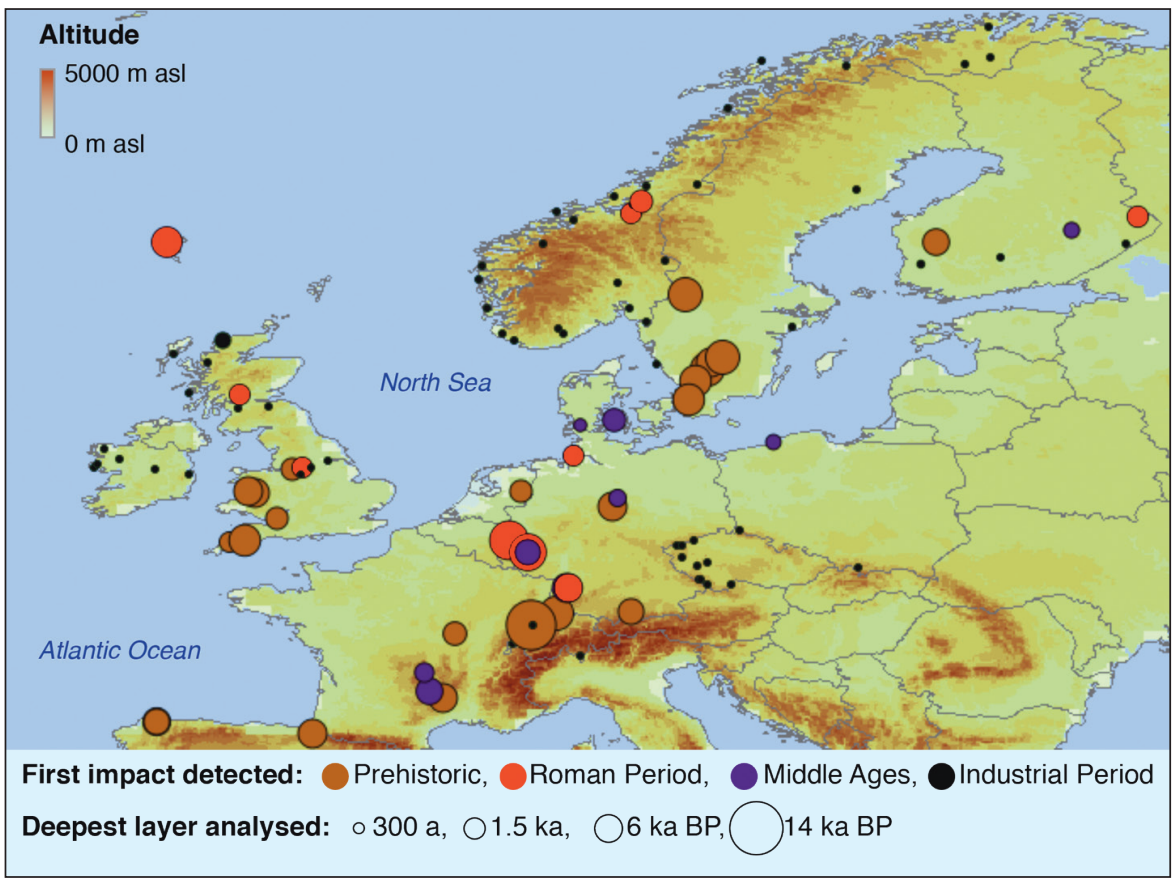

Figure 1: Map of atmospheric Pb contamination in Europe reconstructed using age-dated peat cores. Data used to produce this figure are referenced in the online reference list, indicated by an asterix. A detailed excel database is available upon request to G. Le Roux (gael.leroux@ensat.fr). Some early references, which may not be easily accessible for the reader, have been omitted. For more information, please consult: www.rzuser.uni-heidelberg. de/ i12/estandforlit.htm

al., 2003, 2005; Novak et al., 2003; De Vleeschouwer et al., 2009).

\section{High-resolution, multi-metal studies}

In Figure 2, a peat core from Lindow Bog (Manchester, UK) shows the potential of bogs as archives of paleo-pollution and archeology (Le Roux et al., 2004). Metal/titanium (Ti) ratios can be used to investigate anthropogenic deposition levels because $\mathrm{Ti}$ is a conservative element principally derived from soil erosion and not from smelting, combustion or gasoline use like metals. Therefore, by comparing the $\mathrm{Pb} / \mathrm{Ti}$ and $\mathrm{Cu} / \mathrm{Ti}$ ratios in the samples with those in the upper continental crust (i.e. the source of non-anthropogenic $\mathrm{Pb}$ and $\mathrm{Cu}$ ), it is possible to calculate the contribution of anthropogenic $\mathrm{Pb}$ and $\mathrm{Cu}$, and to derive their flux (Shotyk et al., 2000). The first Pb and Cu contamination appear ca. 1000 BC, which clearly pre-dates Roman mining activities. The timing of the ancient and medieval $\mathrm{Pb}$ pollution, as shown in Figure $2 \mathrm{a}$, is also directly related to socio-economic events (warfares, plague epidemics). The ${ }^{208} \mathrm{~Pb} /{ }^{206} \mathrm{~Pb}$ and ${ }^{206} \mathrm{~Pb} /{ }^{207} \mathrm{~Pb}$ data from the Lindow Bog indicate that English ores were the predominant sources for $\mathrm{Pb}$ atmospheric deposition in England during the pre-Roman, Roman, and medieval periods (Fig. 2b inset). This correlates well with palynological studies by Birks (1965) on the same peat profile of Lindow Bog, which indicate that different phases of vegetation clearance during the aforementioned periods are not only due to animal breeding pressure but also due to human settlements for mining activities.

Changes in atmospheric $\mathrm{Hg}$ deposition can also been found using peat cores. Thus, comparison of these three elements, derived from different sources that were worked at different times, and varying in geochemical behavior, can add value to the peat bog studies (Fig. 2). As it is true for $\mathrm{Pb}$, some small peaks of $\mathrm{Cu}$ appear in the Lindow profile before the Roman Period. Unlike $\mathrm{Pb}, \mathrm{Cu}$ is less susceptible to longrange transport and its enrichment in the peat from Lindow reflects local sources. Mercury does not show variations related to ancient metallurgy, but the clear increase beginning $0.5 \mathrm{ka}$ ago is consistent with the onset of coal burning. The differences in the timing of the $\mathrm{Pb}, \mathrm{Cu}$, and $\mathrm{Hg}$ deposition during the past five centuries remind us of the importance of multi-element studies in deciphering the changing rates and sources of atmospheric pollution (Fig. 2).

\section{Perspectives}

Until recently, the key parameters for a better understanding of heavy metal records in peat have focused upon the ombrotrophic character of the peat deposits, high-resolution multi-metal chronologies, and high quality lead isotope analyses. However, more recent studies have demonstrated that other parameters, such as the local/regional background variations, are crucial for a fully constrained interpretation and assessment of metal inventories, because the natural rates of atmo- 


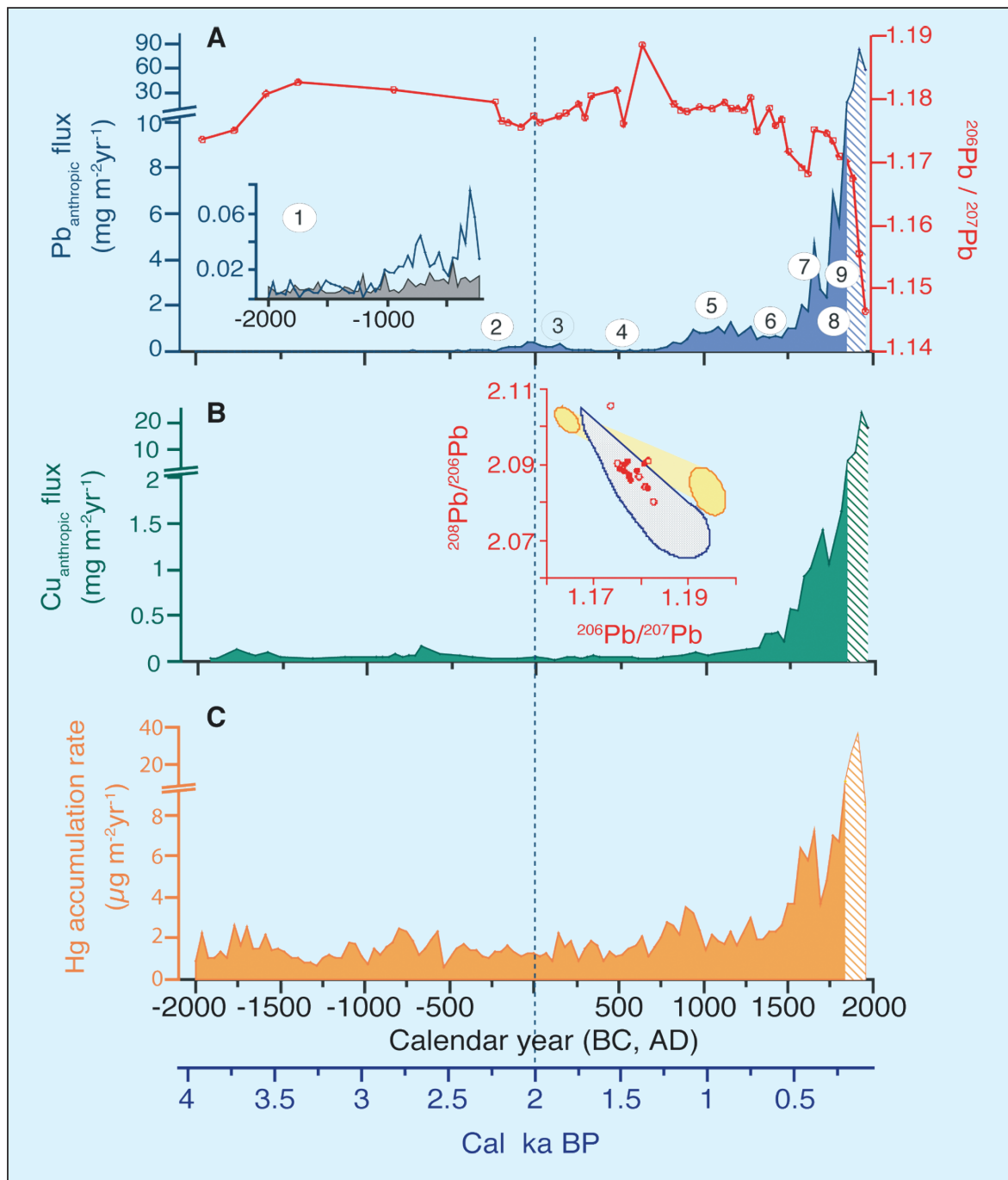

Figure 2: Lead (Pb), copper (Cu) and mercury ( $\mathrm{Hg}$ ) chronologies in Lindow Bog (UK). A) Fluxes of anthropogenic $\mathrm{Pb}$ and ${ }^{206} \mathrm{~Pb} / 207 \mathrm{~Pb}$ from $2000 \mathrm{BC}$ to $1800 \mathrm{AD}$ with focus on the pre-Roman period (Inset) to emphasize the early increase in Pb deposition at 1000 BC (from Le Roux et al., 2004). The natural estimated Pb flux is also represented (light gray). 1) Begin of use of leaded bronze in Great Britain, 2) Iron Age, 3) Roman Occupation (43 AD-410 AD), 4) Dark Ages, 5) Norman-Medieval Period, 6) Hundred Years War, plague epidemic (1349 AD), 7) German workers brought to re-organize the mines (16 th century), 8) plague epidemic (1645 AD), 9) Industrial Revolution. B) Flux of copper (green, unpublished data) and Pb three-isotope plot (inset) with peat samples (red), UKores (blue) and Spanish ores (yellow), indicating UKores as the likely source of Pb atmospheric deposition over Iron Age and Roman Occupation. C) Hg accumulation rate (unpublished data). Hatched section: recent period possibly disturbed by peat farming. spheric dust deposition may have varied considerably with climate change during the Holocene (e.g., Kylander et al., 2005; Shotyk et al., 2001). There is also a clear need for interdisciplinary studies linking paleoenvironments, geochemistry and archeology (i.e., archival records), as well as atmospheric chemistry and transport modeling. There is tremendous opportunity to employ new analytical tools for the characterization of pollutant aerosols (e.g., Scanning electron microscope, Laser Ablation inductively coupled plasma mass spectrometry) as well as to investigate other elements that have been less studied (e.g., Rare Earth Elements, Platinum Group Elements) but may provide new insights into both nutrient input by natural atmospheric dusts during pre-anthropogenic times, and human impacts on the environment.

\section{References}

Nriagu, J.0., 1983: Lead and lead poisoning in the Antiquity, John Wiley, New York.

Shotyk, W., Weiss, D., Appleby, P.G., Cheburkin, A.K., Frei, R., Gloor, M., Kramers, J.D., Reese, S. and van der Knaap, W.O., 1998: History of atmospheric lead deposition since $12,370^{14} \mathrm{C}$ yr BP recorded in a peat bog profile, Jura Mountains, Switzerland, Science, 281 $1635-1640$

Shotyk, W. and Le Roux, G., 2005: Biogeochemistry and Cycling of Lead. In: Sigel, A., et al. (Eds), Biogeochemical Cycles of the Elements. Metal lons in Biological Systems, M. Dekker, New York 43: 240275.

De Vleeschouwer, F, Fagel, N., Cheburkin, A, Pazdur, A., Sikorski, J, Mattielli, N., Renson, V., Fialkiewicz, B. and Piotrowska, N., 2009: Anthropogenic impacts in North Poland over the last 1300 years, The Science of the Total Environment, 407: 5674-5684.

Le Roux, G., Weiss, D., Grattan, J., Givelet, N., Krachler, M., Cheburkin, A., Rausch, N., Kober, B. and Shotyk, W., 2004: Identifying the sources and timing of ancient and medieval atmospheric lead pollution in England using a peat profile from Lindow bog, Manchester, Journal of Environmental Monitoring, 6: 502-510.

\section{The northern peatland carbon pool and the Holocene}

\section{carbon cycle}

David W. Beilman', G.M. MacDonald² and Z. Yu ${ }^{3}$

'Department of Geography, University of Hawai`i Mānoa, USA; beilman@hawaii.edu

Institute of the Environment, University of California, Los Angeles, USA; ${ }^{3}$ Department of Earth and Environmental Sciences, Lehigh University, Bethlehem, USA

\section{Understanding the role of peatlands in the Holocene carbon cycle will help predict the response of northern carbon stores to a changing climate.}

Northern peatlands hold a large proportion of Northern Hemisphere land carbon (equivalent to as much as $1 / 3$ of total global soil carbon) and are significant and active players in the global carbon cycle. An improved understanding of the controls and future dynamics of these carbon-rich ecosystems is possible from study of their Holocene history and previous carbon response to climate change. Peatland information relevant to Earth system dynamics includes the spatiotemporal pattern of expansion to the current $\sim 4 \times 10^{6} \mathrm{~km}^{2}$ occupied by northern peatlands, the variations in carbon accumulation at millennial and multi-centennial timescales, and the distribution of today's 270-450 Pg (1 Pg = 1 gigatonne $=10^{15} \mathrm{~g}$ ) of peatland carbon as it relates to current climate.

\section{Peatland expansion}

Recently published datasets of basal ${ }^{14} \mathrm{C}$ (radiocarbon) dates from extant peatlands indicate that northern peatlands have been sequestering atmospheric $\mathrm{CO}_{2}$ and cycling land carbon at least since the early Holocene (Figs. 1 and 2; MacDonald et al., 2006; Gorham et al., 2007; Yu et al., 2009; Korhola et al., 2010). By 8 cal ka BP, peatlands had developed extensively across the continents in the Northern Hemisphere (Fig. 2e). This rapid wetland expansion contributed to the early Holocene rise and sustained peak in $\mathrm{CH}_{4}$ concentrations after the Younger Dryas until about $8 \mathrm{cal}$ ka BP (Fig. 2c; MacDonald et al., 2006), and 
a subsequent expansion at 4 cal ka BP possibly contributed to the late Holocene $\mathrm{CH}_{4}$ rise (Korhola et al., 2010). The carbon that accumulated on land as these early Holocene peatlands expanded could also have influenced the $\sim 7$ ppmv decrease in $\mathrm{CO}_{2}$ at 11 - 8 cal ka BP (Fig. 2b) if this new carbon pool was large. A range of conservative estimates suggests that 29-98 Pg carbon existed as northern peat carbon by $8 \mathrm{cal} \mathrm{ka}$ BP (MacDonald et al., 2006; Yu et al., 2009) and this pool could have been substantially larger. These spatially referenced datasets of peat basal ages are large (Fig. 1) and continue to grow, providing additional opportunities for creative data-mining to address important Holocene carbon cycle questions.

\section{Carbon accumulation}

Numerous studies also report rates of Holocene carbon accumulation in northern peatlands. A characteristic feature of these data is a highly variable carbon accumulation history both within sites and between regions, indicating the complex balance between past plant growth and total Holocene losses via decomposition. However, a recent synthesis of available data from 33 Northern Hemisphere sites (Fig. 1) reveals high carbon accumulation during the early Holocene at many locations (Fig. $2 \mathrm{~d}$ ). For example, the greatest carbon accumulation appears to have occurred between 11 and 9 cal ka BP in Alaska, and between 10 and $8 \mathrm{cal}$ ka BP at some sites in West Siberia (see Yu et al., 2009). Differences in the timing of peak carbon accumulation between regions were affected by delayed deglaciation, different timing of Holocene Thermal Maximum conditions, changes in the seasonality of insolation (Fig. 2a), and other landscape and atmospheric circulation factors. The available data suggest that an overall slowdown of carbon accumulation may have occurred after about 4 cal ka BP at many sites (Fig. 2d; Yu et al., 2009), which may be related to neoglacial cooling and permafrost formation in continental regions. Evidence for a renewed lateral expansion of peatlands in the mid-Holocene (Korhola et al., 2010) is seemingly at odds with evidence for a slowdown in vertical carbon accumulation after 4 cal ka BP (Fig. 2). Such a discrepancy suggests that the role of the large peat carbon pool in late Holocene $\mathrm{CO}_{2}$ and $\mathrm{CH}_{4}$ changes should be re-evaluated. Existing data are currently limited, but the wide distribution of peatlands across the Northern Hemisphere provides the possibility for much more information and a better understanding of ecosystem

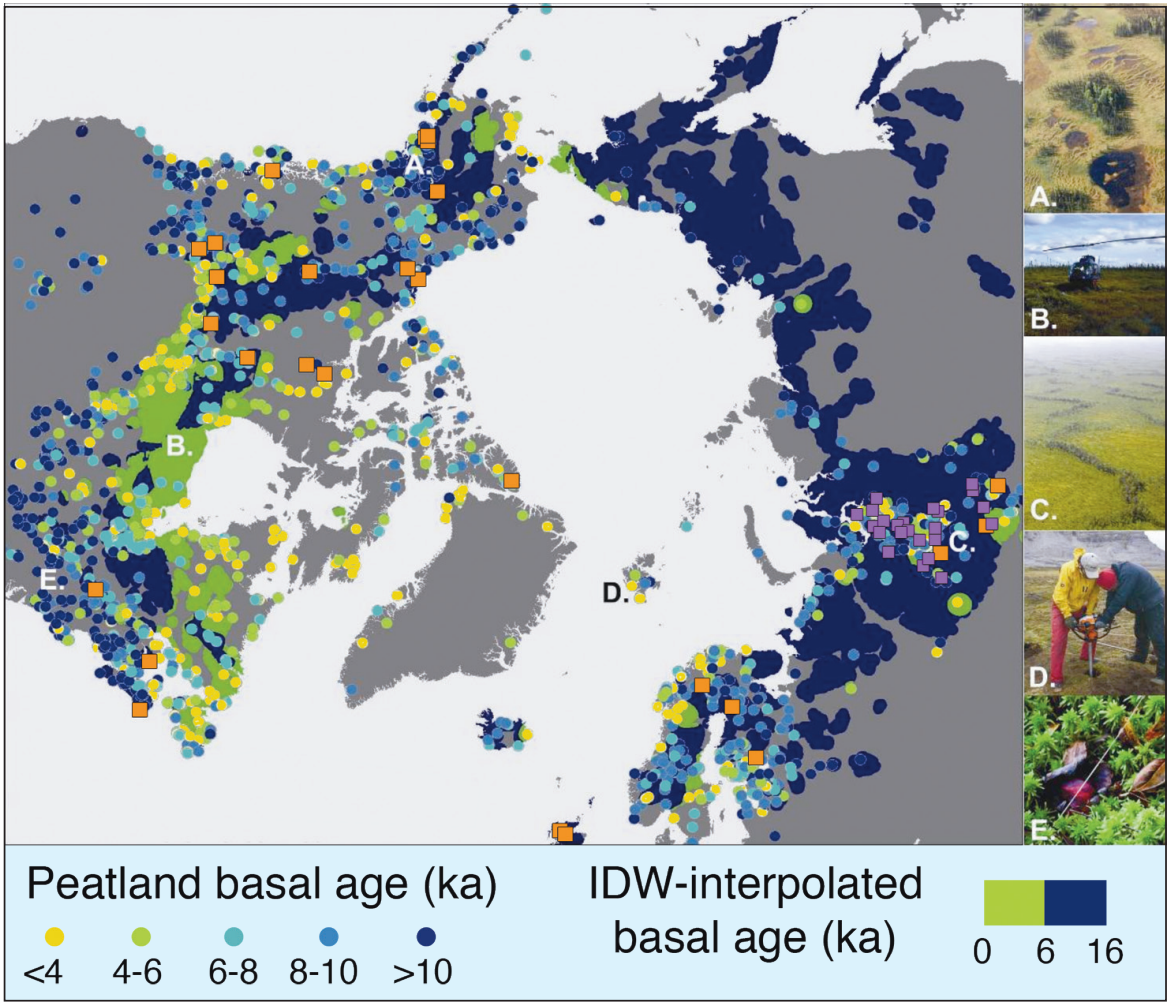

Figure 1: Spatial pattern of the age of peatland establishment across the northern high latitudes showing basal radiocarbon ages (circles; $n=2380$ IntCal04-calibrated ages; MacDonald et al., 2006; Gorham et al., 2007), IDWinterpolated (inverse distance weighted) surface of basal ages and the generalized pattern of establishment within $50 \mathrm{~km}$ of the distribution of boreal/taiga peatlands (colored shading), the location of carbon accumulation sites in Figure $2 d$ (orange squares), and in Figure $3 a$ (West Siberia, purple squares). Figure modified from Yu et al., 2009. Letters correspond to the location of photos to the right of the map.

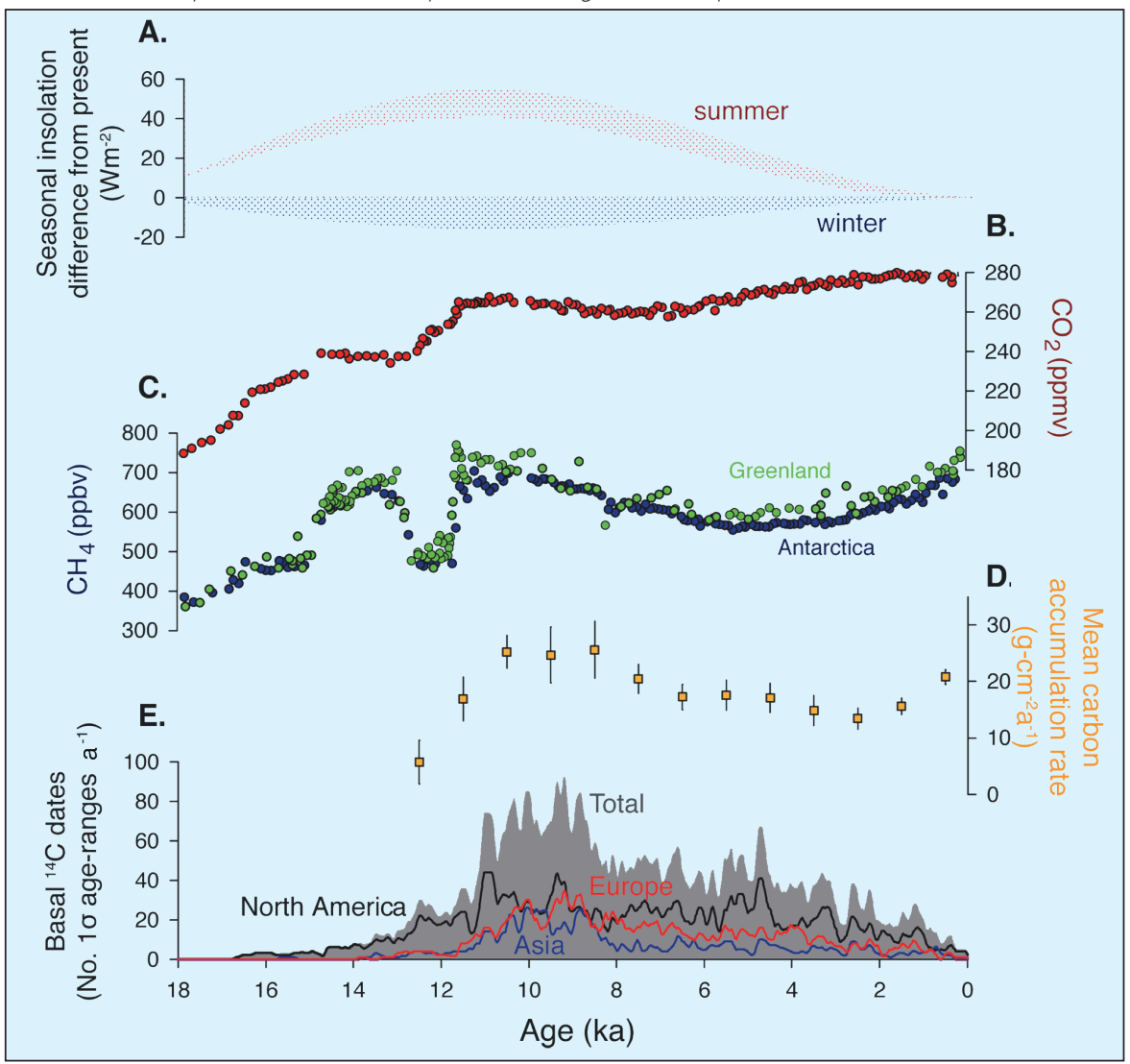

Figure 2: Holocene timing of peatland establishment and carbon accumulation compared to variations in northern insolation and atmospheric $\mathrm{CH}_{4}$ and $\mathrm{CO}_{2}$. $\boldsymbol{A}$ ) Winter (Dec) vs summer (June) insolation difference from the present (Berger and Loutre 1991; stippled bands indicate insolation between 40 and $80^{\circ} \mathrm{N}$ ). B) Atmospheric $\mathrm{CO}_{2}$ recorded in EPICA Dome C Antarctic ice core (red circles; Monnin et al., 2001; Flückiger et al., 2002). C) Atmospheric CH recorded in Greenland (green circles; GISP2; Brooket al., 2000) and Antarctica (blue circles; EPICA Dome C; Monnin et al., 2001; Flückiger et al., 2002). D) Composite curve of time-weighted mean ( \pm SE) carbon accumulation at 33 sites in 1 ka bins (Yu et al., 2009). E) Occurrence frequency of the radiocarbon age of basal peat deposits (1-sigma age ranges) on each of the northern continents (MacDonald et al., 2006). The rapid early Holocene expansion of northern peatlands between about 11 and 8 cal $\mathrm{ka} B P$ is coincident with high carbon accumulation rates at many sites. This period of rapid peatland expansion and accumulation during the summer insolation maximum may have contributed significantly to the early Holocene rise in $\mathrm{CH}_{4}$ and the slowdown and decrease in $\mathrm{CO}_{2}$. Figure modified from MacDonald et al., 2006 and Yu et al., 2009. 

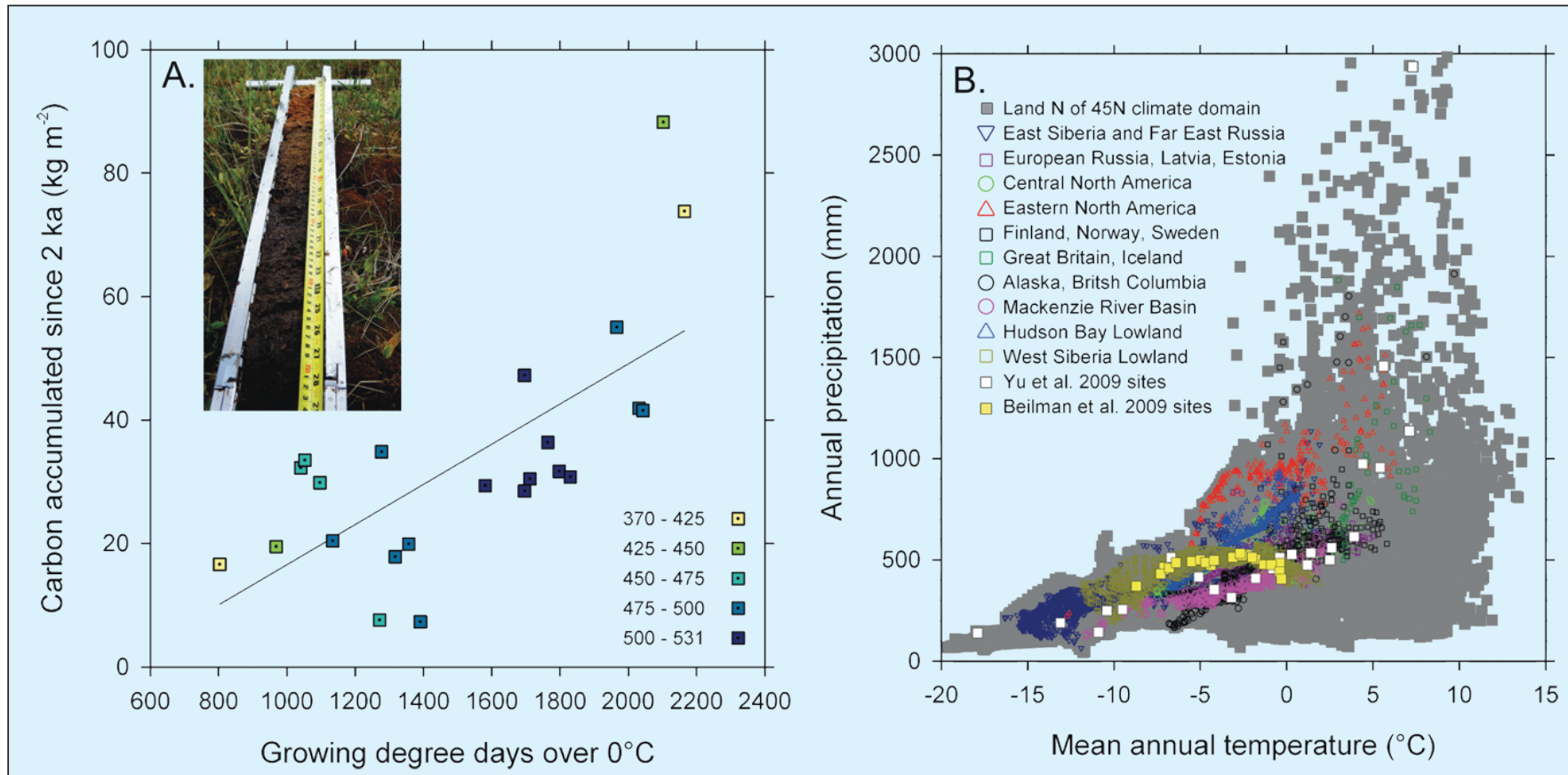

Figure 3: Carbon accumulation since 2 ka in West Siberia and the modern climate space of northern peatland distribution. A) Relationship between modern growing-season temperature and the mass of peat carbon younger than 2 cal ka BP at 23 sites in West Siberia (modified from Beilman et al., 2009). Colors show annual precipitation (mm) at each site as in Figure 3b. Inset photo shows a core (still in box corer) of the first $70 \mathrm{~cm}$ of a $400 \mathrm{~cm}$ deposit; the depth of peat accumulated over the last $2 \mathrm{ka}$ in West Siberia ranges from 11 to $272 \mathrm{~cm}$. B) The distribution in climate space of 0.5 by $0.5^{\circ}$ land grids north of $45^{\circ} \mathrm{N}$ (gray) and grids within northern peatland regions (colored symbols) shown by the colored shading in Figure 1 (modified from Yu et al. 2009). Climate data are gridded 1960-1990 mean annual temperature and annual precipitation.

and land carbon response to Holocene climate change.

The last 2 ka offers an opportunity to investigate the dynamics of terrestrial carbon pools and processes under conditions more similar to the present. By 2 ka ago, northern peatlands had expanded into much of their present extent (Fig. 1), and northern growing-season insolation had decreased to levels similar to today (Fig. 2a). Data from 23 sites across West Siberia show a large range of total carbon accumulated over the last $2 \mathrm{ka}$ ( 7 to $88 \mathrm{~kg} \mathrm{~m}^{-2}$ ), and a pattern between sites that deviates from the pattern of total Holocene carbon accumulation (Beilman et al., 2009). This mismatch suggests that peatlands that were substantial carbon sinks during the early and mid-Holocene have not necessarily been the location of greatest carbon accumulation in the recent past. On the other hand, a strong north-south trend is evident that is positively correlated with mean annual temperature (Beilman et al., 2009) and growing season warmth (Fig. 3a). Developing reconstructions of carbon accumulation rate changes over the recent past could help tease apart the influence of temperature, a direct control on both plant growth and soil respiration, and the influence of hydrological change. Such high-quality data for multi-centennial variations in carbon dynamics are still scant, but would provide insight into the response of land carbon to the relatively well-studied climates of the Medieval Climate Anomaly and the Little Ice Age.
These data and analyses would provide a useful constraint on understanding the relationship between climate and $\mathrm{CO}_{2}$ (see Cox and Jones, 2008).

\section{Peatland carbon and modern climate}

Knowing the current climate domain of today's northern carbon pools is relevant to predicting their fate in the face of global change. Northern peatland carbon typically occurs where annual mean temperatures are between $-12^{\circ}$ and $5^{\circ} \mathrm{C}$ and annual precipitation is between 200 and $1000 \mathrm{~mm}$ (Fig. 3b). However, many important regional differences are evident. Considering carbon-rich regions, the peatlands of West Siberia and the Mackenzie River Basin experience mean annual temperatures $7^{\circ} \mathrm{C}$ colder than those in the Hudson Bay Lowland. The warmest peatlands in these three regions (between -2 and $2^{\circ} \mathrm{C}$ ) receive very different precipitation inputs, with southern West Siberia and southern Mackenzie peatlands receiving half as much annual precipitation as their warm counterparts in the southern Hudson Bay region (Fig 3b; Yu et al., 2009). In this way, regional differences in the response of northern carbon were likely important in the Holocene carbon cycle, and will likely be important in future carbon dynamics. The further application of this kind of climate envelope analysis, and its potential combination with process modeling, provides another opportunity to better understand the possible trajec- tories in different regions of this very large terrestrial carbon pool.

\section{References}

Beilman, D.W., MacDonald, G.M., Smith, L.C. and Reimer P.J., 2009: Carbon accumulation in peatlands of West Siberia over the last 2000 years, Global Biogeochemical Cycles, 23: GB1012, doi:10.1029/2007GB003112.

Cox, P. and Jones C., 2008: Illuminating the modern dance of climate and $\mathrm{CO}_{2}$, Science, 321: 1642-1644, doi:10.1126/science. 1158907.

Korhola, A. Ruppel, M. Seppa, H. Valiranta, M., Virtanen, T. and Weckstrom, J., 2010: The importance of northern peatland expansion to the late-Holocene rise of atmospheric methane, Quaternary Science Reviews, 29: 611-617, doi:10.1016/j.quascirev.2009.12.010.

MacDonald, G.M., Beilman, D.W., Kremenetski, K.V., Sheng, Y., Smith L.C. and Velichko, A.A., 2006: Rapid development of the circumarctic peatland complex and atmospheric $\mathrm{CH}_{4}$ and $\mathrm{CO}$ variations, Science, 314: 285-288, doi:10.1126/science.1131722.

Yu, Z.C., Beilman, D.W. and Jones, M.C., 2009: Sensitivity of Northern Peatland Carbon Dynamics to Holocene Climate Change. In: Baird, A., et al., (Eds), Carbon Cycling in Northern Peatlands, AGU Geophysical Monograph, American Geophysical Union, 184: 5569. doi:10.1029/2008GM000822. A PDF reprint is available by contacting the authors.

For full references please consult:

http://www.pages-igbp.org/products/newsletters/ref2010_1.html 


\section{Past and present carbon accumulation and loss in Southeast Asian peatlands}

Sue PAGE ${ }^{1}$, R. Wüst ${ }^{2}$ AND C. BANKs ${ }^{1,3}$

'Department of Geography, University of Leicester, UK; sep5@le.ac.uk

${ }^{2}$ School of Earth and Environmental Sciences, James Cook University, Townsville, Australia; ${ }^{3}$ National Oceanography Centre, University of Southampton, UK

\section{Tropical peatlands store $\sim 75 \mathrm{Pg}$ carbon and have operated as long-term net carbon sinks throughout the Holocene. However, intensive land development is destabilizing these reservoirs, resulting in large carbon emissions to the atmosphere and loss of valuable low-latitude peat paleorecords.}

\section{Location and carbon storage}

By area, peatlands have their greatest extent in the boreal and temperate zones (Immirzi et al., 1992) but tropical deposits, located in Southeast Asia, Africa, the Caribbean, and Central and South America, are also an important component of the global resource and terrestrial carbon (C) storage in both their above-ground biomass and underlying thick peat mass (Rieley et al., 1996; Page et al., 1999, 2004). A recent study (Page et al., submitted) indicates that tropical peatlands cover $\sim 439,238$ $\mathrm{km}^{2}(\sim 11 \%$ of global peatland area), with a peat $C$ pool of $88.5 \mathrm{Pg}(\sim 17-19 \%$ of the global peat C pool (Immirzi et al., 1992)). Globally, the most important tropical peatlands occur in Southeast Asia $57 \%$ of total area; $68.5 \mathrm{Pg}$ of $\mathrm{C}$, representing $77 \%$ of global tropical peatland carbon stores). In this region, Indonesia holds by far the largest share (57.4 Pg or $65 \%)$, followed by Malaysia (9.1 Pg or 10\%) (Fig. 1).

\section{Peatlands in Southeast Asia: types}

Most Southeast Asian peatlands are ombrotrophic (precipitation-fed), although a few basin peatlands are minerotrophic (receiving surface runoff and/or groundwater), and support a vegetation of dense swamp forest. A combination of low topographic relief, impermeable substrates and high effective rainfall have provided conditions suitable for slow decomposition of organic material and the accumulation of thick (often $>10 \mathrm{~m}$ ) deposits of woody peat.

Three categories of lowland peatlands have been proposed: (i) coastal, (ii) sub-coastal or valley, and (iii) high, interior or watershed (Rieley et al., 1996; Page et al., 1999, 2006). Coastal peatlands occur along maritime fringes and in deltaic areas where they have developed over marine sediments, inland of accreting mangrove and Nipa palm swamps (Anderson, 1983; Staub and Esterle, 1994). Sub-coastal peatlands are further inland at slightly higher elevations (5-15 m asl) where peat formation was initiated as a result of rising ground water levels, linked to

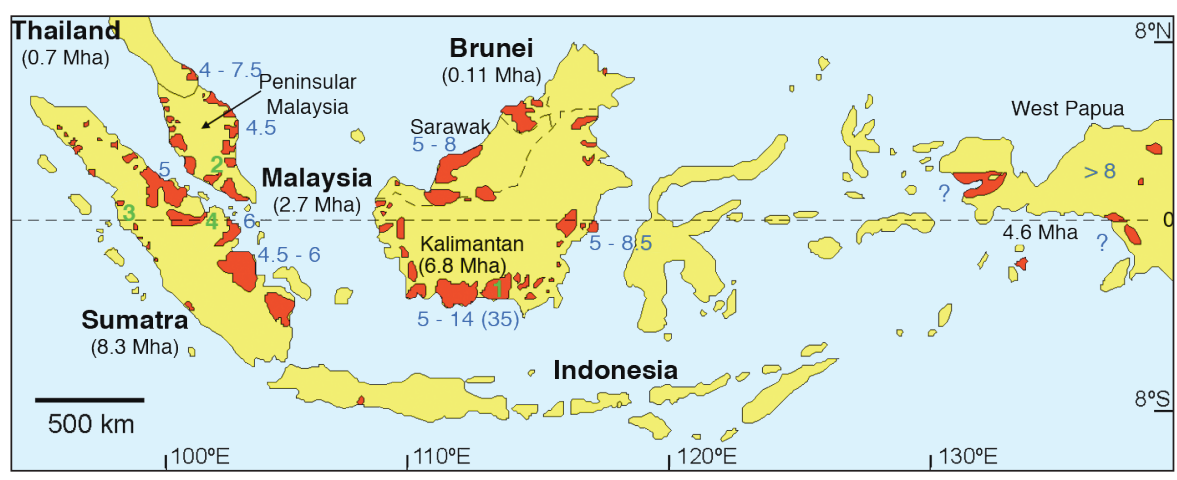

Figure 1: Distribution (red shading; in million ha, after Rieley et al., 1996) and approximate dates of initiation (blue numbers; cal ka BP) for peatland in Southeast Asia. Question marks indicate unknown peatland initiation age. Green numbers indicate the location of peatlands referred to in text: 1) Sungai Sebangau, 2) Tasek Bera, 3) Tao Sipinggan, and 4) Siak Kanan. changes in sea level. High peatlands have been described from Central Kalimantan (Indonesian Borneo; Fig. 1) up to $200 \mathrm{~km}$ inland from the coast, where they cover low-altitude, watershed positions (10$30 \mathrm{~m}$ asl) (Sieffermann et al., 1988, 1992; Page et al., 1999; Morley, 2000). In addition, some isolated basin deposits have formed in and around lakes (e.g., Anshari Dam et al., 2001; van der Kaars et al., 2001; Penny, 2001; Maxwell, 2001; Maxwell and Liu, 2002). et al., 2001, 2004; Wüst and Bustin, 2004;

\section{Peat and carbon accumulation}

Only a few peatlands in Southeast Asia have been investigated for peat structure, age, development, and rates of peat and C accumulation (e.g., Neuzil, 1997; Brady, 1997; Page et al., 2004; Wüst and Bustin, 2004), the onset and development of which range from the Late Pleistocene to the Holocene. Paleoenvironmental studies of peatlands in Borneo reveal initiation dates ranging from Late Pleistocene ( 40 ${ }^{14} \mathrm{C}$ ka BP) in Lake Sentarum basin, West Kalimantan (Anshari et al., 2001, 2004) to

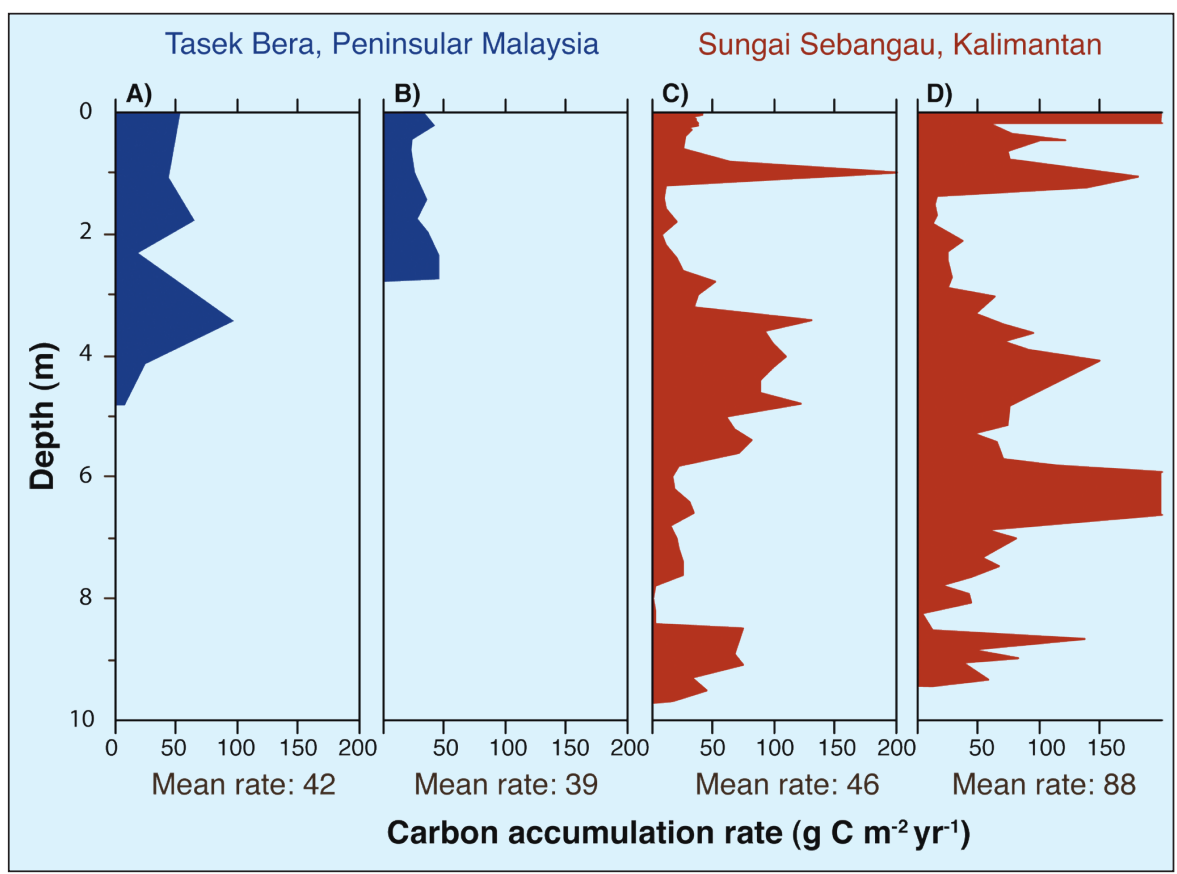

Figure 2: Carbon accumulation rate down-core for a minerotrophic peat on Peninsular Malaysia (Tasek Bera; $\boldsymbol{A}$ ) core B53, B) core B144) (Wüst and Bustin, 2004) and an ombrotrophic peat on Kalimantan (Sungai Sebangau; C) core SA6.5, D) core Kal1, located within $1.5 \mathrm{~km}$ of each other) (Page et al., 2004; Wüst unpub. data). 
$\sim 23{ }^{14} \mathrm{C}$ ka BP for high peat in Central Kalimantan (Page et al., 2004), to the early Holocene (10 - 8 cal ka BP) for other high and sub-coastal deposits (Neuzil, 1997; SiefferIn comparison, the extensive coastal deposits are the youngest peatlands in the region, with initiation around 3.5 - 6 cal ka BP (e.g., Anderson and Muller, 1975; Staub and Esterle, 1994).

A detailed record of peat accumulation from Central Kalimantan (Page et al., 2004) (Figs. 1, 2), reveals a relatively rapid initial rate of peat accumulation of $1 \mathrm{~mm}$ $\mathrm{a}^{-1}$ between $24-26 \mathrm{cal} \mathrm{ka} \mathrm{BP}\left(22-23{ }^{14} \mathrm{C}\right.$ ka $\mathrm{BP})$, equivalent to a $\mathrm{C}$ accumulation rate of $\sim 54 \mathrm{~g} \mathrm{C} \mathrm{m}^{-2} \mathrm{a}^{-1}$. This period probably lasted for several thousand years until the onset of the drier Last Glacial Maximum (LGM) ( $18{ }^{14} \mathrm{C}$ ka ago), when conditions were less favorable to peat formation. During and after the LGM, until 13 cal ka BP, peat and $C$ accumulation rates were low at only $0.04 \mathrm{~mm} \mathrm{a}^{-1}$ and $1.3 \mathrm{~g} \mathrm{C} \mathrm{m}^{-2} \mathrm{a}^{-1}$, respectively. The beginning of the Holocene, however, saw a rapid resurgence: between 8.54 and $7.82 \mathrm{cal} \mathrm{ka} \mathrm{BP}$ the peat accumulation rate increased from 0.60 to $2.55 \mathrm{~mm} \mathrm{a}^{-1}$ with an average $C$ accumulation rate of $92 \mathrm{~g} \mathrm{C} \mathrm{m}^{-2}$ mann et al., 1988; Staub and Esterle, 1994).

$\mathrm{a}^{-1}$ and the formation of more than $3.5 \mathrm{~m}$ of peat over a $\sim 2.2$ ka period ( $~ 9.1-6.9 \mathrm{cal}$ ka BP). Rapid sea-level rise at the end of the LGM led to the transgressive flooding of the Sunda and Sahul Shelves. Sea level changes were associated with warmer sea surface temperatures (Kienast et al., 2001, 2006), which likely resulted in increased precipitation, and the backing up of rivers owing to reduced drainage (Siefferman et al., 1987). In combination, these conditions favored peat accumulation in coastal areas with low topographic relief, such as along the seaboards of Borneo, Sumatra, E and W Peninsular Malaysia, and further inland in Borneo on interfluvial divides (Fig. 1; Wüst et al., 2007).

Towards the end of this period of rapid accumulation for inland high peats ( 6 cal ka BP), large, relatively flat areas of new coastal environments were being exposed throughout the Southeast Asian region as rising sea levels stabilized and fell slightly during the mid-Holocene (Geyh et al., 1979; Hu et al., 2003; Tjia, 1992; Tjia et al., 1984). The combination of favorable topographic and climatic conditions led to rapid peat accumulation across coastal lowlands (Wilford, 1959; Hesp et al., 1998;

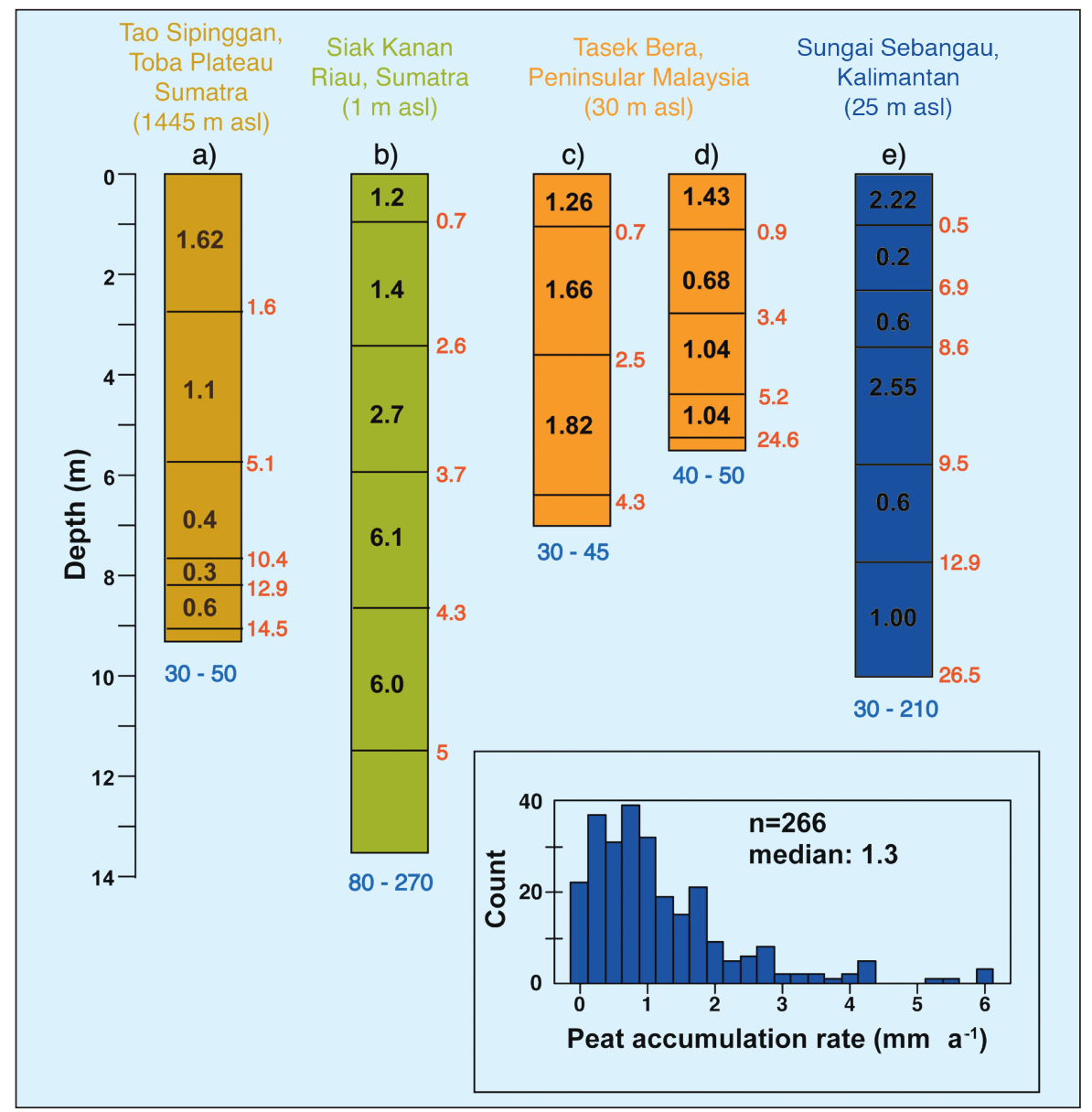

Figure 3: Selected peat sections from various sites in Sumatra $(\boldsymbol{a}, \boldsymbol{b})$, Peninsular Malaysia $(\boldsymbol{c}, \boldsymbol{d})$ and Kalimantan (e) showing approximate age of peat accumulation (cal ka BP, red numbers), peat accumulation rates ( $\mathrm{mm} \mathrm{a}^{-1}$, black numbers) and carbon accumulation rates ( $\mathrm{g} \mathrm{C} \mathrm{m}^{-2} \mathrm{a}^{-1}$, blue numbers); the latter vary between $30-270 \mathrm{~g} \mathrm{C} \mathrm{m}^{-2}$ $a^{-1}$. Data from Maloney and McCormac, 1995 (Tao Sipinggan); Neuzil, 1997 (Siak Kanan); Wüst and Bustin, 2004 (Tasek Bera); Page et al., 2004 (Sungai Sebangau). Inset: Histogram of peat accumulation rates of 266 samples across sites in Sumatra, West Java, Kalimantan, Sarawak, Peninsular Malaysia, Thailand, Sulawesi and New Guinea.
Staub and Esterle, 1994). In the Rajang Delta of Sarawak (Fig. 1), $4.45 \mathrm{~m}$ of peat accumulated between 6.4 and $2.06 \mathrm{cal}$ ka BP ( 1.26 $\mathrm{mm} \mathrm{a}^{-1}$; Staub and Esterle, 1994), whilst on the east coast of Sumatra, peatlands underwent very rapid accumulation with initial rates as high as $6-13 \mathrm{~mm} \mathrm{a}^{-1}$ between 5.3 - 4.3 cal ka BP (Neuzil, 1997). A study from inland Tasek Bera on Peninsular Malaysia (Wüst and Bustin, 2004) also indicates peat initiation at this time, with highest rates occurring after $4.3 \mathrm{cal}$ ka BP. The rapid accumulation of inland peats, subsequently followed by the formation of deep coastal peat deposits, must have provided a large regional sink for atmospheric carbon throughout the Holocene.

\section{From carbon sink to carbon source}

Radiocarbon dating of peat material from sites across Southeast Asia (Fig. 3) reveals a long-term median peat accumulation rate of $\sim 1.3 \mathrm{~mm} \mathrm{a}^{-1}$ (i.e., $67 \mathrm{~g} \mathrm{C} \mathrm{m}^{-2} \mathrm{a}^{-1}$ assuming a peat bulk density of 0.09 and $56 \%$ C content), which is about 2-10 times the rate for boreal and subarctic peatlands (0.2-0.8 $\mathrm{mm} \mathrm{a}^{-1}$ ) (Gorham, 1991). Currently, however, most, if not all, remaining peatlands in Southeast Asia are to some extent degraded with many no longer functioning as $\mathrm{C}$-accumulating systems. Anthropogenic activity is the principal cause of this shift, although longer-term climateinduced changes are also important in some locations (Page et al., 2004). Deforestation, drainage, large-scale conversion to plantation agriculture and regular fires have resulted in carbon flux to the atmosphere and loss of carbon sequestration function. Current $\mathrm{C}$ emissions are of the order $\sim 360 \mathrm{Mt} \mathrm{C} \mathrm{a}^{-1}\left(\sim 170 \mathrm{Mt} \mathrm{C} \mathrm{a}^{-1}\right.$ from drainage-related peat decomposition (Hooijer et al., 2006); $190 \mathrm{Mt} \mathrm{C} \mathrm{a}^{-1}$ from peat fires (Page et al., 2002; van der Werf et al., 2008)), equivalent to $4.5 \%$ of global emissions from fossil fuels.

Further detailed investigations of tropical peatland archives could result in new information about ENSO, monsoons and ITCZ migration, as well as an improved understanding of Holocene climate evolution in Southeast Asia and the long-term role of tropical peatlands in the regional and global C cycle. Unfortunately the opportunities to study these paleorecords are now being compromised by the rapid rate of peatland loss owing to human activities. 


\section{References}

Anshari, G., Kershaw, AP. and van der Kaars, S., 2001: A Late Pleistocene and Holocene pollen and charcoal record from peat swamp forest, Lake Sentarum Wildlife Reserve, West Kalimantan, Indonesia, Palaeogeography, Palaeodlimatology, Palaeoecology, 171 213-228

Page, S.E., Siegert, F., Rieley, J.0., Boehm, H.-D.V., Jaya, A. and Limin, S., 2002: The amount of carbon released from peat and forest fires in Indonesia during 1997, Nature, 420: 61-65.
Page, S.E., Wüst, R.A.J., Weiss, D., Rieley, J.0., Shotyk, W. and Limin, S.H 2004: A record of Late Pleistocene and Holocene carbon accumulation and climate change from an equatorial peat bog (Kalimantan, Indonesia): implications for past, present and future carbon dynamics, Journal of Quaternary Science, 19: 625-635.

Page, S.E., Rieley, J.0. and Wüst, R., 2006: Lowland tropical peatlands of Southeast Asia. In: Martini, P., Martinez-Cortizas, A. and Chesworth, W. (Eds) Peatlands: basin evolution and depository of records on global environmental and climatic changes, Elsevier, Amsterdam (Developments in Earth Surface Processes series). pp. $145-172$
Wüst, R.A.J. and Bustin, R.M., 2004: Late Pleistocene and Holocene development of the interior peat-accumulating basin of tropica Tasek Bera, Peninsular Malaysia, Palaeogeography, Palaeoclimatology, Palaeoecology, 211: 241-270.

For full references please consult:

http://www.pages-igbp.org/products/newsletters/ref2010_1.htm

\section{Inception, history and development of peatlands in the}

\section{Amazon Basin}

Outı Lähteenoja ${ }^{1}$ and Katherine H. Roucoux ${ }^{2}$

'Department of Biology, University of Turku, Finland; outi.lahteenoja@utu.fi

${ }^{2}$ School of Geography, University of Leeds, UK

The existence of peatlands in the Amazonian lowlands has only recently been confirmed, owing to the remoteness of the area. These peatlands are important for regional carbon cycling and habitat diversity, and represent valuable potential resources for paleoecological research.

\section{The Amazon's floodplain peatlands}

Amazonia, the world's largest continuous area of humid tropical lowland rainforest, is famous for its dense river network, large seasonal variations in water level (on average $10 \mathrm{~m}$ at Manaus, Brazil), and extensive floodplains and wetlands covered by Mauritia palms, floodplain forest or savanna-like vegetation (Irmler, 1977; Junk, 1983; Junk and Piedade, 2005; Keddy et al., 2009). Despite the great extent of wetlands within the Amazon Basin, the existence of tropical peatlands has rarely been considered (but see Suszczynski, 1984; Schulman et al., 1999; Ruokolainen et al., 2001; Guzmán Castillo, 2007). Two studies carried out recently in Peruvian lowland Amazonia (Loreto region, Fig. 1) by members of the Amazon Research Team of the University of Turku (Finland) reveal that peat deposits, up to $6 \mathrm{~m}$ thick, are widespread on floodplain wetlands of the Western Amazon Basin (Lähteenoja et al., 2009a, 2009b). Sixteen of seventeen studied wetland sites contained some kind of peat deposit. According to the very rough estimate of Schulman et al. (1999) based on local land-cover maps, satellite images, grey literature and sporadic field observations, Amazonian peatlands may cover up to $150000 \mathrm{~km}^{2}$, an area equivalent to half of Finland, and about $75 \%$ of the area covered by the better-known tropical peatlands of Indonesia (Rieley and Page, 2005; Page et al., this issue).

\section{History and development}

Since their late Holocene inception, the peatlands identified in Peruvian Amazonia have accumulated peat and carbon at relatively high rates $(0.94-4.88 \mathrm{~mm}$ per year, and $26-195 \mathrm{~g} \mathrm{C} \mathrm{m}^{-2}$ per year, respectively)

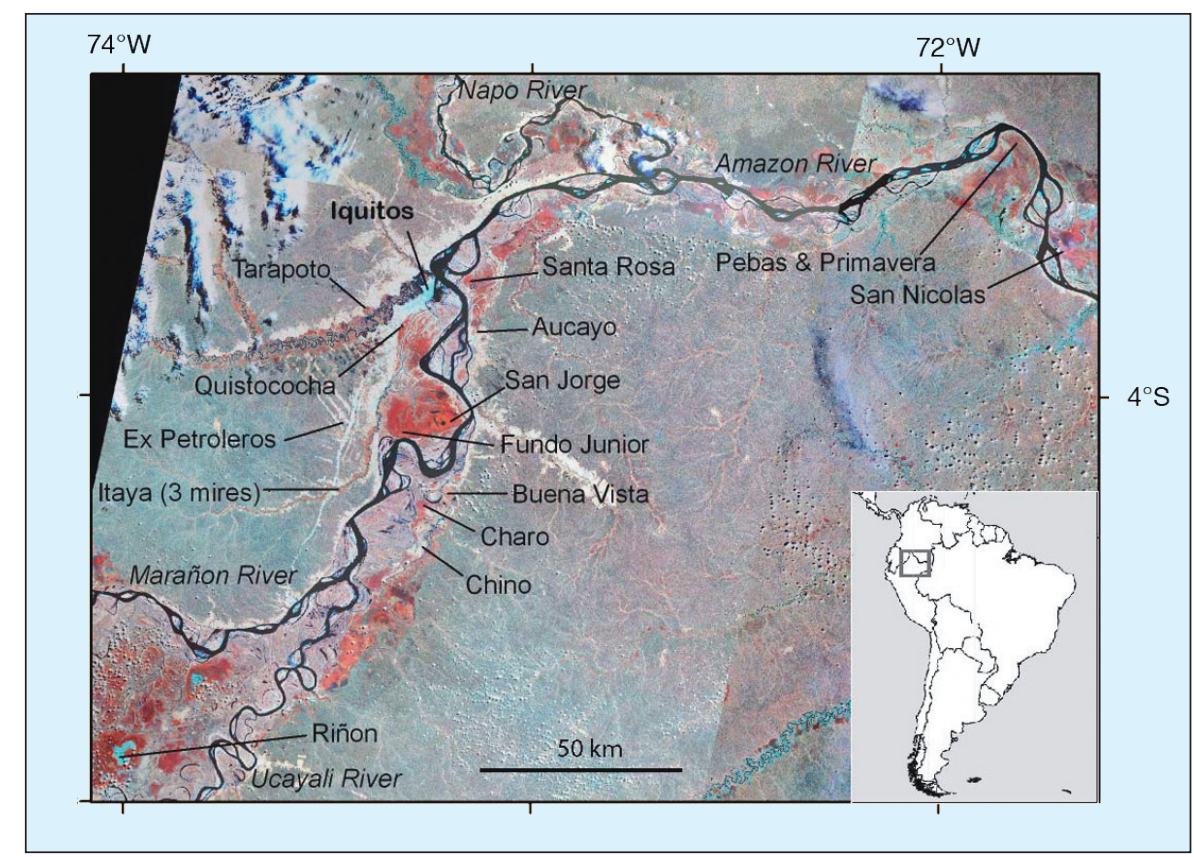

Figure 1: The location of the study sites (from Lähteenoja et al., 2009b, Fig. 1). The map is a mosaic of histogramequalized Landsat TM satellite images (WWw.glcf.umiacs.umd.edu/). Palm swamps and forested wetlands havea reddish tone, more or less treeless open areas (like the open peatland Riñón) are blue-green, and other floodplain forests are pinkish to white.

(Fig. 2) and therefore constitute a strong carbon sink (Lähteenoja et al., 2009b). These accumulation rates are comparable to those of the Indonesian tropical peatlands (Page et al., 2004) and are higher than those of the boreal peatlands (Tolonen and Turunen, 1996).

The basal ages of five dated peat deposits varied from $0.588 \mathrm{cal} \mathrm{ka} \mathrm{BP}$ (at 164 $\mathrm{cm}$ ) to $2.945 \mathrm{cal} \mathrm{ka} \mathrm{BP} \mathrm{(at} 565 \mathrm{~cm}$ ) (Lähteenoja et al., 2009b), which are considerably younger than basal ages determined in peatlands in many other regions of the world (cf., Korhola et al., 2010). There are several possible reasons for this. A paleoecological study of lake sediments in Peruvian Amazonia suggests that the dry conditions of the middle Holocene were followed by a period of increasingly wet conditions beginning some time between 4.2 and 2.54 cal ka BP (Bush et al., 2007). Although our oldest peat initiation dates coincide broadly with the onset of this wet interval, some of the peat deposits have much younger basal ages (Lähteenoja et al., 2009b), indicating that peat formation was not determined purely by climate. Peat initiation may be controlled by the dynamic lateral migration of western Amazonian rivers, characterized by meandering and avulsion (Kalliola et al., 1992; Neller et al., 1992; Pärssinen et al., 1996), which have the potential to erode and bury peat deposits. Peat accumulation probably began when an area with waterlogged conditions was isolated from the immediate destructive influence of rivers. Consequently, the Western Amazon Basin 
may be too dynamic to allow very old peat deposits to form (Lähteenoja et al., 2009b), compared with, for example, those found in the more geologically stable Indonesian tropical lowlands (Page et al., this issue). This reasoning is supported by the presence of several buried peat deposits observed under the mineral subsoil of the peatlands (Lähteenoja et al., 2009b). Older peat deposits might well be found in geologically more stable peripheral areas of the floodplains close to the non-flooded terra firme.

According to peat nutrient analyses and topographic measurements, some of the thickest, oldest and most stable peatlands have attained ombrotrophic (rain fed) conditions, despite their location in the middle of a floodplain environment (Lähteenoja et al., 2009a). The surface of these peatlands has risen above the maximum level of river floods because of their thick peat layer and convex topography (Fig. 2). This change of conditions, from a groundwater-fed system to a rain fed one, affects the ecosystem properties in a drastic way, and, consequently, the variation of ombrotrophic bogs and minerotrophic swamps in the Amazonian lowlands contributes to the regional ecosystem diversity (Fig. 3; Lähteenoja et al., 2009a).

\section{Record of paleoclimate and vegetation dynamics}

The existence of peat deposits (especially ombrotrophic ones) within the Amazon Basin potentially offers an excellent resource for studies of Holocene climate variability, paleohydrology and rainforest vegetation dynamics in the Amazonian lowlands, providing histories extending to the time of peat initiation (cf., Frost and Miller, 1987; Ledru, 2001; Hoorn, 2006). In a new project, due to begin in summer 2010, we will apply pollen, charcoal and sedimentological analyses to three of the peat sequences identified by Lähteenoja et al. (2009b) in order to reconstruct changes in forest composition over the past $3 \mathrm{ka}$, focusing in most detail on the last $1 \mathrm{ka}$, the interval of most direct relevance to current ecological trends. Knowledge of tropical forest history on this timescale is crucial to the interpretation and understanding of recent ecological changes taking place in the forest (Malhi et al., 2002). For example, studies of a network of forest plots across Amazonia (Malhi et al., 2002) show that rates of tree mortality and recruitment (Phillips et al., 2004), growth rates (Lewis et al., 2004) and overall forest biomass (Baker et al., 2004) have increased over the past three decades. Understanding the mechanisms

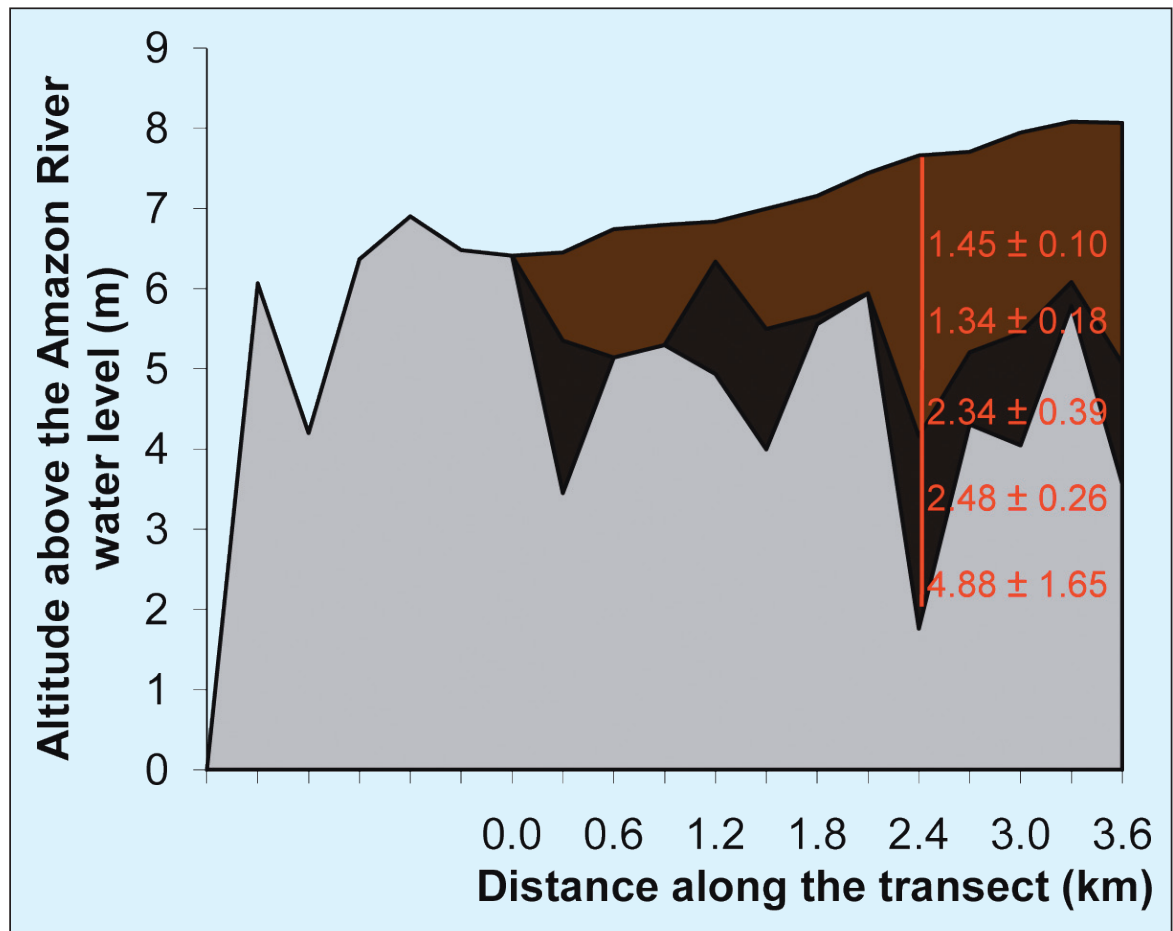

Figure 2: Peat profile and accumulation rates from the San Jorge ombrotrophic bog (Loreto region, Peru). Brown = peat, dark brown = clayey peat, gray = clay. Redrawn from Lähteenoja et al., 2009a). The core location and peat accumulation rates ( $\mathrm{mm} / \mathrm{a}$ ) are shown in red (from Lähteenoja et al., 2009b). behind these changes is important for predicting their consequences for forest biodiversity and for the role of forests in the global carbon cycle (Cox et al., 2008). One possible explanation is that forests are recovering from disturbance events prior to the start of monitoring (Wright, 2005). We intend to test this hypothesis by applying paleoecological techniques to the newly discovered peat sequences. They are ideal for the purpose because: 1) currently no detailed, high resolution records in this region; 2 ) the peat accumulated rapidly so should yield pollen records with decadal scale temporal resolution; and 3) they are located in a region where forest ecology has been monitored in permanent census plots for the past three decades (RAINFOR project: Malhi et al., 2002). The new records will greatly improve our understanding of the mechanisms driving they record an interval for which there are

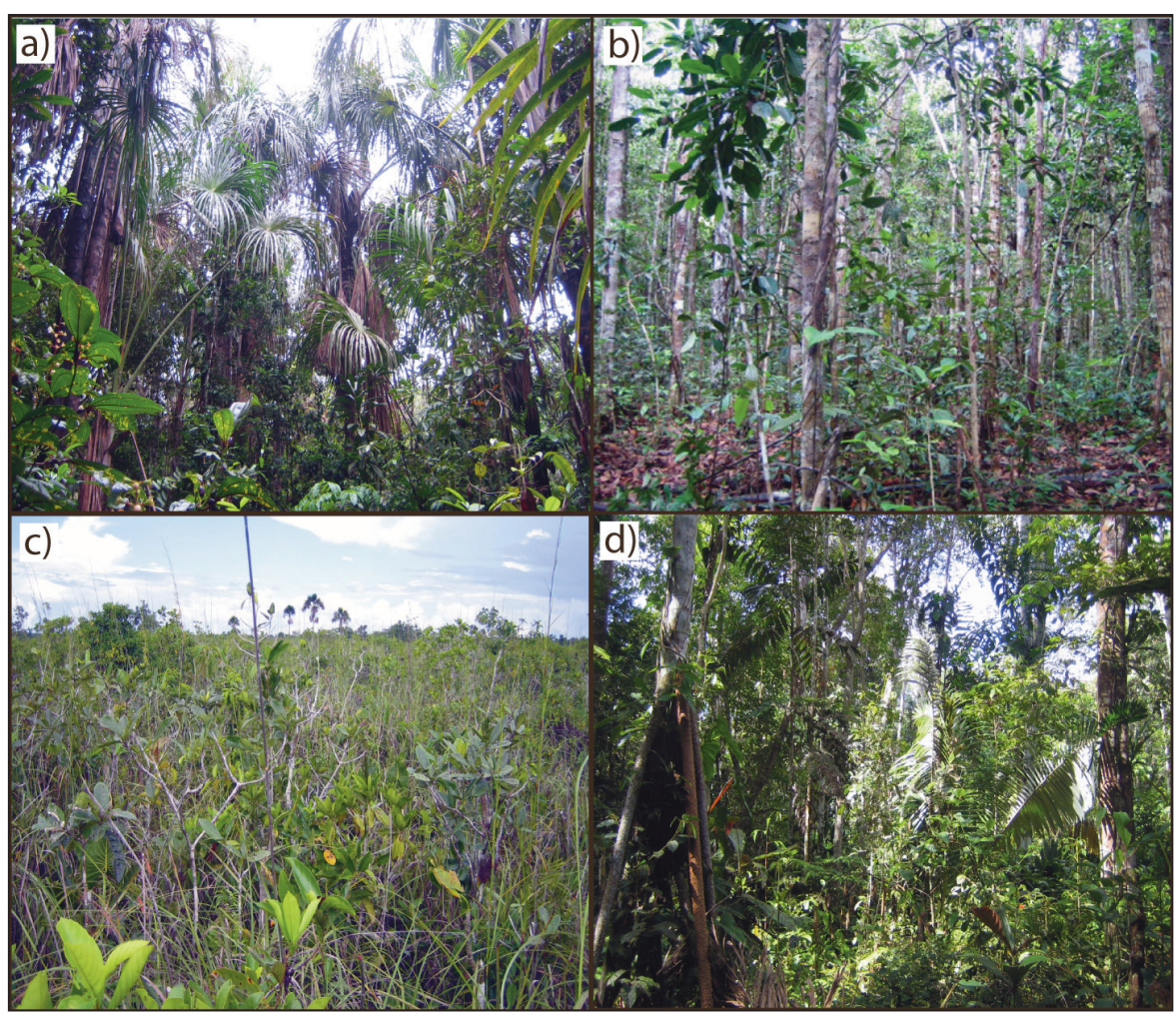

Figure 3: Four of the peatland sites indentified by Lähteenoja et al. (2009a, 2009b) in Peruvian Amazonia (Loreto): a Mauritia flexuosa peat swamp (Quistococha), b) forested peatland (San Jorge), c) savanna-like peatland (Riñón), d) forested peatland (Fundo Junior). 
current changes in tropical forest ecology and the sensitivity of these forests to future climatic change.

In contrast to the Southeast Asian tropical peatlands, these Amazonian peatland sites do not appear to be currently directly affected by anthropogenic actions. Nevertheless, climate change, deforestation, large-scale land-use projects (such as river damming, road construction and development of oil palm plantations) and extensive gas and oil exploration (Malhi et al., 2008) represent an indirect threat to the peatlands insofar as they contribute to drying of the regional climate. Consequently, there is an urgent need to investigate further, and conserve, these littleknown Amazonian ecosystems.

\section{References}

Guzmán Castillo, W., 2007: Valor económico del manejo sostenible de los ecosistemas de aguaje (Mauritia flexuosa). In: Feyen, J., et al. (Eds), International Congress on Development, Environment and Natural Resources: Multi-level and Multi-scale Sustainability, Volume III, Publication of the Universidad Mayor San Simón, Cochabamba, Bolivia, 1513-1521.
Lähteenoja, 0., Ruokolainen, K., Schulman, L. and Alvarez, J., 2009a: Amazonian floodplains harbour minerotrophic and ombrotrophic peatlands, Catena, 79: 140-145.

Lähteenoja, 0., Ruokolainen, K., Schulman, L. and Oinonen, M., 2009b: Amazonian peatlands: an ignored ( sink and potential source, Global Change Biology, 15: 2311-2320.

Ruokolainen, K., Schulman, L. and Tuomisto, H., 2001: On Amazonian peatlands, International Mire Conservation Group Newsletter, 2001(4): 8-10.

Schulman, L., Ruokolainen, K. and Tuomisto, H., 1999: Parameters for global ecosystem models, Nature, 399: 535-536.

For full references please consult:

http://www.pages-igbp.org/products/newsletters/ref2010_1.html

\section{Peatland exchanges of $\mathrm{CO}_{2}$ and $\mathrm{CH}_{4}$ : The importance of presence or absence of permafrost}

Torben R. Christensen ${ }^{1}$, M. Mastepanov ${ }^{1}$, M. Johansson ${ }^{1}$ and D. Charman ${ }^{2}$

'Department of Earth and Ecosystem Science, Lund University, Sweden; torben.christensen@nateko.lu.se 2School of Geography, University of Exeter, UK

\section{The presence of permafrost is shown to have dramatic impacts on land-atmosphere exchanges of key greenhouse gases.}

\section{Permafrost and the carbon cycle}

Permafrost, soil that stays frozen for two or more years in a row, is a hot topic that has attracted a lot of attention in both the scientific and popular literature in recent years. Permafrost underlies 25\% of the land areas in the Northern Hemisphere including substantial areas with peatlands. With a warming climate that is particularly pronounced at high northern latitudes, where most permafrost is present, many questions have been raised regarding what may happen to peatlands and their functioning when permafrost thaws. In areas with infrastructure, such as towns in northern Siberia, or oil and gas pipelines through areas underlain by permafrost, the thawing represents a serious and possibly very expensive issue. Thawing permafrost may, however, have global implications through changes in natural ecosystem greenhouse-gas emissions.

Permafrost areas in the circumpolar North are estimated to hold more than $1600 \mathrm{Pg}$ of organic carbon (C) including almost $300 \mathrm{Pg}$ in the form of peat (McGuire et al., 2009; Tarnocai et al., 2009) most of which has accumulated since the last glacial maximum. In terms of atmospheric exchange of carbon, in the form of $\mathrm{CO}_{2}$ and $\mathrm{CH}_{4}$, the potential for additional releases are probably greater from these areas than anywhere else in the world. While the potential release from the huge stocks of carbon is significant, the actual data and year-round monitoring of atmospheric exchanges remain rare, and continuous flux measurements of $\mathrm{CO}_{2}$ are limited to a handful of sites. Continuous monitor-

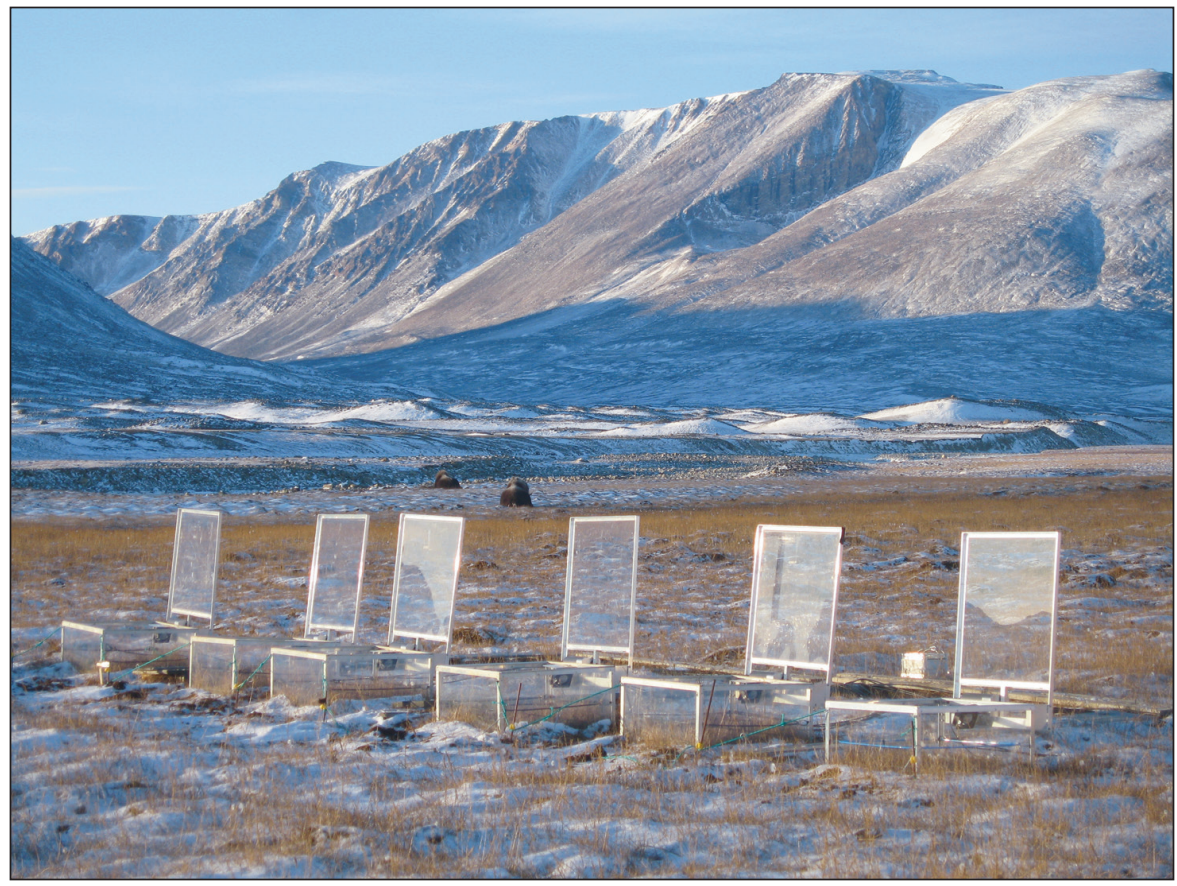

Figure 1: The Zackenberg valley in NE Greenland, an area underlain by continuous permafrost. The automatic chambers were used for the studies of methane emission dynamics during freeze-in (Mastepanov et al., 2008). Local inhabitants, the muskoxen, are present in the background. Photo by C. Sigsgaard, from Christensen et al., 2009 , reprinted with permission.

ing of $\mathrm{CH}_{4}$ fluxes is even rarer; the number of operational sites is less than five. Our empirically based understanding of what permafrost does to the dynamics and interannual variability in atmospheric (and dissolved run-off) fluxes of organic carbon is therefore still very poor. The longer-term dynamics on decadal to centennial timescales are even less well understood.

\section{Carbon dynamics}

Basic features of how ecosystems are functioning with and without permafrost have recently been discovered. At a central
Alaskan site, Schuur et al. (2009) demonstrated that permafrost thawing is accompanied by respiration of previously frozen, ancient organic carbon. In Siberian thaw lakes, methane has been observed forming from recently thawed Pleistocene organic deposits (Walter et al., 2007).

The interannual and across-site variability of $\mathrm{CO}_{2}$ exchange in continuous permafrost ecosystems are driven primarily by growing-season dynamics and moisture conditions. Several studies have shown that growing-season rates of $\mathrm{CO}_{2}$ uptake by these ecosystems is closely re- 


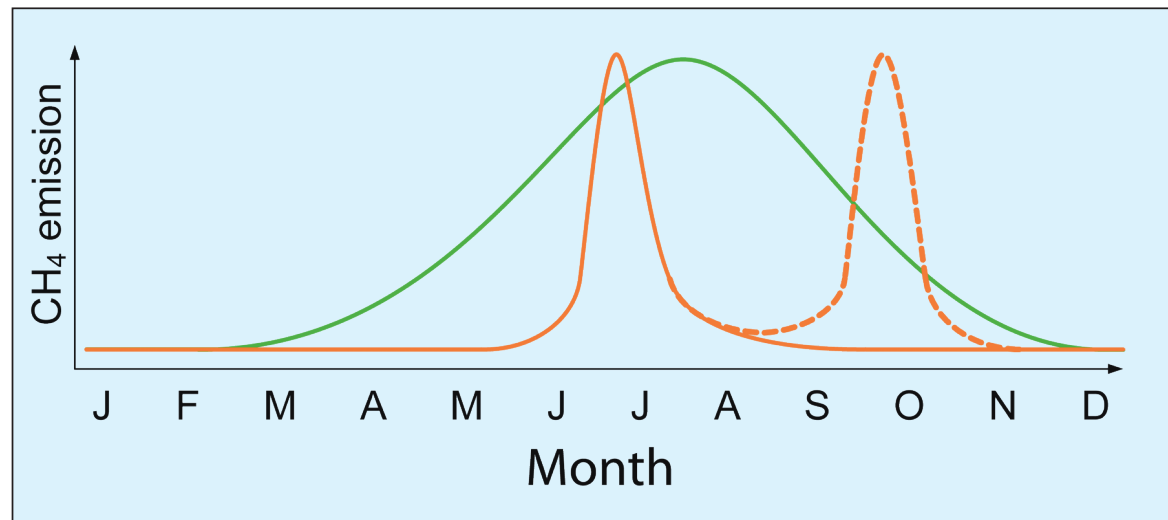

Figure 2: Schematic illustration of the seasonal dynamics of methane emissions from peatlands as observed in Zackenberg (orange) and subarctic Sweden (green), respectively. These very different seasonal patterns reflect differences in both the length of the peatlands growing season (solid lines) and the special emission patterns associated with the freeze-in burst observed in a continuous permafrost environment (dashed line) (based on data from Jackowicz-Korczyński et al. in press and Mastepanov et al., 2008). Figure from Christensen et al., 2009, reprinted with permission.

lated to the timing of snow melt, with earlier snowmelt resulting in greater uptake of atmospheric $\mathrm{CO}_{2}$ (Aurela et al., 2004; Groendahl et al., 2006). The annual C budget is not only controlled by growing-season exchange, but also to a large extent by the losses during the shoulder (snow melt/soil thaw and plant senescence/soil freeze) and winter seasons (Johansson et al., 2006). These more complex impacts on the annual budgets become more important outside permafrost regions, where warmer shoulder-season conditions prevail.

In northern Sweden we have documented changes in permafrost dynamics and effects on ecosystems and feedbacks on climate in terms of methane emissions (Christensen et al., 2004; Johansson et al., 2006) and in relation to catchment scale greenhouse gas exchanges (Christensen et al., 2007). Here, the thawing permafrost generally leads to wetter hydrological conditions and subsequently greater emissions at the landscape scale. The seasonal and interannual pattern at this subarctic site is predictable and the emissions are stable from year to year (Jackowicz-Korczyński et al., in press). In

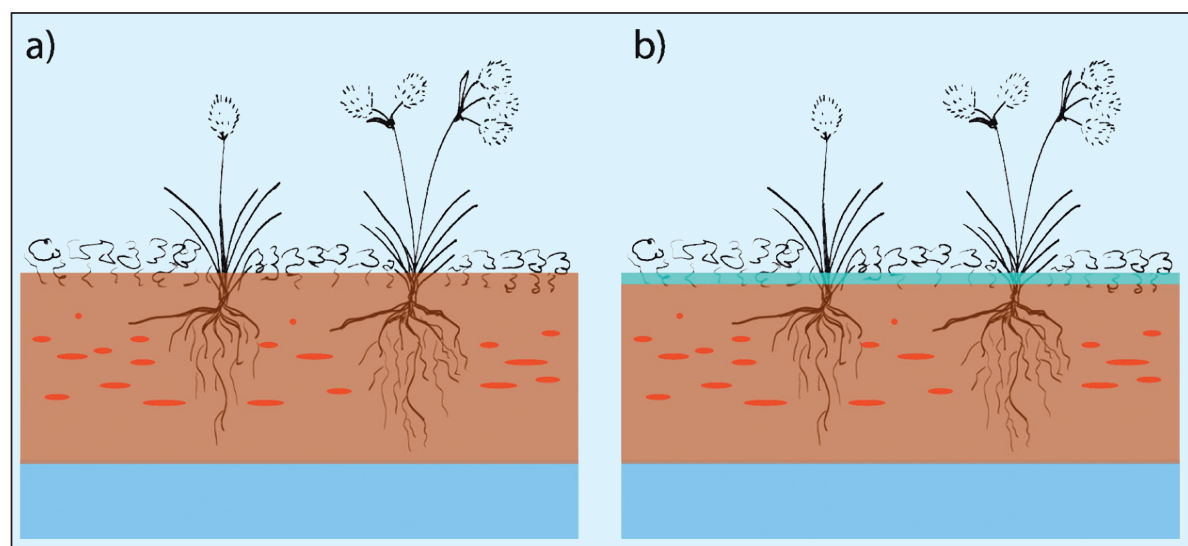

age of methane in this gas can be more than 50\% (Tokida et al., 2005). When the soil starts to freeze from the surface down, a gas-proof layer forms and propagates downwards. The permafrost works as a gas-proof bottom preventing the gas from migrating deeper down. Because the ice has lower density than water, the freezing process causes an increase in the volume of the frozen zone, raising the pressure in the unfrozen layer. This process results in squeezing of the methane-rich gas to the atmosphere. An additional hypothesized necessary condition for the late-season methane burst to occur is the presence of some channels for the pressurized gas to escape to the atmosphere. We suggest it may be residual vascular plant tissues, or cracks in the frozen upper soil layer. autumn emission dynamics at our higharctic measurement site in NE Greenland (Fig. 1). These findings (Mastepanov et al., 2008) show a second seasonal peak of emissions during the freeze-in (Fig. 2). This distinct feature has previously not been observed, most likely because earlier flux studies in continuous permafrost regions have not extended into the frozen season. After further investigation in collaboration with atmospheric scientists, we have reached the preliminary conclusion that it may be a general feature of permafrost areas. This phenomenon helps to explain the observed seasonal dynamics in atmospheric methane concentrations during the autumn (Mastepanov et al., 2008).

The mechanism behind the freeze-in emissions in continuous permafrost areas is hypothesized as a release of methane from the subsurface pool accumulated over the growing season (Fig. 3). The methane is present mainly in gaseous form in entrapped gas bubbles below the water table level. The volume of the gas phase in the peat beneath the water table can be significant (from 0 to 19\%; Tokida et al., 2005), while the volumetric percent-

\section{Records of changes in permafrost}

Longer records of peatland permafrost are available from the geographical margins of the permafrost zone. For example, in Abisko, northern Sweden, permafrost has been monitored for decades. Here, the surface active layer has become thicker over the last three decades. In nine peatlands along a $100 \mathrm{~km}$-long transect the trend is similar and in some peatlands the permafrost has even disappeared completely (Åkerman and Johansson, 2008). This trend is also reflected in larger scale modeling of permafrost (palsa) peatlands in northern Scandinavia (Fronzek et al., 2006) and from observations in North America (Vallee and Payette, 2007; Turetsky et al., 2007). This prevalent trend towards transformation of permafrost landscapes calls for an understanding of ecosystem fluxes both where the permafrost is still present and where it has disappeared.

Modern process studies, monitoring and measurement of fluxes in these ecosystems need to be complemented by paleorecords of longer-term permafrost aggradation and degradation cycles

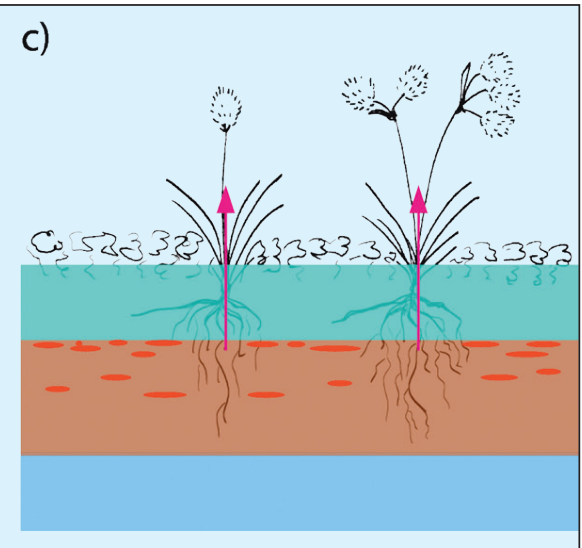

Figure 3: An illustrated hypothesis for how the freeze-in burst of methane emission in continuous permafrost environments is released. a) Soil (brown), which sits on top of the permafrost (blue), is unfrozen during the growing season. As the ground freezes primarily from the surface down (b) the pressure builds up in the unfrozen zone and the accumulated gas (red) in the soil gets pressed out (c) through physical cracks and pores remaining in place from old vascular plants. Figure from Christensen et al., 2009, reprinted with permission. 
(e.g., Kokfelt et al., submitted), to fully understand permafrost dynamics and the relationship with atmospheric methane concentrations over longer timescales. It is clear from paleorecords that peatland permafrost has expanded and contracted over the Holocene at different times in different places (e.g., Vardy et al., 2005; Oksanen, 2006). Although the impacts of Holocene peatland expansion on atmospheric methane are now being explored (Smith et al., 2004; Korhola et al., 2010; Beilman et al., this issue), the implications of Holocene permafrost variability on past global methane concentrations have not yet been assessed. The sparse data on contemporary methane emissions show that peatlands with and without permafrost differ significantly in their functioning. More continuous measurements are required to document ongoing changes. Modern process models of carbon dynamics linked to paleoreconstructions of permafrost could produce critical insights into long-term role and functioning of northern peatlands in the global carbon cycle.

\section{References}

Johansson, T, Malmer, N. Crill, PM Friborg, T, Akerman, J.H. Mastepanov, M. and Christensen, T.R., 2006: Decadal vegetation changes in a northern peatland, greenhouse gas fluxes and net radiative forcing, Global Change Biology, 12: 2352-2369.
Mastepanov, M. Sigsgaard, C, Dlugokencky, EJ., Houweling, S, Strom, L., Tamstorf, M.P. and Christensen, T.R., 2008: Large tundra methane burst during onset of freezing, Nature, 456: 628-U58.

McGuire A.D., Anderson L.G., Christensen T.R., Dallimore S., Guo L., Hayes D.J., Heimann M., Lorenson T.D., Macdonald R.W. and Roulet N., 2009: Sensitivity of the carbon cycle in the Arctic to climate change, Ecological Monographs, 79: 523-555.

Schuur, E.A.G., Vogel, J.G., Crummer, K.G., Lee, H., Sickman, J.0. and Osterkamp, T.E., 2009: The effect of permafrost thaw on old carbon release and net carbon exchange from tundra, Nature, 459: $556-559$

Walter, K.M., Edwards, M.E., Grosse, G., Zimov, S.A. and Chapin, F.S 2007: Thermokarst lakes as a source of atmospheric $\mathrm{CH} 4$ during the last deglaciation, Science, 318: 633-636.

For full references please consult:

http://www.pages-igbp.org/products/newsletters/ref2010_1.html

\section{New on the PAGES Bookshelf}

Two new volumes of the Springer Developments in Paleoenvironmental Research book series are now available. For more information on both titles visit the Springer website

www.springer.com/series/5869?detailsPage=titles\&changeHeader=true

\section{Past Climate Variability in South America and Surrounding Regions: From the Last Glacial Maximum to the Holocene}

Editors: F. Vimeux, F. Sylvestre and M. Khodri 2009, ISBN: 978-90-481-2671-2

This book covers tropical, temperate and high latitudes climate variability, and discusses climate mechanisms, specifically the low to high latitude teleconnections in South America.
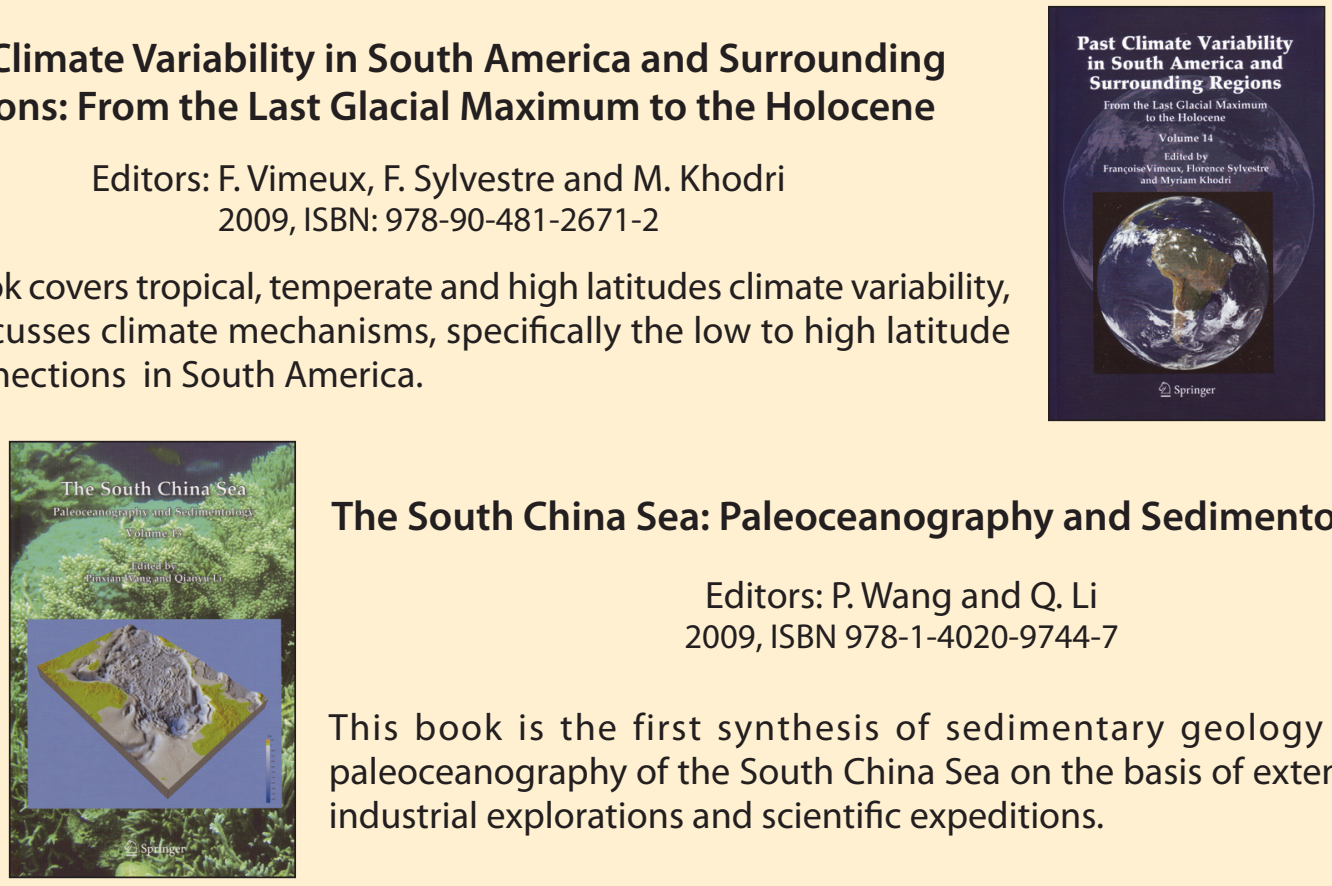

\section{The South China Sea: Paleoceanography and Sedimentology}

Editors: P. Wang and Q. Li

2009, ISBN 978-1-4020-9744-7

This book is the first synthesis of sedimentary geology and paleoceanography of the South China Sea on the basis of extensive industrial explorations and scientific expeditions.

\section{Climate of the last million years: New insights from EPICA and other records}

Editors: H. Fischer, V. Masson-Delmotte, C. Waelbroeck and E.W. Wolff

Quaternary Science Reviews, 2010, 29: ISSN 0277-3791

This special issue of Quaternary Science Reviews stems from the EPICA 2008 Open Science Conference (Venice, Italy), which brought together the international ice core community and a large group of researchers from the marine and terrestrial realm, and climate and ice sheet modeling disciplines. This issue therefore represents a compilation of papers on current advances in the science of this period.

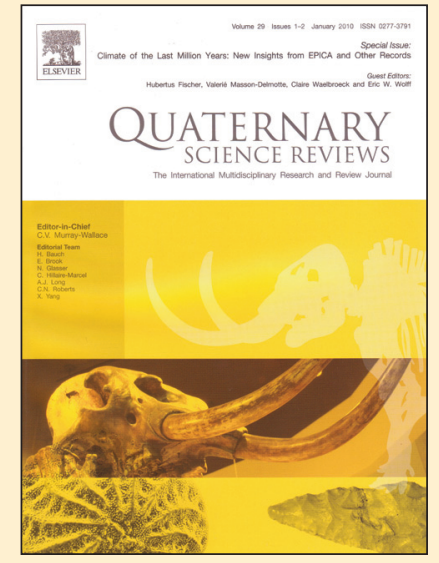

For more information, visit the journal website at www.sciencedirect.com/science/journal/02773791 

gradient of tropical Pacific sea surface temperature over

\section{the last $1.2 \mathrm{ka}$}

Jessica L. Conroy ${ }^{1}$, J.T. Overpeck ${ }^{1,2,3}$ and J.E. Cole ${ }^{1,3}$

'Department of Geosciences, University of Arizona, Tucson, USA; jconroy@email.arizona.edu

${ }^{2}$ Institute of the Environment, University of Arizona, Tucson, USA; ${ }^{3}$ Department of Atmospheric Sciences, University of Arizona, Tucson, USA

Two new climate reconstructions from the tropical Pacific show large changes in the zonal gradient of sea surface temperature during the last $1.2 \mathrm{ka}$, with a much stronger zonal gradient from 1000-1300 AD.

The tropical Pacific is home to the El Niño/ Southern Oscillation (ENSO), the largest source of interannual variability in the global climate system (McPhaden et al., 2006). Our understanding of this important climate mode is limited by incomplete knowledge of the history of ENSO variability and the inability of many climate models to correctly simulate aspects of tropical Pacific climate (Guilyardi et al., 2009). Recently published lake sediment records from the Galápagos archipelago (Conroy et al., 2009a) and a high-resolution marine sediment record from the Makassar Strait (Oppo et al., 2009) add to the emerging picture of past changes in tropical Pacific climate. These new sediment records from the eastern equatorial Pacific (EEP) cold tongue and Indo-Pacific warm pool (IPWP), two key ENSO regions, indicate substantial multidecadal to centennial variability in sea surface temperature (SST) during the last two millennia. Here we use these proxy records and available ENSO reconstructions to explore the changes in the zonal gradient of tropical Pacific SST and ENSO variability over the last $1.2 \mathrm{ka}$.

\section{The zonal gradient of tropical Pacific SST over the last $\mathbf{1 . 2}$ ka}

A sub-decadally resolved sediment record from El Junco Lake (Galápagos archipelago) provides a new climate record from the EEP (Conroy et al., 2009a). The strength of this record is that the proxychanges in the ratio of tychoplanktonic to epiphytic diatoms (or, diatoms that are suspended in the water column via wind turbulence and those living attached to shoreline vegetation)_correlates significantly with instrumental SST during the $20^{\text {th }}$ century (Conroy et al., 2009a). El Junco is a closed-basin lake, and changes in lake level result from changes in rainfall, which in the Galápagos are tightly coupled to EEP SST. When SST is warm, precipitation increases, lake level rises, and there are more tychoplanktonic diatoms in the lake. When lake level drops from decreased precipitation due to cooler SST, a greater fraction of the lake area is near-shore, and

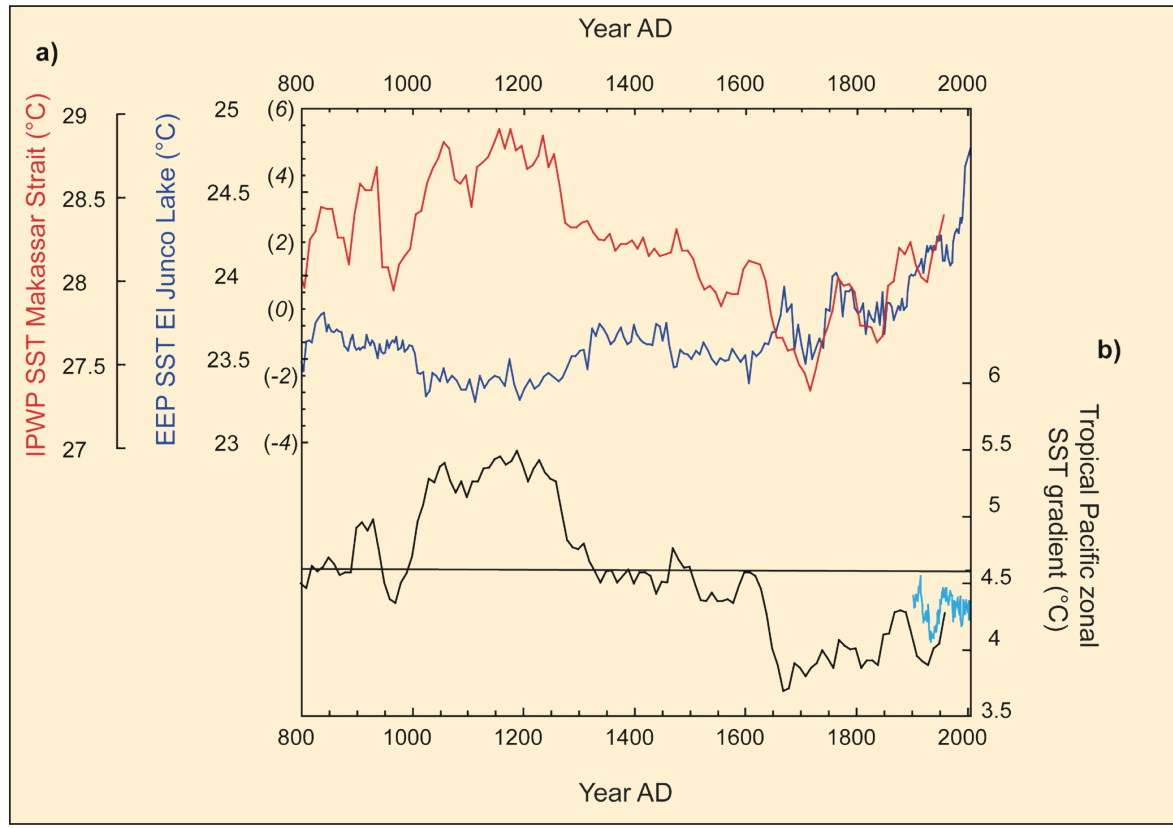

Figure 1: Sea surface temperature (SST) reconstructions and zonal SST gradient of the tropical Pacific over the last 1.2 ka. a) Indo Pacific Warm Pool (IPWP) SST reconstruction in red (Oppo et al., 2009), eastern equatorial Pacific (EEP) SST reconstruction in blue (Conroy et al., 2009a). Numbers in parentheses are diatom index values from Conroy et al. (2009a). b) Zonal SST gradient ( ${ }^{\circ} \mathrm{C}$ ), calculated from the combined IPWP and EEP records. Light blue curve is SST gradient calculated from instrumental SST data in the grid cells containing the proxy records (Smith et al., 2008). Horizontal line indicates long-term mean zonal SST gradient.

more epiphytic diatoms are deposited at the core site. The diatom-inferred SST indicates that the warmest SST in the eastern tropical Pacific in the last 1.2 ka occurred in the last 50 years (Fig. 1a). Although an increase in eutrophication in the $20^{\text {th }}$ century due to cattle grazing around the lake likely contributed to an overall increase in diatom concentration, the increase in nutrients did not alter the ratio of tychoplanktonic to epiphytic diatoms, which responds primarily to lake level. The trend in our ratio begins prior to the increase in concentration, and changes in this ratio are not correlated with diatom concentration. Nutrient loading is also highest near shore, and thus we would expect to see an increase in shore species relative to open water species if there was a preferential impact on some diatom species. However, we observe a decline in the abundance of shoreline species during the last century.

Several pollen time series from the El Junco core and a Galápagos coral record of $\Delta^{14} \mathrm{C}$ (Guilderson and Schrag, 1998) agree with our hypothesis of recent SST warming. However, other records, including El
Junco grain size (Conroy et al., 2008) and a $\delta D$ record derived from botryococcene algae (Sachs et al., 2009) show markedly different multidecadal to century-scale variability compared to the diatom record, even though all these proxies are hypothesized to be related to precipitation. The lack of agreement between different hypothesized climate indicators within the same basin likely indicates different factors influencing various aspects of the lake environment. For example, sand abundance is likely controlled more by the intensity of rainfall than mean rainfall, whereas the diatom record, which responds to lake level changes, is driven by both seasonal and interannual rainfall and the balance between precipitation and evaporation. Differences among the proxies highlight the need for not only a multiproxy approach when evaluating climate proxies, but also modern limnological analyses and calibration with the instrumental record. To date, only the diatom record is significantly correlated with instrumental climate data.

A new, continuous, high-resolution reconstruction of SST from the IPWP was 
recently developed from a foraminifera Magnesium/Calcium (Mg/Ca) record calibrated with instrumental SST (Oppo et al., 2009). The time series of SST calculated from $\mathrm{Mg} / \mathrm{Ca}$ ratios looks similar to regional instrumental SST, providing confidence in the 2-ka reconstruction, although there is some uncertainty regarding the seasonality of the SST proxy (Oppo et al., 2009). To create a high-resolution index of the zonal SST gradient in the tropical Pacific, we combined the El Junco diatom proxy for EEP SST and the reconstruction of IPWP SST (see Fig. 1). We first interpolated each proxy SST record to the same ten-year intervals. We then subtracted the reconstructed Galápagos SST values from the IPWP SST values. We also calculated the

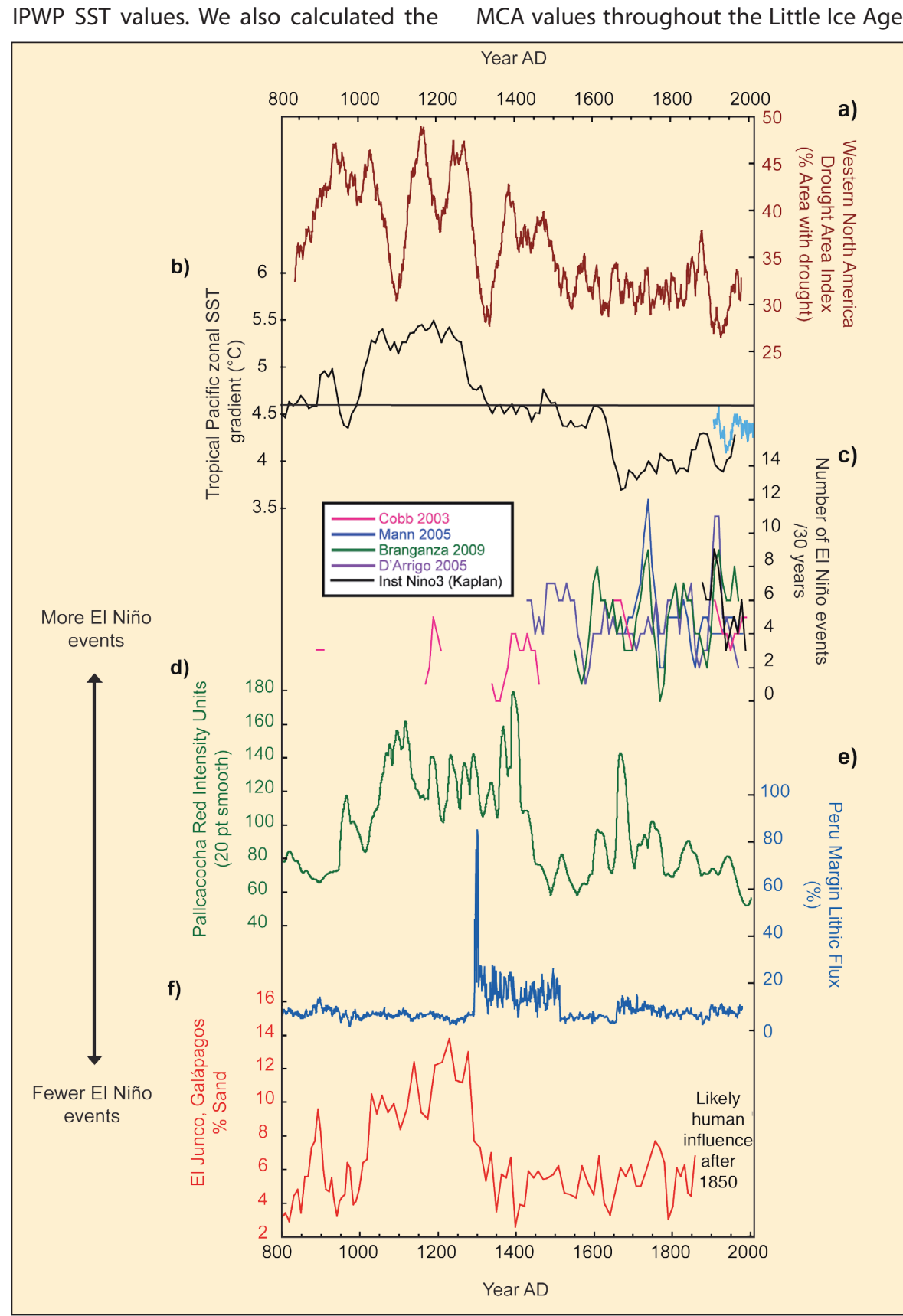

Figure 2: Zonal Sea Surface Temperature (SST) gradient, western North America drought, and ENSO variability over the last 1.2 ka. a) 60-year smooth of drought area index for western North America, indicating \% of area experiencing drought (Cook et al., 2004). b) Calculated zonal SST gradient $\left({ }^{\circ} \mathrm{C}\right)$. c) Number of El Niño events in moving 30-year windows from annual ENSO reconstructions (Cobb et al., 2003; D'Arrigo et al., 2005; Mann et al., 2000; Braganza et al., 2009).d) 20-point smooth of red intensity units from Laguna Pallcacocha, Ecuador, a proxy for El Niño events (Moy et al., 2002). e) Lithic flux from marine sediment core on the Peru Margin. Increased flux indicates increased El Niño events (Rein et al., 2004). f) Percent sand from El Junco Lake sediment core. until present. The strength of the gradient at 1000-1300 AD relative to present $\left(1.5^{\circ} \mathrm{C}\right.$ stronger) is similar in magnitude to the zonal SST gradient anomaly of $1.5-2^{\circ} \mathrm{C}$ calculated by Graham et al. (2007) for the MCA. A climate field reconstruction based on many independent proxy records also indicates a stronger zonal SST gradient during the MCA (Mann et al., 2009).

\section{ENSO, the zonal SST gradient, and} North American drought

Over the past $1.2 \mathrm{ka}$, diverse records indicate that ENSO has experienced significant decadal to centennial variability. However, identifying common patterns among ENSO reconstructions is challenging (Fig. 2). Lack of agreement between proxies may be due to age model error inherent in radiocarbon-dated records or the different spatial expressions of El Niño events (Ashok et al., 2007). Another limitation of most continuous ENSO reconstructions is their inability to separate changes in El Niño event intensity, frequency, and duration from lower frequency climate variability.

To detect event frequency, we require annually resolved ENSO reconstructions (e.g., Cobb et al., 2003; D'Arrigo et al., 2005; Mann et al., 2000; Braganza et al., 2009). We compare several annual ENSO records in Figure $2 \mathrm{c}$ by counting the number of El Niño events for each reconstruction in moving 30-year windows. An El Niño event was defined as a year with a value greater than or equal to one standard deviation for each time series. The annual records show somewhat coherent changes in ENSO frequency through time, although the central Pacific reconstruction (Cobb et al., 2003) records fewer events. This may be due to the different spatial expressions of El Niño events, or because the other ENSO reconstructions contain several records from western North America, where climate cannot be attributed solely to tropical Pacific variability.

It is difficult to separate changes in ENSO variance due to external and internal forcings on multidecadal to century timescales (Wittenberg, 2009). A strengthened zonal SST gradient during medieval times may have inhibited the development of El Niño events (Mann et al., 2005). The enhanced zonal SST gradient we observe from 1000-1300 AD is coincident with slightly fewer events in the segments of the Cobb et al. (2003) coral record relative to segments dating from 1300 AD to present. However, the lower frequency proxy records of El Niño events indicate maximum ENSO frequency from 1000-1400 AD (Fig. 2d-f). Thus, the strength of the zonal 
SST gradient may not be as tightly tied to ENSO variability in the last millennium as it seems to have been during the Holocene (e.g., Koutavas et al., 2006). Alternatively, the limitations of available ENSO proxies may be hindering our understanding of how interannual variability is related to the mean state of the tropical Pacific.

Observations and model simulations indicate that a strong zonal SST gradient in the tropical Pacific favors persistent drought in western North America (e.g., Seager et al., 2007). A comparison of the western North American drought area index (Cook et al., 2004) and the zonal SST gradient indicates that the most widespread droughts of the last 1.2 ka occurred from 1000-1300 AD, when the zonal SST gradient was strongest. However, other climate modes, such as North Atlantic SST variability, also impact western North American hydroclimate, making it difficult to attribute all low frequency droughts in this region to tropical Pacific SST variability (Conroy et al., 2009b).

\section{Directions for future tropical Pacific research}

Understanding the history of tropical Pacific SST and ENSO variability requires a high resolution, multi-site, multi-proxy approach. More annually resolved ENSO reconstructions would be particularly useful, as lower frequency ENSO reconstructions will never be able to separate changes in event frequency, intensity, and duration from longer-term variability. Also, annual records from within the tropical Pacific domain of ENSO are more tightly linked to the physical phenomena of ENSO, and more desirable than reconstructions from outside this domain. A potentially powerful solution to the limitations of existing ENSO proxies is to combine high-resolution SST reconstructions from windows of fossil corals with the continuous records of tropical Pacific lake and marine sediment records. Additional continuous, calibrated, high-resolution SST records from the tropical Pacific will also improve estimates of the zonal SST gradient.

\section{References}

Conroy, J.L., Overpeck, J.T., Cole, J.E., Shanahan, T.M. and Steinitz-Kannan, M., 2008: Holocene changes in eastern tropical Pacific climate inferred from a Galápagos lake sediment record, Quaternary Science Reviews, 27(11-12): 1166-1180.

Conroy, J.L. Restrepo, A., Overpeck, J.T., Steinitz-Kannan, M., Cole, J.E., Bush, M., and Colinvaux, P.A., 2009a: Unprecedented recent warming of surface temperatures in the eastern tropical Pacific Ocean, Nature Geoscience, 2 (1): 46-50.

Graham, N.E., et al., 2007: Tropical Pacific-mid-latitude teleconnections in medieval times, Climatic Change, 83: 241-285.

Mann, M.E., Zhang, Z.H., Rutherford, S., Bradley, R.S., Hughes, M.K. Shindell, D., Ammann, C., Faluvegi, G., and Ni, F.B., 2009: Global Signatures and Dynamical Origins of the Little Ice Age and Medieval Climate Anomaly, Science, 326:1256-1260.

Oppo, D.W., Rosenthal, Y. and Linsley, B.K., 2009: 2,000-year-long temperature and hydrology reconstructions from the Indo-Pacific warm pool, Nature, 460(7259): 1113-1116.

For full references please consult:

http://www.pages-igbp.org/products/newsletters/ref2010_1.htm

\section{Modes of eastern equatorial Pacific thermocline}

\section{variability: Implications for ENSO variability over the last glacial period}

Guillaume Leduc ${ }^{1}$, L. Vidal ${ }^{2}$, O. Cartapanis ${ }^{2}$ and E. Bard ${ }^{2}$

IInstitute for Earth Sciences, Kiel University; gl@gpi.uni-kiel.de

${ }^{2}$ CEREGE, UMR6635, CNRS Université Paul Cézanne Aix-Marseille III, Collège de France

\section{Repeated isotopic analyses of single specimen of the thermocline-dwelling planktonic foraminifer Neogloboquadrina dutertrei provide snapshots of past changes in the amplitude and frequency of El Niño and La Niña.}

One of the most difficult tasks when reconstructing past El Niño-Southern Oscillation (ENSO) activity is to extract a pure ENSO record by avoiding non-ENSO climate signals embedded in climate archives. Among the non-ENSO climatic signals to be avoided, seasons are probably the most important parameter to be considered because their imprint in climate archives overwhelmingly conceal any interannual mode of climatic variability.

To date, few paleoceanographic archives, such as tropical Pacific corals (Cobb et al., 2003) or eastern tropical Pacific laminated sediments (Grelaud et al., 2009), provide the sub-annual time resolution required to separate the ocean variability due to ENSO from that linked to seasonality. Further, these archives are either restricted in time coverage (e.g., decades or centuries for corals, Cobb et al., 2003), or sample warm periods exclusively (Grelaud et al., 2009). From this perspective, further efforts to reconstruct ENSO from marine sediment cores collected in areas strongly impacted by ENSO variability (both the amplitude and frequency of El Niño warm events and La Niña cold events) and with comparatively minor seasonality changes are required.

These conditions are found within the thermocline of the permanently stratified eastern equatorial Pacific warm pool. In this region, the large temperature anomalies associated with interannual thermocline tilt occurring zonally across the Pacific are barely influenced by seasonal changes. Hence any foraminifers living

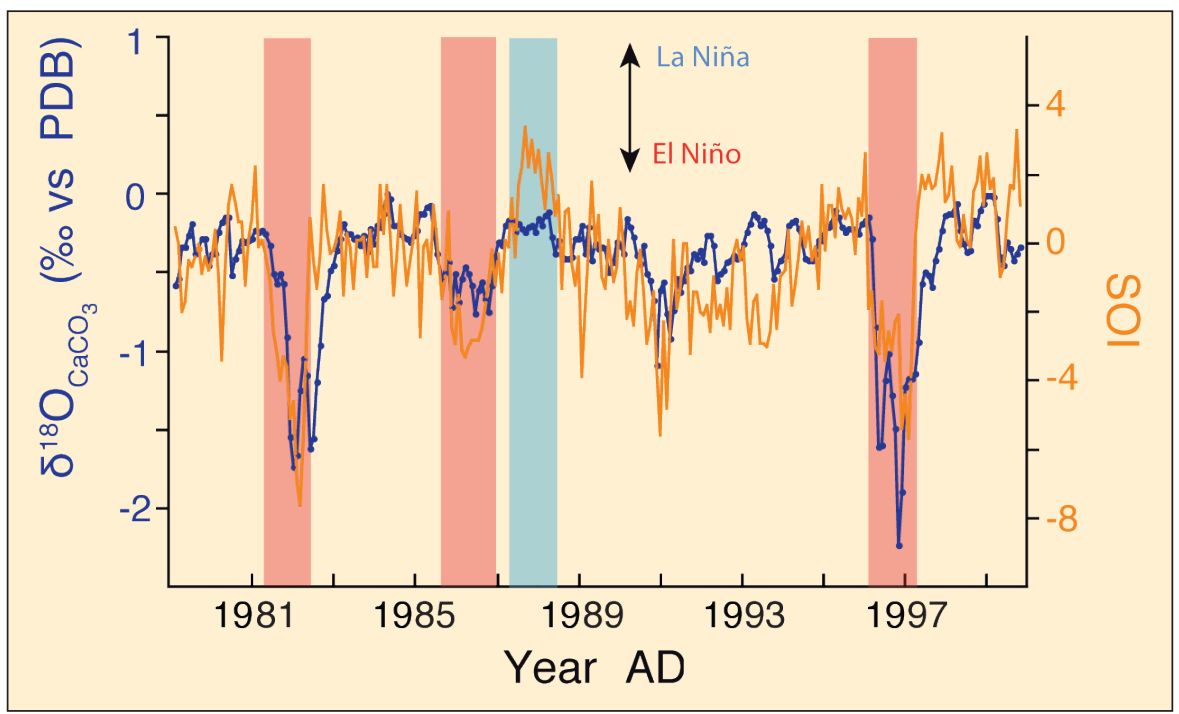

Figure 1: Expected $\delta^{18} \mathrm{O}$ (of $\mathrm{N}$. dutertrei) at equilibrium calculated using temperature and salinity data at 50 $m$ water depth at the core location (blue curve) compared to the Southern Oscillation Index (SOl; orange curve; Australian Bureau of Meteorology) for 1980-2000 AD. Figure modified from Leduc et al., 2009a. 
(a)

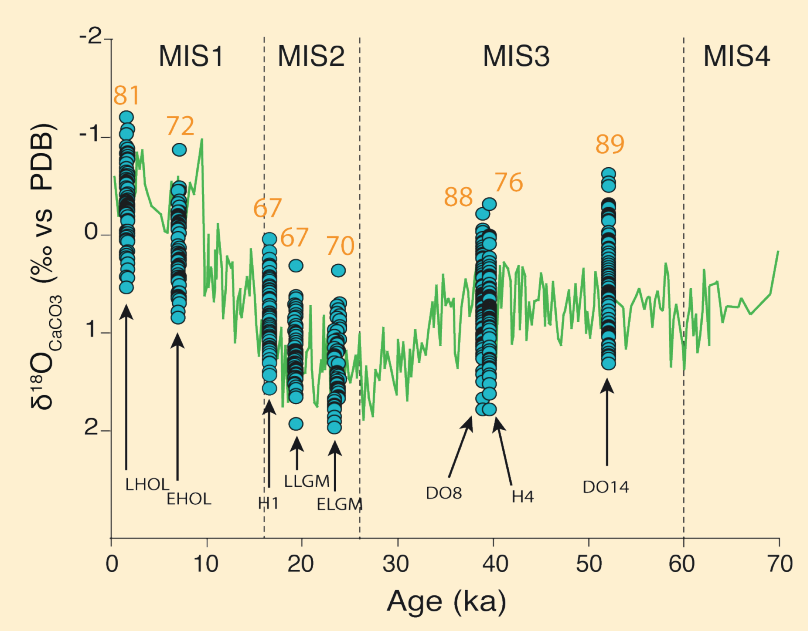

(b)

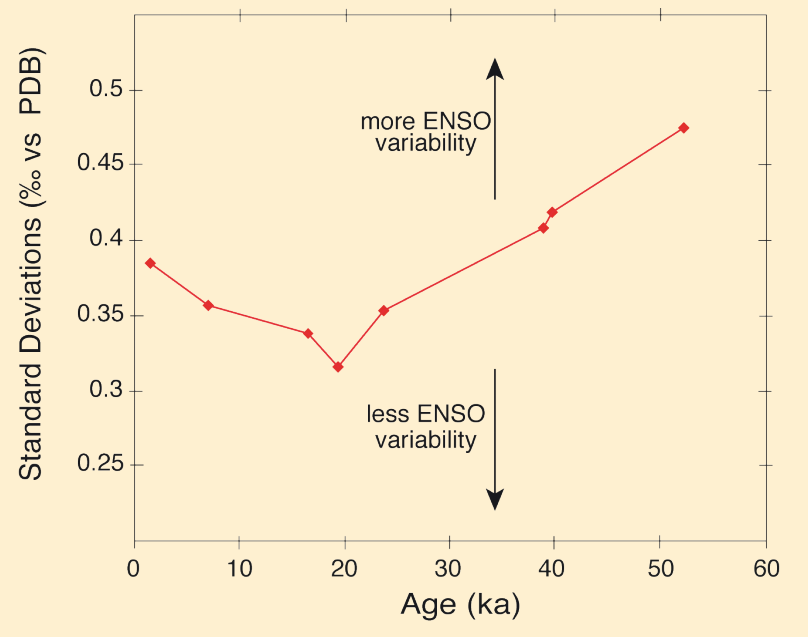

Figure 2: a) Multiple-specimen (green curve) and individual specimen (blue circles) ${ }^{18} \mathrm{O}_{\text {caco3 }}$ measurements performed on N. dutertrei planktonic foraminifera. Orange numbers indicate the number of individual foraminifer tests measured from each interval. Marine Isotopic Stages (MIS) are labeled. $L H O L=L a t e ~ H o l o c e n e, E H O L=E a r l y$ Holocene, H1 and H4 = Heinrich events 1 and 4, LLGM = Late Last Glacial Maximum, ELGM = Early Last Glacial Maximum, DO8 and DO14=Dansgaard-Oeschger interstadials 8 and 14. b) Standard deviations of the individual $\delta^{18} \mathrm{O}$ measurements for each time slice, interpreted as thermocline variability induced by ENSO activity. Figures modified from Leduc et al., 2009a.

within the thermocline may record changes in ENSO activity, with the added benefit that the seasonality effect is expected to be of second order (Fig. 1).

\section{Approach}

We studied a marine sediment core with a well-constrained stratigraphy and containing abundant tests of the thermocline-dwelling planktonic foraminifer $N$. dutertrei (Leduc et al., 2009a). We performed repeated $\delta^{18} \mathrm{O}$ measurements on up to 90 individual foraminifer tests for eight intervals in the sediment core. Each interval integrates approximately 100 years. Ideally, measuring a large number of individual tests at selected core depths provides snapshots of the full hydrographic variability during narrow time windows (see also Koutavas et al., 2006 for a similar approach). The $\delta^{18} \mathrm{O}$ of foraminifers records a mixed signal of temperature and $\delta^{18} \mathrm{O}$ of seawater (a proxy for salinity), therefore the $N$. dutertrei individual measurements provide insight on subsurface water hydrological variability over the studied time intervals. At the core location, ENSO variability has a profound impact on subsurface temperature, with an additional influence on salinity, making the $\delta^{18} \mathrm{O}$ of foraminifers particularly sensitive to ENSO (Fig. 1, Leduc et al. 2009a). Since the subsurface hydrology at the coring site is little affected by seasonal variability, we interpret the scattering of intra-sample $N$. dutertrei $\delta^{18} \mathrm{O}$ measurements as a signal for past changes in amplitude and frequency of ENSO activity. Some secondary overprint of other factors linked to the foraminifer living-depth or to past changes in the thermocline seasonality cannot be ruled out. However the modern oceanography at the studied core site strongly suggests that the first order mode of hydrological variability captured by this method is induced by ENSO activity (Leduc et al., 2009a).

The time slices we have investigated are the late and mid Holocene, Heinrich event 1 (which occurred during the last deglaciation), early and late periods of the Last Glacial Maximum (LGM), and three time slices specifically targeting the cold Heinrich events and warm Dansgaard-Oeschger interstadials that punctuated the last glacial period. This range of samples encompasses most of the modes of climatic variability that affected the last 50 ka, such as glacial-interglacial, Milankovitch (precession) and rapid (millennial) climate changes that shaped most of the paleo-records covering this period.

\section{Results of individual N. dutertrei $\delta^{18} \mathrm{O}$ measurements}

The $\delta^{18} \mathrm{O}$ variability for all time slices ranges from $\sim 1.5$ to $2.1 \%$ o, corresponding to $\sim 8$ to $>10^{\circ} \mathrm{C}$ (Fig. 2a), i.e., comparable to what is found between El Niño and La Niña years nowadays at coring site (Fig. 1). Overall, the $\delta^{18} \mathrm{O}$ distributions did not dramatically change among the time intervals we studied. This indicates that ENSO persisted throughout the time interval studied and that the past modes of ENSO activity under radically different climatic backgrounds are unlikely to have been much different from today.

To better quantify the scattering of individual $\delta^{18} \mathrm{O}$ measurements, we calculated the standard deviation of isotopic data for each time slice as a measure of ENSO activity. The standard deviation data suggest that smooth, long-term ENSO changes occurred over the last 50 ka. Over this time period, ENSO activity decreased steadily during the last glacial period, reaching a minimum of variability during the Last Glacial Maximum (LGM). The ENSO variability then increased again from the LGM to the present (Fig. 2b).

Some features of this reconstruction of past ENSO are particularly interesting. First, these results provide the first indications of reduced ENSO activity during the LGM, which is particularly important in providing useful targets for model intercomparison exercises. Further, the smooth changes in ENSO during the last glacial period, which encompasses periods of contrasting climatic backgrounds-such as Heinrich events and Dansgaard-Oeschger interstadials-confirm recent hypotheses proposing that millennial-scale changes in the tropical Pacific hydrological cycle were decoupled from ENSO variability (Leduc et al., 2009b). Finally, the highest ENSO variability is found during the Marine Isotope Stage 3, at a time when the background climate was neither fully glacial nor fully interglacial. This suggests that the main driver of ENSO is decoupled from global climatic conditions.

\section{New perspectives from intra- sample isotopic variability}

The efforts we made to minimize nonENSO hydrological signals contained in marine sediment cores also provided new and unexpected results that contrast with what is widely acknowledged in the literature. For example, the gentle ENSO activity increase recorded between the mid- and late-Holocene is not statistically significant, which contrasts with a series of other paleo-ENSO reconstructions suggesting a prominently increased ENSO activity during the Holocene period (see Koutavas et al., 2006, and references therein). This re- 
sult can potentially be due to the low resolution in our record. On the other hand, this result also raises the question whether Holocene climatic signals from archives in ENSO-sensitive regions contain non-ENSO signals, such as seasonally-induced InterTropical Convergence Zone migrations.

Most reconstructions of past changes in climatological parameters linked to ENSO activity do not account for the potential impact of past seasonality. Yet seasons can have a considerable impact on the geological record of past climate (Leduc et al., 2010; Laepple and Lohmann, 2009). We emphasize that a careful examination of records of past hydrologi- cal changes from oceanic regions without seasonal cycles, together with sampling strategies collecting the full spectrum of hydrological variability within the time intervals studied, would help to clarify which climatic phenomenon modulates the first-order climatic signal archived in geological records.

\section{Acknowledgements}

This study benefitted from thorough insights provided by one anonymous reviewer.

\section{Data}

The data are available on the World Data Center on the NOAA website at ftp://ftp.ncdc.noaa. gov/pub/data/paleo/contributions_by_author/leduc2009/leduc2009.txt

\section{References}

Koutavas, A., deMenocal, P.B., Olive, G.C. and Lynch-Stieglitz, J., 2006 Mid-Holocene El Niño-Southern Oscillation (ENSO) attenuation revealed by individual foraminifera in eastern tropical Pacific sediments, Geology, 34: 993-996.

Laepple, T. and Lohmann, G., 2009: Seasonal cycle as a template for climate variability on astronomical timescales, Paleoceanography, 24: PA4201, doi:10.1029/2008PA001674.

Leduc, G., Vidal, L., Cartapanis, 0. and Bard, E., 2009(a): Modes of eastern equatorial Pacific thermocline variability: Implications for ENSO dynamics over the last glacial period, Paleoceanography, 24 PA3202, doi:10.1029/2008PA001701

Leduc, G., Vidal, L., Tachikawa, K. and Bard, E., 2009(b): ITCZ rather than ENSO for abrupt climate changes across the tropical Pacific? Quaternary Research, 72: 123-131.

Leduc, G., Schneider, R., Kim, J.-H. And Lohmann, G., 2010: Holocene and Eemian Sea surface temperature trends as revealed by alkenone and $\mathrm{Mg} / \mathrm{Ca}$ paleothermometry, Quaternary Science Reviews, doi:10.1016/j.quascirev.2010.01.004, in press.

\title{
Southern Hemisphere intermediate water formation and the bi-polar seesaw
}

\author{
Simon J.A. Jung ${ }^{1}$, D. Kroon ${ }^{1}$, G. Ganssen² ${ }^{2}$, F. Peeters ${ }^{2}$ and R. Ganeshram ${ }^{1}$ \\ 'School of GeoSciences, The Grant Institute, Edinburgh, UK; simon.jung@ed.ac.uk \\ Department of Paleoecology \& Paleoclimatology, Faculty of Earth and Life Sciences, Vrije Universiteit Amsterdam, The Netherlands.
}

\section{Periodic intensifications of Antarctic Intermediate Water flow occurred as part of the millennial-scale climate oscillations in the glacial period.}

During the last glacial period, a profound millennial-scale climate variation prevailed. First discovered in Greenland ice cores, it has subsequently been documented around the globe, yet the underlying mechanisms controlling this variability have not been indentified. Adding to the complexity of this rapid climate change is an interhemispheric asynchronicity, known as the bipolar seesaw. A significant clue towards unraveling the controls of millennialscale variability came from the deep ocean off Portugal (Shackleton et al., 2000). Here, stable oxygen isotope variability in surface dwelling planktic foraminifera shows clear ties to Greenland climate variability, whereas the respective record based on benthic foraminifers living on the seafloor relates to Antarctic climate variation, reflecting the southern origin of the Antarctic Bottom Water that prevails in the abyssal Atlantic off Portugal.

One likely mechanism for the climatic asynchronicity involves an interhemispheric imbalance in heat storage (Stocker and Johnsen, 2003). Surface ocean records from the South Atlantic Ocean (Barker et al., 2009) indeed show a climate change pattern opposed to that in Greenland ice cores supporting the view that asynchronous heat storage is instrumental in off-setting Northern and Southern Hemisphere climate change at the millennial-scale.

The role of southern-source intermediate water (Antarctic Intermediate Water,
AAIW) in the bipolar seesaw is of global relevance due to its large volume and associated energy storage capacity. However, data-based evidence is rare. Benthic stable isotope data from the intermediate depth SW Pacific (Pahnke and Zahn, 2005) show periods of intensified glacial AAIW formation during the cold Heinrich Events in the North Atlantic. During Heinrich Events, the large continental ice masses surrounding

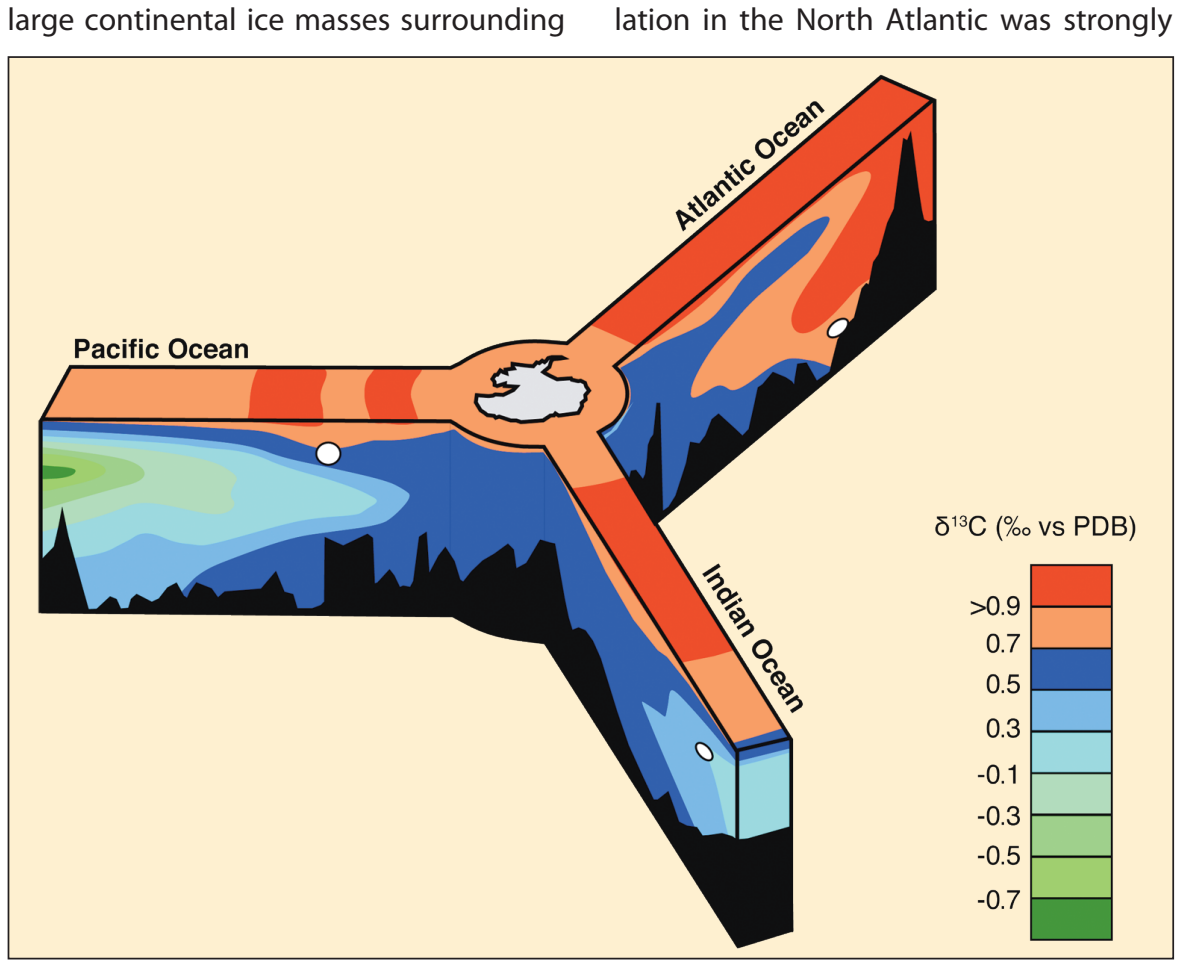

Figure 1: Distribution of $\delta^{13} \mathrm{C}$ in the modern ocean (redrawn from Charles and Fairbanks, 1992). White circles indicate the location of sediment cores NIOP 905 (Indian Ocean; Jung et al., 2009), MD95-2042 (Atlantic Ocean; Shackleton et al., 2000) and MD97-2120 (Pacific Ocean; Pahnke and Zahn, 2005). 
reduced. To assess the wider implications of these findings, glacial AAIW records from other parts of the world ocean, such as the Indian Ocean, are required.

To assess the millennial-scale changes in surface and intermediate waters in the northern Indian Ocean and their relation to the bipolar seesaw, we studied core NIOP 905 collected off the coast of Somalia (Fig. 1) from a water depth of $\sim 1580 \mathrm{~m}$, and compared it with Greenland and Antarctic ice core records. The $\delta^{15} \mathrm{~N}$ and the planktic $\delta^{18} \mathrm{O}$ records in Figure 2 largely reflect variations in surface seawater properties. The benthic $\delta^{18} \mathrm{O}$ and $\delta^{13} \mathrm{C}$ isotope records, however, reflect the intermediate water history in the region.

Both, the $\delta^{15} \mathrm{~N}$ and $\delta^{18} \mathrm{O}$ show that the sea surface history in the Arabian Sea strongly resembles Greenland climate change (Fig. 2a, c). Accordingly, they were used to tie the Arabian Sea core to the Greenland ice-core timescale. Striking new results are that 1) surface ocean and intermediate depth changes occur out-ofphase (Fig. 2c, d) and 2) the intermediate water variability shows a close relation with Antarctic climate history (Fig. 2d, f), hence hosting evidence for a bi-polar seesaw pattern. Whilst the surface ocean change reflects Northern Hemisphere climate change, the Intermediate Water record seems to be tied to that in the south.

The benthic $\delta^{13} \mathrm{C}$ record of core NIOP 905 (Fig. 2e) can be used as a proxy for the age of a water mass along its flow path because of the continuous remineralization of isotopically light detrital organic matter. This process results in lower levels of $\delta^{13} \mathrm{C}$ in the dissolved carbon pool (see Jung et al., 2009) for full discussion; compare Fig. 1). The $\delta^{13} \mathrm{C}$ results from core NIOP 905 show peak values during Heinrich Events (Fig. $2 \mathrm{e})$, implying that $\delta^{13} \mathrm{C}$ changes in the intermediate depth Indian Ocean were antiphased with those of deep water in the Atlantic Ocean. That is, when the overturning circulation in the Atlantic Ocean was reduced during the Heinrich periods, enhanced intermediate water flow occurred in the Northern Indian Ocean. Periodic advection of a southern source intermediate water mass such as glacial AAIW may explain our data.

To date, AAIW forms primarily in the southeastern Pacific and the southwestern Atlantic Ocean (Sloyan and Rintoul, 2001). Today, the AAIW does not reach the northern Indian Ocean (Fig. 1). In the absence of intermediate water formation locally in the glacial northern Indian Ocean (for full discussion see Jung et al., 2009) the most likely explanation for our new data involves a change in intermediate water formation

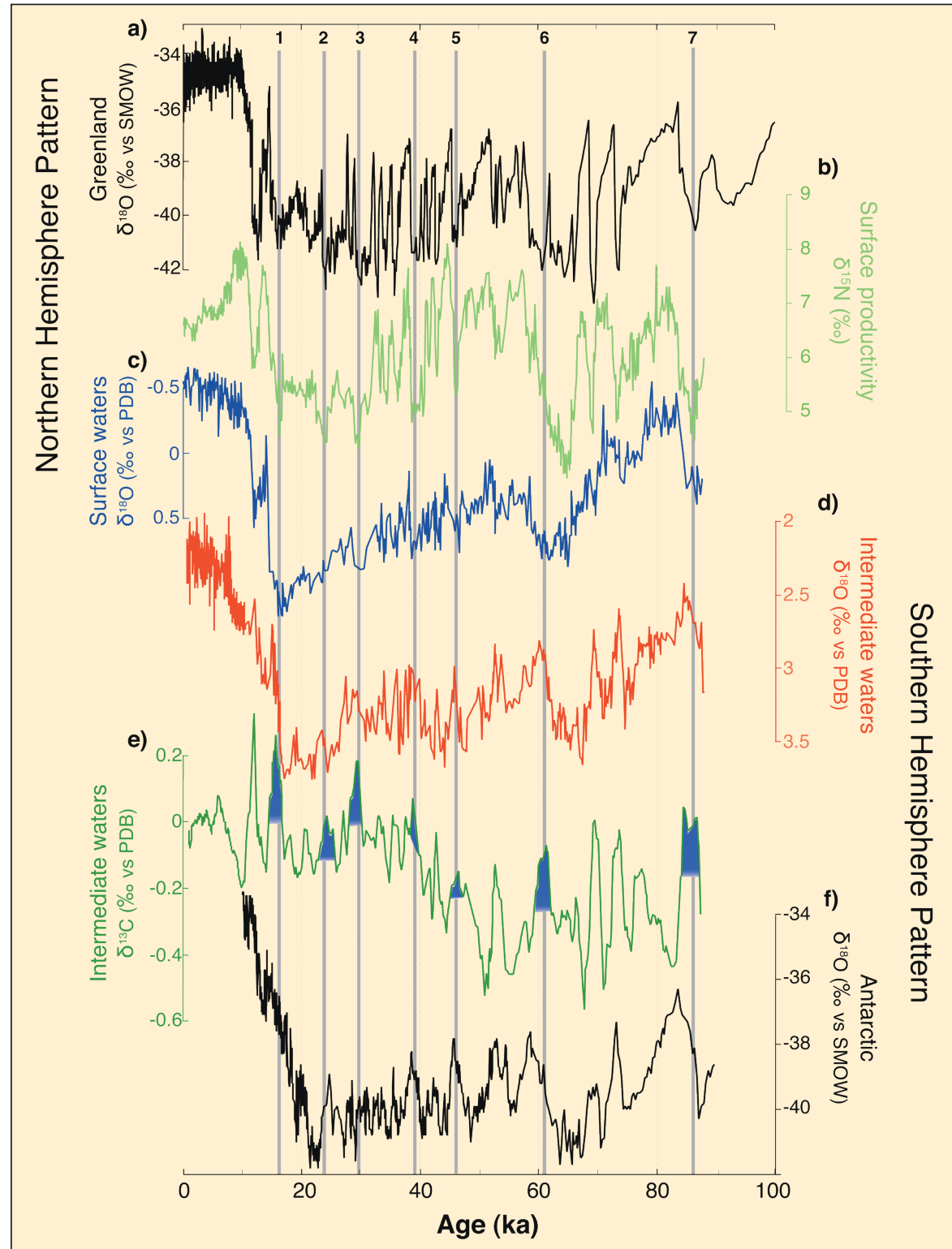

Figure 2: Comparison of (top to bottom) a) the stable oxygen isotope record of the Greenland GISP ice core (Blunier and Brook, 2001, and references therein), b) the $\delta^{15} \mathrm{~N}$ record of core NIOP 905 (see Fig. 1 for location), a proxy for surface water productivity, c) $\delta^{18} \mathrm{O}$ record of the planktic foraminifer Neogloboquadrina dutertrei from core NIOP 905 , reflecting variations in surface waters (Ivanochko et al., 2005), d) the oxygen and e) carbon isotope records of the epibenthic foraminifer Cibicidoides kullenbergi from core NIOP 905, reflecting variations in intermediate waters (Jung et al., 2009), and $\boldsymbol{f}$ ) $\delta^{18} \mathrm{O}$ record from Byrd Ice Core, Antarctica. Vertical gray bars indicate the timing of the North Atlantic Heinrich Events. Blue shaded areas indicate periods of increased ventilation of intermediate water. The age model of core NIOP 905 is constrained by 24 AMS ${ }^{14} \mathrm{C}$ dates (Ivanochko et al., 2005). Beyond the reach of the radiocarbon method, the NIOP 905 records were aligned with Greenland climate change, in line with previous results from the Arabian Sea (Altabet et al., 2002; Schulz et al., 1998).

in the Southern Hemisphere. Both the similarity in timing between Antarctic climate change (Blunier et al., 1998; EPICA, 2006) and the intermediate water oxygen isotope variability off Somalia (Fig. 2) together with the almost simultaneous changes in benthic $\delta^{13} \mathrm{C}$ and $\delta^{18} \mathrm{O}$ values (Fig. 2), support the notion that episodically enhanced formation of glacial AAIW has reached the northern Indian Ocean.

During periods of enhanced glacial AAIW flow ( $\left({ }^{13} \mathrm{C}\right.$ maxima in Fig. 2e), minima in the benthic oxygen isotope record (Fig. 2d) reflect warming of intermediate water in the source regions of glacial AAIW in the Southern Hemisphere. Part of the oxygen isotope change, however, is due to changes in ice volume. While roughly half of the oxygen isotope change reflects variations in global ice volume (Shackleton et al., 2000), the remaining $\delta^{18} \mathrm{O}$ reduction equals a temperature rise of up to $2^{\circ} \mathrm{C}$, in line with an earlier study on intermediate water temperature in the Pacific Ocean (Stott et al., 2007).

Evidence of enhanced glacial AAIW flow during periods of near-collapsed meridional overturning circulation in the North Atlantic is crucial for the understanding of the bipolar seesaw. At times of maximum cold conditions in the North Atlantic, the $\delta^{18} \mathrm{O}$ records suggest that the intermediate water layers in the Indian (Jung et al., 2009) and SW Pacific Ocean (Pahnke and Zahn, 2005), fed by glacial AAIW, have warmed. If true, this might have implications for climate change around Antarctica and in the North Atlantic region. First, 
excess heat storage in glacial AAIW would have reduced the energy available for heating the atmosphere in the sub-/polar Southern Hemisphere and consequently attenuated the millennial-scale warm events over Antarctica. Second, by temporarily warming glacial AAIW, the amount of energy/heat available for equilibrating interhemispheric energy imbalances was reduced. This supports the notion that excess heat storage in glacial AAIW might have been instrumental in maintaining cold conditions in the North Atlantic.

The timing of the glacial AAIW warm events seems to point to a specific sensitivity of the climate system as a whole to changes in AAIW formation. It is currently difficult to substantiate the specific role of AAIW in the bipolar seesaw. Given the mounting evidence reflecting the wider significance of Southern Hemisphere climate change, it is increasingly likely that variations in the ocean-atmosphere dynamics in this part of the world exert a profound control on climate change on a global scale. This would contrast with the view of a rather "passive" role of the Southern Hemisphere, i.e., largely responding to climate changes triggered elsewhere.

\section{Data}

Data are stored at the National Climate Date Center, Boulder, Colorado (http://www.ncdc.noaa. gov/paleo/data.html).

\section{References}

Altabet, M.A., Higginson, M.J. and Murray, R.W., 2002: The effect of millennial-scale changes in the Arabian Sea denitrification on atmospheric $\mathrm{CO}_{2}$, Nature, 415: 159-162.

Barker, S., Diz, P., Vautravers, M., Pike, J., Knorr, G., Hall, I.R. and Broecker, W.S., 2009: Interhemispheric Atlantic seesaw response during the last deglaciation, Nature, 457: doi:10.1038/nature07770.

Blunier, T. and Brook, E.J., 2001:Timing of millennial-scale climate change in Antarctica and Greenland during the last glacial period, Science, 291: 109-112.

Ivanochko, T.S., Ganeshram, R.S., Brummer, G.-J.A., Ganssen, G., Jung, S., Moreton, S.G. and Kroon, D., 2005: Variations in tropical convection as an amplifier of global climate change at the millennial scale, Earth and Planetary Science Letters, 235: 302-314.

Jung, S.J.A., Kroon, D., Ganssen, G., Peeters, F. and Ganeshram, R., 2009 Enhanced Arabian Sea intermediate water flow during glacial North Atlantic cold phases, Earth and Planetary Science Letters, 280: $220-228$

For full references please consult:

http://www.pages-igbp.org/products/newsletters/ref2010_1.htm

\section{The $2^{\text {nd }}$ PAGES past interglacials workshop}

\section{Mytilene, Greece, 24-27 August 2009}

\section{Chronis Tzedakis $^{1,2}$, D. Raynaud ${ }^{3}$ and J.F. McManus ${ }^{4}$}

'Department of Geography, University College London, UK; p.c.tzedakis@ucl.ac.uk; 2Department of Environment, University of the Aegean, Mytilene, Greece; ${ }^{3}$ Laboratoire de Glaciologie et Géophysique de l'Environnement, Grenoble, France; ${ }^{4}$ Lamont-Doherty Earth Observatory, Columbia University, USA

In the context of future climate change, there is a need to understand the sensitivity of the Earth System to different forcings. Though not strict analogues for an anthropogenic future, past interglacials can be thought of as a series of natural experiments in which boundary conditions varied considerably, with consequent effects on the character of climate change. Their examination, therefore, can provide a more complete view of the range and underlying physics of natural climate variability. Examination of the paleoclimate record reveals a large diversity between interglacials in terms of their intensity, duration and internal variability. This raises fundamental questions about the Earth's climate, but a general theory accounting for the occurrence of interglacials with differing characteristics remains elusive (Tzedakis et al., 2009). This has provided the impetus for a comprehensive comparison of interglacials of the last $800 \mathrm{ka}$ within the context of the PAGES Working Group on Past Interglacials (PIGS).

The first PIGS workshop, held at Bernin, France, 2-4 October 2008, defined specific priority topics, which would form the themes of three subsequent workshops: (1) intra-interglacial variability; (2) magnitude and duration of interglacials; and (3) explaining the structure of interglacials from the forcing. The overall aim is to integrate the various themes emerging from the workshops in order to arrive at an improved understanding of the factors determining interglacial diversity.

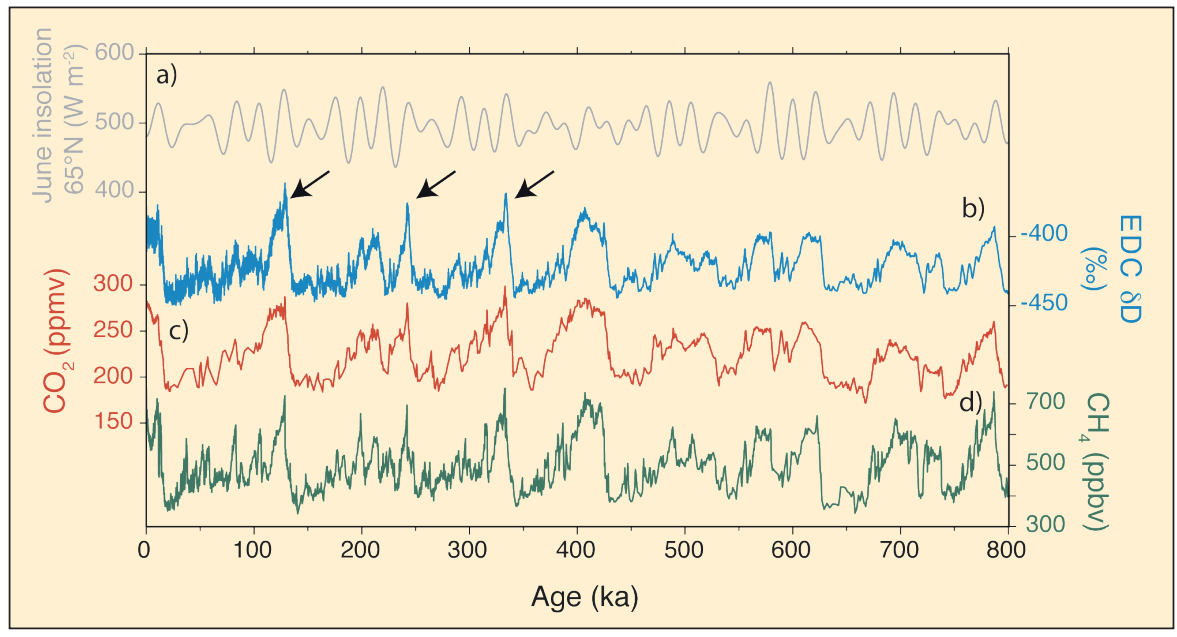

Figure 1: EPICA Dome C (EDC) ice core records plotted against a) June insolation for $65^{\circ} \mathrm{N}$ (Berger, 1978). EDC records are (b) deuterium ( $\delta D$ ) composition of the ice (Jouzel et al., 2007); (c) atmospheric CO, concentration (Lüthi et al., 2008); (d) atmospheric $\mathrm{CH}_{4}$ concentration (Loulergue et al., 2008). Black arrows indicate relatively short-lived maxima in temperature ( $\delta D)$ and greenhouse gas concentrations that were discussed in depth at the meeting.

At the second PIGS workshop held at the University of the Aegean, on the Island of Lesvos (24 - 27 August, 2009), 25 scientists from 10 countries (including $2 \mathrm{PhD}$ students, 3 young scientists, and 7 newcomers to PIGS), representing the marine, ice core, terrestrial and modeling communities, met to assess our current understanding of the following issues: (i) evidence for intra-interglacial variability; (ii) (relative) timing and local or regional significance of reported events; (iii) transient jumps and declines in temperature and greenhouse gas (GHG) concentrations at the onset of interglacials (Fig. 1); (iv) comparison of interglacial and glacial climate instability.

The first day focused on general considerations of interglacial trends and variability. Ice core data (Antarctic temperatures and GHGs) were examined first, along with atmospheric $\mathrm{CO}_{2}$ reconstructions beyond $800 \mathrm{ka}$. This was followed by presentations of modeling results of interglacial climates and simulations of $\mathrm{CO}_{2}$ concentrations. After a presentation of the potential of specific molecular markers to reconstruct paleofires, the discussion moved to an evaluation of interglacial climate (in)stability and associated mechanisms from paleoceanographic data and reviews from the Mediterranean and the tropical Pacific, as well as sea-level reconstructions.

The presentations of the second day focused on specific case studies: Holocene millennial-scale oscillations in ocean circu- 
lation both from data and modeling perspectives were considered first. This was followed by an examination of the role of millennial-scale variability as an intrinsic feature of the past five terminations. Marine and ice core data from MIS 5e and 11 were presented next, along with a general consideration of Antarctic variability within interglacial periods. After a discussion of new simulations of Last Interglacial climates, the presentations ended with an examination of interglacial climate oscillations in speleothem and long pollen records from southern Europe.
Two major themes were identified during discussions, and these will now form the focus of two separate projects. One will emphasize the importance of rigorous statistical treatment of intra-interglacial variability and its relationship to mean global state. The other will examine the role of higher frequency variability in orbital-scale changes such as deglaciations (or interglacial inceptions).

The third PIGS workshop will be hosted by Jerry McManus and take place later this year in the U.S. (exact place and time to be appointed). This workshop will focus on the duration of interglacials.

\section{References}

Berger, A., 1978: Long-term variations of daily insolation and Quaternary climatic changes, Journal of Atmospheric Science, 35 2362-2367

Jouzel, J., et al., 2007: Orbital and millennial Antarctic climate variability over the past 800,000 years, Science, 317: 793-796.

Loulergue. L., et al., 2008: Orbital and millennial-scale features of atmospheric $\mathrm{CH}_{4}$ over the past 800,000 years, Nature, 435: 383-386.

Lüthi, D. et al., 2008: High-resolution carbon dioxide concentration record 650,000-800,000 years before present, Nature, 453 $379-382$

Tzedakis, P.C., et al., 2009: Interglacial diversity, Nature Geoscience, 2 $751-755$

\title{
Understanding future sea level rise: The challenges of dating past interglacials P A L S E A PALSEA workshop, Woods Hole, USA, 20-25 September 2009
}

\author{
William G. Thompson ${ }^{1}$, M.B. Andersen ${ }^{2}$, A. Dutton ${ }^{3}$ And M. Siddall ${ }^{2}$ \\ 'Woods Hole Oceanographic Institution, Woods Hole, USA; wthompson@whoi.edu \\ 2University of Bristol, UK; ${ }^{3}$ The Australia National University, Canberra, Australia
}

The aim of the joint PAGES-IMAGES Working Group "Paleo-constraints on sealevel rise" (PALSEA; www.climate.unibe. ch/ siddall/working_group.html) is to extract information about ice sheet response to temperature change from the history of sea level over the Quaternary, particularly interglacial periods, within a range of temperatures bracketing the modern. A better understanding of the relationship between global temperature and sea level is crucial for projections of future sea level rise expected from global warming. Currently, substantial uncertainty exists for such projections, primarily due to a lack of understanding about ice sheet dynamics. The $2^{\text {nd }}$ PALSEA workshop focused on challenges in uranium-thorium (U-Th) coral dating, with discussions centered on three themes: technical issues in U-Th mass spectrometry, open-system behavior of U-series nuclides, and development of a Quaternary sea level database.

\section{Analytical developments}

Developments in mass spectrometry continue to improve coral age precision and extend the range of the U-Th geochronometer (Andersen et al., 2008). As a result, assuring comparability of ages reported by different labs is crucial. Ideally, all measurements should be traceable to the same set of reference standards. Unfortunately, internationally recognized standards are not currently available. A widely used $\mathrm{U} / \mathrm{Th}$ uraninite reference standard, HU-1, is now in short supply and may no longer be suitable as a reference standard, as different aliquots have different

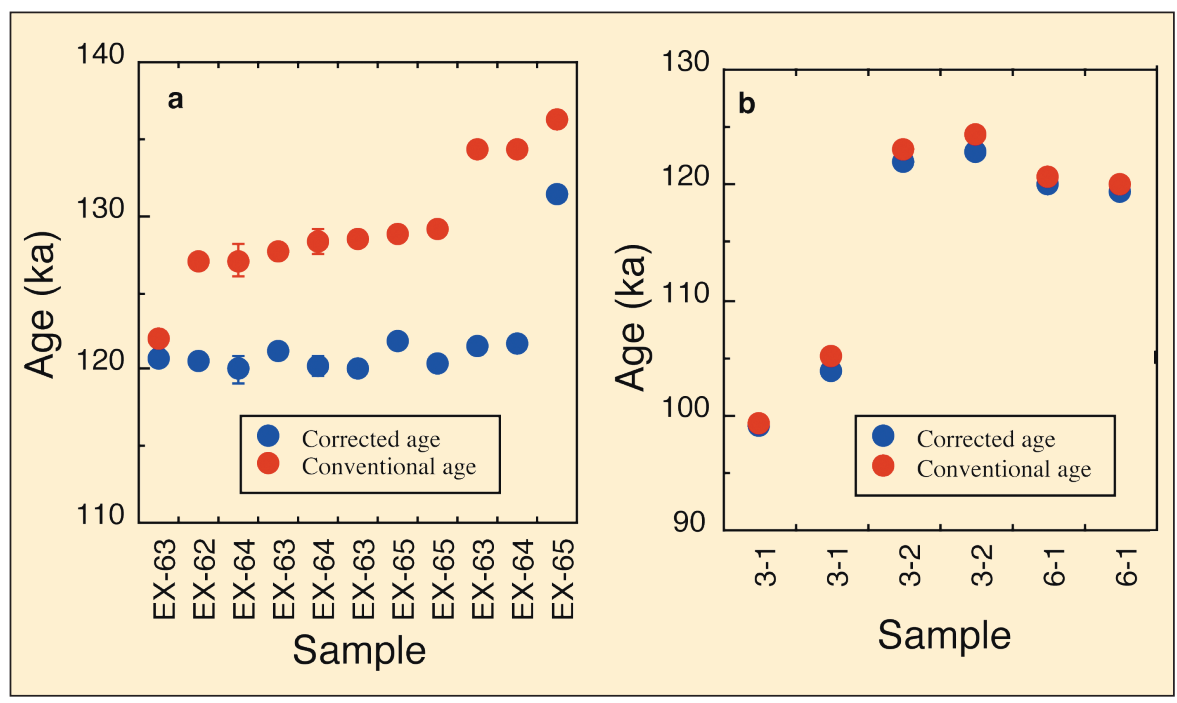

Figure 1: The impact of open-system processes on coral ages (Thompson, unpublished data): a) Discrete sample replicates from a single large Western Australian head coral. Conventional ages range from 122 to $136 \mathrm{ka}$. Corrected ages cluster tightly at $121 \pm 1 \mathrm{ka}$ (mean and 2 SD), with the exception of one age at $131 \mathrm{ka}$. $\boldsymbol{b}$ ) Ages from a Caribbean Last Interglacial reef outcrop (3 corals; 2 replicates each). Initial uranium isotope ratios fall between 1.147 and 1.151, satisfying a 'strictly reliable' screening criterion. However, one coral age is $\sim 20$ ka younger than it should be and reproduces poorly, due to late uranium addition. These two examples illustrate that neither rigorous screening criteria nor correction methods succeed in producing accurate ages in every case, highlighting the importance of replicating ages from discrete pieces of the same coral and comparing ages with stratigraphic observations from the field as an additional means of excluding erroneous ages.

isotope ratios when measured at current levels of precision and the assumption of radioactive equilibrium no longer appears valid. The time is ripe for the development of new standards. As a result of workshop discussions, a strategy for their production and distribution has been initiated in collaboration with the National Environment Research Council's Geosciences Laboratory, UK, drawing on the experiences of the EARTHTIME project (www.earth-time. org). As part of the workshop, an informal U-Th dating inter-lab comparison involving 14 labs was run. This exercise provided extremely useful information for the par- ticipants and a more comprehensive intercomparison is being planned.

\section{Open-system effects}

The impact of open-system behavior of $U$ series isotopes on the quality of coral ages is well documented, and both sample screening (Gallup et al., 1994) and age correction (Thompson et al., 2003) methods are employed to alleviate this problem. While practices for sample screening and/ or age correction are still keenly debated, workshop participants agreed on a number of key points: 1) It is clear that many corals yield ages that do not agree within

\section{,}


the analytical uncertainty when several individual pieces of the same coral are measured, thus age replication is crucial to establish the level of age uncertainty associated with sample heterogeneity; 2) The stratigraphic context of corals provides a key constraint on relative ages that has been largely underutilized. Publications should include this information, rather than just sample elevations; 3) Both sample screening and age correction approaches rely heavily on the ${ }^{234} \mathrm{U} /{ }^{238} \mathrm{U}$ ratio of seawater; yet the history of ocean uranium isotopic composition is not well known. Furthermore, ${ }^{234} \mathrm{U} /{ }^{238} \mathrm{U}$ values for screening and correction are not consistent between different lab groups. It is important to adopt a uniform history of ocean ${ }^{234} \mathrm{U} / 238 \mathrm{U}$ for quality and correction criteria, and to incorporate seawater ${ }^{234} \mathrm{U} /{ }^{238} \mathrm{U}$ uncertainty into error estimates for the ages.

\section{Compilation}

A key goal of PALSEA is to establish a comprehensive Quaternary sea level database. This data is presently scattered across the scientific literature with widely varying reporting formats, screening and correction criteria, and decay constants. Stratigraphic information is often incomplete, and elevations are not tied to consistent benchmarks. It is highly desirable to compile ex- isting data in a uniform format that can be made available to the wider community, and to adopt a uniform set of standards for future data reporting. Thus PALSEA is currently compiling existing data, which will be available on the PALSEA website. Data management software, that processes raw ICP-MS data, produces publication quality data tables, and links seamlessly with the EarthChem database developed through the EARTHTIME project, and discussions are underway to adapt this software for the U-Th chronometer.

\section{Ice sheet recommendations}

Relative sea level histories permit the reconstruction of former ice sheetsa fundamental boundary condition for modeling past climate. PALSEA suggests the following ice sheet guidelines for the Paleoclimate Modeling Intercomparison Project (PMIP): 1) Alternative ice sheet boundary conditions, generated by independent glacial isostatic adjustment (GIA) models must be considered. 2) An existing database (Dyke et al., 2002) that uses evidence of ice-sheet extent should be used. 3) GIA models use different relative sea level databases, many with inconsistent or outdated reconstructions. To address this problem PALSEA aims to develop an open-access, quality-controlled database of relative sea level using consistent age estimates for use in isostatic models. This will allow improvements in isostatic models in the future, which should be incorporated into PMIP simulations.

\section{Public outreach}

The meeting included a public outreach event: "Where land and sea meet: Managing shoreline change over the next 100 years", funded by the Woods Hole Oceanographic Institution Morss Colloquium. This event brought together PALSEA scientists with economic, legal, and policy experts for a series of brief presentations and a panel discussion responding to audience questions.

\section{Acknowledgements}

The organizers thank the following organizations for their support: IMAGES, PAGES, and the Woods Hole Oceanographic Institutions' Ocean and Climate Change Institute.

\section{References}

Andersen, M.B., Stirling, C.H., Potter, E.-K., Halliday, A.N., Blake, S.G., McCulloch, M.T., Ayling, B.F. and O'Leary, M., 2008: High-precision U-series measurements of more than 500,000 year old fossil corals, Earth and Planetary Science Letters, 265: 229-245.

Dyke, A.S., Andrews, J.T., Clark, P.U., England, J.H., Miller, G.H., Shaw, J. and Veillette, J., 2002: The Laurentide and Innuitian ice sheets during the Last Glacial Maximum, Quaternary Science Reviews, 21: $9-32$.

Gallup, C.D., Edwards, R.L. and Johnson, R.G., 1994: The timing of high sea levels over the past 200,000 years, Science, 263: 796-800.

Thompson, W.G., Spiegelman, M.W., Goldstein, S.L. and Speed, R.C., 2003: An Open-System model for the U-series age determinations of fossil corals, Earth and Planetary Science Letters, 210 365-381.

\section{High- to mid-latitude northern atmospheric circulation changes during the last climate cycle}

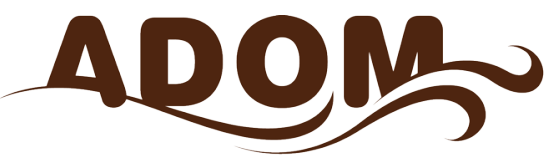

\section{$1^{\text {st }}$ ADOM Workshop, Hyères-les-Palmiers, France, 1- 4 November 2009}

\section{Denis-Didier Rousseau', C. Hatté2 ${ }^{2}$ I. Tegen ${ }^{3}$ and workshop participants \\ ${ }^{1}$ Ecole Normale Superieure, Laboratoire de Meteorologie Dynamique (UMR INSU-CNRS 8539) and CERES-ERTI, Paris, France ${ }^{2}$ Laboratoire des Sciences du Climat et de l'Environnement (UMR CNRS, CEA, UVSQ 8212), Gif-sur-Yvette, France; ${ }^{3}$ Leibniz Institute for Tropo- spheric Research, Leipzig, Germany}

How dusty was the world during the last climate cycle? Modeling efforts are performed focusing specifically on the role of dust in driving past climate changes. At the first workshop of the PAGES Working Group "Atmospheric circulation Dynamics during the last glacial cycle: Observations and Modeling" (ADOM), presentations were given on paleodust records from ice core, terrestrial and marine eolian archives, on process studies of dust emission and transport, and on modeling dust as an environmental agent.

When summarizing the presentations of this meeting, a question immediately comes to mind: How can loess sequences be related to dust records from ice cores? Due to the importance of small-scale transport and deposition processes of dust, loess sequences are difficult for modelers to apprehend. Loess series can provide information on dust sources because a close connection can be established between deposit and source(s). On the other hand, in ice cores one only observes the result of long distance transport, making attribution to a specific source area more difficult. Up to now, there is no precise information on the geological characteristics for precisely identifying key source regions. What are the meteorological and geological features that control dust emission processes in the different source locations (Fig. 1)? What are the properties of the emitted dust particles? How is dust transported from its source localities? These questions are as yet unsolved. However, due to their ability to record long-distance dust transport, ice cores may help clarify these issues, all of which address the critical questions of the origin of dust and the processes involved in dust emission and transport towards the deposition location.

How dust affects the climate is another key question that was raised during the meeting. Observational data provide information on actual deposition, while models, which address the radiative forc- 
ing effect of dust on the climate, estimate the probable dust concentration in the atmosphere from which deposition fluxes are calculated, generally using simplified parameterizations.

In contrast to greenhouse gases, it is unclear how globally representative the ice core record of dust is. Debating this issue, the participants raised two problems: i) Which grain size range should we investigate, as most records correspond to large dust particles? ii) If small size particles are being investigated, washout of the atmospheric dust load must be addressed through consideration of precipitation parameters along the dust transport pathway. This information is only available from models.

Another question was raised following the presentations related to the Chinese sequences. Contrary to European loess, they do not record Dansgaard-Oeschgerlike events, yet reveal events apparently synchronous to the North Atlantic Heinrich events. What are the changes in the climatic zones driving millennial-scale variations in dust deposition? The time resolution of the records is particularly critical as highlighted during the meeting and must be improved, as it will impact the global versus regional comparisons.

As the different presentations referred to different time intervals, the participants discussed whether one or more whole glacial intervals should be considered, or whether one should focus only on par-

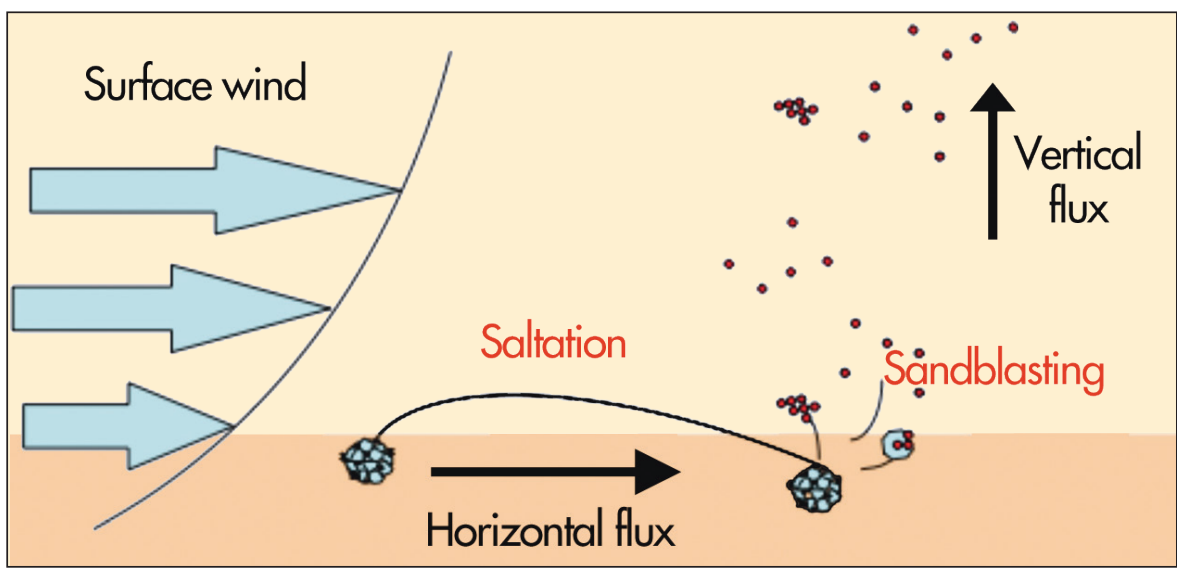

Figure 1: Schematic of the processes involved in dust emission. When wind velocity is of sufficient strength over a surface that is not totally protected by vegetation, stones or pebbles, the grains that constitute the superficial layer of the soil, begin to move. When these grains mobilized by wind (saltation) fall back to the land surface, a part of their kinetic energy is transferred to soil aggregates, which are disrupted, allowing finer particles (generally $<20$ $\mu \mathrm{m}$ ) to be emitted into the atmosphere (sandblasting) (modified from G. Bergametti, unpublished).

ticular events/intervals. Addressing these questions led to the following questions: What dust was really present in the atmosphere in terms of the size of the particles and quantities? Are the modern atmospheric processes compatible with the strong dust loading of the past?

Concerning the source areas, questions remain on the potential for dust emission and initial mixing altitude (low and high elevation), as well as the frequency and strength of particular dust events. For example, to what altitude can dust grains be uplifted under different climate conditions? Concerning more specifically the Greenland record, is the transport of possible emitted dust material from China still a robust assumption? Indeed the transport pathway from China to Greenland is still questionable based on present-day models and geochemical analyses performed on dust particles. What is the history of air masses responsible for dust transport, and what role does seasonality play in the transport? Although it has been used to explain transport to Antarctica, the question also remains as to how useful radon is as a tracer of air mass transport. The second ADOM meeting, to be held early 2011 will aim to address some of these questions.

\section{Acknowledgements}

The organizers wish to thank the supporters of this workshop; PAGES, the European Science Foundation, and the French National Institute of Sciences of the Universe - National Centre for Scientific Research (INSU-CNRS).

\section{The West African Quaternary Research Association inaugural international workshop}

\section{Ibadan, Nigeria, 26 - 30 October 2009}

IZUChUKWU MiKe AKAEGBobI

Department of Geology, University of Ibadan, Nigeria; izumike20022002@yahoo.com

The first West African Quaternary Research Association (WAQUA) international workshop aimed to enhance the growth of Quaternary paleoscience and generate interest among younger scientists in research works that focus on paleontology, archaeology, past environments and climate, coastal erosion and sea level changes in the West African subregion. The workshop also sought to promote regional collaborations and intensify scientific exchange. Sessions were held under the theme "The West African Quaternary Paleoclimatic/Sea Level Changes and Human Responses: Evidences from Marine and Terrestrial Sources" with the aim of understanding how information stored in geological archives can be used to reconstruct environmen- tal/climatic variability of the past $2 \mathrm{Ma}$, for climate modeling and forecasting of the future. The workshop further focused on human adaptations to climatic variations and coastal erosion during the Late Quaternary. A general discussion was also organized to identify research priorities and form working groups to address paleoscientific issues covering the last $2 \mathrm{Ma}$.

\section{Workshop sessions}

The workshop was attended by over 50 participants from different countries in West, East and Southern Africa. The first day opened with keynote presentations and a plenary session. Two keynote presentations were given that discussed the importance of Africa's paleo-climatic ar-

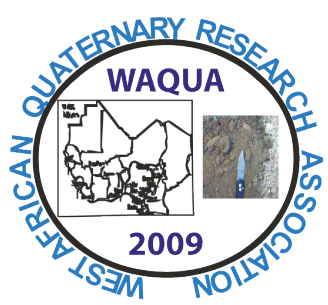

chives covering the last approx. 2 ka in determining climate change and human impact in Africa.

The keynote address by Mohammed Umer highlighted how the fragmentation of West African rainforest and major water bodies during the Last Glacial Maximum were associated with a shift to a drier climate. However, the mechanisms driving those changes that occurred abruptly after 5.5-5 cal ka BP need further investigation, such as the relation between insolation forcing and ocean temperature-vegetation feedbacks. He also noted that 19-23 ka precession cycles could be a forcing element for the enhanced monsoons at 35-30 cal ka BP, the Early Holocene and for the dry LGM (e.g., see Umer et al., 2004). 
Continuous long and high-resolution sequences are needed for testing the effect of orbital forcing over full glacial-interglacial cycles.

Another keynote by Julius Lejju dealt with Holocene environmental history and human interaction based on sedimentary records and archeological findings around the Great Lake Regions of Central Africa. This paper reported significant changes in environmental and socio-cultural conditions from the Holocene to present.

This was followed by a series of plenary papers focused on the interdependencies of climate change and groundwater budget across the West African Sahel Zone, and the impact and consequences of sea level rise on coastal erosion. It was revealed that societal impacts associated with climate change include drought, land degradation, biodiversity loss, decreased human well-being and poor agricultural output, ultimately affecting food security.

Euloge Ogouwale then described the history of climate change during the Quaternary in West Africa citing examples from the Benin Republic. The results revealed that the impact of the dry climatic condition in Benin Republic is visible in the landscape vegetation.

The second day focused on climatic variability and human health, and the consequences of ecosystem changes on the livelihood and sustainability of humans in West Africa during the Holocene. The session highlighted integrated studies that combine marine and terrestrial proxies to correlate changes in oceanic, continental and atmospheric conditions. For example, Ilham Bouimetarhan presented historical records that show that the Sahel region has experienced several shifts towards

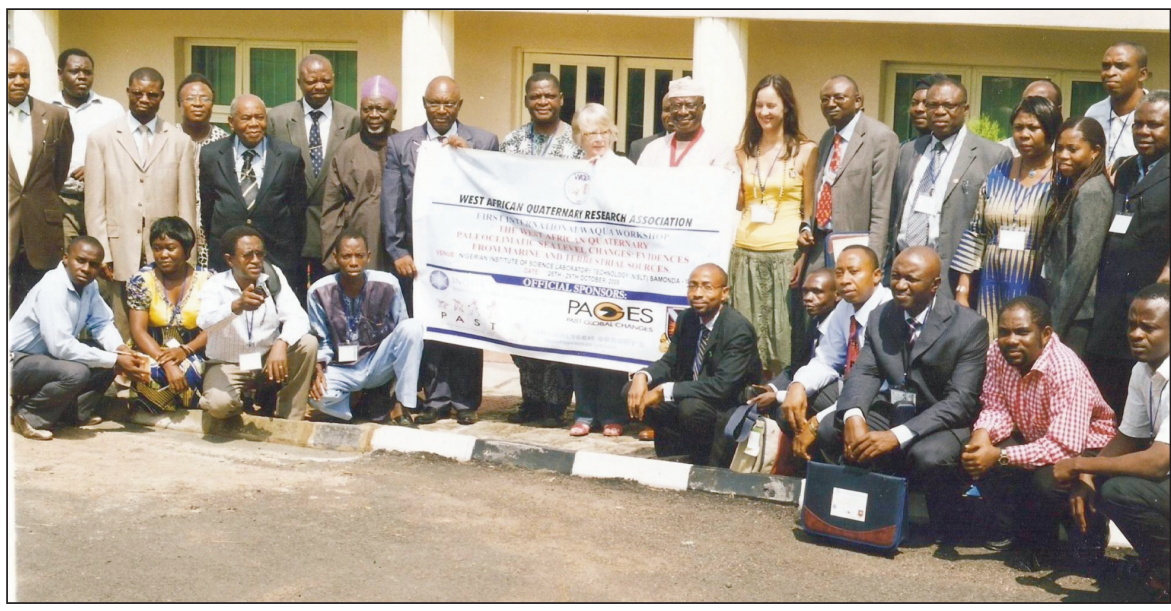

Figure 1: Participants of the 1st WAQUA international workshop.

more arid climate during the last glacial period. The data indicated that abrupt onsets of arid conditions in the West African Sahel co-occurred with cold North Atlantic sea surface temperatures during Heinrich surge events, which is explained by southward migration of the InterTropical Convergence Zone and its associated tropical rain belt by a few degrees latitude over West Africa. These results documented the occurrence of multi-millennial-scale droughts in the Sahel during the past 57 ka (see Ilham Bouimetarhan et al., 2009).

\section{Post-workshop meeting}

A general meeting was held immediately following the workshop sessions. The following actions were taken and decisions made:

- An interim committee was set up to run the affairs of WAQUA until a general election is conducted. Dr. Akaegbobi (Nigeria) and Dr. Yabi (Benin Republic) were nominated and approved as Chairman and Vice Chairman respectively. Other members include Mr. Ediang (Secretary), Prof. Anike and Dr. Mrs. Meludu.
- Four Working Groups were formed to develop topical research priorities: 1) Lake Sediments as Archives for Paleoclimatic Changes; 2) Coastal Sea Level Changes; 3) Ecosystem Changes and Human Livelihood; 4) Archeology and Paleontology. - The papers presented during the workshop will be prepared for publication in a special volume in Quaternary International.

- The next WAQUA workshop will be held in Cotonou, Republic of Benin, in 2010.

\section{Acknowledgements}

The organizers would like to thank the following sponsors for their support of this meeting: The International Union for Quaternary Research, PAGES, Paleontological Scientific Trust, and HalaalTech Quarrying and Construction Company Nigeria Limited.

\section{References}

Bouimetarhan, I., Dupont, L Schefuß, E Mollenhauer, G., Mulitza, S. Zonneveld, K., 2009: Palynological evidence for climatic and oceanic variability off NW Africa during the late Holocene, Quaternary Research, 72: 188-197.

Mohammed, M.U., Legesse, D., Gasse, F., Bonnefille, R., Lamb, H., Leng, M. and Lamb, A., 2004: Late Quaternary Climate Changes in The Horn of Africa. In: Battarbee, R., Gasse, F., Stickley, F. (Eds) Past climate variability through, Europe and Africa, Kluwer Academic Press.

\section{PAGES Calendar 2010}

(5) Australasia 2k Workshop: Towards data synthesis 31 May - 2 June 2010 - Melbourne, Australia http://www.pages-igbp.org/science/2k/aus2k/ aus $2 \mathrm{kmeeting} 2010 . \mathrm{html}$

\section{(5) PAGES Regional Workshop Japan}

5 - 6 June 2010 - Nagoya, Japan

http://www.pages-igbp.org/calendar/

\section{SCAR Open Science Conference: Witness to the past} and guide to the future

3- 6 Aug 2010 - Buenos Aires, Argentina

http://www.dna.gov.ar/scar2010/index.htm

\section{(2) Paleo-ocean acidification and carbon cycle perturbation events}

26 - 28 Aug 2010 - Catalina Island, USA

http://www.pages-igbp.org/calendar/ $10^{\text {th }}$ International Conference on Paleoceanography 29 Aug - 3 Sep 2010 - La Jolla, USA

http://icp10.ucsd.edu/

\author{
(3) $2^{\text {nd }}$ PAGES Global Monsoon Symposium \\ 13 - 15 Sep 2010 - Shanghai, China \\ http://www.pages-igbp.org/calendar/
}

(3) Regional Integration of human-environment
interactions: Climate change "hotspots"
13 - 15 Sep 2010 - Southampton, UK
http://www.pages-igbp.org/calendar/

(3) PAGES International Floodplain Lakes Workshop 16 - 19 Sep 2010 - Arkansas, USA

http://comp.uark.edu/ shausman/PAGESworkshop/floodplain. html 
The following articles are excerpts from the proceedings special issue of PAGES $1^{\text {st }}$ Young Scientists Meeting (July 2009), which are published in the open-access online journal IOP Conference Series: Earth and Environmental Science. For full articles visit the online proceedings special issue at http://iopscience.iop.org/1755-1315/9/1

Terrestrial $\mathrm{N}_{2} \mathrm{O} / \mathrm{NO}_{x}$ emissions during abrupt climate change

Mirjam Pfeiffer and Jed O. Kaplan

http://iopscience.iop.org/17551315/9/1/012001

$\mathrm{N}_{2} \mathrm{O}$ emitted by the terrestrial biosphere during abrupt climate change events could have amplified externally forced warming. In order to quantify the magnitude of change in emissions for the abrupt warming that occurred at the transition from Oldest Dryas to Bølling during the last deglaciation at a local scale, we combine high-resolution multiproxy records obtained from the Gerzensee site in Switzerland with a modeling approach using the ARVE-DGVM and a novel scheme for process-based simulations of terrestrial $\mathrm{N}_{2} \mathrm{O}$ and $\mathrm{NO}_{\mathrm{x}}$ emissions.

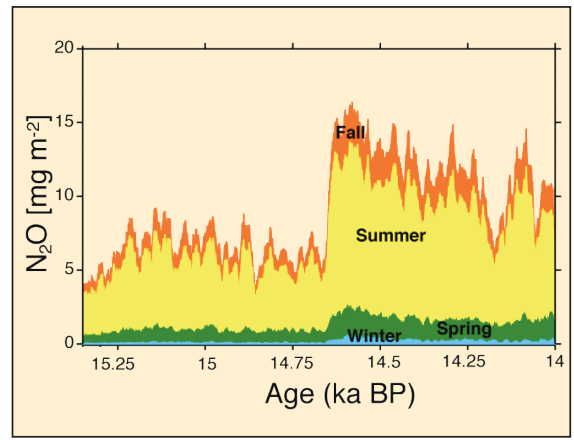

Simulated change in seasonal $\mathrm{N}_{2} \mathrm{O}$ emissions during the Oldest Dryas/Bølling transition at Gerzensee, Switzerland.

We apply a prescribed vegetation change derived from the pollen record as well as temperature and precipitation reconstructions derived from $\delta^{18} \mathrm{O}$ values in lake carbonates as model drivers. Our results show a pronounced increase in mean annual $\mathrm{N}_{2} \mathrm{O}$ and $\mathrm{NO}_{x}$ emissions for the time of the transition, with highest amounts generally being emitted during summer. While summertime emissions tend to be limited by soil moisture, temperature controls emissions during winter. For the time between 14.67 and 14.62 cal ka BP, our simulated $\mathrm{N}_{2} \mathrm{O}$ emissions show rates of increase as high as $1 \%$ per year, indicating that local reactions of emissions to changing climate could have been considerably faster than the atmospheric concentration changes observed in polar ice.

\section{Isotopes of nitrate: A proxy for changes in sources}

Meredith G. Hastings

http://iopscience.iop.org/17551315/9/1/012002

The nitrogen isotopic composition of nitrate has been suggested to contain information about the sources of nitrate. However, it has been difficult to prove this directly for several reasons: many records are a combination of nitrogen signals, not atmospheric nitrate deposition alone; after the nitrate is deposited, processing (biological, chemical, physical) can alter the original signal; and/or the isotopic signatures of nitrate sources are not well quantified. Atmospheric nitrate is the major sink of nitrogen oxides that are released into the atmosphere by both natural and manmade sources including lightning, soils, forest fires and fossil fuel combustion.

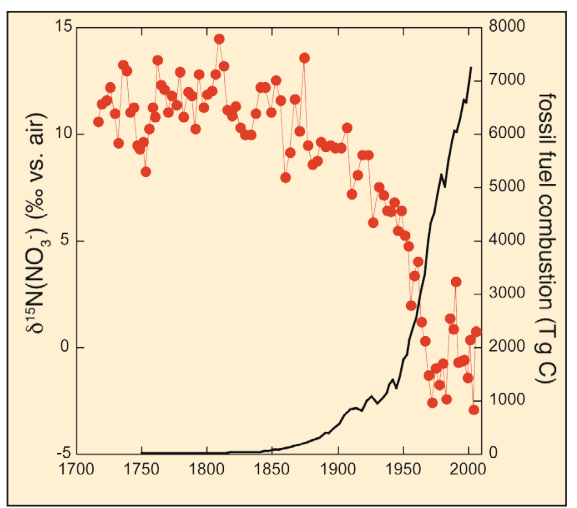

$\delta^{15} \mathrm{~N}$ of nitrate (red circles) from Greenland ice and estimates of fossil fuel combustion (black line; $h$ ttp:// cdiac.ornl.gov/trends/emis/tre_glob.html) (modified from Hastings et al., Science, 2009).

Results from a Greenland ice core show a clear change in the nitrogen isotopic composition of atmospheric nitrate $\left(\delta^{15} \mathrm{~N}\right)$ over the last 300 years, which is coherent with the rise in fossil fuel combustion, a major source of nitrogen oxides in the modern environment. There are several processes that can modify the isotopic signals captured in polar ice, however, we would not expect any of these processes to have changed significantly over the last 300 years. These results suggest an intriguing possibility that ice core records may reveal how natural sources of nitrate (lightning, biomass burning, biogenic processes in soils) have varied over time and how these variations in the atmosphere and biosphere are connected to changes in climate.

\section{Past coastal vegetation reveals millennial changes in sea level}

\section{Catalina González and Lydie M. Dupont}

http://iopscience.iop.org/17551315/9/1/012003

A Cariaco Basin pollen record shows the development of tropical coastal vegetation during Marine Isotope Stage 3 and gives insight into the timing of sealevel changes during Heinrich meltwater events. Rapid and abrupt expansions of salt marsh vegetation in northernmost South America were associated with the North Atlantic cold stadials encompassing Heinrich events. Intervals of salt marsh expansion have an internal plant community structure, which consists of a recurrent alternation of three different plant types. According to these observational results, soil development and salinity gradients

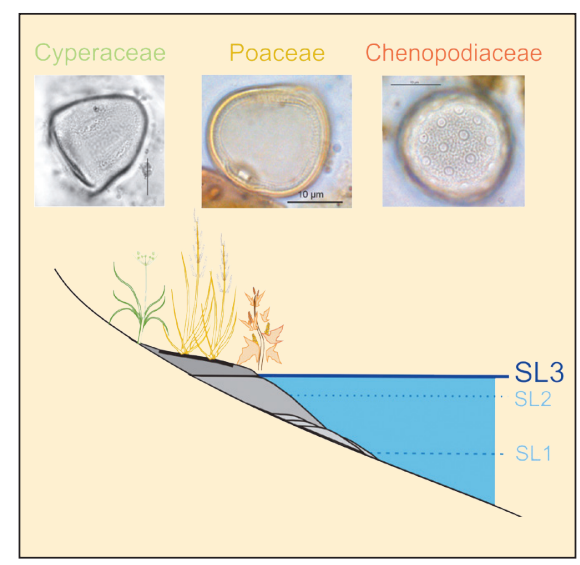

The alternation of different plant types provides independent evidence of changes in salinity and soil height, and thus allows for past sea level reconstructions.

are the main factors determining plant succession patterns, which are ultimately linked to regional sea-level and hydrological changes. Based on the interpretation of ecological preferences of individual plant types, we examined two contrasting interpretations of the pollen data, and 
concluded that during the onset of Heinrich events, sea-level might have risen synchronously with temperature changes over Antarctica.

\section{Have northern peatlands changed the Holocene global carbon cycle?}

YI Wang, N.T. Roulet, S. Frolking, L.A.

MYSAK, X. LIU AND Z. JIN

http://iopscience.iop.org/1755-

1315/9/1/012004

Because the estimated present-day carbon storage of Northern Peatlands (NP) is about $300-500$ petagram, and the NP has been subject to a slow but persistent growth over the Holocene epoch, it is desirable to include the NP in studies of Holocene carbon cycle dynamics. Here we use an Earth System Model of Intermediate Complexity to study the first-order effect of NP on global carbon cycle dynamics in the Holocene. We prescribe the reconstructed NP growth based on data obtained from numerous sites (located in Western Siberia, North America, and Finland) where peat accumulation records have been developed. Using an inverse method, we demonstrate that the longterm debates over potential source and/or sink of terrestrial ecosystem in the Holocene are clarified, and our results suggest that the primary carbon source for the changes (sinks) of atmospheric and terrestrial carbon is the ocean, presumably, due to the deep ocean sedimentation pump (the so-called alkalinity pump). This paper complements the study of Wang et al. (2009, Climate of the Past) by sensitivity tests using modified boundary conditions. Our paper does not consider the factors of anthropogenic land use and land cover change in the Holocene.

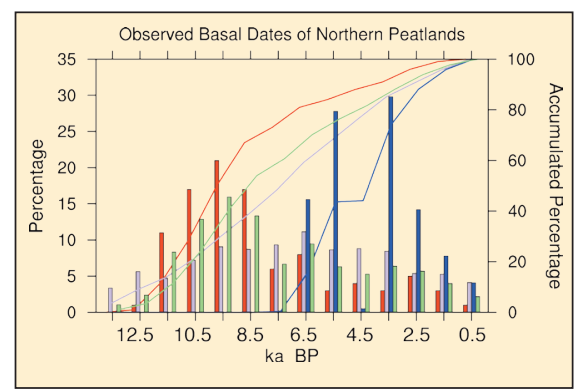

The observed basal date frequency of the NP for Western Siberia (red), North America (purple), Finland (blue), and total (green). Notice that the solid curves correspond to accumulative percentages of the observed basal date frequency with the same colour coding (right $Y$-axis).

\section{Ecosystem antiquity and turnover in eastern North America}

Yao Liu, S.T. Jackson, S. Brewer and J.W. WiLLIAMS

http://iopscience.iop.org/17551315/9/1/012005

We explored formal approaches to identifying and interpreting the antiquity and turnover of terrestrial ecosystems in eastern North America using pollen records. To assess ecosystem transitions with uncertainty, we applied cluster analyses, receiver-operating characteristic (ROC) analyses, and likelihood estimation of

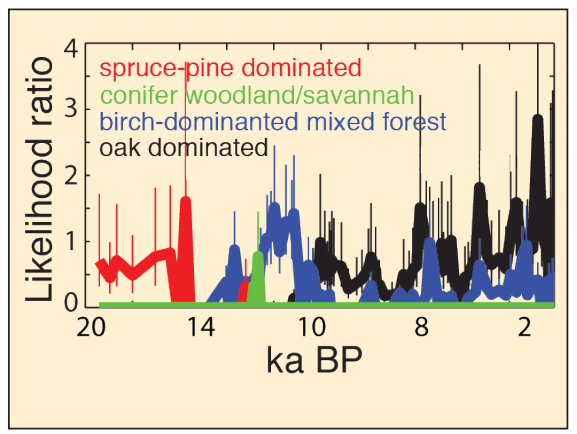

Likelihood of analogs to modern "pollen-ecosystems" for Tannersville Bog (Pennsylvania, USA) since the Last Glacial Maximum. Vertical bars show $50 \%$ confidence intervals.

ecosystem analog in a simple Bayesian model. These approaches provide better presentation and interpretation of the evolving nature of ecosystem transitions. Antiquity and turnover were assessed for 479 fossil pollen sites across eastern North America. Results of analyses on a pollen sequence from Tannersville Bog provide an illustration. We mapped antiquities for four ecosystems of eastern North America defined by their pollen assemblages. Approaches discussed in this study provided a vehicle for addressing further questions such as: What are the spatial and temporal patterns of emergence of specific ecosystems? Does ecosystem emergence occur simultaneously or time-transgressively? How are these processes governed by Holocene climate dynamics?

\section{Water availability from tree-rings in South-Central Chile}

\section{Rocio Urrutia, A. Lara, M.P. Peña and D.A. Christie}

http://iopscience.iop.org/17551315/9/1/012006

Based on reports of decreasing trends in precipitation over the last decades in South-Central Chile and an increasing demand for water, water availability can be considered a main limitation for the future development of the region. This fact is further aggravated by projected climatic scenarios that simulate warmer and drier regional climate towards the end of this century. This issue makes the study of past water availability crucial to understand what is going to occur with this resource in the future. This paper compares two water availability reconstructions in the Valdivian rainforest ecoregion. The treering reconstructions cover the last three centuries and correspond to precipitation in the northerly region and to streamflow in the southern region. Both reconstructions differ especially in their multidecadal variability, but match at higher frequency variations, such as at the bidecadal, decadal and annual scale. The decadal and bidecadal similarities between both regional reconstructions might be partially explained by common cyclic solar forcing, while the sub-decadal regional differences might reflect the differential effects of ENSO events at both locations and the stronger influence of the Antarctic Oscillation $(A A O)$ on the southern region. The current and projected increasing trend in the AAO could further enhance the observed decreasing streamflow in the southern area.

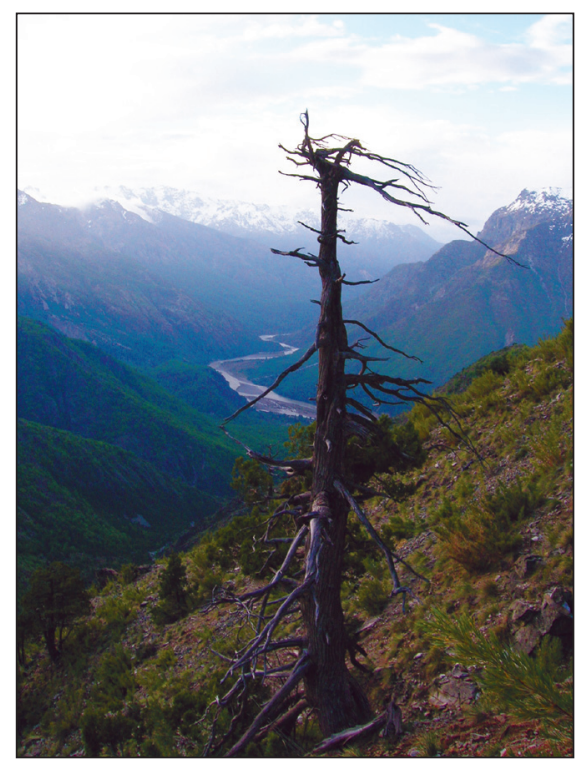

Austrocedrus chilensis, the tree-species used in the water availability reconstructions from Chile.

\section{Four proxies, one story: Precipitation in South America}

Cristiano M. Chiessi, S. Mulitza, J. Pätzold AND G. WefER

\section{http://iopscience.iop.org/1755-} 1315/9/1/012007

Southeastern South America is not only the most densely populated region on the continent but also a region that shows intensive agriculture, large-scale hydropower generation, and a rapidly growing demand for industrial and urban water supply-all activities that strongly rely on precipitation. Instrumental records in- 


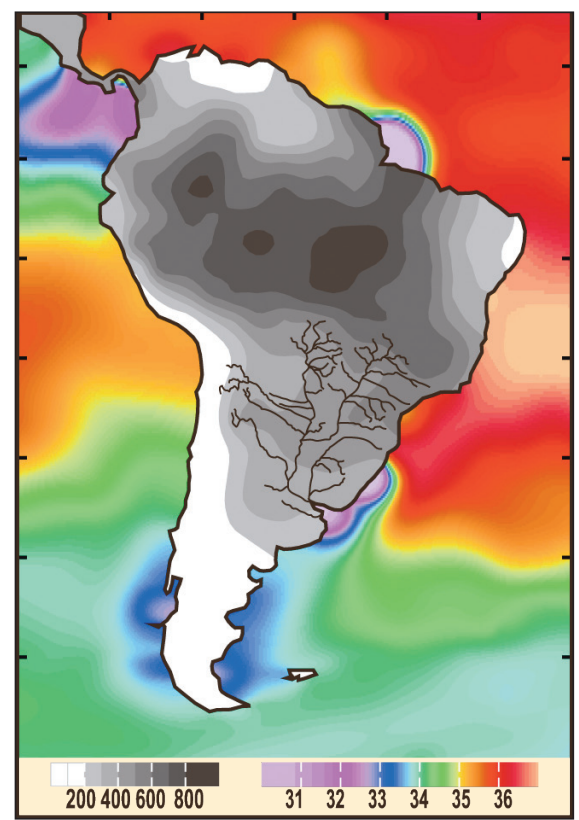

Map of S. America showing Southern Hemisphere summer (main rainy season in southeastern S. America) precipitation (gray shading, $\mathrm{mm}$ season ${ }^{-1}$ ), sea surface salinity (color shading, practical salinity units, psu), and the main drainages in southeastern S. America.

dicate marked changes in precipitation during the last decades raising concerns about potential negative impacts of future droughts and floods. But regional instrumental records are not long enough to allow detrending natural and anthropogenic components of precipitation variability, which are necessary to fully understand multidecadal climate oscillations. To accomplish this, one must rely on a comprehensive understanding of the natural variability of the climate system on a regional level. We explored how different proxies (i.e., stalagmite oxygen isotopic composition, pollen \%, charcoal accumulation rates, and bulk sediment elemental ratios) record Holocene precipitation variability over southeastern South America. We found generally a good agreement between the different records both on orbital and centennial timescales. Dry mid Holocene, and wet late Holocene, Younger Dryas and a period between $\sim 9.4$ and 8.12 cal ka BP seem to be pervasive features. Moreover, we show how proxy-specific sensitivity can greatly improve past precipitation reconstructions and our understanding of natural climate variability.

\section{A North Atlantic diatom tale of Heinrich Event 1}

IsABelle M. GIL, L.D. KeIGWin and F.G. ABRANTES

http://iopscience.iop.org/1755-

1315/9/1/012008

Heinrich event $1(\mathrm{H} 1)$ is a climate event resulting from the release of a huge volume of sea ice and icebergs into the North Atlantic from the Northern Hemisphere ice sheets. High-resolution diatom records from the Bermuda Rise (BR) and the Laurentian Fan (LF) reveal its impacts on North Atlantic surface circulation and its timing. The event is composed of three phases: The first two correspond to major pulses of Ice Rafted Debris (IRD) and the third phase relates to its immediate aftermath. At both sites, diatom abundances start to rise at $16.8 \mathrm{ka}$. This increase is marked by diatoms related to cold environments over the LF and brackish and fresh water diatom species over the BR. This last record implies icebergs migration to subtropical latitudes and nutrient-rich meltwater. During the second phase, both sites record maximum diatom abundances when sea-ice conditions are dominant over the LF and brackish-fresh water diatom contributions culminate over the BR. The last phase witnesses the persistence of low salinity water over the LF, while a decrease towards the disappearance of diatoms occurs over the BR. The disturbances induced by $\mathrm{H} 1$ appear to end 14.6 ka over the $B R$, while over the LF, the high diatom production persists until $14.1 \mathrm{ka}$ and the salinity anomaly until $13.8 \mathrm{ka}$.

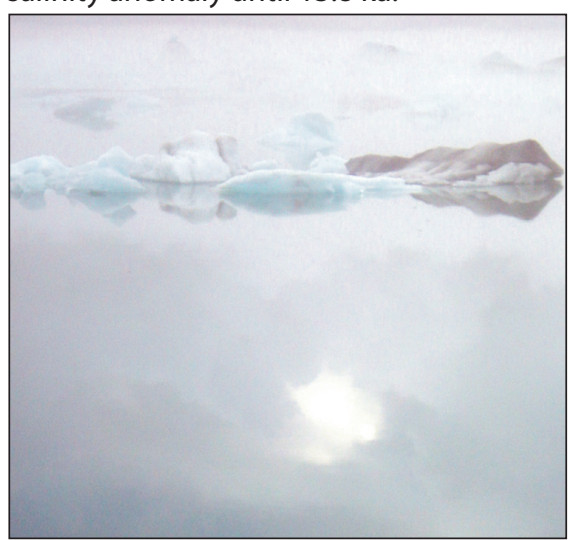

Drifting icebergs in the North Atlantic. Photo from http://WWW.morguefile.com/

\section{Spatial patterns in Central Asian climate and glaciers}

\section{Summer Rupper And Michele Koppes}

http://iopscience.iop.org/17551315/9/1/012009

Chronologic and geomorphologic studies of past glacial advances suggest that glacier response to climate change during the global last glacial maximum (LGM) was highly variable across Central Asia. This study focuses on reconciling the record of Central Asian glacier changes with the pattern of climate change around the region and testing the sensitivity of glaciers to changes in LGM boundary conditions. In particular, a suite of general circulation model simulations (GCMs) and a glacier equilibrium line altitude (ELA) model are compared to reconstructed glacier ad-

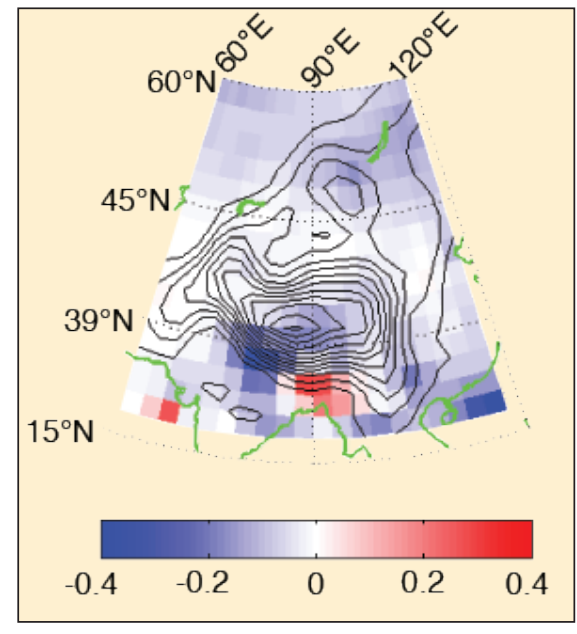

Change in mean annual precipitation $\left(m y^{-1}\right)$ for $21 \mathrm{ka}$ minus 0 ka, averaged across twelve GCM simulations.

vances from geomorphic data and used to test the sensitivity of Central Asian glaciers to simulated climate changes at the LGM. Results highlight temperature changes as being the most important influence on glacier ELA changes during the LGM. Additionally, temperature changes are relatively consistent across the suite of GCMs, with the exception of the southern Himalaya. Further research will necessarily need to focus on detailed analysis of the inter-model differences in temperature in the southern Himalaya and acquiring additional paleoclimate proxies in the region in order to further constrain the GCMs.

\section{Using past climates to explore El Niño dynamics}

\section{Steven J. Phipps and Jaclyn N. Brown}

http://iopscience.iop.org/17551315/9/1/012010

The paleoclimate record shows that there was an increase in the frequency and magnitude of El Niño events during the

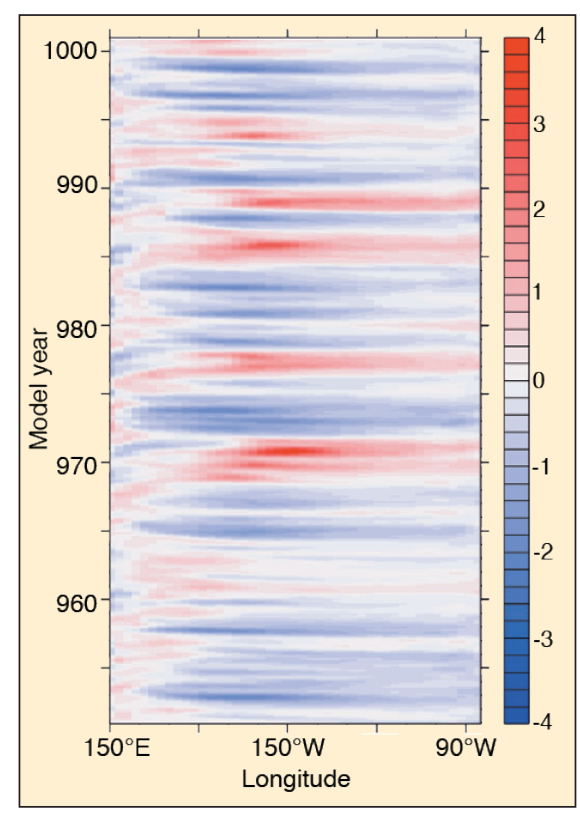

Sea surface temperature anomalies $\left({ }^{\circ} \mathrm{C}\right)$ at the equator show the propagation of simulated El Niño events within the model. 
Holocene. Exploring these changes, using both data and models, provides a means of understanding El Niño dynamics. We therefore use a climate system model to explore the role of the Earth's orbital geometry in driving changes in El Niño variability over the past $8 \mathrm{ka}$. In the early Holocene, we find that increased insolation over the Asian landmass results in an intensification of the Asian summer monsoon system. This causes a strengthening of the Walker Circulation over the Pacific Ocean, leading to an amplification of the easterly trade winds in the central and western Pacific. The stronger trade winds represent a barrier to the eastward propagation of westerly wind bursts, therefore inhibiting the onset of El Niño events. We find that orbitally driven insolation changes are able to explain changes in El Niño variability over the past $8 \mathrm{ka}$. The stability of the background state of the tropical Pacific has decreased over this period, creating conditions more favorable for the development of El Niño events.

\section{Holocene Mediterranean vegetation change: Links to land use?}

Pamela M. Collins, J.O. Kaplan and B.A.S.

\section{DaVIS}

http://iopscience.iop.org/1755-

1315/9/1/012011

The circum-Mediterranean region experiences a strongly seasonal climate with rainy winters and intense summertime drought, steep topography, and a multimillennial history of intensive human land use, all of which make its soils vulnerable to erosion. Indeed, historical and stratigraphic records document severe and long-term soil erosion in several locations in the Mediterranean. Additionally, a forest-to-scrub transition in Mediterranean vegetation occurred between the midHolocene (6 ka BP) and the present. Our study contributes to the open debate on the causes of this shift in vegetation cover by asking the question: Could human-induced soil erosion have altered the land's capacity to support different vegetation

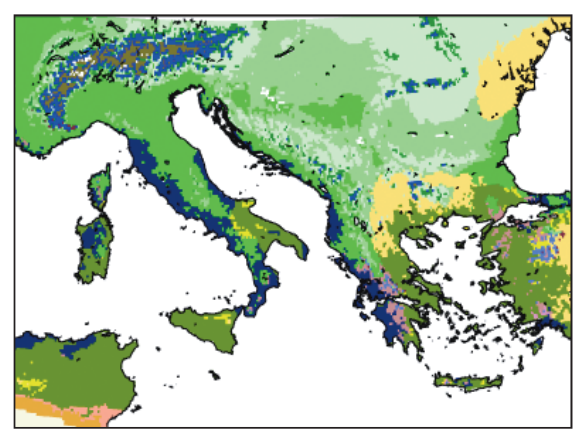

Modeled potential natural vegetation. How might this picture change if the land had never been farmed or deforested? types? We test the sensitivity of large-scale vegetation patterns to changes in soil physical properties such as depth, content of coarse fragments, and organic matter content, using the Mediterranean region as a case study. We find that while simulated biomes are sensitive to changes in some soil physical properties at some locations, threshold values for soil change to affect vegetation are very high. Additional work is planned to analyze the role that other soil physical properties and climate change could have played in influencing Holocene land cover change in the Mediterranean and to improve model representations of relevant processes.

\section{Nearshore sedimentation in Chesapeake Bay}

\section{Cindy M. Palinkas, E.W. Koch and N. Barth}

http://iopscience.iop.org/17551315/9/1/012012

Sediment characteristics, especially grain size and organic content, in nearshore Chesapeake Bay environments show significant temporal and spatial variability. This can impact benthic organisms, particularly submersed aquatic vegetation (SAV), which are important components of the ecosystem. In order to better understand how these changes are reflected in the stratigraphic record, the radiochemical and textural properties of sediment at

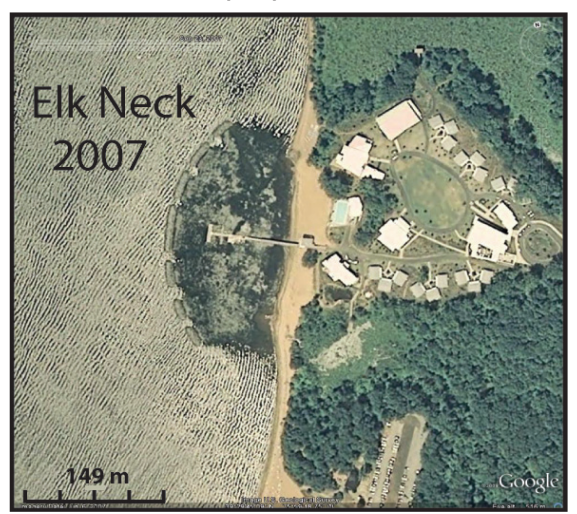

Breakwaters reduce inshore physical energy (wavy lines), increasing fine sediment accumulation that can negatively affect submersed aquatic vegetation (dark patches)

four sites are examined. Fine and organic material are observed to increase at some nearshore locations, whereas others have experienced a shift toward lower-organic, coarser sediments. These changes are likely related to local variations in sedimentary processes. Other, more recent, perturbations are due to breakwater construction, which can trap fine and organic material in the protected area. Accumulation rates inshore of the breakwater are 2-4 times higher than in adjacent exposed locations and this change is coincident with breakwater construction. Thus, because sedimentary processes vary according to physical setting, local trends must be discerned to determine whether a given site may be suitable for SAV restoration.

\section{Sea level rise intensifies saltwater ingressions to coastal lakes}

MıchAL WosZCZYK, W. SPYCHALSKI, M. LUTYŃSKA AND R. CIEŚLIŃSKI

http://iopscience.iop.org/17551315/9/1/012013

The Baltic Sea level along the Polish coast has risen since at least the mid $19^{\text {th }}$ century and during the last few decades an accelerated rate was observed. The rise in mean sea level was accompanied by an increase in the frequency of storm surges, which in turn, are one of the main driving forces for saltwater ingressions to freshwater coastal lakes and groundwater aquifers.

From hydrochemical research of coastal Lake Sarbsko it emerges that seawater can be pumped into the lake beneath the sand barrier during winter storm surges when a gradient in hydrostatic pressure develops between the seaward and landward sides of the beach barrier. The evidence comes from increased pore water salinity in the lake at sites lo-

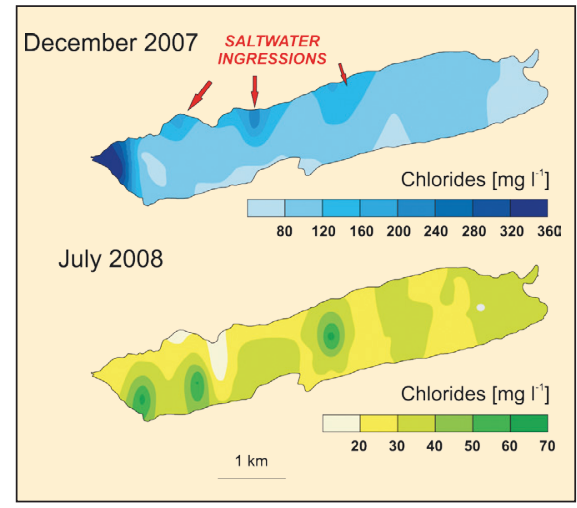

Distribution of chlorides in pore waters from the $5-\mathrm{cm}$ top-layer of surface sediments of Lake Sarbsko.

cated along the barrier head when the sea level is at its yearly maximum (Figure). On the other hand, distinctly decreased storm activity during summer months resulted in a significant drop in pore water salinity. Moreover, a paleoecological study of a lake sediment core taken in the salt-water affected section of Lake Sarbsko revealed that in the last few decades, the intensity of saline groundwater supply to the lake has distinctly increased. 


\section{Mid-late Holocene environments of Agua Buena, Argentina}

Diego Navarro, A. Mehl, M.A. Zarate and M.M. PAEZ

http://iopscience.iop.org/1755-

1315/9/1/012014

In southern South America the acquisition of high-quality Holocene paleoclimate data is a priority due to the paucity of complete, continuous and well-dated records. We report preliminary results from a combined sedimentological and palynological study of an alluvial fan sequence and laterally connected sedimentary deposits at Agua Buena, east of the Andes. The main geomorphological units of the area were identified and mapped based

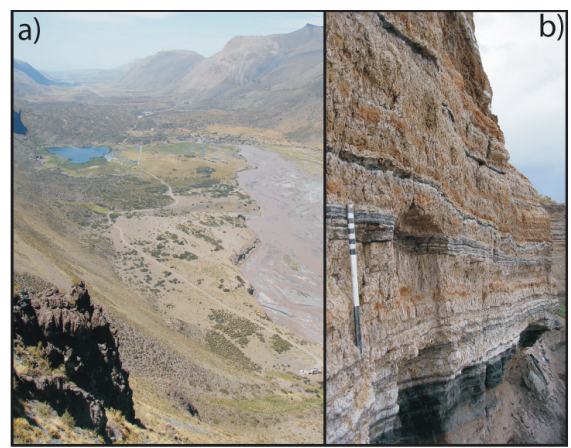

a) Atuel river upper basin landscape and $\boldsymbol{b}$ ) one of the stratigraphic profiles analized.

on satellite image analysis and multiple field surveys. The sedimentological and pollen results allowed us to reconstruct the development of some environments. The Agua Buena record corresponds to the distal facies of a large alluvial fan that has been active since ca. $4.1 \mathrm{ka}$. Organicrich levels were formed during the development of wetlands ("vegas") dominated by Cyperaceae, Juncaceae and Poaceae. These highly productive environments with almost permanent water saturation were important between 4.1 and $2.8 \mathrm{cal} \mathrm{ka}$ $\mathrm{BP}$, indicating relatively stable conditions. After $2.8 \mathrm{cal} \mathrm{ka} \mathrm{BP}$, the organic content was comparatively lower with increasing sedimentation rates that are indicative of higher fluvial discharges. This information is fundamental to interpret pollen and charcoal records in the area and to evaluate their representativeness and potential to reconstruct past local and regional vegetation.

\section{${ }^{230} \mathrm{Th} / \mathrm{U}$-dating of a very young, low U stalagmite from Cuba}

Claudia Fensterer, D. Scholz, D. Hoffmann, A. Mangini and J.M. Pajón

http://iopscience.iop.org/17551315/9/1/012015

A key aspect of unraveling past climate variability, identifying potential forcing mechanisms and quantifying and predicting future climate change is the accurate determination of the timing of the changes. This is especially important in order to obtain information about the phasing of climate change and about the links between climate changes in different regions. Speleothems can be accurately and precisely dated using uranium (U)-

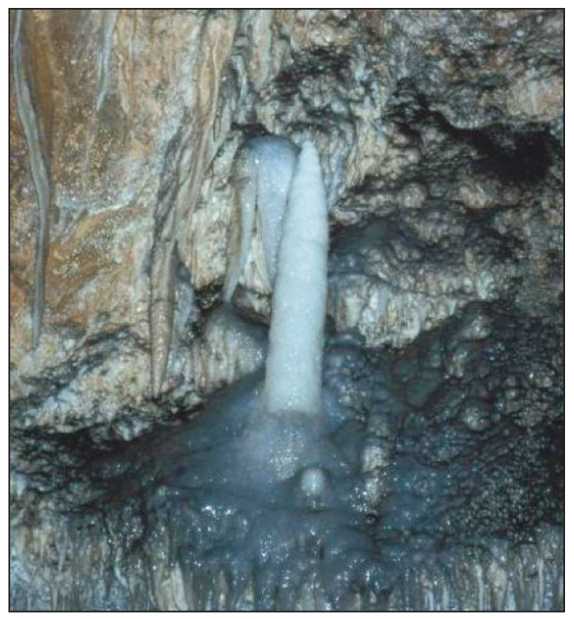

Dated stalagmite "Cuba Grande" (720 mm long) inside the cave in western Cuba. Photo: Paolo Terzan

series disequilibrium methods and, thus, provide an important archive for highresolution climate reconstructions. However, dating of very young samples with low uranium content is difficult, especially since site-specific detrital contamination may have a significant influence on the ages obtained for such samples. We have dated a late Holocene stalagmite from Cuba using two different mass spectrometric methods (TIMS and MC-ICPMS). The stalagmite grew within the last 1.4 ka and has extremely low ${ }^{230}$ Thorium (Th) concentrations (between 0.01 and 0.06 $\mathrm{pg} / \mathrm{g}$ ). The effect of potential contamination by detrital initial ${ }^{230} \mathrm{Th}$ is large. Using an age model based on the ${ }^{230} \mathrm{Th} / \mathrm{U}$ ages determined on samples with low or negligible ${ }^{232} \mathrm{Th}$ concentration, we find that the $\left({ }^{238} \mathrm{U} /{ }^{232} \mathrm{Th}\right)$ activity ratio of the detrital phase is an order of magnitude larger than the usually applied bulk earth value indicating the importance of an accurately determined correction factor.

This project is part of the DFG Program INTERDYNAMIK.

\section{Quercus macrocarpa - providing multiple proxies in the Prairies}

Jessica R. Vanstone and D.J. Sauchyn

http://iopscience.iop.org/17551315/9/1/012016

Comparisons between patterns of annual layers of Quercus tree-rings and climate records suggest that these parameters may serve as potential climate proxies, where-

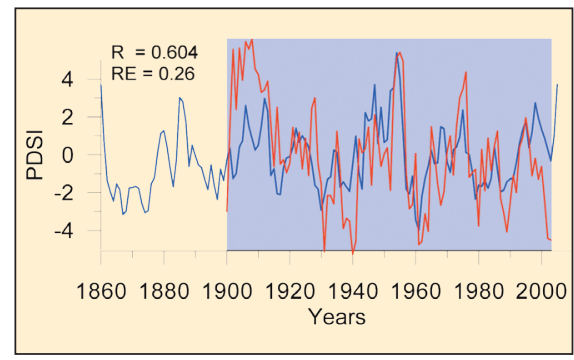

Latewood reconstruction of Palmer Drought Severity Index (blue line) compared to observed (red line) from near Estevan (Saskatchewan) for the period 1860 - 2005. Blue shading represents the calibration period. by climatic factors influence the size and density of vessels within the ring, either by acting as a limiting factor for growth or through fine tuning of the wood structure to environmental (water) conditions. This study assesses the potential of $Q$. macrocarpa to provide multiple dendroclimatic proxies for the Canadian Prairies, by investigating growth responses of annual, early- and late-wood widths to regional climate variability. Results indicate that ring width chronologies from southeastern Saskatchewan capture regional signals related to moisture and drought conditions. Correlations suggest that latewood widths are more representative of annual ring-widths, than are earlywood widths, and are the best proxy of seasonal fluctuations in climate. Regression models that include latewood widths were thus able to account for more variance in the Palmer Drought Severity Index (PDSI) than when annual ring-widths were used as the only proxy. This study demonstrates that Q. macrocarpa can provide multiple dendroclimatic proxies for investigating large scale climatic fluctuations at annual and sub-annual timescales and is novel in terms of sub-annual analysis of tree-rings in a region that previously lacked dendrochronological research.

\section{Teberda River runoff variability based on tree rings}

Vladimir V. Matskovsky, E.A. Dolgova and O.N. Solomina

http://iopscience.iop.org/17551315/9/1/012017

We use seven tree-ring chronologies from high elevation sites to reconstruct Teberda River (Northern Caucasus, Russia) runoff for May, July and August. Teberda River is $60 \mathrm{~km}$ long with the watershed surface equal to $1080 \mathrm{~km}^{2}$, the mean watershed altitude is $2210 \mathrm{~m}$. 56\% of Teberda River's runoff is provided by snow and ice melt. Six chronologies were developed from Pinus sylvestris and one from Abies nordmanniana. We used principal component regression and all possible combinations of seven predictors were tried to get the best 
result on the cross-validation. Although we didn't create annually resolved quantitative reconstructions of Teberda River runoff because of insufficient correlation between tree growth and hydrological parameters, our smoothed reconstruction of May, July and August runoff can tell much about low-frequency variations of these parameters. Two of three reconstructions showed high wavelet coherence with instrumental data on decadal timescales and were analyzed for spectrum stability. Minima of moving trends at the end of the reconstructions along with weakening of decadal cycles may be a marker of significant change of Teberda River hydrological regime during the second half of the $20^{\text {th }}$ century.

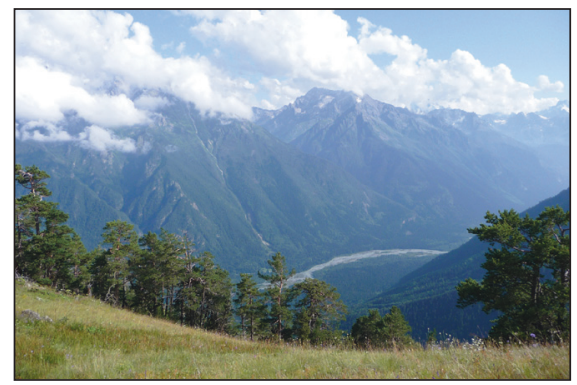

The view of Teberda River from the Mt. Khatipara timberline.

\section{Variability of the $\mathrm{Mg} / \mathrm{Ca}$ ratio in planktonic foraminifers}

Jennifer Fehrenbacher and Pamela Martin

http://iopscience.iop.org/1755-

1315/9/1/012018

The Magnesium/Calcium (Mg/Ca) ratio in planktonic foraminifers is a wellestablished and widely used proxy for reconstructing sea surface and thermocline temperatures in the past. The proxy is complicated by dissolution on the sea
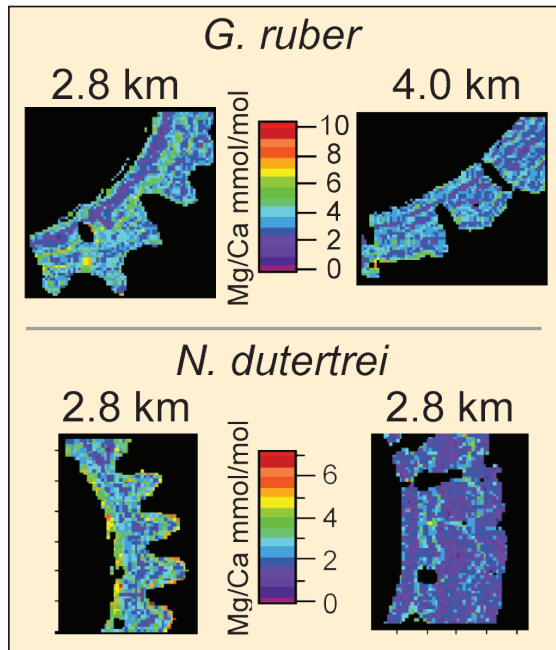

Sample electron microprobe $\mathrm{Mg} / \mathrm{Ca}$ image maps of G. ruber from a shallow and deep core and N. dutertrei both from the shallow core. The G. ruber images highlight the variable nature of the $\mathrm{Mg} / \mathrm{C}$ a ratio within this species and how dissolution alters its variability. The $\mathrm{N}$. dutertrei images reveal the complex $\mathrm{Mg} / \mathrm{Ca}$ variability of this species, which may be dependent on shell floor, which results in an underestimation of past temperatures. Though the dissolution effect is well documented, questions remain in understanding how dissolution alters shell $\mathrm{Mg} / \mathrm{Ca}$ variability. How does dissolution lower the $\mathrm{Mg} / \mathrm{Ca}$ ratio? Is there preferential dissolution of higher Mg calcite? We sought to answer some of these questions by generating electron microprobe images of core top samples of planktonic foraminifera obtained from shallow and deep cores from the western tropical Atlantic. Both cores are bathed in North Atlantic Deep Water and dissolution is driven by depth (e.g., the pressure effect on calcite). We assume deeper core samples experienced more intense dissolution. $\mathrm{Mg} / \mathrm{Ca}$ ratio image maps were generated for two species widely used in temperature reconstructions, G. ruber and $N$. dutertrei. Images and histograms of the $\mathrm{Mg} / \mathrm{Ca}$ ratio of $\mathrm{G}$. ruber reveal a preferential decrease in high $\mathrm{Mg} / \mathrm{Ca}$ calcite. Preliminary results of $N$. dutertrei suggest the variability within this species is dependent upon the surface crystallinity, thus, determining the effect of dissolution on $N$. dutertrei was difficult to ascertain.

\section{G. inflata Mg/Ca calibrations and temperature reconstructions for Termination I}

\section{Elizabeth J. Farmer, M.R. Chapman and J.E.} ANDREWS

http://iopscience.iop.org/17551315/9/1/012019

$\mathrm{Mg} / \mathrm{Ca}$ ratios from planktonic foraminifers are now widely used as a proxy for ocean temperature. Paired $\mathrm{Mg} / \mathrm{Ca}$ and $\delta^{18} \mathrm{O}$ analyses from a range of species with different depth habitats allow a profile of water column properties to be built up for a specific location over time. However, Mg incorporation varies significantly between species and locations and such detailed multi-species reconstructions require accurate species-specific, and even regionspecific Mg/Ca-temperature calibrations.

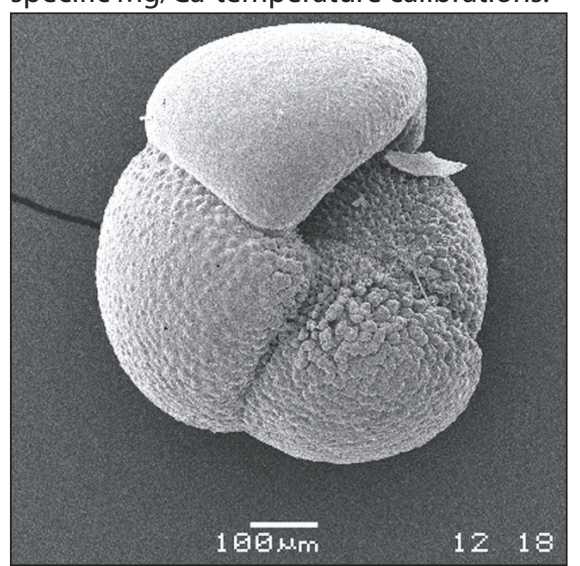

Scanning electron microscope image of the thermocline-dwelling planktonic foraminifer $\mathrm{G}$. inflata.
We present preliminary results based on a new $\mathrm{Mg} / \mathrm{Ca}$ calibration $(\mathrm{Mg} / \mathrm{Ca}=$ $0.92 \mathrm{e}^{0.039 T}$ ) for the thermocline-dwelling foraminifer Globorotalia inflata, derived using a suite of North Atlantic coretops. We compare the performance of this new calibration with existing ones, using the downcore $\mathrm{Mg} / \mathrm{Ca}$ record from core SU90$03\left(40^{\circ} \mathrm{N}, 32^{\circ} \mathrm{W}\right)$ over the Holocene and the larger climatic shift of Termination I. The new calibration successfully reconstructs present day conditions at the core site and appears to better estimate the cooler temperatures at the lower limit of $G$. inflata's temperature range. There are significant differences between the calibrations, highlighting how calibration choice affects both absolute temperatures and the amplitude of events, particularly over large-scale climatic transitions. This has major implications for errors associated with the reconstruction of seawater $\delta^{18} \mathrm{O} /$ paleosalinity and surface temperature gradients based on $\mathrm{Mg} / \mathrm{Ca}$ records from multiple foraminiferal species.

\section{G. truncatulinoides depth migration over the Holocene}

\section{Caroline Cléroux and Jean Lynch-Stieglitz}

http://iopscience.iop.org/17551315/9/1/012020

By comparing the oxygen isotopic composition $\left(\delta^{18} \mathrm{O}\right)$ of surface dwelling and benthic foraminifers from cores along a depth transect to $G$. truncatulinoides $\delta^{18} \mathrm{O}$ in one of the deeper cores, we calculated the calcification depth of this species over the past $12 \mathrm{ka}$ in the Florida Straits. A significantly different calcification depth between 8-10 ka and the late Holocene has been found and the signal is observed in two other locations over the western North Atlantic American continental margin. The cause of this migration is unknown and is a hitch to the assumption that deepdwelling foraminifera calcify at constant depth level. We now present new Mg/Ca ratio and stable isotopic measurements on G. truncatulinoides and G. crassaformis

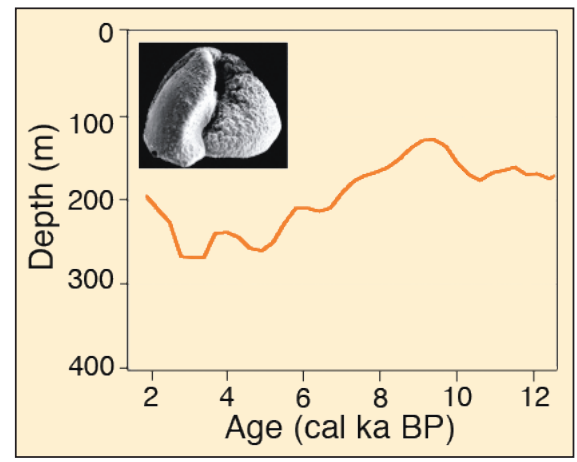

Picture and calcification depth of G. truncatulinoides in the Florida Strait for the last $12 \mathrm{ka}$. 
and a preliminary interpretation to understand the cause of the migration of $G$. truncatulinoides. We show that subsurface temperature and salinity did not change significantly suggesting that they are not the cause of the migration. However, carbon isotopic data $\left(\delta^{13} \mathrm{C}\right)$ seem to indicate changes in nutrients and/or productivity and provide the best hypothesis for the observed calcification depth change.

\section{Monthly Holocene temperature variability from Caribbean corals}

Cyril Giry, T. Felis, S. Scheffers and C. Fensterer

http://iopscience.iop.org/1755-

1315/9/1/012021

As new high-resolution paleoclimate records emerge from various archives, it becomes progressively evident that fluctuations in Holocene tropical climate were larger than previously considered. While orbitally-induced insolation changes control sea surface temperature (SST) variations on millennial timescales, the tropical Atlantic Ocean exhibits prominent

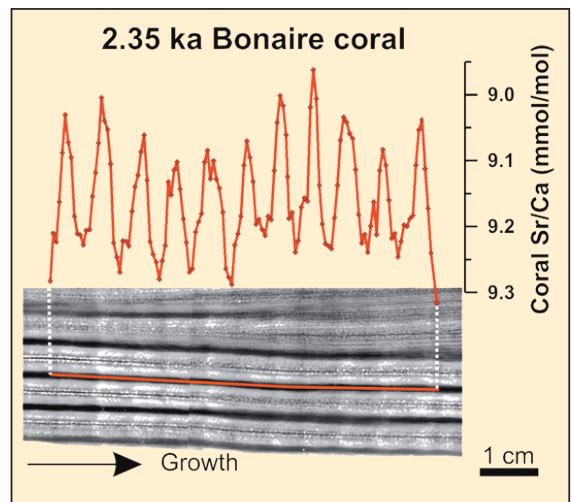

Monthly-resolved Sr/Ca record of a fossil Diploria strigosa coral from Bonaire. The sampling transect along the dense thecal wall is indicated on the X-radiograph (red line).

interannual to interdecadal SST variability that modulates the strength of the trade winds and influences the distribution and intensity of rainfall over the surrounding landmasses. We used Strontium/Calcium ( $\mathrm{Sr} / \mathrm{Ca}$ ) variations in annually-banded fossil corals (Diploria strigosa) from coastal deposits on Bonaire (Southern Caribbean Sea) to reconstruct seasonal and interannual to interdecadal SST variability at monthly resolution.

A 40-year-long monthly-resolved coral Sr/Ca record from $2.35 \mathrm{ka}$ BP (U-series dating) exhibits clear seasonal cycles and pronounced interannual variability at periods of 6-7 years. Our investigations reveal that the Sr/Ca SST proxy is not influenced by diagenetic alteration of the skeleton or skeletal growth rate. As tropical Atlantic SST variability on these timescales is influenced by the competing influence of nat- ural modes of ocean/atmosphere variability, longer records of multiple fossil corals will provide estimates on the range of seasonal and interannual to interdecadal SST variability in the Southern Caribbean Sea during key periods of the Holocene.

This project is part of the DFG Program INTERDYNAMIK.

\section{Forward modeling cave dripwater isotopes}

\section{Sarah A Truebe, T.R. Ault and J.E. Cole}

http://iopscience.iop.org/17551315/9/1/012021

Speleothem oxygen isotope records from arid regions are often interpreted as indicators of the total amount and/or seasonal balance of precipitation. We address the possible influence of in situ processes such as groundwater storage and mixing

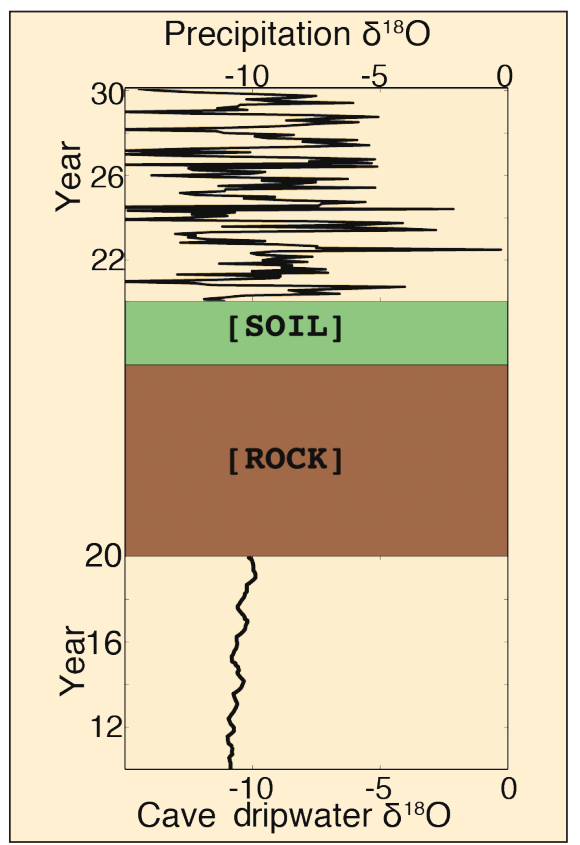

Precipitation $\delta^{18} \mathrm{O}$ input (top) and model output dripwater $\delta^{18} \mathrm{O}$ (bottom). Although our idealized precipitation input has no statistically significant variance on timescales longer than the seasonal cycle, modelsimulated subsurface storage and mixing can generate substantial decadal to multi-decadal variability. on speleothem $\delta^{18} \mathrm{O}$ values by simulating surface-to-cave moisture flux with a twolayer soil/rock model. Observations indicate that dripwater $\delta^{18} \mathrm{O}$ values are most comparable to winter precipitation values. However, using modern climate data to drive our model, we show that seasonality and duration of the regional summer monsoon can affect how much summer precipitation reaches the cave. We then use randomly generated data with the same statistical distribution as actual climate data to drive our model. When graphed as frequency spectra, these "model" $\delta^{18} \mathrm{O}$ series exhibit a high degree of variance at decadal to multidecadal frequencies, despite being driven by synthetic data that includes only a seasonal cycle. This suggests that some background level of variance in speleothem $\delta^{18} \mathrm{O}$ records could be due to nonclimatic processes, such as subsurface water storage and mixing. Interpreting climatic vs nonclimatic controls on speleothem $\delta^{18} \mathrm{O}$ variability could be achieved by replicating records from different caves or from monitoring modern cave systems to understand the influence of in situ processes.

\section{Speleothem $\delta^{18} \mathrm{O}$ and paleoprecipitation in Asia}

\section{Jung-Eun Lee and Abigail L. Swann}

http://iopscience.iop.org/17551315/9/1/012021

Oxygen isotope measurements from speleothems have been used to infer past hydrological cycles because the isotopic composition of precipitation is observed to decrease with increasing precipitation rates over low latitude coastal and island stations (the "amount effect"). Here, we show that local precipitation amount can be inferred from the differences in oxygen isotopic composition if the measurement site is in a subtropical coastal region where water vapor is transported directly from the ocean. Our work indicates that sites further inland may not be suitable for studying the changes in local precipitation amount but still reflect the combined changes of precipitation amount and changes in vapor transport pattern. We have shown that Hulu Cave is a reasonable site to interpret precipitation from oxygen isotopes in precipitation $\left(\delta^{18} \mathrm{O}_{\mathrm{p}}\right)$ : the estimated precipitation difference between present-day and the Last Glacial Maximum (LGM) from the measured $\delta^{18} \mathrm{O}_{\mathrm{p}}$ difference (1 2\%o) would be $0.8-2.2 \mathrm{~mm} /$ day (drier during the LGM) assuming our model simulates evapotranspiration reasonably well at this site.

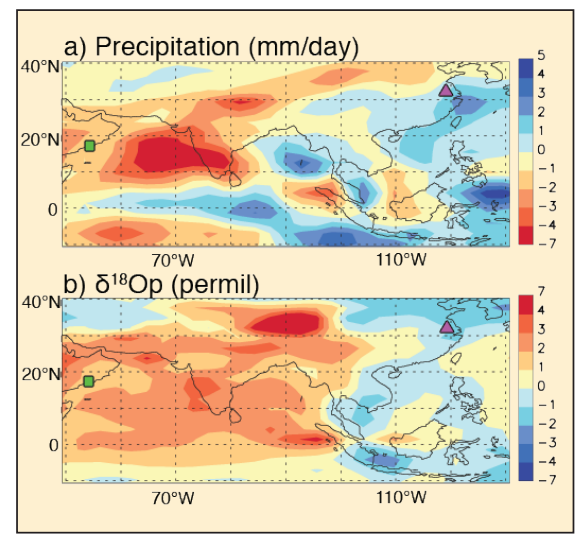

The differences in $(\boldsymbol{a})$ precipitation and $(\boldsymbol{b}) \delta^{18} \mathrm{O}$ between the LGM and present. The triangle and square denote the location of the Hulu Cave and Qunf Cave, respectively. 
The area of Hungary is dominated by Cenozoic sedimentary formations. However, karst regions built up by Mesozoic limestones are also important, containing extensive cave systems (like the Aggtelek Caves listed as a World Heritage). Hungary also has the biggest lake of Central Europe, Lake Balaton, which started to form in the late Pleistocene. Thus, paleoclimate research has been conducted in Hungary in various fields, ranging from major mass extinctions (Permian-Triassic and Triassic-Jurassic) to sedimentological and paleobotanic studies on Quaternary deposits and to paleohydrology. Classical investigations on sedimentary features and paleontology-paleobotany have mainly been done by individual researchers and small research groups at the Hungarian Geological Institute, the Hungarian Natural History Museum, the Eötvös Loránd University of Budapest (hosting also the Geological Research Group of the Hungarian Academy of Sciences and a new tree-ring laboratory) and the University of Szeged. Meteorologist researchers of the Eötvös Loránd University and the Hungarian Meteorological Service deal with climate modelling with special emphasis on future climate scenarios. A large interdisciplinary project summarizing state-of-art knowledge of local effects of climate change and possible future scenarios was conducted in recent years.

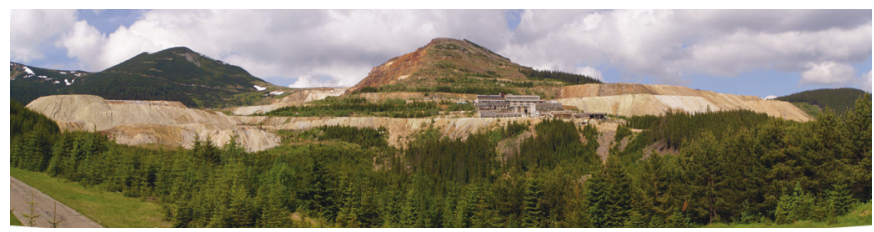

Recent analytical developments at the Institute for Geochemical Research (IGCR), Hungarian Academy of Sciences, has enabled Hungary to launch high-resolution geochemical studies on travertines, speleothems, molluscs, soils, tree rings and cave ice deposits. In order to co-ordinate paleoclimate-related geochemical research both within the Institute and in Hungary, the GEOCHEMISTRY and PALEOCLIMATE Research Group was established at the IGCR in 2006.

\section{Funding}

The research projects are mainly subsidized by the Hungarian National Research Fund, however, financial support has also been provided by the Ministry of Environment and Water.

\section{National PAGES Contact}

- Attila Demeny (Speleothems, sediments)

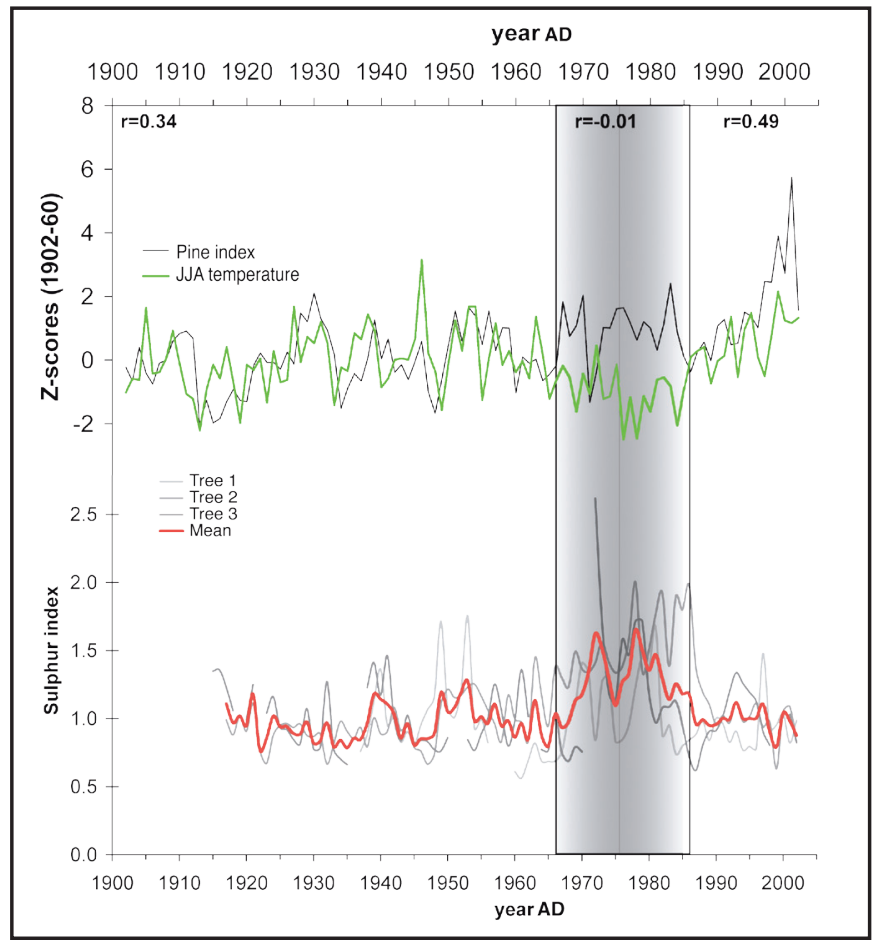

Tree rings not only reflect temperature and precipitation amount, but can also be used to detect changes in environmental chemistry. Tree ring samples studied in the course of the MILLENNIUM project show changes in sulphur content due to local mine activities in Romania (Kern et al., 2009, Dendrochronologia 27, 121-128). 


\section{national PA(SES Spain}

PAST GLOBAL CHANGES

The Spanish PAGES Committee was created in 1996, and co-ordinated by the Spanish IGBP Committee, which is endorsed by the Ministry of Innovation and Science. Spanish PAGES-related science is undertaken by over 40 research groups working on paleoenvironmental studies, located at Universities (70\%), CSIC, the Spanish Council for Research (20\%), and other public and private research institutions (10\%). PAGES-Spain has also strong links with the Spanish Committee for Research in Global Change (CEICAG), created in 2004. Over the last decades, PAGES Spanish-funded research has focused on the reconstruction of climatic and hydrological records, using a wide range of techniques and archives from terrestrial (fluvial, limnological, dendro, speleothems), coastal and marine sites, and from documentary sources (historical records). PAGES-Spain has also promoted links with research groups developing climate and paleohydrological models to allow further quantitative and mechanistical understanding of past global changes.

\section{Internationally funded projects}

PAGES-Spain scientists are involved in several multinational projects funded by the European Union, and other international programs.

Examples of key projects are:

- GEOCLINMAR - Geomorphological evolution of coastal environments

- MILLENNIUM - European climate of the last millennium

- Past4Future - towards reconstructing abrupt climate changes during interglacials

\section{Spanish-funded projects}

In Spain, research funding is provided by the Ministry of Innovation and Science, as well as by research programs of Regional Autonomous Governments. Examples of key projects are:

- FLOOD-MED - Flood hazards in Mediterranean rivers

- CALIBRE - Rapid climate changes in the Iberian Peninsula based on proxy calibration

- CIMERA - Linking Iberian Climates with the Atlantic Meridional Overturning Circulation

- GEOCLIMED - Geomorphological analysis of marine and terrestrial quaternary sequences from the Mediterranean Spanish littoral

- FluVAlps - Fluvial variability in the Alps during the last 3,000 years

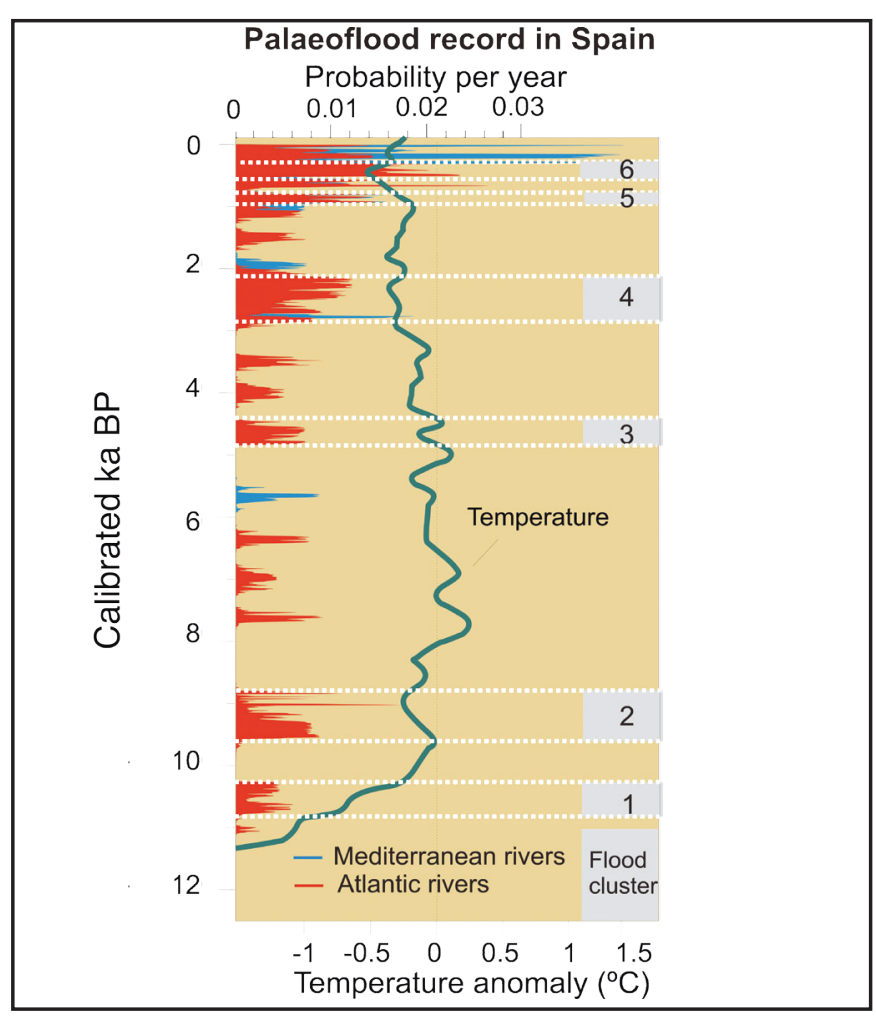

Summed probability for the radiocarbon dating from slackwater flood deposits in Spanish rivers, and periods of main dating clusters (FLOOD-MED Project).

\section{Spanish PAGES National Committee}

- Gerardo Benito (Fluvial records)

- Cari Zazo (Coastal records)

- Antoni Rosell (Marine records)

- Blas Valero Garcés (Paleolimnological records)

- Mariano Barriendos (Documentary records) 
- Inside PAGES

- New on the PAGES bookshelf

- PAGES calendar

- A taste of the YSM proceedings issue

- National PAGES

\section{Special Section: Peatlands: Paleoenvironments and Carbon Dynamics}

\section{Editorial:}

- Peatlands: Paleoenvironments and Carbon Dynamics

\section{Science Highlights:}

- Peatland archives of late-Holocene climate change in northern Europe

F.M. Chambers, J.R.G. Daniell and ACCROTELM Members

- Using peatland archives to test paleoclimate hypotheses

R.K. Booth, S.T. Jackson and M. Notaro

- Peatlands as a model system for exploring and reconciling chronologies

M. Blaauw, J.A. Christen and D. Mauquoy

Peatland records of solar activity

B. van Geel and D. Mauquoy

- A multi-proxy high-resolution approach to reconstructing environmental change 13 M. Lamentowicz, W.O. van der Knaap, J.F.N. van Leeuwen, S. Hangartner, E.A.D. Mitchell,

\section{T. Goslar, W. Tinner and C. Kamenik}

- Stable isotopes and organic geochemistry in peat

E.L. McClymont, E. Pendall and J. Nichols

- Peat cellulose isotopes as indicators of Asian monsoon variability

B. Hong, M. Uchida, X.T. Leng and Y.T. Hong

Peat as an archive of atmospheric pollution and environmental change

F. De Vleeschouwer, G. Le Roux and W. Shotyk

- The northern peatland carbon pool and the Holocene carbon cycle

D.W. Beilman, G.M. MacDonald and Z. Yu

- Past and present carbon accumulation and loss in Southeast Asian peatlands

S. Page, R. Wüst and C. Banks

- Inception, history and development of peatlands in the Amazon Basin

O. Lähteenoja and K.H. Roucoux

- Peatland exchanges of $\mathrm{CO}_{2}$ and $\mathrm{CH}_{4}$ : The importance of permafrost

T.R. Christensen, M. Mastepanov, M. Johansson and D. Charman

PAGES International Project Office Zähringerstrasse 25 3012 Bern - Switzerland Tel.: +41316315611 Fax: +41316315606 pages@pages.unibe.ch www.pages-igbp.org/

\section{Editors:}

Series Editors:

Louise Newman and Thorsten Kiefer

Guest Editors:

Stephen T. Jackson and Dan Charman

\section{ISSN $1811-1602$}

Printed on recycled paper by Läderach AG - Bern, Switzerland

\section{Science Highlights: Open Section}

- El Niño/Southern Oscillation and SST changes over the last $1.2 \mathrm{ka}$

S.J.A. Jung, D. Kroon, G. Ganssen, F. Peeters and R. Ganeshram

\section{Workshop Reports}

- The $2^{\text {nd }}$ PAGES past interglacials (PIGS) workshop

- Understanding future sea level rise: The challenges of dating past interglacials

- High- to mid-latitude northern atmospheric circulation changes

- The West African Quaternary Research Association inaugural workshop

The PAGES International Project Office and its publications are supported by the Swiss and US National Science Foundations and NOAA. 